\title{
Clinical rationale and in vivo assessment of novel radiopaque UHMWPE sublaminar wires in growth- guidance surgery for early onset scoliosis
}

Citation for published version (APA):

Bogie, R. (2017). Clinical rationale and in vivo assessment of novel radiopaque UHMWPE sublaminar wires in growth-guidance surgery for early onset scoliosis. [Doctoral Thesis, Maastricht University]. Maastricht University. https://doi.org/10.26481/dis.20171123rb

Document status and date:

Published: 01/01/2017

DOI:

10.26481/dis.20171123rb

Document Version:

Publisher's PDF, also known as Version of record

Please check the document version of this publication:

- A submitted manuscript is the version of the article upon submission and before peer-review. There can be important differences between the submitted version and the official published version of record.

People interested in the research are advised to contact the author for the final version of the publication, or visit the DOI to the publisher's website.

- The final author version and the galley proof are versions of the publication after peer review.

- The final published version features the final layout of the paper including the volume, issue and page numbers.

Link to publication

\footnotetext{
General rights rights.

- You may freely distribute the URL identifying the publication in the public portal. please follow below link for the End User Agreement:

www.umlib.nl/taverne-license

Take down policy

If you believe that this document breaches copyright please contact us at:

repository@maastrichtuniversity.nl

providing details and we will investigate your claim.
}

Copyright and moral rights for the publications made accessible in the public portal are retained by the authors and/or other copyright owners and it is a condition of accessing publications that users recognise and abide by the legal requirements associated with these

- Users may download and print one copy of any publication from the public portal for the purpose of private study or research.

- You may not further distribute the material or use it for any profit-making activity or commercial gain

If the publication is distributed under the terms of Article $25 \mathrm{fa}$ of the Dutch Copyright Act, indicated by the "Taverne" license above, 


\section{Clinical rationale and in vivo}

assessment of novel radiopaque UHMWPE sublaminar wires in growth-guidance surgery for early onset scoliosis

Rob Bogie 


\section{Copyright}

(C) 2017 by Rob Bogie, Leende. All rights reserved

Layout \& Design: Topic-art - Eric Lemmens

D\&L graphics - www.dlgraphics.nl

Printed by: Schrijen-Lippertz

ISBN: 978-90-8590-065-8

\section{Research Funding}

This research forms part of the Project P2.05 Spineguide of the research program of the BioMedical Materials institute, co-funded by the Dutch Ministry of Economic Affairs

Financial support for the publication of this thesis was provided by:

Anna Fonds I NOREF

T. Theeuwes Orthopedie

Maastricht University

DSM Biomedical

Nederlandse Orthopaedische Vereniging

Dutch Spine Society

St. Anna Ziekenhuis Geldrop

MSBAua Geldrop 


\section{Clinical rationale and in vivo assessment of novel radiopaque UHMWPE sublaminar wires in growth-guidance surgery for early onset scoliosis}

\section{Proefschrift}

ter verkrijging van de graad van Doctor aan de Universiteit Maastricht, op gezag van de Rector Magnificus, Prof.dr. Rianne M. Letschert volgens het besluit van het College van Decanen, in het openbaar te verdedigen op donderdag 23 november 2017 om 14.00 uur door

\section{Rob Bogie}

Geboren op 18 november 1977 te Weert 


\section{Promotor}

Prof. dr. L.W. van Rhijn

\section{Copromotores}

Dr. P.C. Willems

Dr. J.J. Arts

\section{Manuscript leescommissie}

Prof. dr. M. Poeze (voorzitter)

Prof. dr. M. Van Kleef

Prof. dr. M. De Kleuver (Radboudumc Nijmegen)

Dr. M.C. Kruijt (UMC Utrecht)

Dr. M. Ter Laak 


\section{TABLE OF CONTENTS}

\section{Chapter 1}

General introduction and aims and outline of the thesis

\section{Chapter 2}

The use of sublaminar wires for growth-guidance in early onset scoliosis surgery: A systematic review of the literature

\section{Chapter 3}

The use of metal sublaminar wires in modern growth-guidance scoliosis surgery. A report of 4 cases

Chapter 4

UHMWPE sublaminar wires in posterior spinal instrumentation: stability and biocompatibility assessment in an ovine pilot study

\section{Chapter 5}

Novel radiopaque ultra-high molecular weight polyethylene sublaminar wires in a growth-guidance system for the treatment of early-onset scoliosis: Feasibility in a large animal study

\section{Chapter 6}

Large animal models in fusionless scoliosis correction research: a literature review

\section{Chapter 7}

The development of a representative porcine early onset scoliosis model with a standalone posterior spinal tether

\section{Chapter 8}

Summary

\section{Chapter 9}

General discussion

\section{Chapter 10}

Valorisation

Nederlandse samenvatting 

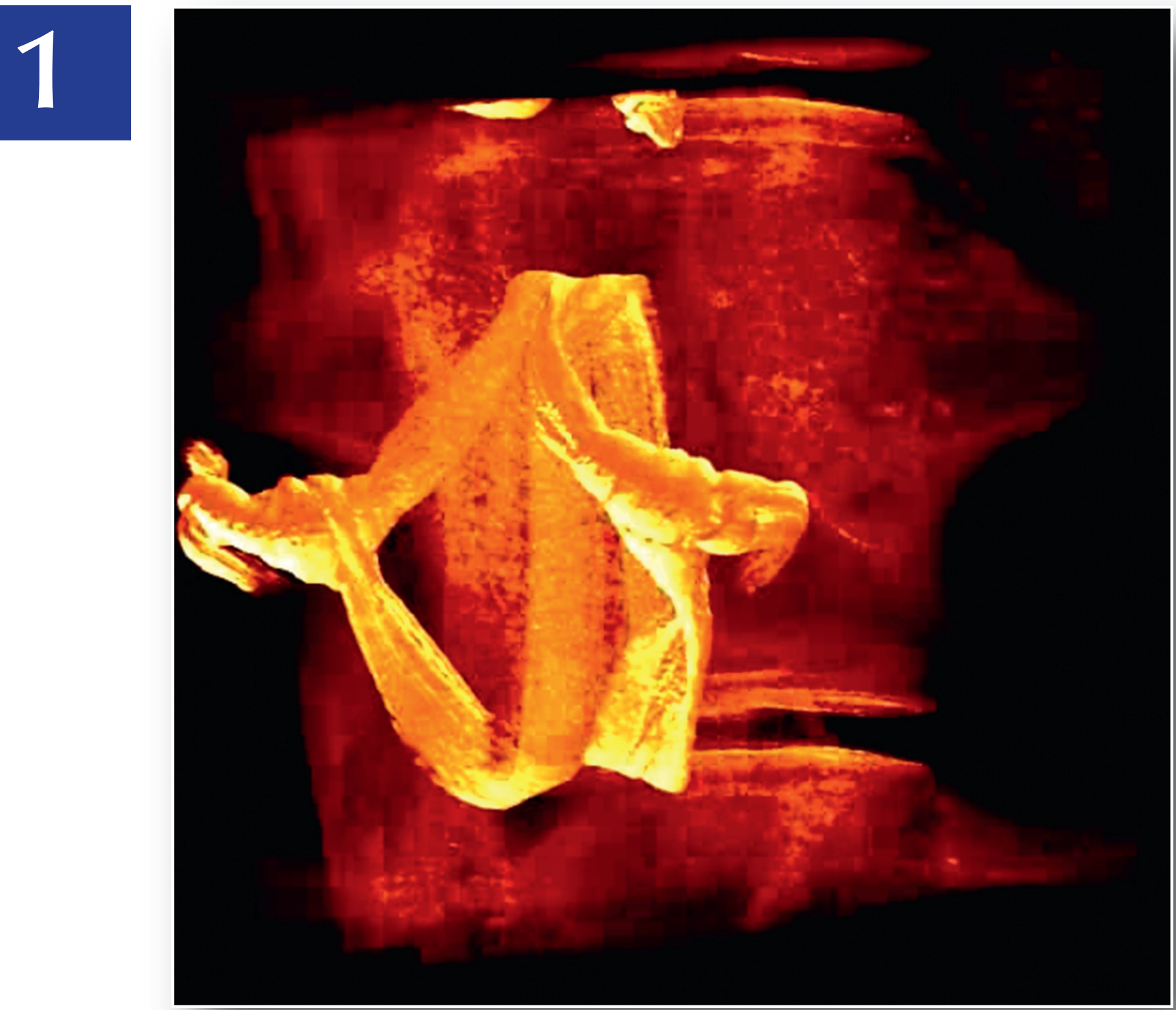
ChaPTER 1

General introduction and aims

and outline of the thesis 
Chapter 1

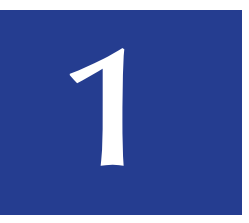




\section{GENERAL INTRODUCTION}

Scoliosis is a disorder, which is characterized by a complex three-dimensional deformity of the spine with lateral and rotational components. Axial rotation occurs as a result of vertebral bodies rotating towards the convexity and consequently vertebral arches rotating into the concavity of the curve. Although it may be asymptomatic, clinical symptoms generally consist of back-pain, restricted function of the spine and in severe cases pulmonary and cardiovascular dysfunction as a result of thoracic cage compromise. In addition, cosmetic and psychosocial consequences of scoliosis can significantly affect a patient's well being. Scoliosis results from both known and unknown causes in patients of all ages. Scoliosis that develops during growth with unknown specific cause is described as 'idiopathic'. Adolescent idiopathic scoliosis (AIS) is the most common type of pediatric scoliosis accounting for $85 \%$ of all causes. ${ }^{1,2}$ The natural history of scoliosis is dependent on the patient's skeletal maturity, underlying cause, the curve pattern and curve magnitude. ${ }^{1}$ Scoliosis can be differentiated either by etiology or by age of onset. Early onset scoliosis (EOS) is defined as scoliosis of any etiology before the age of $10 .^{3} \mathrm{EOS}$ is a heterogeneous group of patients. Prognosis and natural history vary widely depending on whether the etiology is congenital, neuromuscular, syndromic or idiopathic. ${ }^{4}$

The condition of EOS is characterized by the presence of a highly progressive spinal deformity because of large growth potential, in which thoracic volumes can rapidly become compromised. ${ }^{7}$ Many treatments have been proposed for EOS including casting, bracing and surgery. Casting techniques were commonly used before the introduction of spinal instrumentation. Mehta reported extensive experience with serial casting. ${ }^{8}$ Principles of this casting technique include the use of a specialized casting table, moderate traction, and emphasis on derotation of the thorax and spine. ${ }^{9,} 10$ Risks of skin complications exist when using this derotation casting and precise technique is essential. Anesthesia is usually required for casting. Casts are changed every 8 to 12 weeks. Casting has been shown to delay the progression of curvature and has shown effective in children with smaller curvatures. Braces are used in an attempt to slow curve progression during growth, and depending on the flexibility of the curve. If rigid curves exists and minor correction is achieved on bending $x$-rays, bracing will not be effective. Conclusive evidence 


\section{Chapter 1}

\begin{tabular}{|c|c|c|}
\hline Types of EOS & Characteristics & Associated Diagnoses \\
\hline \multirow[t]{3}{*}{ Congenital } & Structural abnormality of the spine or thorax present at birth. & Cardiac, renal abnormalities \\
\hline & Failure of formation (eg, hemivertebra). & $\begin{array}{l}\text { Other musculoskeletal abnormalities } \\
\text { (upper limb, club foot) }\end{array}$ \\
\hline & Failure of segmentation (eg, fused vertebra or ribs). & $\begin{array}{l}\text { Associated with VATER/VACTERL } \\
\text { syndromes } \\
\text { Intraspinal abnormalities (ie, } \\
\text { diastematomyelia, tethered cord) }\end{array}$ \\
\hline Neuromuscular & $\begin{array}{l}\text { Progressive spinal curvatures caused by disorders of the brain, } \\
\text { spinal cord and muscular system. } \\
\text { Often a long, sweeping scoliosis curve. }\end{array}$ & $\begin{array}{l}\text { Examples: Cerebral palsy, muscular } \\
\text { dystrophies (Duchenne), Spinal } \\
\text { Muscular Atrophy (SMA), spinal cord } \\
\text { injuries }\end{array}$ \\
\hline Syndromic & $\begin{array}{l}\text { Includes any other syndromes associated scoliosis (excluding } \\
\text { neuromuscular or congenital scoliosis syndromes). }\end{array}$ & $\begin{array}{l}\text { Examples: Connective tissue } \\
\text { disorders, Marfan syndrome, } \\
\text { neurofibromatosis, skeletal } \\
\text { dysplasias, Prader-Willi syndrome }\end{array}$ \\
\hline Idiopathic & Scoliosis without a known attributable cause. & $\begin{array}{l}\text { Higher incidence of Arnold-Chiari } \\
\text { malformation and syringomyelia } \\
\text { compared with adolescent } \\
\text { idiopathic scoliosis }\end{array}$ \\
\hline & $\begin{array}{l}\text { Infantile (diagnosed <3 y): Many milder curves will resolve } \\
\text { but need observation. } \\
\text { Juvenile (diagnosed } 4-10 \text { y): Often left sided curves. } \\
\text { Slight male predominance. }\end{array}$ & \\
\hline
\end{tabular}

Table 1. Summary of the Different Types of EOS and Their Unique Features Reprinted by permission of Yang et al. ${ }^{5}$

that brace treatment improves the natural history of EOS is still lacking. ${ }^{11}$ As a result of the progressive nature of EOS and when bracing cannot prevent further progression, surgical treatment by means of correction and fusion of the spine is often performed. In this manner, further curve progression is securely stopped. Campbell et al introduced the term 'thoracic insufficiency syndrome' as the inability 

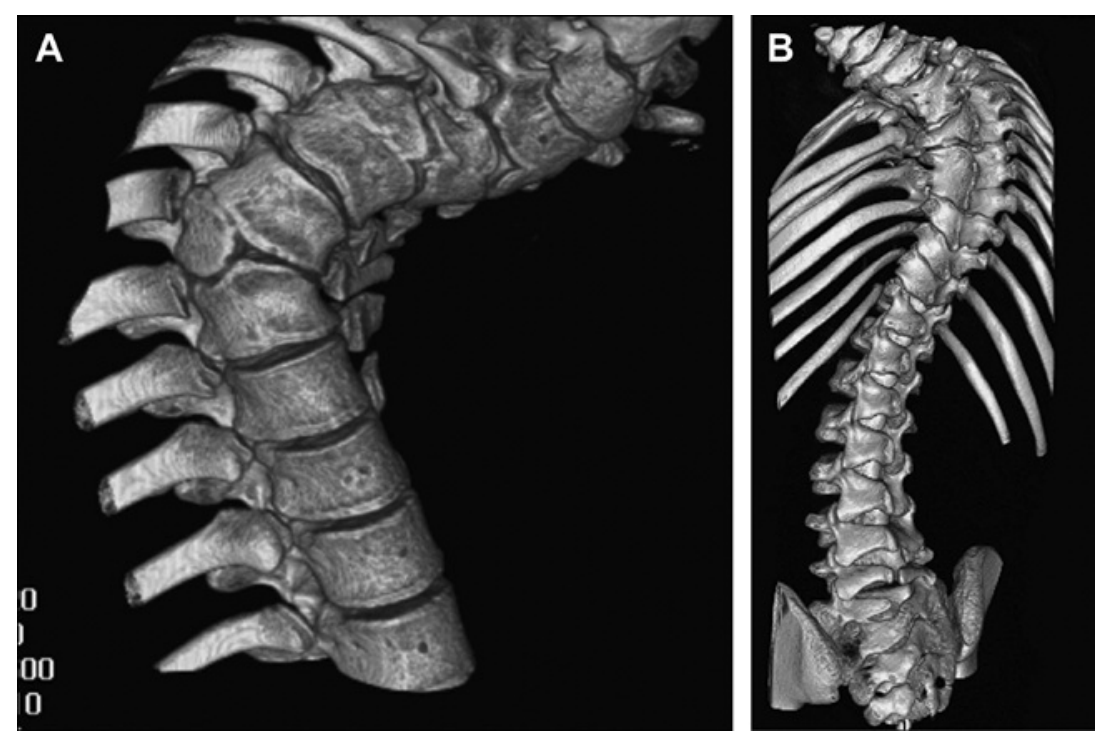

Figure 1. 3-D 3D CT reconstructions of 2 different patients with congenital scoliosis. (A) Failure of formation with a hemivertebrae visualized at the apex of the deformity. (B) Failure of segmentation with unilateral bar and fused ribs at the apex of deformity. Reprinted by permission of El-Hawary et al. ${ }^{6}$
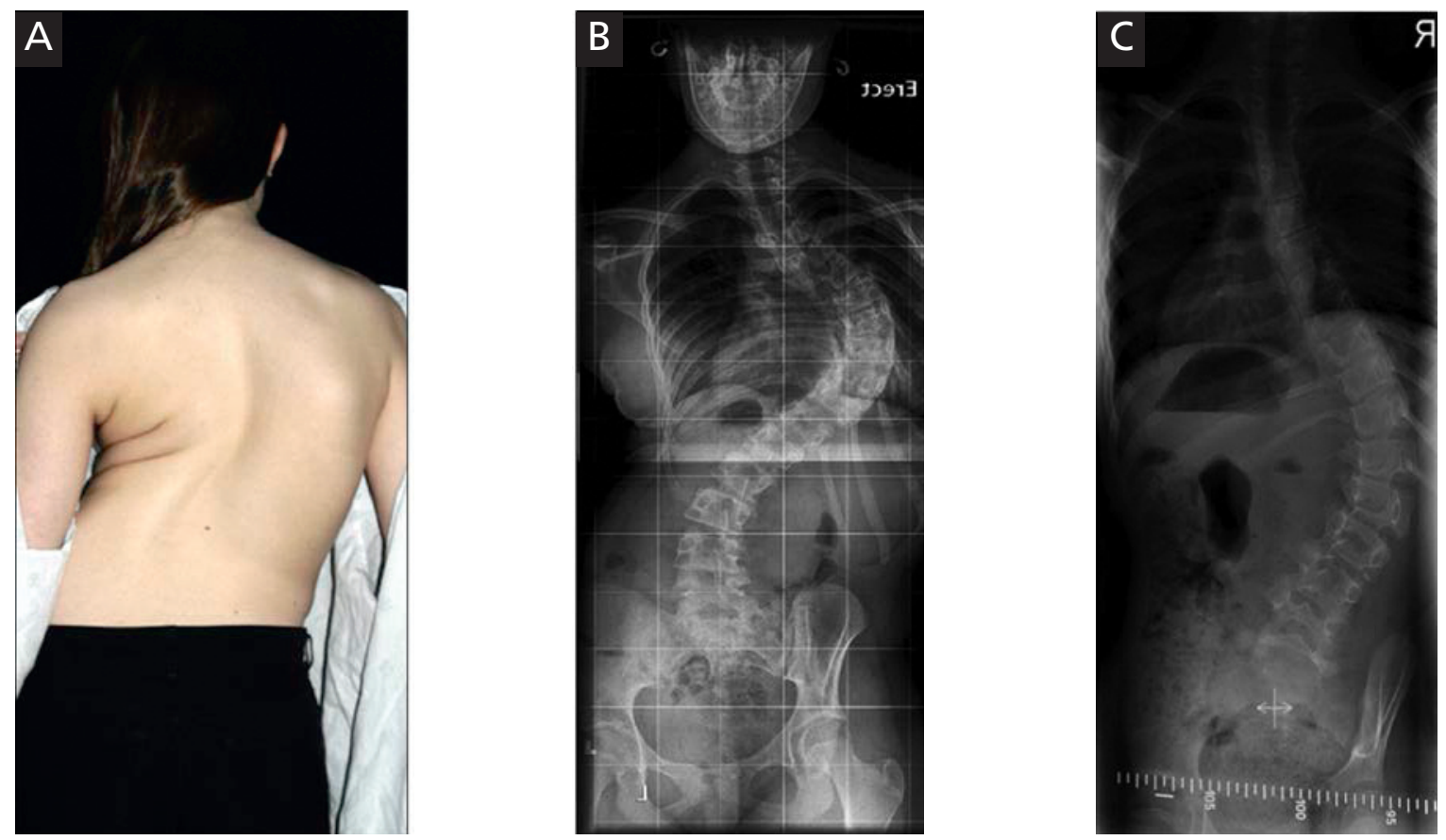

Figure 2. (A) Example of an idiopathic scoliosis. (B) Standing posteroanterior radiograph of the same patient indicating a scoliosis of greater than $90^{\circ}$. Reprinted by permission of El-Hawary et al. ${ }^{6}$ (C). Example of a neuromuscular scoliosis. 


\section{Chapter 1}

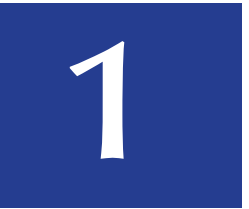

of the thorax to support normal respiration or lung growth, which is mainly caused by EOS. ${ }^{12}$ When performing spinal fusion in EOS, further pulmonary compromise can develop with a poor quality of life. ${ }^{13,14}$ This posterior spinal fusion, which is generally performed, can lead to the so-called 'crankshaft phenomenon' i.e., continued anterior spinal growth can result in progressive curvatures with increased vertebral rotation. With increasing recognition of the negative effects of early fusion on the immature spine, non-fusion techniques have emerged. Fusionless scoliosis surgery may provide substantial advantages over both bracing and definitive spinal fusion. The goal is to harness the patient inherent spinal growth and redirect it to achieve correction, rather than progression of the curve. ${ }^{1}$

\section{GROWTH-FRIENDLY INSTRUMENTATION}

\section{EOS, spinal growth and lung development}

EOS treatment should strive to allow for curve control, achieve maximum spinal length and mobility, and maximize pulmonary function, with a minimum of operations and surgical risks. ${ }^{15}$ In recent years, a substantial amount of 'growthfriendly' surgical techniques have been developed in an attempt to avoid, delay or limit spinal fusion. Often this fusionless surgery is performed to postpone arthrodesis, which, if performed early, prevents vertebral/thoracic growth and affects sitting height. ${ }^{16}$ The height of the spine accounts for $60 \%$ of total sitting height. Sitting height correlates strictly with trunk height and is about $34 \mathrm{~cm}$ at birth on average. The loss of sitting height is often related to the severity of the deformity in young children with severe spinal deformities. The risk of progression of the deformity is highest during periods of accelerated growth. ${ }^{17}$ Growth is a succession of acceleration and deceleration phases consisting of three periods. The first period is from birth to age $5 ; 27 \mathrm{~cm}$ increase of sitting height with $12 \mathrm{~cm}$ occurring during the first year. Second period is from 5 to 10 years $(2.5 \mathrm{~cm} /$ year height increase). The third period is during puberty and is characterized by a gain of $12-13 \mathrm{~cm} .{ }^{17}$ Although almost $60 \%$ of the sitting height is achieved by age 5 , only about $30 \%$ of the thoracic volume has been achieved and by 10 years of age thoracic volume has reached $50 \%$ of the adult size. Surgical intervention in EOS may therefore have more profound effect on chest growth than on spine growth. ${ }^{15}$ Most spinal deformities originate in 
the T1-S1 segment. At birth this segment measures about $20 \mathrm{~cm}$ and reaches $45 \mathrm{~cm}$ at maturity. The T1-S1 segment accounts for nearly 50\% of the sitting height, twothirds for the thoracic spine and one-third for the lumbar spine. The T1-S1 spine grows around $2 \mathrm{~cm} /$ year during the first 5 years of age, $1 \mathrm{~cm} /$ years between 5 and 10 years and $1.8 \mathrm{~cm}$ between 10 and maturity. ${ }^{17}$

Several authors have demonstrated deleterious effects of early fusion on pulmonary function. ${ }^{13,14}$ The 'golden' period for both thoracic spine and thoracic cage growth is between 0 and 10 years of age and coincides with lung development. It is important to preserve both thoracic growth and lung volume during this critical period.

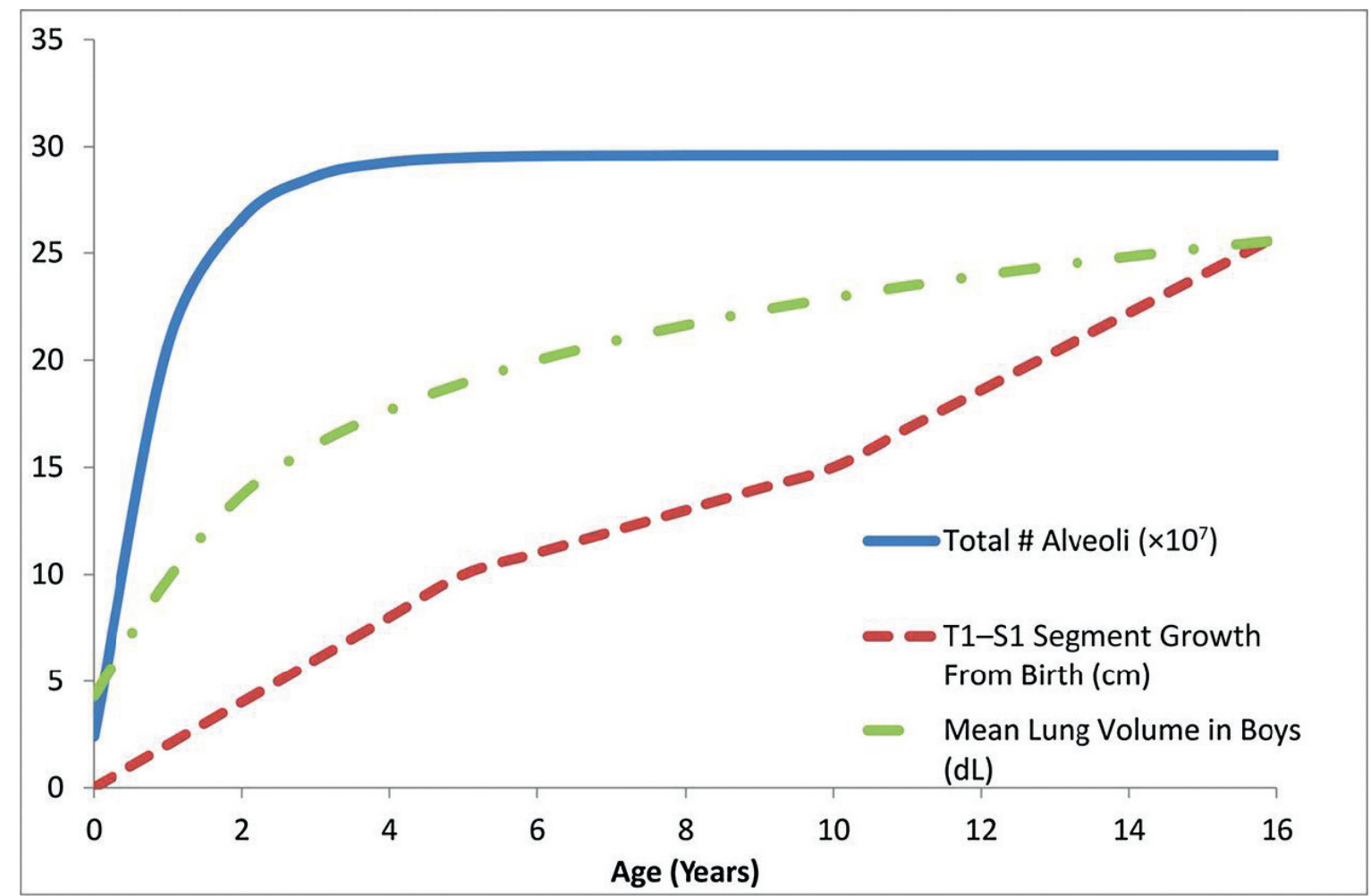

Figure 3. Composite plots of total alveolar number, T1-S1 segment growth from birth, and mean lung volume with age. The number of alveoli, mean lung volume, and spinal growth increase rapidly in the first few years of life. Reprinted by permission of Yang et al. ${ }^{5}$ 


\section{Chapter 1}

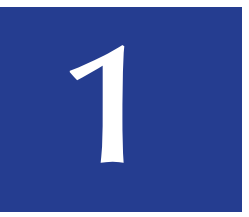

\section{Classification of growth-friendly implants}

Assessing remaining spinal growth and the spinal length involved in the deformity can facilitate the choice between a conventional definitive fusion of the spine and a growth-friendly treatment. If a long section of the spine is involved in the deformity and/or large amount of growth is to be expected, a growth-friendly treatment may be preferable, especially in EOS. At present, there is no instrumentation able to fully control the three-dimensional nature of EOS. Growth-friendly implants can be classified into 3 categories based upon the forces of correction the implants exert on the spine: compression-based, distraction based and guided growth. ${ }^{11}$

\section{Compression based}

Compression-based systems correct spinal deformities by applying a compression force to the convexity of the curves causing growth inhibition on this side. According to the Hueter-Volkmann law growth of the vertebral physis can be decreased by compression and increased by inhibition. ${ }^{18,19}$ The compression force can be generated mechanically at the time of implantation or result from longitudinal growth inhibition of vertebral endplates hindered by a spinal implant. Examples of compression-based systems are vertebral staples and anterior spinal tethers. ${ }^{11}$ Modern vertebral body staples consist of shape-memory-alloy (i.e. Nitinol) that allows the staple to clamp into a $C$ shape when it is warmed to body temperature. Vertebral body stapling has shown minor results in curvatures $>35$ degrees in terms of intra-operative correction. ${ }^{20}$ Flexible tethers attached to vertebral anchors have also been used to modulate spinal growth. Literature reviewing the effect of these techniques is limited and the use of tethering in human scoliosis is mainly described in case reports and experimental animal models. ${ }^{1,21,22}$ In EOS surgery, especially in patients with stiff large curvatures, compression-based implants do not seem to be indicated.

\section{Distraction based-implants}

Distraction-based implants intent to correct and maintain the spinal deformity via mechanically applying a distractive force across the concavity of the curvature. These implants can be attached to the spine, ribs or pelvis depending on the patient's age, characteristics of the curve and available bone stock. ${ }^{23}$ Harrington originally 
reported this distraction method with the use of a single rod in the convexity of the curve to correct scoliosis in 1962 and performed a partial spinal fusion. ${ }^{24}$ The first distraction-based growing rod was described in 1978 at the Scoliosis Research Society. The growing rod technique has undergone several modifications. Innovations such as low profile designs, growing connectors, dual rod application, and the use of rib fixation and/or pedicle screws have improved outcome and diminished hardware problems. ${ }^{23}$ Generally accepted indications for growing rods include progressive deformity $>50$ degrees, significant remaining growth and flexible curves. ${ }^{25,} 26$ Most growing rods are used for curvatures $>60$ degrees in patients younger than 10 years of age. With the use of the growing rod techniques repeated distraction surgery is necessary. Magnetic controlled growing rods (MCGR) have been developed to avoid these invasive repeated distraction procedures and show similar results in terms of curve control. ${ }^{27,}{ }^{28}$ Recently the FDA cleared the use of MCGR, in which lengthening can be applied from an external remote without anesthesia after the initial implantation. Although infection rates are less in MCGR surgery, instrumented related complications are still high with the use of this new technique. ${ }^{29}$

Another distraction-based technique is the vertical expandable prosthetic titanium rib (VEPTR). Compared with the growing rod the VEPTR features circumferential rib anchors and telescopic lengthening. As opposed to axial connectors, which generally need to be placed at the thoracolumbar region, the system has a lengthening mechanism that allows expansion in the kyphotic segment of the thoracic spine. Originally the VEPTR was used in the treatment of thoracic insufficiency, increasing the available space for lung function. Recently, growing rods are used in combination with the VEPTR as a hybrid construct. Complications of the VEPTR are similar to traditional growing rods and results in terms of curve progression and spinal growth are promising. ${ }^{30,31}$ All anchor points are subject to failure, either acute or chronic, depending on stresses applied, duration of attachment and bone quality. Migration through a rib, with associated rib fractures, by the VEPTR anchors is a common problem. ${ }^{32}$ The frequency of surgical lengthening procedures does not seem to differ as in growing rods. Lengthening procedures are best performed in intervals of 6 months or less. Curve correction, however, achieved by distraction-based techniques is limited, with average Cobb angle reduction of 


\section{Chapter 1}

$50 \%$ or less. Both growing rods and VEPTR are used in EOS surgery and the concept of a hybrid construct involving both techniques is an attractive one. The risk of repetitive procedures is the occurrence of spontaneous fusion and impairment of thoracic cage motility. ${ }^{33}$ Moreover, the psychological impact of the repeated distractions procedures, high costs of multiple operative procedures and limited effect on curve correction debates their use in EOS patients.
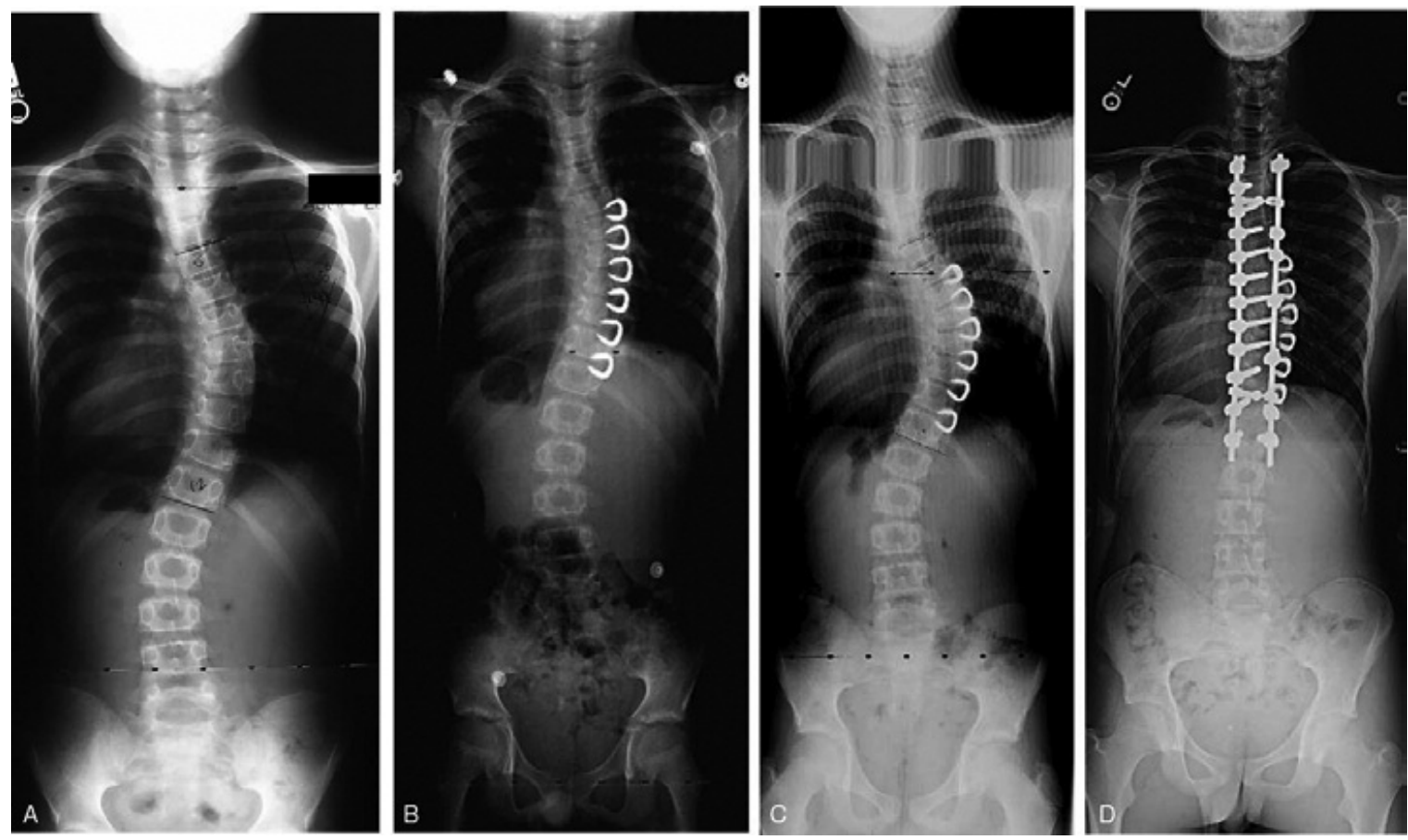

Figure 4. Example of a scoliosis patient (A) who underwent T6-T12 vertebral body stapling for a thoracic scoliosis (B) Initial correction, (C) progression of curvature after one year postoperative. (D) After T2-L1 posterior spinal fusion. Reprinted by permission of Bumpass et al. ${ }^{34}$ 

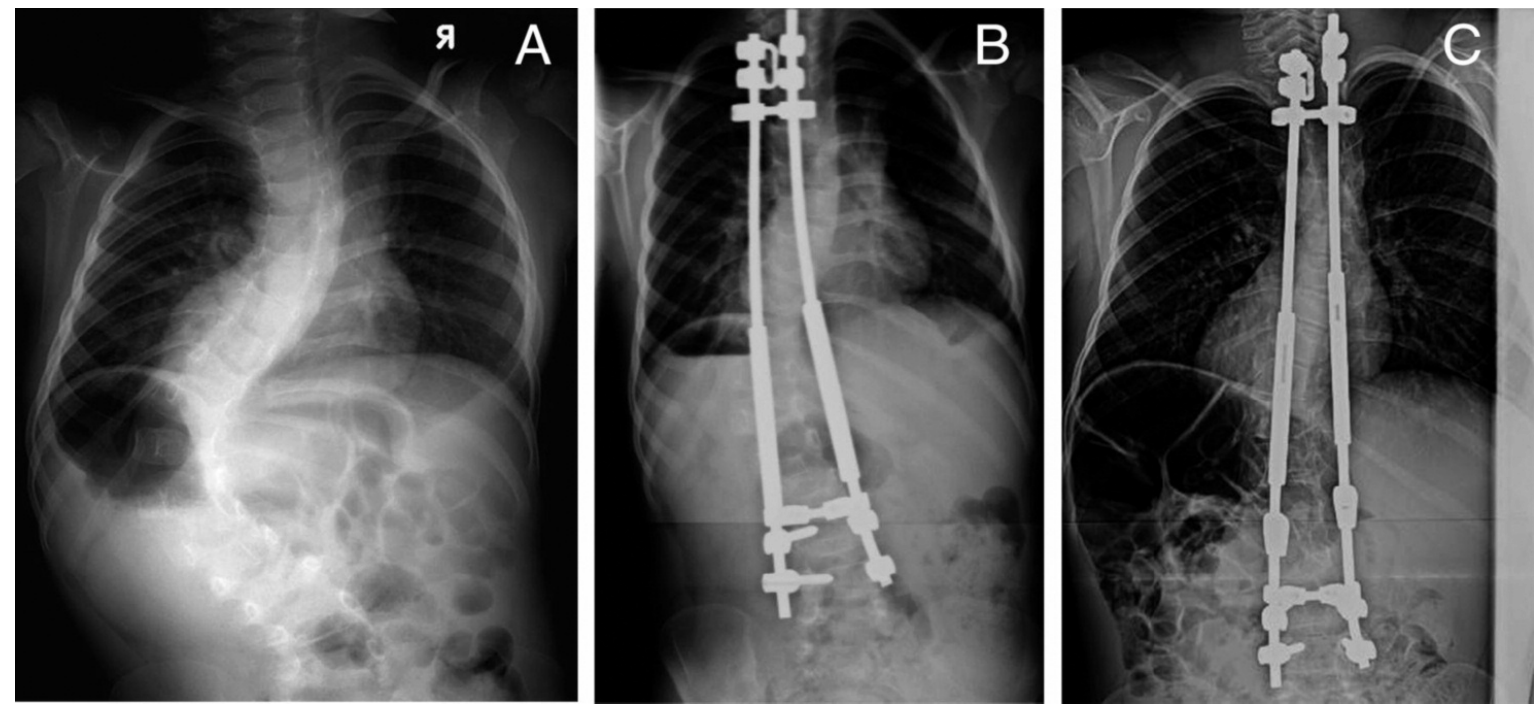

Figure 5. Preoperative $(A)$ and postoperative $(B)$ radiographs of patient with traditional growing rods. Radiographs obtained 5 years after the initial placement of growing rods (C) show that the scoliosis continues to be well controlled. Reprinted by permission of Yang et al. ${ }^{5}$
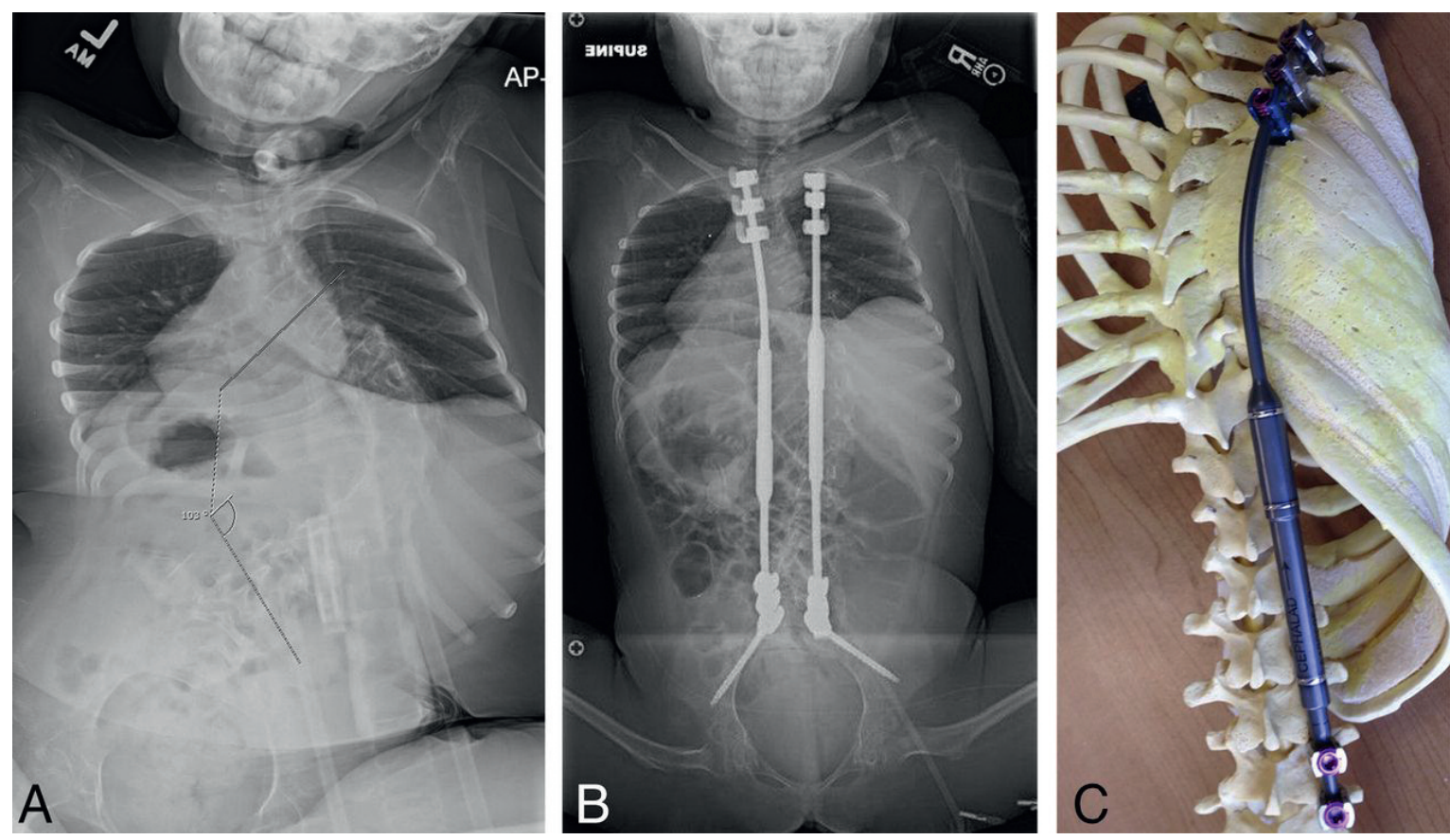

Figure 6. (A) Preoperative anteroposterior radiograph of a 7-year-old girl with spinal muscular atrophy and thoracolumbar curve. (B) Postoperative posteroanterior radiograph demonstrating a construct including the MCGR device. (C) Model demonstrating an MCGR device. Reprinted by permission of Yang et al. ${ }^{5}$ 


\section{Chapter 1}

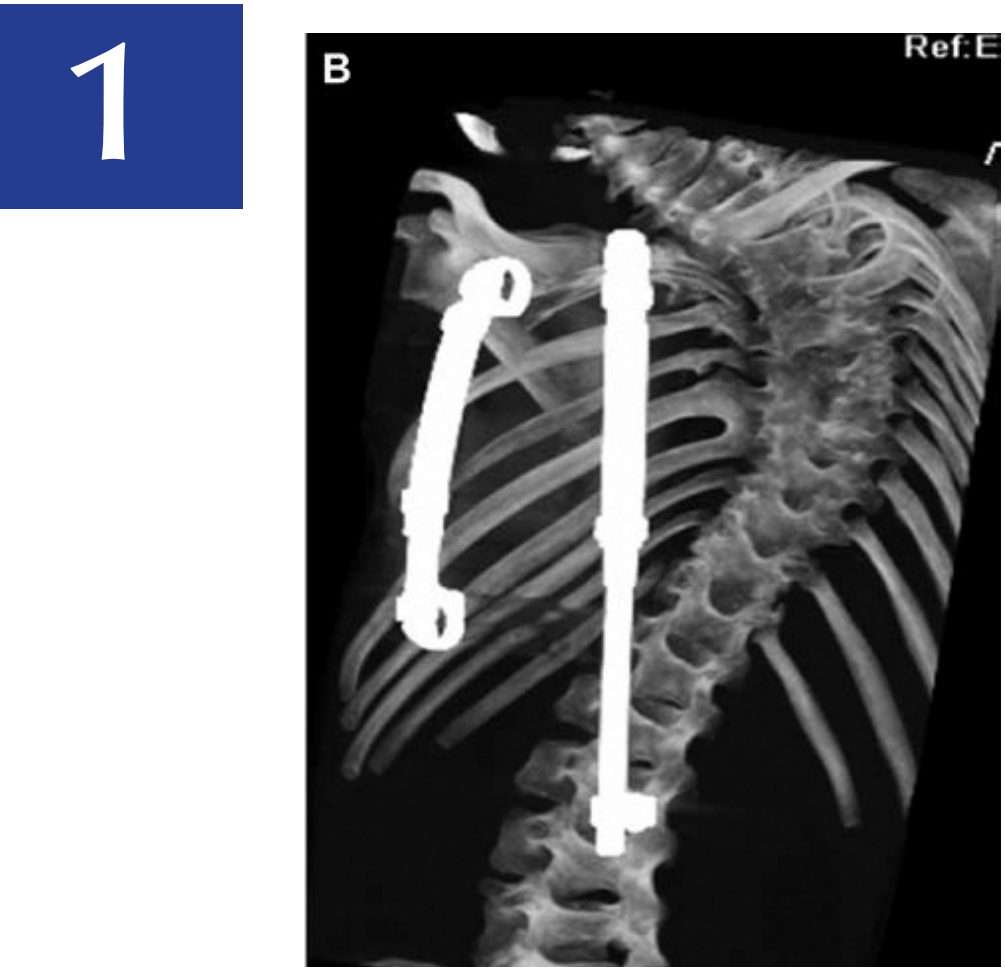

Figure 7. Three-dimensional CT reconstruction of the 7-year-old girl with congenital scoliosis who has been treated with a hybrid rib-based distraction surgery (VEPTR), which is anchored to the ribs as well as to the spine. Reprinted by permission of El-Hawary et al. ${ }^{6}$
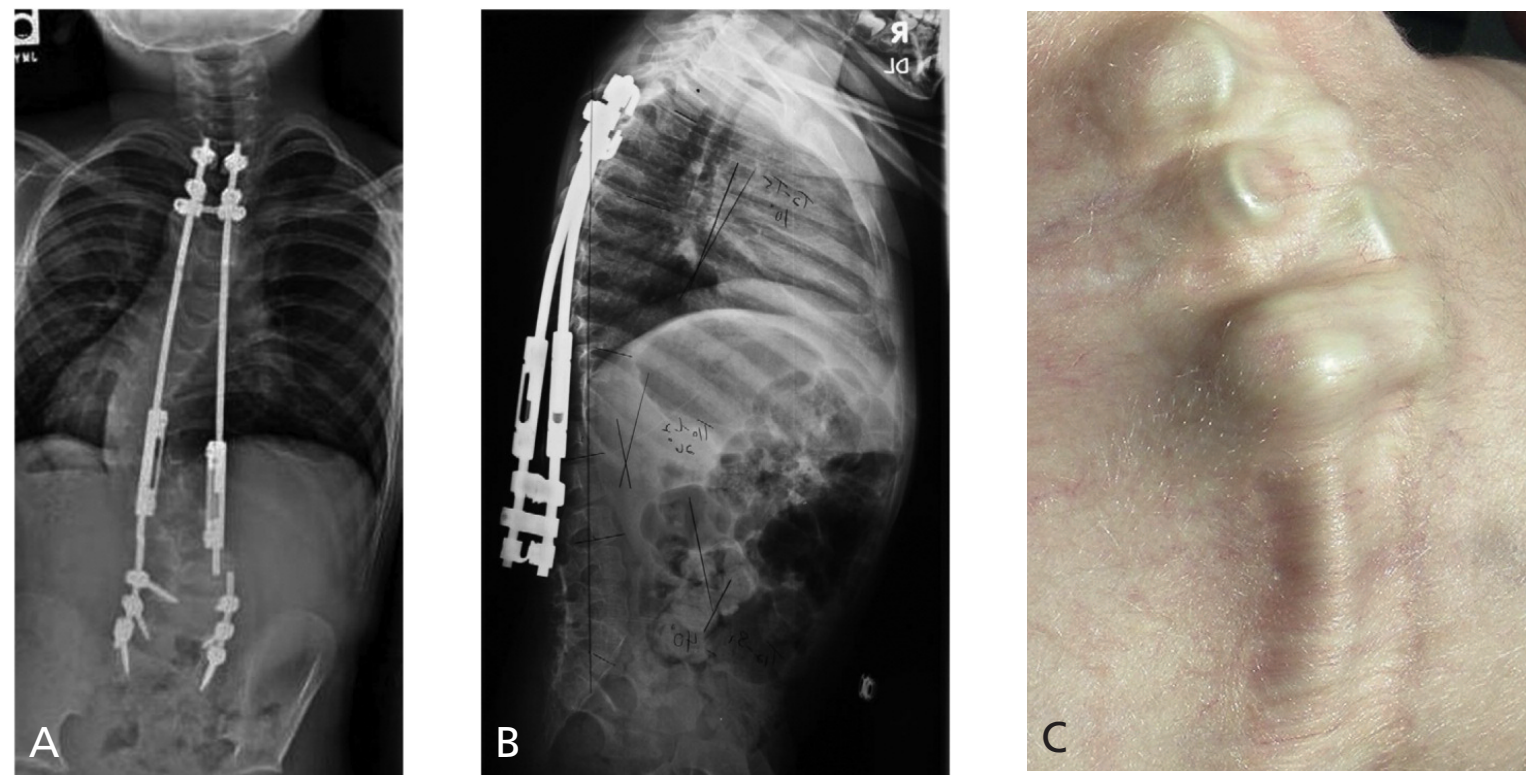

Figure 8. Complication after growth rod instrumentation. (A). Growing rod breakage. (B) Screw pull out of the growing rods at lumbar level. (C) Instrumentation prominence under the skin. Reprinted by permission of Akbarnia et al. ${ }^{32}$ and Yang et al. ${ }^{5}$ 


\section{Growth-guided systems}

Growth-guided systems attempt to correct spinal deformity by anchoring multiple vertebrae to rods. By applying mechanical forces apical translation is induced at the index surgery. By not rigidly attaching the anchors to the rods, sliding can take place along the rods and longitudinal growth is permitted. ${ }^{11}$ An important benefit is that repetitive distraction procedures are not necessarily required. The Luque trolley is an example of the first used growth-guidance technique. ${ }^{35}$ At first, a single rod was used in which sublaminar wires anchored the construct. Later, a dual rod technique was used and hardware problems decreased. As a result of ongoing hardware failure, spontaneous fusions and loss of correction of the curve, this technique has been widely abandoned. More recently, the Modern Luque trolley was developed, in which rods can slide at the apex of the deformity. Sliding anchors are inserted transmuscularly, to limit the risk of spontaneous fusion. ${ }^{36,37}$ Large patient series are still lacking to assess the feasibility of this construct. A disadvantage is that the capacity of the Luque trolley to facilitate growth can be exceeded.

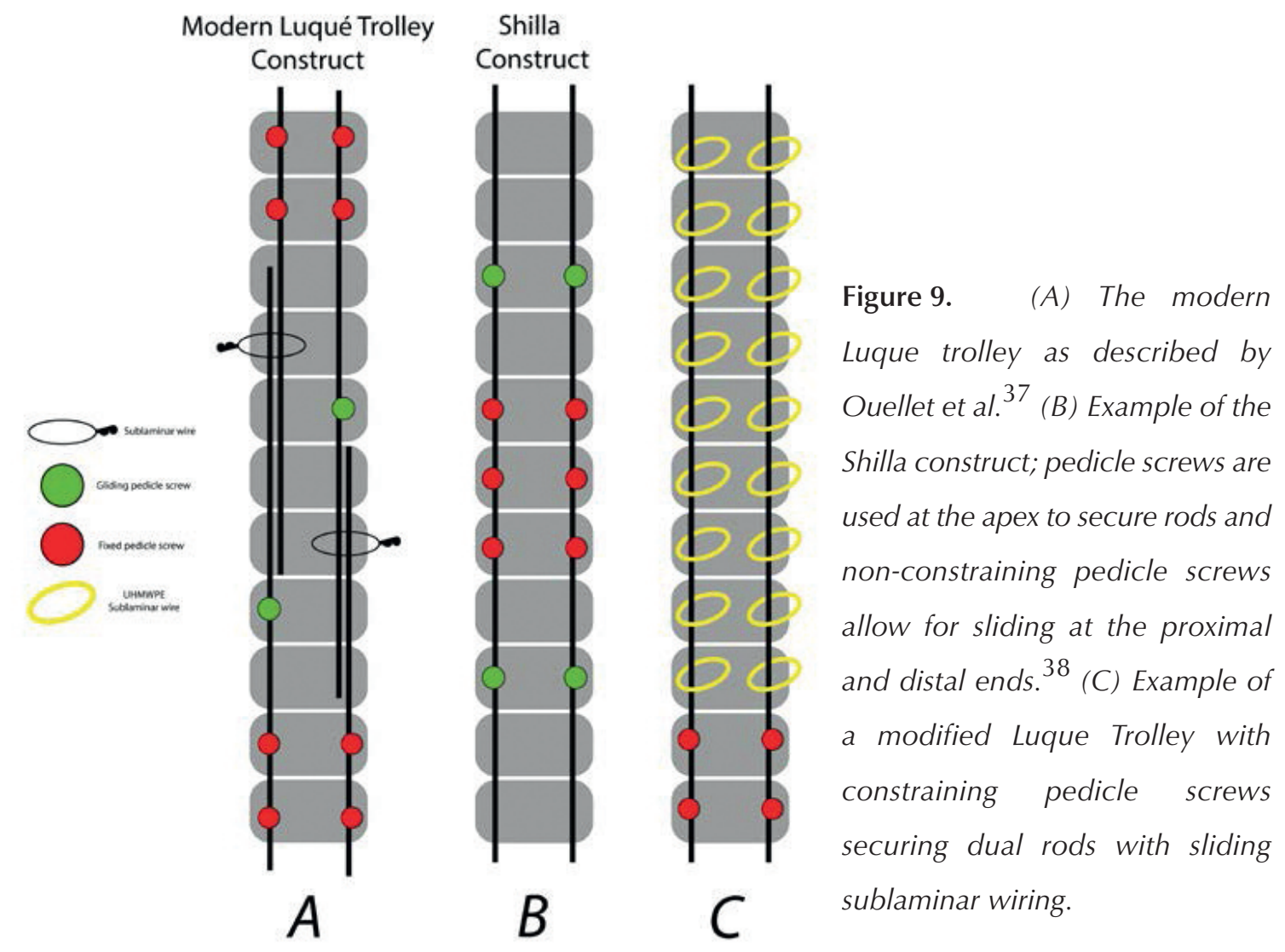




\section{Chapter 1}

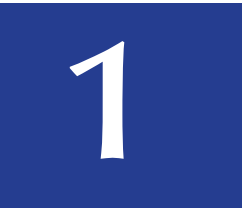

Another growth-guidance technique is the Shilla system in which dual rods are fixed to the apex of the curve using fixed apical pedicle screws with a limited fusion of often 3 vertebrae. Sliding pedicle screws are inserted extra-periosteally in the proximal and distal extremities of the rods, enabling sliding of the growing spine segments along the rods thus facilitating longitudinal spinal growth. ${ }^{16}$ Continued spinal growth without implant failure of the Shilla system was reported in an animal model. ${ }^{39}$ In a recent study of 40 patients, however, a high complication rate of up to $73 \%$ was described. Continued spinal growth was achieved, though not quantified. Deformity was controlled without scheduled repeated surgical procedures. ${ }^{38}$ Sliding pedicle screws can be used as an alternative to other sliding anchors (e.g. sublaminar wires). Metal-on metal articulation with ongoing sliding in the rod-screw construct will eventually produce wear particles, which can lead to the formation of seroma and sinuses. Concentrations of Ti and Vanadium (V) ions in the blood have been found in patients after instrumentation of this type of growth guidance sliding instrumentation. ${ }^{40}$

\section{SUBLAMINAR WIRING}

Anchoring systems used in growth-friendly systems consist of rods, sliding pedicle screws, hooks and/or sublaminar wires and cables. Classically, these wires are usually applied in a sublaminar fashion and then cinched around the rod. The first to introduce the use of stainless steel wires in spine surgery, for notched bone grafting was Gallie in 1937. ${ }^{41}$ In 1977, Luque introduced the Luque rod with sublaminar wires for segmental spinal fixation. ${ }^{42}$ Luque was the first to use monofilament 18 gauge stainless steel wire to complete multisegmental fixation to the spine. ${ }^{35}$ In 1984 Dove was the first to report the Hartshill rectangles with double-stranded stainless steel wires. ${ }^{43}$ With these double-stranded stainless steel wires many new spinal wiring techniques and cables developed, e.g. the Songer cable ${ }^{44}$, the Scott wiring technique ${ }^{45}$ and Sof-wire ${ }^{46}$. Subsequently, in 1996, Doran introduced a (second generation) multistranded titanium cable. ${ }^{47}$ The multi-filament cables are mostly secured using a metal clamp. Besides stainless steel wires and titanium cables, cobalt chromium wires and polyester bands are now used in segmental wiring, especially in fusion scoliosis surgery. ${ }^{48-50}$ These polymeric bands better conform to the 
undersurface of the lamina, which could lead to a decrease in neurologic injury. In growth-guidance surgery, sublaminar cables can provide apical translation of the curve and allow for continued longitudinal growth by sliding along the rods. With the use of a tensioning device, a gradual translation of the curve and fixation to the spine can be accomplished. By applying cables or bands with higher fatigue strength and enhanced sliding properties without the risk of metallosis, sublaminar wiring could play an dominant role in new growth-guidance systems for the correction of long segment EOS.
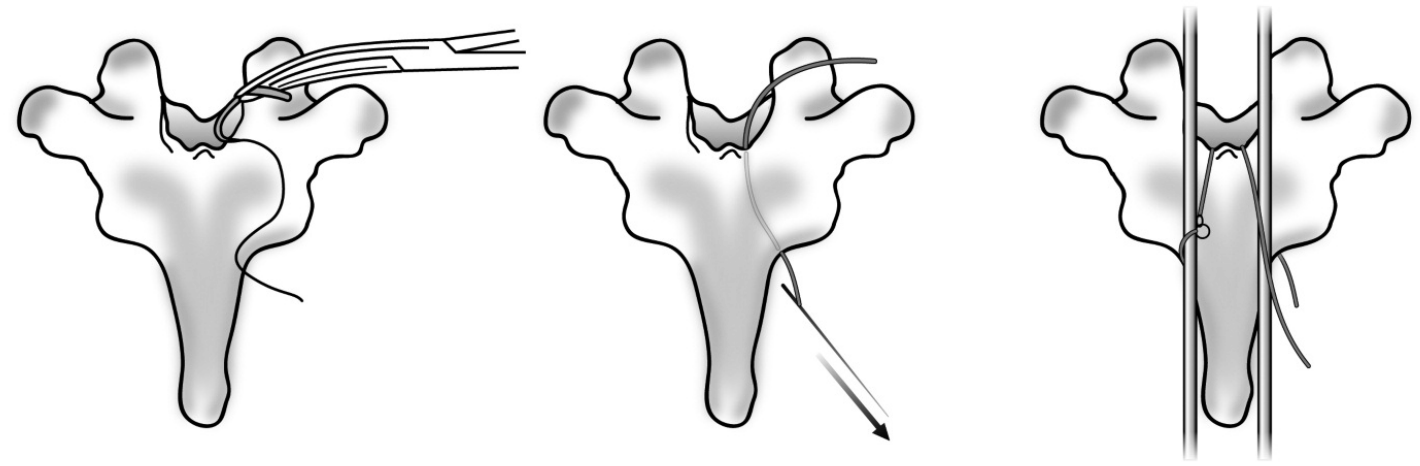

Figure 10. Technique of sublaminar wiring.
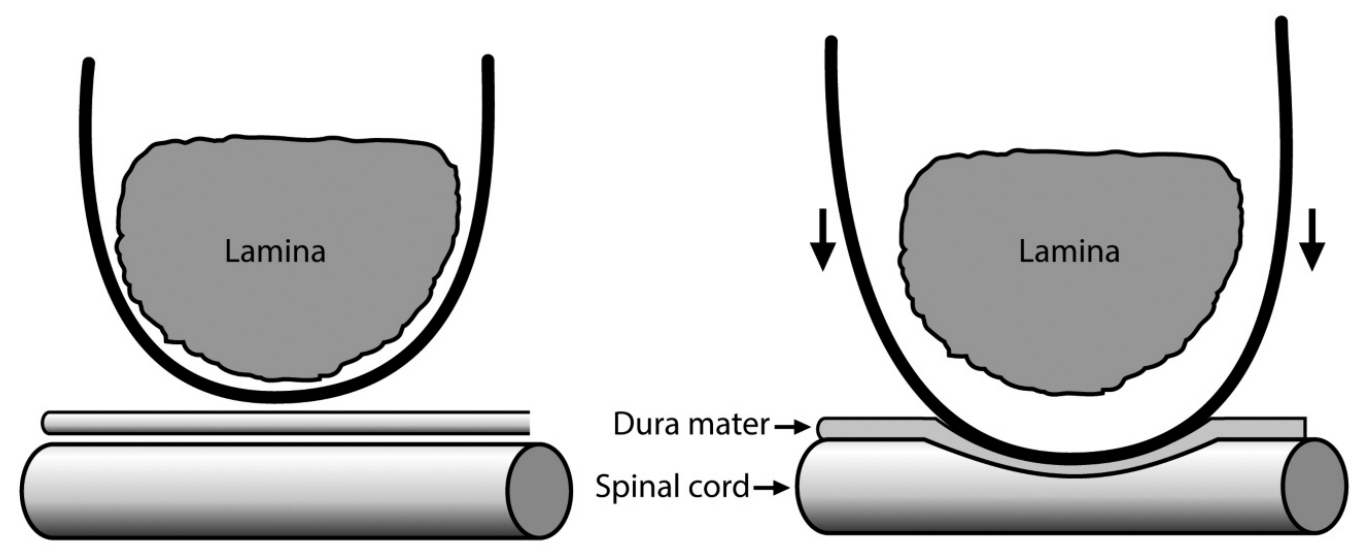

Figure 11. During insertion or removal of metal sublaminar wires, injury to the dural sac can occur. 


\section{Chapter 1}

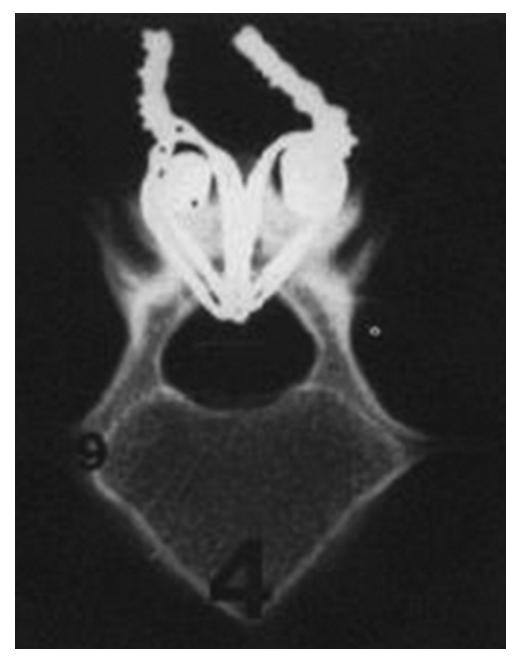

Figure 12. CT image of stainless steel sublaminar wires occupying the spinal canal.

\section{AIMS AND OUTLINE OF THE THESIS}

The research described in this thesis is part of a multidisciplinary public-private funded research project BMM Spineguide (BioMedical Materials), in which the overall aim was to assess feasibility and proof of concept of using ultra-high molecular weight polyethylene (UHMWPE) sublaminar wires in a growth-guidance scoliosis correction system. The UHMWPE wires are made with Dyneema Purity ${ }^{\circledR}$ fibers (DSM Biomedical B.V., Geleen, the Netherlands). The BMM Spineguide research project entailed material technology aspects, biomechanical testing, in vitro animal trials and FEA computer modeling. The mechanical properties of the UHMWPE cables were shown to be superior to titanium sublaminar wires, and to literature data available for other sublaminar cable or wire systems in terms of tensile and fatigue strength, while possessing stiffness at least comparable to metal cables. ${ }^{51}$

The proposed UHMWPE wires should act as sliding anchors along a dual rod instrumentation system for the treatment of early onset scoliosis (EOS). The goal is to achieve an adequate correction of the curvature by providing a strong fixation to the spine and instrumentation, whilst allowing spinal growth. By choosing UHMWPE sublaminar wires we propose that the occurrence of metal wear particles and concomitant tissue reactions will be minimized, hardware failure because of wire breakage will be diminished because of the high fatigue strength of these wires, while continued spinal growth will be allowed. 
The focus of the research as described in this thesis was placed on the biological safety and efficacy of the UHMWPE sublaminar wires according to several research aims:

Aim 1: To perform a systematic review of the literature on the historical use of growth-guided sublaminar wiring for EOS surgery.

Since the introduction of the Luque trolley the concept of growth-guidance scoliosis surgery with sliding sublaminar wires has been applied in different constructs with varying results. These historical outcomes are described in a systematic review in Chapter 2.

Aim 2: Outline the benefits and complications of currently used metal sublaminar wires in treatment of EOS patients.

In Chapter 3 we present a case series of patients with EOS, who were surgically treated at the $\mathrm{MUMC}^{+}$with a posterior adjusted Luque trolley instrumentation consisting of a dual rod/pedicle system and metal sublaminar cables. Benefits of this trolley growth-guided concept are outlined and furthermore complications of the use of metal sublaminar wires are described.

Aim 3: Assess safety and biocompatibility of the UHMWPE sublaminar wires in a large animal model.

Stability and biologic safety of UHMWPE sublaminar wires were evaluated in an ovine pilot study described in Chapter 4. We also assessed if these sublaminar wires provide sufficient sliding to facilitate longitudinal spinal growth.

Aim 4: Assess safety, biocompatibility and quantify spinal growth of novel radiopaque UHMWPE sublaminar wires in a large animal model.

Polymer sublaminar cable systems are currently used in scoliosis surgery, in which spinal fusion is performed. If used in growth-guidance surgery, these polymer cables must withhold strong forces and high continuous load and abrasion of the wires could increase the chance of instrument failure and subsequent loss of curve correction. Therefore radiological evaluation of novel polymer cables during followup after instrumentation necessitates radiopacity of the wires. In Chapter 5 new 


\section{Chapter 1}

developed radiopaque UHMWPE sublaminar wires were evaluated in an ovine study to assess radiopacity, stability and biocompatibility of the wires. Furthermore, spinal growth after instrumentation was quantified.

Aim 5: Based on a review of the literature start the development of a scoliosis animal model in which instrumentation can be assessed after the formation of a scoliotic curvature.

For the preclinical testing of new fusionless scoliosis devices a consistent large animal model representative of an idiopathic scoliosis would be ideal. In Chapter 6 a review of large animal scoliosis models is provided. A classification is given according to the mechanism by which the spinal column and thoracic cage have been modulated and technical details, which play a role in the development of an animal scoliosis model, are explained. With the knowledge of this literature review we intended to develop a representative porcine scoliosis model, which is proposed in Chapter 7. The purpose was to develop an early onset scoliosis model with the use of an offset device and a posterior spinal UHMWPE tether without performing rib procedures. These additional rib procedures can violate the thoracic cage and affect subsequent corrective procedures. Eventually, we aim to create a reproducible experimental scoliosis model to test for future growth-guidance instrumentation with radiopaque UHMWPE sublaminar wires. 


\section{REFERENCES}

1. Guille JT, D'Andrea LP, Betz RR. Fusionless treatment of scoliosis. Orthop Clin North Am. 2007;38:541-5, vii.

2. Weinstein SL. Natural history. Spine (Phila Pa 1976). 1999;24:2592-600.

3. Williams BA, Matsumoto H, McCalla DJ, et al. Development and initial validation of the Classification of Early-Onset Scoliosis (C-EOS). J Bone Joint Surg Am. 2014;96:1359-67.

4. Akbarnia BA, Marks DS, Boachie-Adjei O, Thompson AG, Asher MA. Dual growing rod technique for the treatment of progressive early-onset scoliosis: a multicenter study. Spine (Phila Pa 1976). 2005;30:S46-57.

5. Yang S, Andras LM, Redding GJ, Skaggs DL. Early-Onset Scoliosis: A Review of History, Current Treatment, and Future Directions. Pediatrics. 2016;137.

6. El-Hawary R, Chukwunyerenwa C. Update on evaluation and treatment of scoliosis. Pediatr Clin North Am. 2014;61:1223-41.

7. Matsumoto H, Williams BA, Corona J, et al. Psychosocial effects of repetitive surgeries in children with early-onset scoliosis: are we putting them at risk? J Pediatr Orthop. 2014;34:172-8.

8. Mehta $\mathrm{MH}$. Growth as a corrective force in the early treatment of progressive infantile scoliosis. J Bone Joint Surg Br. 2005;87:1237-47.

9. D'Astous JL, Sanders JO. Casting and traction treatment methods for scoliosis. Orthop Clin North Am. 2007;38:477-84, v.

10. Sanders JO, D'Astous J, Fitzgerald M, Khoury JG, Kishan S, Sturm PF. Derotational casting for progressive infantile scoliosis. J Pediatr Orthop. 2009;29:581-7.

11. Skaggs DL, Akbarnia BA, Flynn JM, et al. A classification of growth friendly spine implants. J Pediatr Orthop. 2014;34:260-74.

12. Campbell RM, Jr., Smith MD, Mayes TC, et al. The characteristics of thoracic insufficiency syndrome associated with fused ribs and congenital scoliosis. J Bone Joint Surg Am. 2003;85-A:399-408.

13. Karol LA, Johnston C, Mladenov K, Schochet P, Walters P, Browne RH. Pulmonary function following early thoracic fusion in non-neuromuscular scoliosis. J Bone Joint Surg Am. 2008;90:1272-81. 


\section{Chapter 1}

14. Vitale MG, Matsumoto $\mathrm{H}$, Bye $M R$, et al. A retrospective cohort study of pulmonary function, radiographic measures, and quality of life in children with congenital scoliosis: an evaluation of patient outcomes after early spinal fusion. Spine (Phila Pa 1976). 2008;33:1242-9.

15. Yazici M, Emans J. Fusionless instrumentation systems for congenital scoliosis: expandable spinal rods and vertical expandable prosthetic titanium rib in the management of congenital spine deformities in the growing child. Spine (Phila Pa 1976). 2009;34:1800-7.

16. Odent T, Ilharreborde B, Miladi L, et al. Fusionless surgery in early-onset scoliosis. Orthop Traumatol Surg Res. 2015;101:S281-8.

17. Dimeglio A, Canavese F. The growing spine: how spinal deformities influence normal spine and thoracic cage growth. Eur Spine J. 2012;21:64-70.

18. Mehlman CT, Araghi A, Roy DR. Hyphenated history: the Hueter-Volkmann law. Am J Orthop (Belle Mead NJ). 1997;26:798-800.

19. Stokes IA, Spence H, Aronsson DD, Kilmer N. Mechanical modulation of vertebral body growth. Implications for scoliosis progression. Spine (Phila Pa 1976). 1996;21:1162-7.

20. Betz RR, Ranade A, Samdani AF, et al. Vertebral body stapling: a fusionless treatment option for a growing child with moderate idiopathic scoliosis. Spine (Phila Pa 1976). 2010;35:16976.

21. Crawford $\mathrm{CH}, 3$ rd, Lenke LG. Growth modulation by means of anterior tethering resulting in progressive correction of juvenile idiopathic scoliosis: a case report. J Bone Joint Surg Am. 2010;92:202-9.

22. Newton PO, Farnsworth CL, Faro FD, et al. Spinal growth modulation with an anterolateral flexible tether in an immature bovine model: disc health and motion preservation. Spine (Phila Pa 1976). 2008;33:724-33.

23. Gomez JA, Lee JK, Kim PD, Roye DP, Vitale MG. "Growth friendly" spine surgery: management options for the young child with scoliosis. J Am Acad Orthop Surg. 2011;19:722-7.

24. Harrington PR. Treatment of scoliosis. Correction and internal fixation by spine instrumentation. J Bone Joint Surg Am. 1962;44-A:591-610.

25. Akbarnia BA, Breakwell LM, Marks DS, et al. Dual growing rod technique followed for three to eleven years until final fusion: the effect of frequency of lengthening. Spine (Phila Pa 1976). 2008;33:984-90. 
26. Yang JS, Sponseller PD, Thompson GH, et al. Growing rod fractures: risk factors and opportunities for prevention. Spine (Phila Pa 1976). 2011;36:1639-44.

27. Akbarnia BA, Cheung $\mathrm{K}$, Noordeen $\mathrm{H}$, et al. Next generation of growth-sparing techniques: preliminary clinical results of a magnetically controlled growing rod in 14 patients with early-onset scoliosis. Spine (Phila Pa 1976). 2013;38:665-70.

28. Dannawi Z, Altaf F, Harshavardhana NS, El Sebaie H, Noordeen H. Early results of a remotely-operated magnetic growth rod in early-onset scoliosis. Bone Joint J. 2013;95B:75-80.

29. Teoh $\mathrm{KH}$, Winson DM, James $\mathrm{SH}$, et al. Do magnetic growing rods have lower complication rates compared with conventional growing rods? Spine J. 2016;16:S40-4.

30. Campbell RM, Jr., Hell-Vocke AK. Growth of the thoracic spine in congenital scoliosis after expansion thoracoplasty. J Bone Joint Surg Am. 2003;85-A:409-20.

31. Sankar WN, Acevedo DC, Skaggs DL. Comparison of complications among growing spinal implants. Spine (Phila Pa 1976). 2010;35:2091-6.

32. Akbarnia BA, Emans JB. Complications of growth-sparing surgery in early onset scoliosis. Spine (Phila Pa 1976). 2010;35:2193-204.

33. Akbarnia BA, Campbell RM, Dimeglio A, et al. Fusionless procedures for the management of early-onset spine deformities in 2011: what do we know? J Child Orthop. 2011;5:15972.

34. Bumpass DB, Fuhrhop SK, Schootman M, Smith JC, Luhmann SJ. Vertebral Body Stapling for Moderate Juvenile and Early Adolescent Idiopathic Scoliosis: Cautions and Patient Selection Criteria. Spine (Phila Pa 1976). 2015;40:E1305-14.

35. Luque ER. Segmental spinal instrumentation for correction of scoliosis. Clin Orthop Relat Res. 1982:192-8.

36. Ouellet JA, Ferland CE, Racloz G, et al. Evaluation of the Modern Luque Trolley Construct for Treatment of Early Onset Scoliosis Using a Gliding Implant in an Immature Animal Model. Clin Spine Surg. 2016.

37. Ouellet J. Surgical technique: modern Luque trolley, a self-growing rod technique. Clin Orthop Relat Res. 2011;469:1356-67.

38. McCarthy RE, McCullough FL. Shilla Growth Guidance for Early-Onset Scoliosis: Results After a Minimum of Five Years of Follow-up. J Bone Joint Surg Am. 2015;97:1578-84.

39. McCarthy RE, Sucato D, Turner JL, Zhang H, Henson MA, McCarthy K. Shilla growing rods in a caprine animal model: a pilot study. Clin Orthop Relat Res. 2010;468:705-10. 


\section{Chapter 1}

40. Lukina E, Laka A, Kollerov M, et al. Metal concentrations in the blood and tissues after implantation of titanium growth guidance sliding instrumentation. Spine J. 2016;16:380-8.

41. Gallie WE. Skeletal Traction in the Treatment of Fractures and Dislocations of the Cervical Spine. Ann Surg. 1937;106:770-6.

42. Luque ER. Treatment of scoliosis without external support. Orthop Transact. 1977;1:37.

43. DOVE J. Internal Fixation of the Lumbar Spine The Hartshill Rectangle. Clinical orthopaedics and related research. 1986;203:135-40.

44. Songer MN, Spencer DL, Meyer PR, Jr., Jayaraman G. The use of sublaminar cables to replace Luque wires. Spine. 1991;16:S418-21.

45. Johnson GV, Thompson AG. The Scott wiring technique for direct repair of lumbar spondylolysis. The Journal of bone and joint surgery British volume. 1992;74:426-30.

46. Crockard A. Evaluation of spinal laminar fixation by a new, flexible stainless steel cable (Sof'wire): early results. Neurosurgery. 1994;35:892-8; discussion 8.

47. Doran SE, Papadopoulos SM, Miller LD. Internal fixation of the spine using a braided titanium cable: clinical results and postoperative magnetic resonance imaging. Neurosurgery. 1996;38:493-6; discussion 6-7.

48. Gaines RW, Jr., Abernathie DL. Mersilene tapes as a substitute for wire in segmental spinal instrumentation for children. Spine. 1986;11:907-13.

49. Mazda K, Ilharreborde B, Even J, Lefevre Y, Fitoussi F, Pennecot GF. Efficacy and safety of posteromedial translation for correction of thoracic curves in adolescent idiopathic scoliosis using a new connection to the spine: the Universal Clamp. Eur Spine J. 2009;18:158-69.

50. Cluck MW, Skaggs DL. Cobalt chromium sublaminar wires for spinal deformity surgery. Spine (Phila Pa 1976). 2006;31:2209-12.

51. Roth AK, Boon-Ceelen K, Smelt H, et al. Radiopaque UHMWPE sublaminar cables for spinal deformity correction: Preclinical mechanical and radiopacifier leaching assessment. J Biomed Mater Res B Appl Biomater. 2017. 
General introduction and aims and outline of the thesis

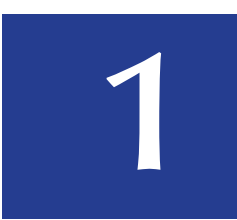



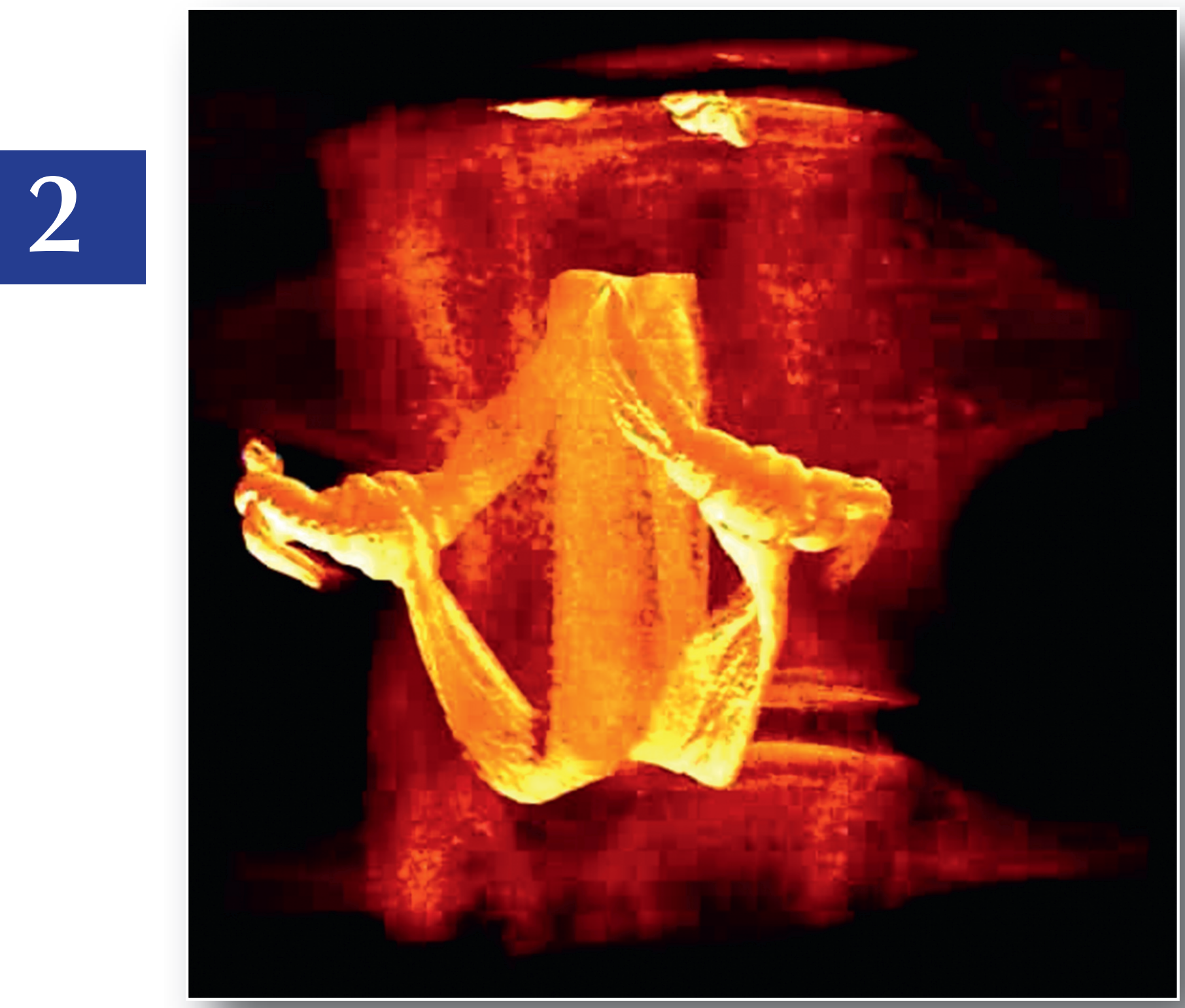


\section{CHAPTER 2}

\section{The use of sublaminar wires for}

growth-guidance in early onset scoliosis surgery: A systematic review of the literature.

Submitted

Rob Bogie, Simone N. Koole, Jacobus J. Arts, Walter W. van der Weegen, Lodewijk R. van Rhijn, Paul C. Willems 


\section{Chapter 2}

\section{ABSTRACT}

Study design. Systematic review

Objective. To review the literature on the use of growth-guided sublaminar wiring for EOS surgery.

Summary of Background Data. As a result of improved mechanical properties in scoliosis surgery, hybrid systems with sublaminar wiring and pedicle screw/rod instrumentation have regained popularity. To investigate feasibility in growth-guidance scoliosis surgery, in which sliding of the sublaminar wires along the rods may allow for spinal growth, reported pitfalls and results associated with this technique were reviewed.

Methods. Electronic databases (MEDLINE, Cochrane Library) were searched for studies reporting on instrumented surgery using sublaminar wires for EOS. Only articles describing a growth-guidance technique without performing full spinal fusion were included.

Results. Seven eligible articles (124 patients) were identified. On average 12 levels (range 616) were instrumented. Follow-up ranged from 26 to 56 months. Average preoperative Cobb angles varied from $51^{\circ}$ to $82^{\circ}$ and correction postoperatively ranged from 47 to $78 \%$. Loss of correction varied between 0 to $80 \%$. Spinal growth of instrumented levels varied widely from 23 to $100 \%$ of expected growth. Overall, $14 \%$ broken rods and $10 \%$ rod migration or rotation was reported. $16 \%$ of the patients experienced broken and/or pull-out of the wires. 2 Studies reported the occurrence of metallosis.

Conclusion. Growth-guided instrumentation with sublaminar wiring in EOS shows a substantial rate of instrument failure and subsequent loss of curve correction. It does, however, allow for partial preservation of spinal growth. Because of high continuous loads in a growthguidance model, instrument failure can be expected. Presumably, with the insertion of pedicle screws as a strong anchor point in a modified Luque-trolley, and by applying wires with higher fatigue strength and enhanced sliding properties, some of these failures could be overcome. Thus, the concept of growth-guided spinal instrumentation with sublaminar wiring could be a plausible surgical treatment for EOS. 


\section{INTRODUCTION}

In the management of early onset scoliosis (EOS) bracing is often the first choice of treatment. ${ }^{1}$ If brace treatment is not feasible or fails to control the deformity, surgical treatment is indicated. ${ }^{1}$ Especially when progressive curves develop (> 50 $\mathrm{Cobb}$ angle) spinal fusion is a proven surgical method for correction and to stop further progression. However, by eliminating spinal growth over the fused segments a short trunk stature can develop with resulting volumetric growth restriction of the thoracic cage, and subsequent pulmonary impairment. ${ }^{2}$ This decrease in lung volume is a common limiting factor in the life expectancy of children with EOS. ${ }^{3}$ Posterior segmental spinal fusion using hybrid systems (rods, hooks, sublaminar wires and pedicle screws) is currently the gold standard. ${ }^{4}$ Luque was the first to develop the concept of segmental spinal instrumentation (SSI) using sublaminar wires without fusion of the spine. ${ }^{5}$ This technique was eventually abandoned as a result of high complications rates; implant failure and poor deformity control. ${ }^{6,7}$ With the introduction of pedicle screw instrumentation as a strong anchor point and improved wire properties, hybrid systems have regained popularity in scoliosis surgery. ${ }^{8}$ The Universal Clamp system (Zimmer Spine SAS, Bordeaux, France), consists of a polyester sublaminar cable and rod-pedicle screw system. ${ }^{9}$ The Nesplon cable system (Alfresa Pharma, Osaka, Japan) uses a UHMWPE sublaminar cable in combination with rods and pedicle screws. ${ }^{10}$ These systems are currently used as an aid in achieving correction together with bony fusion of the spine. However, sliding of the sublaminar cables along the rods may allow for spinal growth after surgical correction of the deformity. Therefore, these hybrid systems could be used as growth-guidance trolley systems in children with EOS, with the possible advantage that repetitive interventions during spinal growth may not be required. ${ }^{11}$

To evaluate the feasibility of modern trolley systems for its use in growth guidance scoliosis surgery we performed a systematic literature review to search for segmental sublaminar wiring instrumentation used for the surgical treatment of EOS in which preservation of spinal growth was attempted. 


\section{Chapter 2}

\section{MATERIALS AND METHODS}

This review was conducted in accordance with the PRISMA statement for reporting systematic reviews and meta-analysis. Primary outcome parameters consisted of amount of preserved spinal growth, correction of the curve and possible loss of correction. Indications, complications and re-operations were recorded additionally.

\section{Inclusion criteria}

Inclusion criteria were the following: articles on surgical treatment of early onset scoliosis with the use of sublaminar wiring, in which the used techniques and outcomes in terms of curve correction, complications and residual spinal growth had been described. Only articles describing a growth-guidance technique without performing full spinal fusion were included. Early onset scoliosis was defined as scoliosis of any etiology before the age of $10 .{ }^{12}$ Only English language publications were included. Exclusion criteria were: case reports with less than 5 patients, animal studies and biomechanical studies. Articles describing the use of sublaminar wires in cervical spinal surgery and adolescent and adult scoliosis surgery were also excluded.

\section{Search strategy}

Electronic databases (MEDLINE and the Cochrane Library (Central Register of Controlled Trials)), were searched from inception until December 2016, using the search string "Spinal Curvatures OR Scoliosis OR Spine AND (Bone Wires OR Spinal Fusion OR Spine growth and development) AND sublaminar cable OR sublaminar wire OR segmental wiring)". The search strategy is developed in conjunction with an experienced librarian. Two observers (RB, SK) independently screened all identified studies based on title and abstract for eligibility, in case of doubt consensus was reached by discussion. Next, the full text manuscripts of all studies included after this first step were again independently reviewed (RB,PW). Consensus in case of doubt was reached by discussing the full text manuscripts. Additionally, systematic reviews were checked for not yet identified studies, and the reference lists of included studies were hand searched. Data was extracted by one observer (RB) who used a pre-set standardized data extraction form including reference data, study 
year, indication, patient demographics, instrumentation level, used materials, spinal growth, curve pattern, complications and re-operations.

\section{RESULTS}

\section{Study details and design}

Through electronic database searching 294 articles were identified, and 2 additional articles were found with hand searching. Of these, 197 were excluded based on title and abstract. After reviewing 99 studies in full text, 92 articles were excluded. Exclusion details after full text analysis were: no described spinal growth, full spinal fusion, and the use of other wiring techniques than sublaminar wiring. Seven articles, all retrospective cohort studies, were included for data extraction and analysis (Figure 1). ${ }^{11,13-18}$

\section{Patient Demographics}

The seven studies included a total of 124 patients with a male/female ratio of 1.1 to 1. One study did not categorize the patients on the basis of gender. ${ }^{11}$ Mean ages in the presented groups ranged from 3.1 to 9 years). An average of 12.3 levels (range 6-16) was instrumented (pedicle screws and sublaminar wires). Follow-up ranged from 26 tot 56 months (median group follow-up 43 months). (Table 1.) All articles characterized their patient groups as early onset scoliosis patients with dominantly neuromuscular disease.

\section{Instrumentation and surgical technique}

All patients underwent posterior spinal segmental instrumentation. In two studies the posterior instrumentation was combined with an anterior procedure: Patterson et al performed an anterior growth arrest as a separate additional procedure. According to the authors, this procedure was added to prevent curve deterioration. An average of four intervening discs and end-plates were excised and fresh rib grafts were added. ${ }^{16}$ In the study described by Pratt et al a Luque trolley was combined with convex epiphysiodesis in 18 out 25 patients. ${ }^{17}$ Epiphysiodesis was carried out first in the same manner as the technique described by Patterson. ${ }^{16}$ All posterior procedures involved hybrid instrumentations with rods and wires. Ouellet used 


\section{Chapter 2}

294 Articles identified through da ta base searching

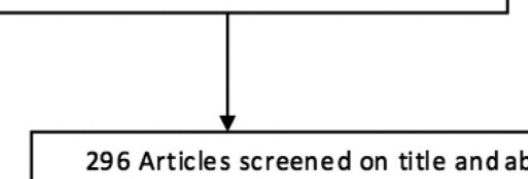

6 Articles identified through other sources
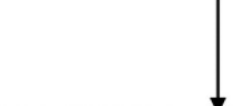

197 Articles excluded on abstract with reason

- Cervical studies $[n=54]$

- Case report $[n=18]$

- Reviews [n=4

- Animal $[n=4]$

- Other materials $[n=30]$

- Study design [ $n=29]$

- Biomechanical [n=25]

- Dominantly adult patient $[n=4]$

- Trauma [n=16]

- $\quad$ Lang uage $[n=6]$

- Kyphosis [n=5]

- Other $[n=2]$

92 articles excluded with reason

- $\quad$ Full spinal fusion $[n=62]$

- Wires not dominantly used in

instrumentation $[\mathrm{n}=28]$

- $\quad$ No spinal growth measured $[n=2]$

7 Articles included in quantitative synthesis

Figure 1. Studyflow according to Prisma statement.

pedicle screws (both sliding and fixed screws) together with rods and sublaminar wires. ${ }^{19}$ In total 49 single rods and 78 double rods were secured to the spine using sublaminar wiring techniques. In the study assessed by Eberle et al all rods were secured to the pelvis and in 7 cases Galveston rods were used..$^{13}$ All instrumentations consisted of stainless steel sublaminar wires (16-18G), with exception of Ouellet et al, in which a different technique with titanium rods, wires and sliding pedicles screws was used. In 3 studies postoperative brace therapy was carried out and in 4 studies no postoperative immobilization was used. (Table 1.) 


\section{Curve pattern}

Preoperative curvatures were mostly described as thoraco-lumbar or C-type curves with limited further specification. In all studies only frontal curves (Cobb angles) were assessed preoperatively and during follow-up. Sagittal curve patterns and rotation were not analyzed in the pre-and postoperative course. Average preoperative Cobb angles varied from 51 to 82 degrees and correction postoperatively ranged from $47 \%$ to $78 \%$. However, loss of correction was considerable in 2 studies (65\% and $80 \%$ loss of correction). ${ }^{13,15}$ Patterson described no differences in Cobb angle immediately postoperative in patients with an additional anterior surgery and patient with SSI alone. However, loss of curvature was $18 \%$ in the SSI group and $6 \%$ in the 2 -stage group. ${ }^{16}$ In the study of Pratt et al patients with a Luque Trolley alone, Cobb angle worsened for all patients. In the group treated with Luque trolley and convex epiphysiodesis, Cobb angle worsened in seven patients during 5-year follow-up, remained unchanged in four and improved in two patients. ${ }^{17}$ (Table 2.)

\section{Spinal growth}

Growth of the spine was assessed in various ways. Mostly radiographic rulers were used to calculate the spinal growth. Patterson et al measured the displacement between one Luque rod (L-rod configuration) on the other. This method produces an estimate of growth as long as the L-portion of the rod does not move relative to the vertebra to which it is wired. ${ }^{16}$ In case of rod slippage this could lead to overestimation of the growth. Therefore Patterson et al developed a second measuring method by assessing the vertical height of the instrumented vertebrae by anatomical landmarks. ${ }^{16}$ Other described techniques consisted of measuring the relative distance of the rods ends to the wires or hooks. ${ }^{14}$ Spinal growth of the instrumented levels ranged from $1.6 \mathrm{~cm}$ tot $4.6 \mathrm{~cm}$. 2 studies also added the term 'predicted growth or expected growth'. 11, 15, 16 The Winter shortening formula was used to assess the predicted growth in 2 studies $(0.07 \mathrm{~cm} \times$ no. of levels $x$ years of growth remaining). ${ }^{20,} 21$ Ouellet et al used the Dimeglio's maximum growth estimation of $0.1 \mathrm{~cm}$ per year per vertebrae as the expected growth reference. ${ }^{22}$ In their study a total growth of $2.3 \mathrm{~cm}$ (63\% of expected growth) across an average of 10 instrumented vertebrae was recorded before revision surgery. Subsequent to 


\section{Chapter 2}

\begin{tabular}{|c|c|c|c|c|c|c|}
\hline $\begin{array}{l}\text { Author, } \\
\text { year }\end{array}$ & Design & $\begin{array}{l}\text { Patients } \\
\text { (n) }\end{array}$ & Indication & $\begin{array}{l}\text { Av. age } \\
\text { (years) }\end{array}$ & $\mathrm{F}: \mathrm{M}$ & $\mathrm{FU}(\mathrm{m})$ \\
\hline $\begin{array}{l}\text { Luque } \\
1980\end{array}$ & $\begin{array}{l}\text { Consecutive cohorts } \\
\text { Retrospective }\end{array}$ & 47 & $\begin{array}{c}\text { Neuromuscular } \\
\text { (paralytic scoliosis) }\end{array}$ & $7.2(3-8)$ & $28: 19$ & 56 \\
\hline $\begin{array}{l}\text { Mardjetko } \\
1991\end{array}$ & Retrospective & 9 & $\begin{array}{c}\text { Neuromuscular } \\
\text { Congenital and syndromal }\end{array}$ & $9(2.6-11)$ & $2: 7$ & 48 \\
\hline $\begin{array}{l}\text { Patterson } \\
1990\end{array}$ & $\begin{array}{l}\text { Consecutive cohorts } \\
\text { Retrospective }\end{array}$ & 13 & EOS (not specified) & $5.5(1.5-9)$ & $6: 7$ & 32 \\
\hline $\begin{array}{l}\text { Pratt } \\
1998\end{array}$ & $\begin{array}{l}\text { Consecutive cohorts } \\
\text { Retrospective }\end{array}$ & 25 & $\begin{array}{c}\text { EOS } \\
\text { (infantile and juvenile } \\
\text { idiopathic scoliosis) }\end{array}$ & $3.1(1.5-7.4)$ & $8: 17$ & 60 \\
\hline $\begin{array}{l}\text { Ouellet } \\
2011\end{array}$ & $\begin{array}{l}\text { Consecutive cohorts } \\
\text { Retrospective }\end{array}$ & 5 & $\begin{array}{c}\text { EOS } \\
\text { (idiopathic/cerebral } \\
\text { palsy/syndromal) }\end{array}$ & $6.5(3.8-8.5)$ & - & 48 \\
\hline $\begin{array}{l}\text { Rinsky } \\
1985\end{array}$ & $\begin{array}{l}\text { Consecutive cohorts } \\
\text { Retrospective }\end{array}$ & 9 & $\begin{array}{c}\text { EOS } \\
\text { (cerebral palsy/ syndromal) }\end{array}$ & $8.5(6-11)$ & $7: 2$ & 28 \\
\hline $\begin{array}{l}\text { Eberle } \\
1988\end{array}$ & $\begin{array}{l}\text { Consecutive cohorts } \\
\text { Retrospective }\end{array}$ & 16 & $\begin{array}{c}\text { Paralytic scoliosis } \\
\text { (secondary to poliomyelitis) }\end{array}$ & $7(5-12)$ & 5:11 & 26 \\
\hline
\end{tabular}

Table 1. Study details.

F:M: Female Male ratio; FU: follow-up; (m): months; EOS: Early Onset Scoliosis.

revision surgery the average total growth was $73 \%$ of the expected growth $(3 \mathrm{~cm})$ over a 4-year period. ${ }^{11}$ Mardjetko et al reported a $35 \%$ of the predicted growth. ${ }^{15}$ In the study of Patterson 2 out of 4 patients with SSI alone had a normal spinal growth and 2 patients grew about $50 \%$ or less of predicted rate. Of the nine patients who had anterior growth arrest four were growing at normal rates, 3 patients had 30-50\% predicted rates and 2 patients had shown little or no spinal growth. ${ }^{16}$ The second 


$\begin{array}{cccc}\text { Surgical technique } & \text { Curvature } & \begin{array}{c}\text { Anterior } \\ \text { procedure }\end{array} & \text { Laminar wire type } \\ \begin{array}{c}\text { Single Harrington rod } \\ \text { with hooks + SL wiring }\end{array} & \begin{array}{c}\text { Thoracic (10) } \\ \text { Dorsolumbar (23) } \\ \text { Lumbar (14) }\end{array} & - & \text { 18G Stainless steel } \\ \text { wire loops }\end{array}$

study performing an additional anterior procedure in 18 out of 25 patients (partial arthrodesis) described a $2.9 \mathrm{~cm}$ spinal growth of the instrumented levels in the group without epiphysiodesis in contrast to $2.0 \mathrm{~cm}$ in the group with a partial epiphysiodesis (levels not specified, average of 10 vertebrae). In both groups, these results were obtained after 5 years follow-up. ${ }^{17}$ 


\section{Chapter 2}

\begin{tabular}{|c|c|c|c|c|c|c|}
\hline $\begin{array}{l}\text { Author, } \\
\text { year }\end{array}$ & $\begin{array}{c}\text { Number of } \\
\text { patients }\end{array}$ & $\begin{array}{c}\text { Level } \\
\text { instrumentation }\end{array}$ & FU (m) & $\begin{array}{c}\text { Cobb } \\
\text { Preop }\left(^{\circ}\right)\end{array}$ & Corr (\%) & $\begin{array}{l}\text { Corr loss } \\
\text { at FU (\%) }\end{array}$ \\
\hline $\begin{array}{l}\text { Luque } \\
1980\end{array}$ & 47 & $\begin{array}{c}\text { Level not specified, } \\
\text { Average } 8 \text { segments } \\
(6-15)\end{array}$ & 56 & $72(30-120)$ & 78 & $0-32 \%$ \\
\hline $\begin{array}{l}\text { Mardjetko } \\
1991\end{array}$ & 9 & $\begin{array}{c}\text { Range } \mathrm{S} 1-\mathrm{C} 7 \text {, } \\
\text { average } 12 \text { segments }\end{array}$ & 48 & $51(30-70)$ & 47 & $75 \%$ \\
\hline
\end{tabular}

\begin{tabular}{|c|c|c|c|c|c|c|}
\hline $\begin{array}{l}\text { Patterson } \\
1990\end{array}$ & 13 & $\begin{array}{l}\text { Level not specified, } \\
\text { apex T7-10 }\end{array}$ & 32 & $\begin{array}{c}\text { Total } 59(33-125) \\
9 \text { pt SSI } 44(33-60) \\
4 \text { pt 2-stage } 66(38-125)\end{array}$ & $\begin{array}{l}55 \\
53 \\
59\end{array}$ & $\begin{array}{c}9 \% \\
18 \% \\
6 \%\end{array}$ \\
\hline $\begin{array}{l}\text { Pratt } \\
1998\end{array}$ & 2 & $\begin{array}{c}\text { Level not specified, } \\
\text { average } 10 \text { levels }\end{array}$ & 60 & $\begin{array}{c}7 \text { pt SSI } 56(46-67) \\
14 \text { 2-stage* } 65(40-95) \\
42 \text {-stage ** NS }\end{array}$ & $\begin{array}{l}\text { NS \# } \\
60 \\
\text { NS \#\# }\end{array}$ & $\begin{array}{l}\text { NS } \\
23 \\
\text { NS }\end{array}$ \\
\hline $\begin{array}{l}\text { Ouellet } \\
2011\end{array}$ & 5 & Range T1-L5 & 48 & $60(45-70)$ & 65 & $10(17 \%)$ \\
\hline $\begin{array}{l}\text { Rinsky } \\
1985\end{array}$ & 9 & 13 segments & 28 & $67(51-106)$ & 57 & $21(32 \%)$ \\
\hline $\begin{array}{l}\text { Eberle } \\
1988\end{array}$ & 16 & 14 segments & 26 & $82(45-106)$ & $64 \%$ & 39 (80\%) \\
\hline
\end{tabular}

Table 2. Clinical outcomes.

FU: follow-up; Cobb preop.: Cobb angle preoperatively: Corr: correction; NS: not specified.

\# For Luque trolley alone Cobb angle worsened for all patients. \#\# For juvenile idiopathic scoliosis with a 2 stage procedure, Cobb angle worsened in three patients and improved in one.

* 2 stage group refers to infantile idiopathic scoliosis patient group.

** refers to juvenile idiopathic scoliosis patient group. 


\begin{tabular}{|c|c|c|c|}
\hline $\begin{array}{l}\text { Growth } \\
\text { instrumented segments }\end{array}$ & Complications & Re-operations & Brace therapy \\
\hline $4.6 \mathrm{~cm}$ & $\begin{array}{l}\text { Index procedure: } \\
3 \text { broken rods } \\
6 \text { broken wires } \\
1 \text { infection } \\
1 \text { paraesthesia. }\end{array}$ & $\begin{array}{l}\text { 1-4 per pt } \\
\text { Eventually Harrington bars } \\
\text { replaced by double } L \text { rods }\end{array}$ & no \\
\hline $\begin{array}{l}\text { Average } 1.6 \mathrm{~cm} \\
35 \% \text { predicted growth } \\
\text { group 'poor results' } 1 \mathrm{~cm} \\
23 \% \text { predicted growth (5) } \\
\text { group 'good results' } 2.6 \mathrm{~cm} \\
48 \% \text { predicted growth (4) }\end{array}$ & $\begin{array}{c}\text { (7 pt instrument failure) } \\
6 \text { broken rods ( } 3 \text { pt bilaterally) } \\
4 \text { rod migration/rotation } \\
6 \text { broken wires or pull-out } \\
2 \text { instrument failure } \\
\text { in spinal canal }\end{array}$ & $\begin{array}{l}\text { All pt were revised at } \\
\text { av. of } 4 \text { yr FU; } \\
\text { group with 'poor results' } \\
\text { av. of } 3.2 \text { re-operations }\end{array}$ & $\begin{array}{l}\text { 8/9 pt full-time } \\
\text { bracing }\end{array}$ \\
\hline $\begin{array}{c}\text { SSI alone: } \\
\text { Normal growth (2) } \\
50 \% \text { or less (2) } \\
2 \text { stage procedures } \\
\text { Normal growth (4) } \\
30-50 \% \text { predicted growth (3) } \\
\text { No spinal growth growth (2) }\end{array}$ & 1 wound infection & 0 & $\begin{array}{l}38 \text { months } \\
\text { brace }(9 \mathrm{pt})\end{array}$ \\
\hline $\begin{array}{c}\text { SSI alone (7) } 2.9 \mathrm{~cm} \\
\text { (49\% expected growth) } \\
2 \text { stage procedures (18) } 2.0 \mathrm{~cm} \\
\text { Average } 32 \% \text { expected growth }\end{array}$ & $\begin{array}{c}32 \%: 8 \text { implant failure } \\
3 \text { broken rods and wires, } \\
2 \text { broken wires alone } \\
3 \text { rod prominence } \\
\text { due to rod slippage, } \\
1 \text { infection }\end{array}$ & 9 re-operations: & no \\
\hline $\begin{array}{l}2.3 \mathrm{~cm} \text { (63\% expected growth) } \\
3 \mathrm{~cm} \text { (73\% expected growth) } \\
\text { subsequent to revision surgery }\end{array}$ & $\begin{array}{c}3 / 22 \text { broken cables } \\
\text { (asymptomatic, no revision) } \\
2 \text { outgrew initial constructs } \\
\text { (revised) } \\
1 \text { curve regression }\end{array}$ & 8 re-operations & $\begin{array}{c}12 \text { weeks Boston } \\
\text { brace }\end{array}$ \\
\hline $0.8 \mathrm{~cm}$ & $\begin{array}{c}1 \text { rod migration } \\
2 \text { broken rods; all } 3 \text { revised } \\
7 \text { pt with loss of correction, }\end{array}$ & 3 & no \\
\hline $2.7 \mathrm{~cm}$ & $\begin{array}{l}6 \text { rod fracture } \\
4 \text { rod rotation } \\
1 \text { infection }\end{array}$ & $\begin{array}{c}7 \\
\text { Different areas of } \\
\text { fusion at exploration }\end{array}$ & no \\
\hline
\end{tabular}




\section{Chapter 2}

\section{Complications}

In all index procedures broken rods were observed in 17 patients (14\%). All patients with broken rods were revised. Rod migration or rotation was reported in 12 patients (10\%). 20 patients experienced broken and/or pullout of the wires (16\%). In the study of Luque wires broke at the apex of the curve when a single bar was used at the concave site of the curve, and at the end of the curve when a single bar was used at the convexity of the curve. The other authors did not specify level of wire breakage. One patient with paraesthesia was reported by Luque. ${ }^{14}$ No other neurological deficits were described. Luque reported after revision surgery additional 9 broken rods, 10 broken wires and 4 infections. ${ }^{14}$ Mardjetko had 2 patients in which the short transverse segment of the rod had rotated towards the spinal canal, such that this segment was intralaminar. ${ }^{15}$ Despite this occurrence, no neurological damage was observed. In 4 patients in different studies a deep infection occurred, for which a debridement was performed. In the study of Pratt et al. in one patient a junctional kyphosis developed at the caudal end of the two Luque trolleys and a revision operation was necessary. ${ }^{17}$ In this study curve progression was associated with wire and rod breakage in two patients with a Luque trolley alone.

\section{Re-operations}

Different numbers of re-operations were performed in four studies. ${ }^{13-15,17}$ Luque described 1-4 re-operations per patient in which the Harrington bars were replaced by double $\mathrm{L}$ rods. In this revision group again high complications rates were recorded: 9 broken rods and 10 broken wires, 4 infections and 1 paraesthesia. Breakage of the rods and the necessity to accommodate for growth of the spine were the main reasons for revision in this study. In six patients eventually an arthrodesis was performed because of infection or persistent instrument failure. In these cases, achieved spinal growth until arthrodesis surgery was not specified. In the study of Mardjetko et al, at 4 years follow-up, all patients underwent revision surgery as a result of instrument failure. In all nine patients requiring revision, a variable degree of corrosive staining was encountered and all patients demonstrated some degree of spontaneous fusion. ${ }^{15}$ Abundant fibrous tissue and stiff curves were also found in revision cases by Pratt et al. Ouellet performed 3 additional surgeries to extend the constructs; 2 patients had outgrown their constructs and one revision was performed 
as a result of curve detoriation. ${ }^{11}$ In the remaining studies instrument failure or deep infection was the main cause of revision (Table 2). ${ }^{13,17,18}$

\section{DISCUSSION}

The ideal operative treatment for EOS would be a technique that safely achieves curve correction and prevents curve deterioration while maintaining longitudinal spinal growth and thus enabling adequate volumetric thoracic cage and lung development. The Harrington system was one of the first surgical techniques for the correction of EOS. ${ }^{6,23}$ Often, this distraction-based technique was used in combination with posterior arthrodesis of the spine. ${ }^{24-26}$ Moe et al subsequently emphasized that if this technique is used without arthrodesis, the use of a full-time brace is essential. ${ }^{27} \mathrm{SSI}$ by means of sublaminar wiring and fixation of 1 or 2 rods was originally described by Luque, without the need for bracing and with the aim of preserving spinal growth. ${ }^{5}$ This technique provided improved correction and stability over the Harrington Rod system. However, high complication rates necessitated fusion of the spine and therefore the Luque Trolley technique without fusion has been abandoned. ${ }^{6,28-30}$

Currently, hybrid constructs with a combination of sublaminar wiring and pedicle screw/rod instrumentation have emerged and beneficial concepts of the Luque Trolley are implemented in these systems. ${ }^{9}$ As yet, these techniques are almost exclusively performed in combination with arthrodesis of the spine. For the use of SSI with sublaminar wiring in growth-guidance surgery, the risks, pitfalls and results associated with this technique have to be assessed. Despite the fact that the Luque trolley and alterations to this technique have been widely used in pediatric scoliosis surgery, literature on this technique without performing a fusion of the spine is rare. We have therefore performed a systematic review of the literature and found 7 studies describing the results of SSI with the use of sublaminar wires without full spinal fusion. Different surgical techniques were described in the included studies. All included articles described a growth-guidance technique with the use of sublaminar wiring. Ouellet described the use of a modern Luque trolley, which also involved the use of sliding pedicle screws. ${ }^{11}$ All authors obtained a high degree of postoperative curve correction (47-78\%). Mardjetko et al and Eberle reported loss 


\section{Chapter 2}

of correction up to $80 \%{ }^{13,17}$ Pratt therefore suggested a convex epiphysiodesis together with the SSI. This technique was previously described by Patterson. ${ }^{16}$ Patterson described no significant improvement in Cobb angle immediately after surgery in patients who had anterior surgery compared to those who had SSI alone. However, less curve deterioration was seen in the group with a 2-stage procedure over 2 years. ${ }^{16} 4$ out of the 7 articles reported a loss of correction of less than $20 \%$. A limiting factor in analysis of the curves was the lack of registration of sagittal curve patterns and rotation. Correction offered by other distraction based techniques, like the vertical expandable prosthetic titanium rib (VEPTR) and growing rods, is often less than $50 \%$ of the preoperative curvatures. ${ }^{31}$

A high degree of instrumentation failure was recorded by 6 of the 7 studies found. With the use of sublaminar wires in growth-guidance surgery, instrument failure can be expected as a result of the high continuous load on the instrumentation. Unfortunately, the authors did not record the amount of spinal growth until revision.

Five studies described the occurrence of rod migration or rotation during follow-up. The ' $\mathrm{L}$ ' configuration of the Luque rods was originally designed to decrease the chance of rod rotation or migration. Mardjetko, however, had 2 patients in whom the transverse segment of the L-rod was migrated intralaminarly after rotating towards the spinal canal. ${ }^{15}$ In the past, alterations of Luque trolley were designed to improve stability to the system; Allen and Ferguson designed the Galveston technique as a better means of achieving fixation to the sacrum. ${ }^{28}$ This technique was applied by Eberle et al (this review) and did not prevent to occurrence of rod fracture and rod migration in this study. ${ }^{13}$ In all 3 patients with instrumentation to the sacrum assessed by Mardjetko, both Luque rods subsequently fractured, demonstrating the high forces and risks when elongating the instrumentation to the sacrum. ${ }^{15}$

Sublaminar wiring has been associated with high complication rates wiring such as neurological damage, wire breakage and difficulties with wire removal. ${ }^{32-}$ $3716 \%$ of all described patients in the study groups experienced wire breakage or wire pull-out. No severe neurological deficits were recorded. The level of wire breakage was generally not specified. Luque described wire breakage at different levels when using a single bar; wire breakage was seen at the apical levels when 
using a concave bar, however, when a convex rod was used wire breakage was seen at the end of the curvature, showing the maximum stress load in each situation. ${ }^{14}$ If wire breakage led to instrumentation failure with loss of correction, revision surgery was performed with subsequently arthrodesis of the spine. Other reasons for revision surgery were: deep infection, spinal 'outgrowth' of the instrumentation and curve deterioration. Complications associated with wire removal were not described. Other new developed growth-sparing spine implants also experienced high rates of instrument failure. For example, the vertical expandable prosthetic titanium rib (VEPTR) and growing rods, which are spine-based distraction techniques, have frequently encountered instrumentation breakout, rod breakage and instrument prominence. ${ }^{38}$ The Luque trolley, however, acts as a growth-guidance system. Shilla ${ }^{T M}$ system (Medtronic, Minneapolis, MN USA), a novel growth-guidance system, utilizes sliding pedicle screws in which rods are able to slide during spinal growth. Although early results are encouraging, metal on metal articulation can lead to metal wear particles. ${ }^{39,40}$ Metallosis-associated complications with the formation of seroma and sinuses and concentrations of Ti and Vanadium (V) ions in the blood have been found in patients after instrumentation of this growth guidance sliding instrumentation. ${ }^{41}$ Pratt and Mardjetko (this review) also encountered the occurrence of metallosis. ${ }^{15,17}$ To avoid metal-wires associated complications and to allow for enhanced sliding, artificial polymeric and poly-ethylene sublaminar bands already have been developed for its use in scoliosis surgery. ${ }^{42,43}$ Ouellet et al have tested a pedicle screw coupled to a peak cable tie lined with a polyethylene spacer in an ovine model to function as an alternative sliding anchor, which allowed for $96 \%$ of growth between the instrumented segments. However, this study showed high rates of instrument failure. ${ }^{19}$ Recently, the results of the Shilla growth guidance system and growing rods were compared by Luhman et al. In general, the Shilla system compared favorably with the growing rods in terms of correction and maintenance of the curve and spinal length and growth. At four years follow-up average growth per month (T1-S1) was $0.14 \mathrm{~cm}$ for the Shilla group and $0.11 \mathrm{~cm}$ for the growing rod group. ${ }^{44}$ Luque recorded a spinal growth of $4.6 \mathrm{~cm}$ on an average of 8 instrumented segments. Expected spinal growth (Winter formula) of these instrumented levels, however, is $2.8 \mathrm{~cm}$. Luque states that this phenomenon is as a result of elongation of the immobilized area by repeated surgeries (1-4 re-operations 


\section{Chapter 2}

per patient) and the elimination of postural curves. This suggests that the actually vertebral height gain or growth restriction could not be obtained in this manner. Patterson described 6 patients (total 13) with normal growth of the instrumented segments. A remarkable finding is that 4 patients in the group with an anterior growth arrest had a normal spinal growth.16 Pratt recorded a small difference of growth $(0.9 \mathrm{~cm})$ between the group with and without epihysiodesis. ${ }^{17}$ This could suggest a high rate of spontaneous fusion in the group without epiphysiodesis. Mardjetko et al encountered extensive spontaneous fusions in all patients. ${ }^{15}$ An experimental study in dogs showed that longitudinal growth occurred after SSI (with sublaminar wiring) without the presence of fusion of the spine. Furthermore, overtightening of the wires slowed the growth by $50 \%$ in this study. They stated that the tightness of the sublaminar wires probably transmitted more compression to the anterior vertebral growth centers. ${ }^{45}$ In 2 animal studies conducted by our research group substantial growth was observed after SSI in an ovine spine. In these studies, however, spontaneous fusion had occurred without significantly restricting spinal growth. ${ }^{43,46}$ Another disadvantage of the Luque trolley is that the capacity of the Luque trolley to facilitate growth can be exceeded. Pratt et al demonstrated this occurrence in 14 patients. After 5 year follow-up, resolving curves began to progress because spinal growth expanded the capacity of the Luque trolley. By purposefully leaving the rods long as stated by Rinsky et al, expected spinal growth could be accommodated. Most growth-friendly spinal implants will experience a growthcapacity problem as long as the spine will grow. This phenomenon seems to have more impact in growth-distraction surgery; with the use of the VEPTR and growing rods, repeated lengthening procedures are necessary, often in intervals of 6 months or less. ${ }^{47}$ In a recent study, the Shilla growth guidance system had a 4 -fold decrease in additional surgeries compared to growing-rods. ${ }^{44}$

This review has several limitations; All included studies conducted were retrospective cohort studies. Mardjetko has outlined only cases requiring revision and did not contain a consecutive cohort. Results from this study therefore were biased and mainly negative results were described. ${ }^{15}$ Another limitation of this review is that the studies generally consisted of small group sizes. Three out of seven studies had a group size of less than 10 patients. ${ }^{11,15,18}$ 
In EOS surgery, the concept of a growth guided spinal segmental instrumentation with sublaminar wiring in EOS surgery is still an attractive option. As a result of the growth-guidance principle, the number of re-operations occurring with lengthening procedures during distraction-based growth-sparing surgery can also be decreased. The high rate of instrument failure and subsequent loss of curve correction remains a concern. The amount of growth preservation appears to vary widely between the included studies and high rates of spontaneous fusion have been reported. Insertion of pedicle screws as a strong anchor point in a modified Luque trolley and applying low-friction wires with higher fatigue strength can probably decrease instrumentation failure and enhance the torsion forces of the instrumentation. In this manner rod migration with subsequently loss of correction can also be prevented. ${ }^{8}$ With the emergence of polyester and ultra high molecular weight poly-ethylene sublaminar wires, metallosis associated problems can be prevented and sliding properties can be improved. ${ }^{9,43}$ 


\section{Chapter 2}

\section{REFERENCES}

1. Akbarnia BA. Management themes in early onset scoliosis. J Bone Joint Surg Am. 2007;89 Suppl 1:42-54.

2. Vitale MG, Matsumoto $\mathrm{H}$, Bye $\mathrm{MR}$, et al. A retrospective cohort study of pulmonary function, radiographic measures, and quality of life in children with congenital scoliosis: an evaluation of patient outcomes after early spinal fusion. Spine 2008;33:1242-9.

3. Campbell RM, Jr., Smith MD, Mayes TC, et al. The effect of opening wedge thoracostomy on thoracic insufficiency syndrome associated with fused ribs and congenital scoliosis. J Bone Joint Surg Am. 2004;86-A:1659-74.

4. Hicks JM, Singla A, Shen FH, Arlet V. Complications of pedicle screw fixation in scoliosis surgery: a systematic review. Spine (Phila Pa 1976) 2010;35:E465-70.

5. Luque ER. Segmental spinal instrumentation for correction of scoliosis. Clin Orthop Relat Res. 1982:192-8.

6. Herndon WA, Sullivan JA, Yngve DA, Gross RH, Dreher G. Segmental spinal instrumentation with sublaminar wires. A critical appraisal. J Bone Joint Surg Am. 1987;69:851-9.

7. Ferguson RL, Allen BL, Jr. The technique of scoliosis revision surgery utilizing L-rod instrumentation. J Pediatr Orthop. 1983;3:563-71.

8. Wild A, Jager M, Kramer R, Werner A, Krauspe R. A new technique for the surgical management of deformities in the growing spine. Biomed Tech (Berl) 2002;47:270-1.

9. Gazzeri R, Faiola A, Galarza M, Tamorri M. Universal Clamp system in thoracolumbar spinal fixation: technical note. Acta Neurochir (Wien) 2009;151:1673-80.

10. Takahata M, Ito M, Abumi K, et al. Comparison of novel ultra-high molecular weight polyethylene tape versus conventional metal wire for sublaminar segmental fixation in the treatment of adolescent idiopathic scoliosis. J Spinal Disord Tech. 2007;20:449-55.

11. Ouellet J. Surgical technique: modern Luque trolley, a self-growing rod technique. Clin Orthop Relat Res. 2011;469:1356-67.

12. Williams BA, Matsumoto H, McCalla DJ, et al. Development and initial validation of the Classification of Early-Onset Scoliosis (C-EOS). J Bone Joint Surg Am. 2014;96:1359-67.

13. Eberle CF. Failure of fixation after segmental spinal instrumentation without arthrodesis in the management of paralytic scoliosis. J Bone Joint Surg Am. 1988;70:696-703.

14. Luque ER. Paralytic scoliosis in growing children. Clin Orthop Relat Res. 1982:202-9. 
15. Mardjetko SM, Hammerberg KW, Lubicky JP, Fister JS. The Luque trolley revisited. Review of nine cases requiring revision. Spine (Phila Pa 1976) 1992;17:582-9.

16. Patterson JF, Webb JK, Burwell RG. The operative treatment of progressive early onset scoliosis. A preliminary report. Spine (Phila Pa 1976) 1990;15:809-15.

17. Pratt RK, Webb JK, Burwell RG, Cummings SL. Luque trolley and convex epiphysiodesis in the management of infantile and juvenile idiopathic scoliosis. Spine (Phila Pa 1976) 1999;24:1538-47.

18. Rinsky LA, Gamble JG, Bleck EE. Segmental instrumentation without fusion in children with progressive scoliosis. J Pediatr Orthop. 1985;5:687-90.

19. Ouellet JA, Ferland CE, Racloz G, et al. Evaluation of the Modern Luque Trolley Construct for Treatment of Early Onset Scoliosis Using a Gliding Implant in an Immature Animal Model. Clin Spine Surg. 2017;30:E460-E465

20. Figueiredo UM, James JI. Juvenile idiopathic scoliosis. J Bone Joint Surg Br. 1981;63-B:616.

21. Wenger DR, Carollo JJ, Wilkerson JA, Jr. Biomechanics of scoliosis correction by segmental spinal instrumentation. Spine (Phila Pa 1976) 1982;7:260-4.

22. Dimeglio A, Canavese F. The growing spine: how spinal deformities influence normal spine and thoracic cage growth. Eur Spine J. 2012;21:64-70.

23. Harrington PR. Treatment of scoliosis. Correction and internal fixation by spine instrumentation. J Bone Joint Surg Am. 1962;44-A:591-610.

24. Bonnett C, Brown JC, Grow T. Thoracolumbar scoliosis in cerebral palsy. Results of surgical treatment. J Bone Joint Surg Am. 1976;58:328-36.

25. Bonnett C, Brown JC, Perry J, et al. Evolution of treatment of paralytic scoliosis at Rancho Los Amigos Hospital. J Bone Joint Surg Am. 1975;57:206-15.

26. Lonstein JE, Akbarnia A. Operative treatment of spinal deformities in patients with cerebral palsy or mental retardation. An analysis of one hundred and seven cases. J Bone Joint Surg Am. 1983;65:43-55.

27. Moe JH, Kharrat K, Winter RB, Cummine JL. Harrington instrumentation without fusion plus external orthotic support for the treatment of difficult curvature problems in young children. Clin Orthop Relat Res. 1984:35-45.

28. Allen BL, Jr., Ferguson RL. The Galveston technique for $L$ rod instrumentation of the scoliotic spine. Spine (Phila Pa 1976) 1982;7:276-84. 


\section{Chapter 2}

29. Bentley G, Haddad F, Bull TM, Seingry D. The treatment of scoliosis in muscular dystrophy using modified Luque and Harrington-Luque instrumentation. J Bone Joint Surg Br. 2001;83:22-8.

30. Davies AG, McMaster MJ. The effect of Luque-rod instrumentation on the sagittal contour of the lumbosacral spine in adolescent idiopathic scoliosis and the preservation of a physiologic lumbar lordosis. Spine (Phila Pa 1976) 1992;17:112-5.

31. Akbarnia BA, Marks DS, Boachie-Adjei O, Thompson AG, Asher MA. Dual growing rod technique for the treatment of progressive early-onset scoliosis: a multicenter study. Spine (Phila Pa 1976) 2005;30:S46-57.

32. Bernard TN, Jr., Johnston CE, 2nd, Roberts JM, Burke SW. Late complications due to wire breakage in segmental spinal instrumentation. Report of two cases. J Bone Joint Surg Am. 1983;65:1339-45.

33. Cervellati S, Bettini N, Bianco T, Parisini P. Neurological complications in segmental spinal instrumentation: analysis of 750 patients. Eur Spine J. 1996;5:161-6.

34. Geremia GK, Kim KS, Cerullo L, Calenoff L. Complications of sublaminar wiring. Surg Neurol. 1985;23:629-

35. Diab M, Smith AR, Kuklo TR, Spinal Deformity Study G. Neural complications in the surgical treatment of adolescent idiopathic scoliosis. Spine 2007;32:2759-63.

36. Reames DL, Smith JS, Fu KM, et al. Complications in the surgical treatment of 19,360 cases of pediatric scoliosis: a review of the Scoliosis Research Society Morbidity and Mortality database. Spine 2011;36:1484-91.

37. Wilber RG, Thompson GH, Shaffer JW, Brown RH, Nash CL, Jr. Postoperative neurological deficits in segmental spinal instrumentation. A study using spinal cord monitoring. J Bone Joint Surg Am. 1984;66:1178-87.

38. Akbarnia BA, Emans JB. Complications of growth-sparing surgery in early onset scoliosis. Spine (Phila Pa 1976) 2010;35:2193-204.

39. McCarthy RE, McCullough FL. Shilla Growth Guidance for Early-Onset Scoliosis: Results After a Minimum of Five Years of Follow-up. J Bone Joint Surg Am. 2015;97:1578-84.

40. McCarthy RE, Sucato D, Turner JL, Zhang H, Henson MA, McCarthy K. Shilla growing rods in a caprine animal model: a pilot study. Clin Orthop Relat Res. 2010;468:705-10.

41. Lukina $\mathrm{E}$, Laka A, Kollerov $\mathrm{M}$, et al. Metal concentrations in the blood and tissues after implantation of titanium growth guidance sliding instrumentation. Spine J. 2016;16:380-8. 
42. Mazda K, Ilharreborde B, Even J, Lefevre Y, Fitoussi F, Pennecot GF. Efficacy and safety of posteromedial translation for correction of thoracic curves in adolescent idiopathic scoliosis using a new connection to the spine: the Universal Clamp. Eur Spine J. 2009;18:158-69.

43. Bogie R, Roth A, Faber S, et al. Novel Radiopaque UHMWPE Sublaminar Wires in a Growth-Guidance System for the Treatment of Early Onset Scoliosis: Feasibility in a Large Animal Study. Spine (Phila Pa 1976) 2014.

44. Luhmann SJ, McCarthy RE. A Comparison of SHILLA GROWTH GUIDANCE SYSTEM and Growing Rods in the Treatment of Spinal Deformity in Children Less Than 10 Years of Age. J Pediatr Orthop. 2016.

45. McAfee PC, Lubicky JP, Werner FW. The use of segmental spinal instrumentation to preserve longitudinal spinal growth. An experimental study. J Bone Joint Surg Am. 1983;65:935-42.

46. Bogie R, Voss L, Arts JJ, et al. UHMWPE Sublaminar Wires in Posterior Spinal Instrumentation: Stability and Biocompatibility Assessment in an Ovine Pilot Study. Clin Spine Surg. 2016.

47. Akbarnia BA, Breakwell LM, Marks DS, et al. Dual growing rod technique followed for three to eleven years until final fusion: the effect of frequency of lengthening. Spine (Phila Pa 1976) 2008;33:984-90. 

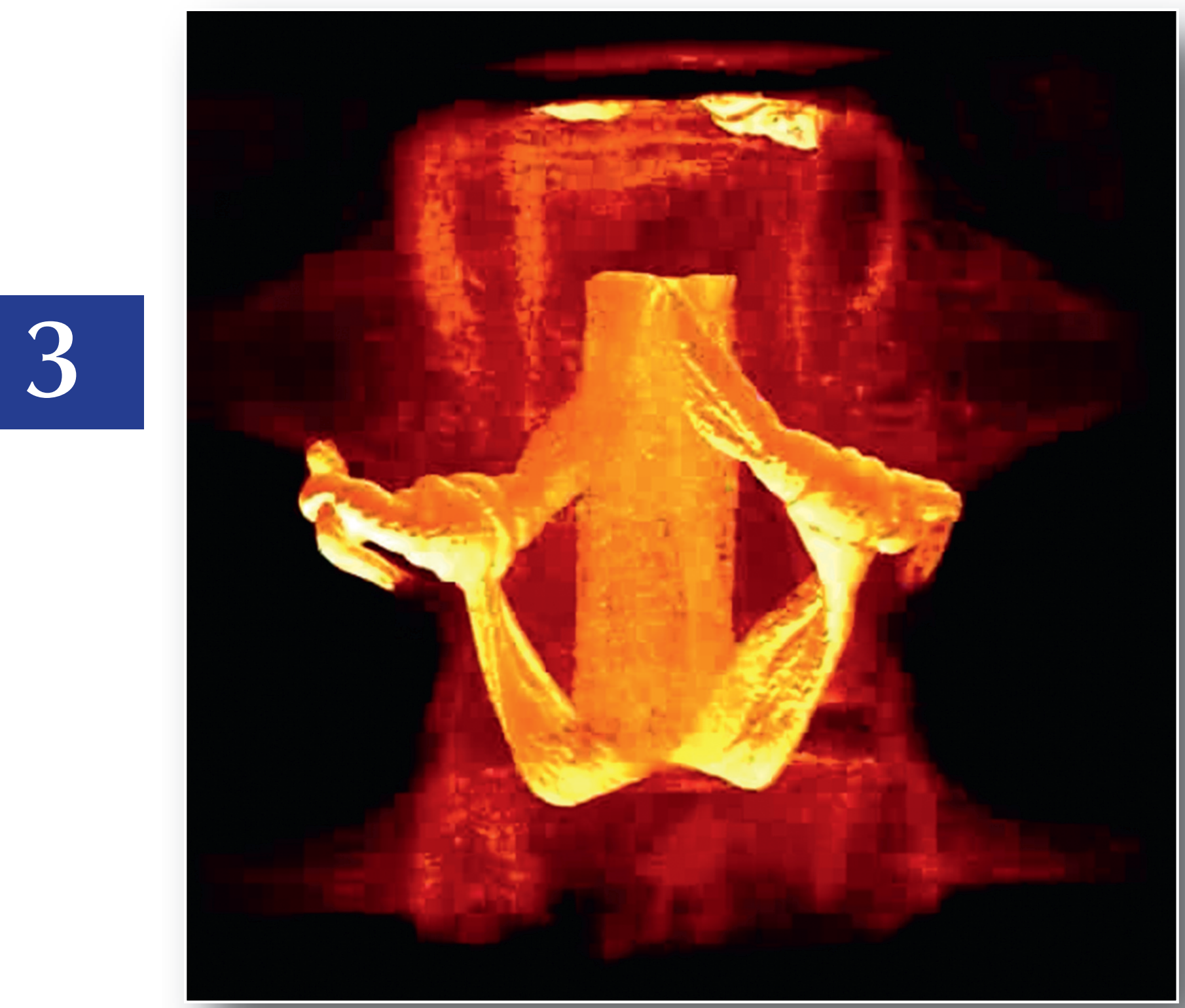


\section{CHAPTER 3}

\section{The use of metal sublaminar wires in modern growth- guidance scoliosis surgery. A report of 4 cases.}

Submitted

Rob Bogie, Jacobus J. Arts, Simone N. Koole, Lodewijk W. van Rhijn, Paul C. Willems 


\section{Chapter 3}

\section{3}

\section{ABSTRACT}

Background. To avoid early fusion and allow residual growth of the spine in early onset scoliosis treatment, growth guided scoliosis surgery can be performed. Four patients with early onset scoliosis are presented in which a growth-guidance instrumentation is used with sliding Titanium (Ti) sublaminar cables. Residual growth of the spine can be preserved using metal sublaminar wiring, however, several drawbacks of this technique and type of material are illustrated.

Methods. Four patients with progressive neuromuscular scoliosis were treated with a posterior stabilization. A fusionless growth-guidance instrumentation was used consisting of a combination of lumbar pedicle screws and sliding Ti sublaminar cables along Cobalt Chrome rods.

Results. In two cases the described growth guidance technique provided sufficient stability and correction of the curvature with preservation of growth. In two patients the instrumentation failed due to upper thoracic sublaminar wire breakage. The ongoing abrasion of the rod-wire interface caused severe metallosis. In these cases a debridement and revision surgery was performed with partial fusion of the spine.

Conclusions. Growth-guidance techniques with sliding metal sublaminar wires seem a valuable solution for the preservation of spinal growth in EOS surgery. High curvatures, however, have a higher chance of failure and demand for more corrective strength and support of the instrumentation with a higher chance of failure. The use of metal sublaminar wires in a 'sliding' instrumentation can lead to early breakage and metallosis.

Level of evidence. Level 4, case series.

Clinical relevance. Surgeons should be aware of possible complications associated with the use of metal laminar wires in spinal fusion and growth-guidance scoliosis surgery. The implementation of materials containing higher fatigue strength and lower friction properties (e.g. UHMWPE wires), may avoid these potential complication risks. 


\section{INTRODUCTION}

In the management of early onset scoliosis (EOS), fusion can lead to a short trunk stature with resulting volumetric growth restriction of the thoracic cage, which restricts pulmonary development. ${ }^{1}$ The occurrence of the crankshaft phenomenon with secondary deformity, also discourages early spinal fusion. ${ }^{2}$ With the advancement of pedicle screw fixation and with further improvement of sublaminar wiring techniques and mechanical properties, growth-guidance systems are promising techniques to serve as an alternative to spinal fusion in EOS surgery. Examples are the Shilla system ${ }^{3}$ and a modern Luque trolley ${ }^{4}$, which both rely on pedicle screws and/or titanium sublaminar wires sliding along metal rods. In this manner, partial growth of the spine can be preserved.

Sublaminar wires have been widely used in conjunction with posterior instrumentation in scoliosis surgery. Luque was the first to introduce the Luque-rod segmental spinal instrumentation (LSSI). ${ }^{5}$ LSSI consisted of segmental spinal fixation in which L-rods were attached to the spine using sublaminar wires. However, this type of wiring has some serious drawbacks, such as neurological damage, wire breakage and difficulties with wire removal. ${ }^{6-11}$ Since the successful introduction of pedicle screw instrumentation in scoliosis surgery, nowadays sublaminar wiring is mainly used in hybrid systems. Due to the difficulty of pedicle screw insertion in the deformed spine, sublaminar wiring remains a valuable option to support posterior instrumentation and to realize apical translation of the curve. ${ }^{12,13}$ In case of spinal fusion, the wire must be capable of upholding the corrective load until bony fusion has occurred. If bony fusion has failed metal fatigue can lead to wire breakage. ${ }^{14,15}$ With the use of sublaminar wires in growth-guidance systems (nonfusion surgery), there is an inherent risk that the high continuous load and abrasion of the wires with the metal rods could increase the chance of instrument failure and subsequent loss of curve correction.

To illustrate the risks and benefits of the use of metal sublaminar wires in a growth-guidance system for the correction of EOS, we present 4 cases in which a modified Luque trolley has been used. 


\section{Chapter 3}

\section{Case 1.}

A 10-year-old girl with severe neuromuscular scoliosis (congenital myopathy) presented with a progressive thoraco-lumbar curve (Cobb angle 69 ${ }^{\circ}$, Figure 1a). Due to curve progression and trunk imbalance she was indicated for posterior hybrid instrumentation surgery with a modified Luque trolley. In September 2012, a posterior stabilization and correction was performed using a hybrid system consisting of lumbar pedicle screws (L3-L5) and two $4.75 \mathrm{~mm}$ Cobalt Chrome (CoCr) rods (CD Horizon® Solera $^{\mathrm{TM}}$, Medtronic Sofamor Danek, Memphis TN, USA) along the curvature. Correction and fixation was achieved by gradually applying tension of Titanium (Ti) sublaminar cables (Atlas ${ }^{\circledR}$ cable, Medtronic, Memphis TN, USA) at lumbar and thoracic levels (T3-L1). Postoperative radiographic control showed no signs of complications and correction of the curve was satisfactory (Cobb angle 33\%, Figure 1b). After 5 months, routine follow-up radiography revealed fracturing of 5 upper thoracic sublaminar cables with loss of correction of the curve (Cobb angle $44^{\circ}$, Figure 1c). The broken sublaminar Ti cables were surrounded by severe metallosis (Figure 2a), for which surgical debridement was performed. Revision surgery was performed with
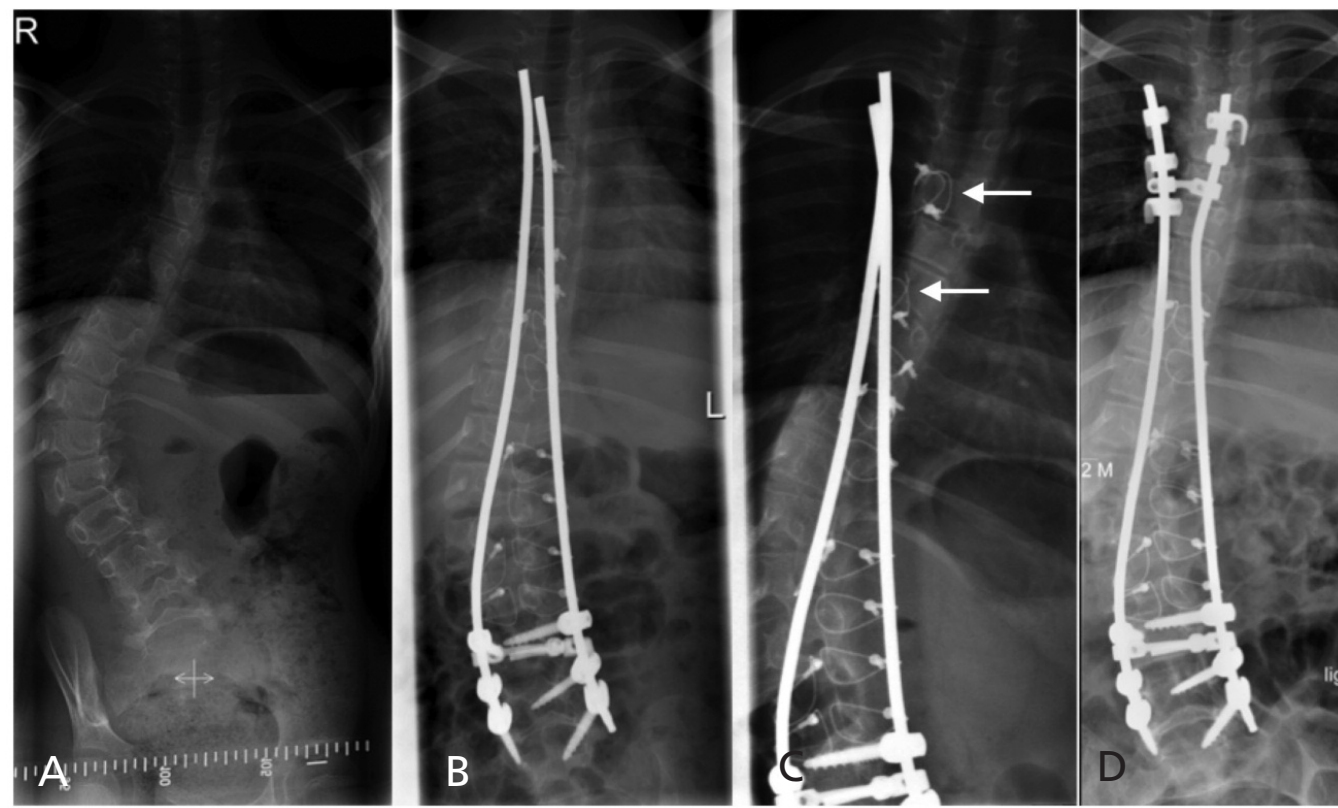

Figure 1. Coronal radiographs. (A) Scoliosis preoperatively. (B) Instrumented spine postoperatively. (C) Observation of the thoracic broken sublaminar cables (arrows) at 5-month follow-up. (D) 3 years after revision surgery. 


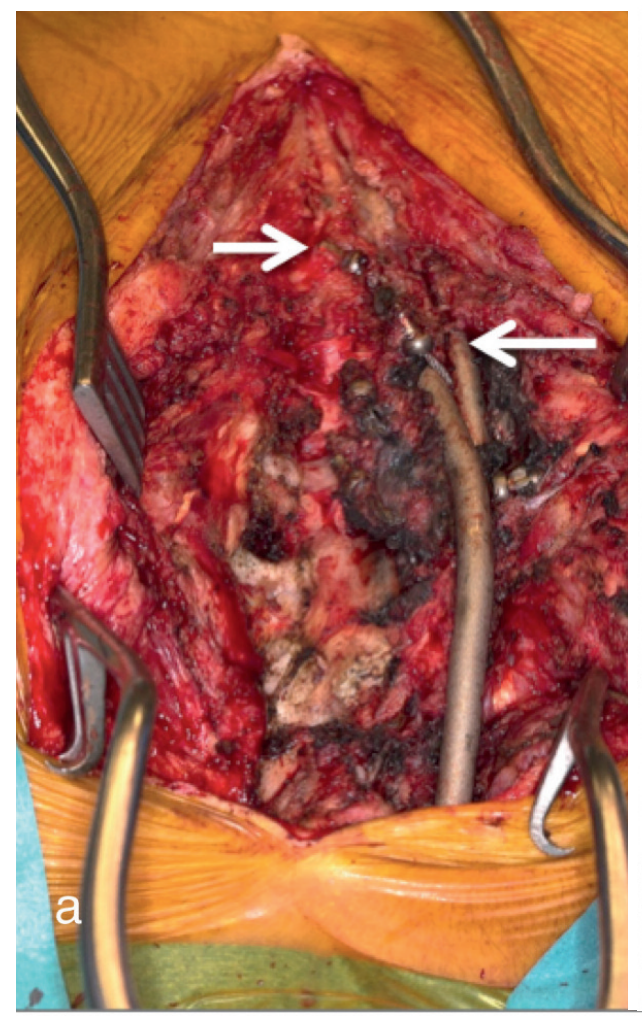

Figure 2a. Severe metallosis surrounding the broken $\mathrm{Ti}$ cables. (arrows)

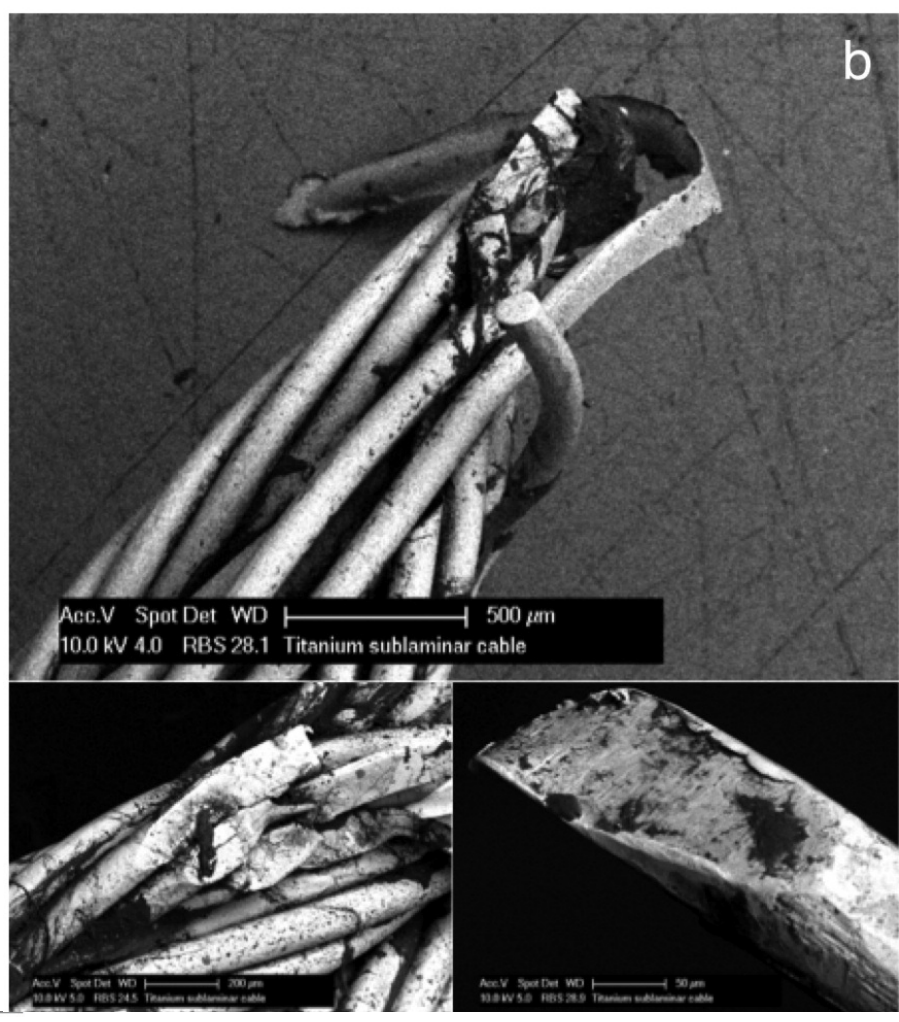

Figure 2b. Electron microscopy analysis of a broken Ti cable. The oblique surface of fracture demonstrates signs of metal fatigue failure.

replacement of the proximal wires by hooks and a spinal fusion at the thoracic levels was performed. The postoperative course was uncomplicated and curve correction was preserved at 3 -year radiological follow-up (Cobb angle $27^{\circ}$, Figure $1 \mathrm{~d}$ ).

\section{Case 2.}

In March 2014, a 4-year old girl with spinal muscle atrophy type 2 and a progressive mild thoracic scoliosis (Cobb angle $29^{\circ}$ ) was scheduled for stabilization surgery, as bracing therapy was not tolerated and progressive sitting balance problems were experienced. The instrumentation consisted of lumbar pedicle screw insertion (L3L5) and CoCr rods along the spine fixed with Ti cables at levels T4-L2. At the upper instrumented level a crosslink was used to enhance stability. After a follow-up of 2 years no complications had occurred and integrity of the instrumentation was 


\section{Chapter 3}

sustained. Postoperatively, the curve was corrected (Cobb angle $10^{\circ}$ ) and radiographs showed the sliding effect of the sublaminar wires along the rods, which had allowed growth of the thoracic segments (Figure 1b,c). Sitting balance was improved and a growth of the instrumented levels of approximately $2 \mathrm{~cm}$ was achieved within 2year follow-up (Cobb angle still $10^{\circ}$ ).
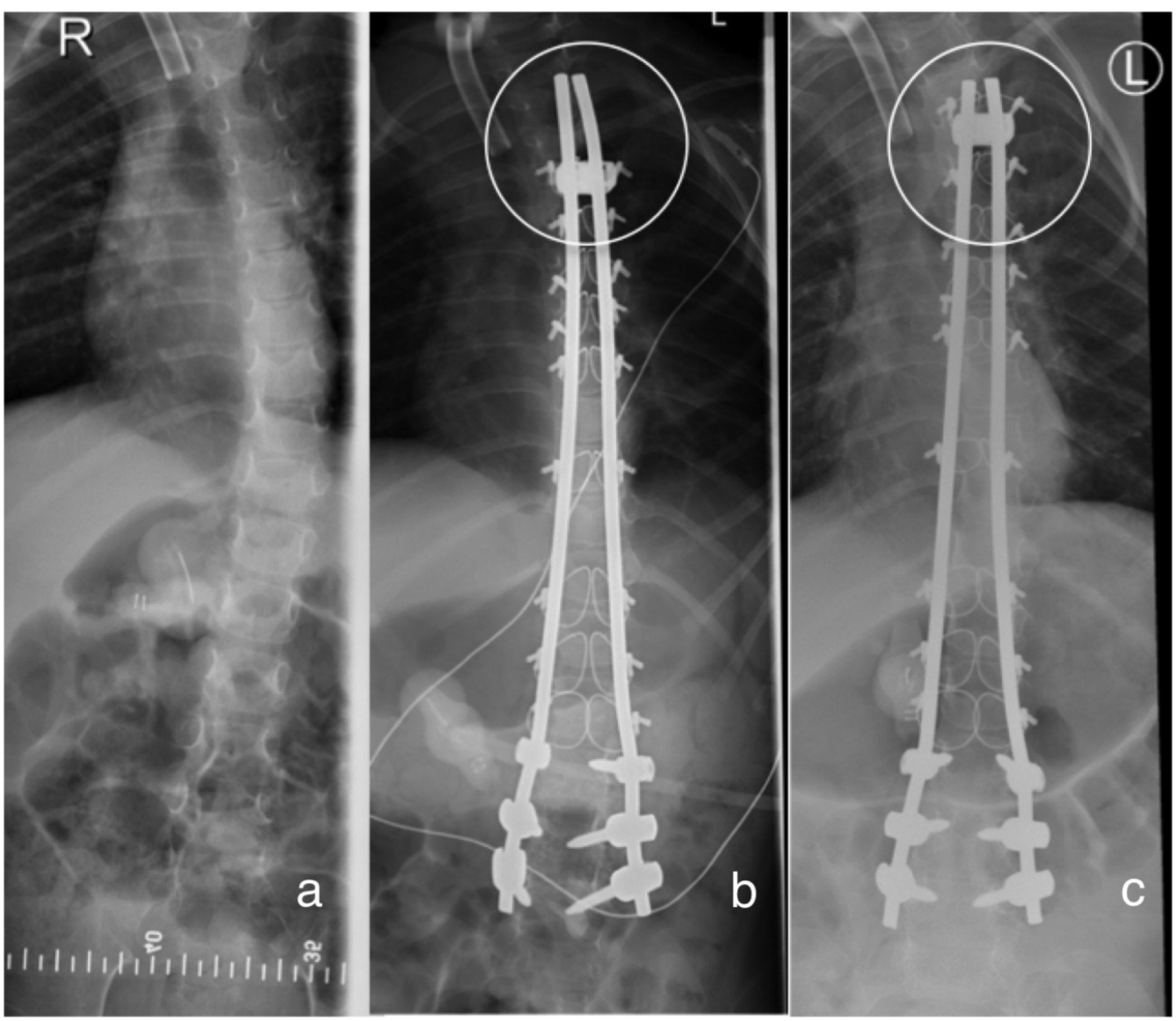

Figure 3. Coronal radiographs. (a) Preoperative curvature. (b) Postoperative instrumentation with correction of the curve. (c) Preserved stability of the instrumentation at 2-year follow-up showing the sliding effect at the most proximal rod/wire juncture (circles). Growth was determined as the difference in length between the proximal rod-crosslink distance direct postoperatively and at 2-year follow-up radiography. 


\section{Case 3.}

In March 2012, a 7-year old girl diagnosed with Rett syndrome, underwent a posterior spinal stabilization for a progressive thoraco-lumbar scoliosis with a Cobb angle of $67^{\circ}$ (Figure 3a). A hybrid posterior instrumentation with bilateral pedicle screws in L4, L5 and S1) and CoCr rods was used. At the levels T4 to L3 sublaminar Atlas ${ }^{\circledR}$ cables were attached to the rods. Curve correction and implant positioning was satisfactory (Cobb angle $44^{\circ}$ ). The postoperative course was uneventful. After 1 year follow-up the patient complained of back pain without neurological signs or symptoms. The radiographs revealed 2 broken sublaminar cables (level T4 and T5) with resulting loss of curve correction (Figure 4c, Cobb angle 60\%). During revision surgery metallosis was observed in the surrounding tissue and debrided at the site of the broken cables. These sublaminar cables were removed and replaced with transverse process hooks and a spinal fusion was performed at the thoracic levels (Figure $4 d$ ). After 4 years follow-up instrumentation and curve correction were unaffected. As a result of fusion of the spine and placement of the transverse process hooks no residual growth of the instrumented spine was observed.

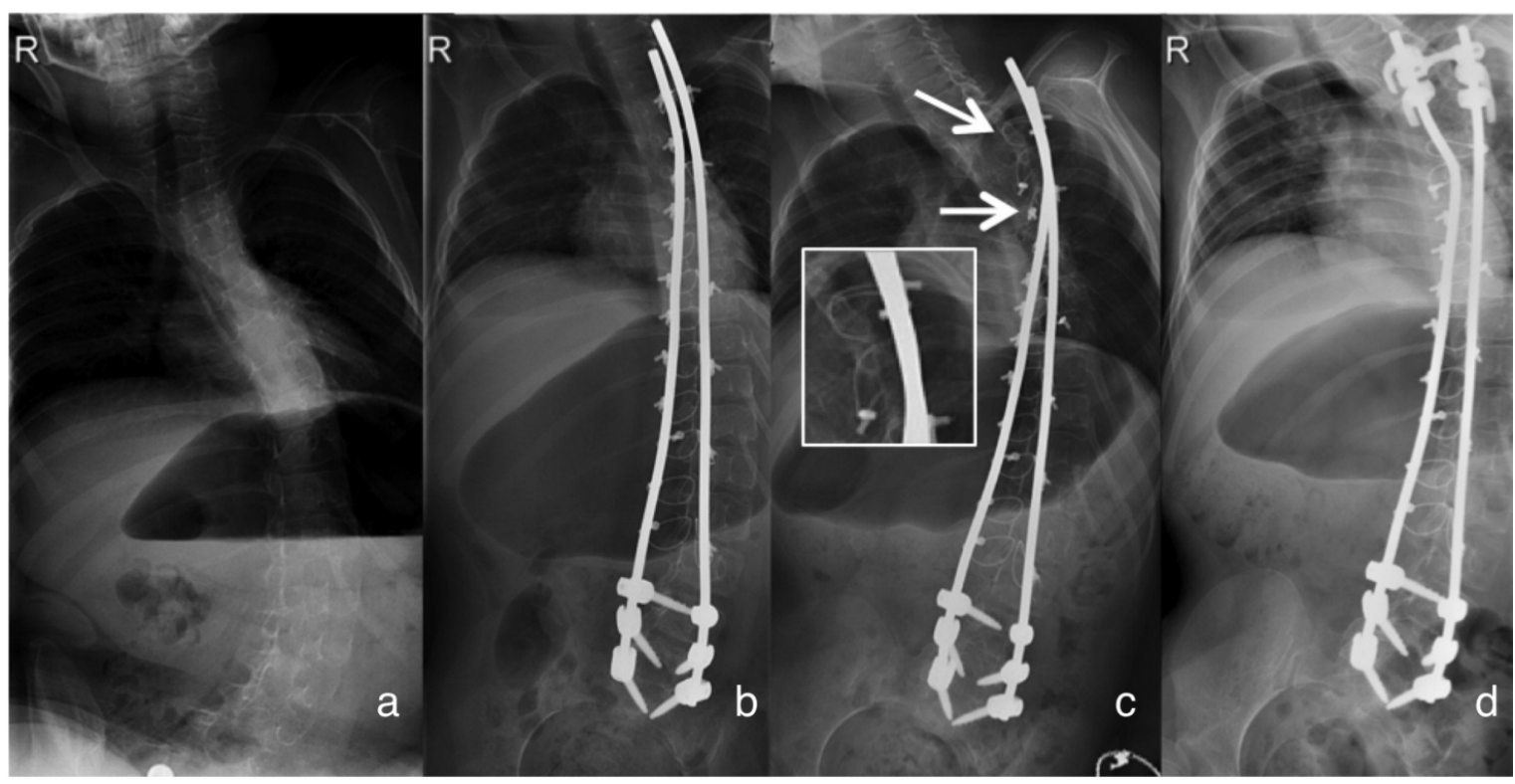

Figure 4. Coronal radiographs. (a) Preoperative curvature of the spine. (b) Postoperative radiograph. (c) Radiograph revealing the 2 broken cables at level T4 and T5 (arrows). (d) Postoperative radiograph following revision surgery. 


\section{Chapter 3}

\section{Case 4.}

In March 2009, a posterior spinal stabilization was performed in a 9-year old boy with a progressive thoracolumbar scoliosis because of spinal muscle atrophy type 1 with chronic respiratory failure for which he used nocturnal non-invasive respiratory support. The combination of a thoraco-lumbar coronal curve of $24^{\circ}$ with a progressive thoracic kyphosis of $88^{\circ}$ and poor sitting balance in the wheelchair necessitated surgery. A hybrid instrumentation was used consisting of lumbar pedicle screws (L3-L5) and thoracic sublaminar wiring (Th4-L1) fixed to $2 \mathrm{CoCr}$ rods. Postoperatively, the thoraco-lumbar curvature showed a coronal Cobb angle of $14^{\circ}$ and reduction of the kyphosis to $63^{\circ}$ (Figure 5). The postoperative rehabilitation was uncomplicated and during the last check-up, 6 years postoperatively, there were no complaints and radiologic evaluation showed preserved instrumentation stability and correction. The growth-guided function of the wire/rod combination permitted a growth of 10 centimeters of the instrumented spine in 6 years. This considerable residual growth resulted in sliding of the 2 upper cables out of the rods, which probably contributed to an increase of the kyphosis to $76^{\circ}$ (Figure 5c).
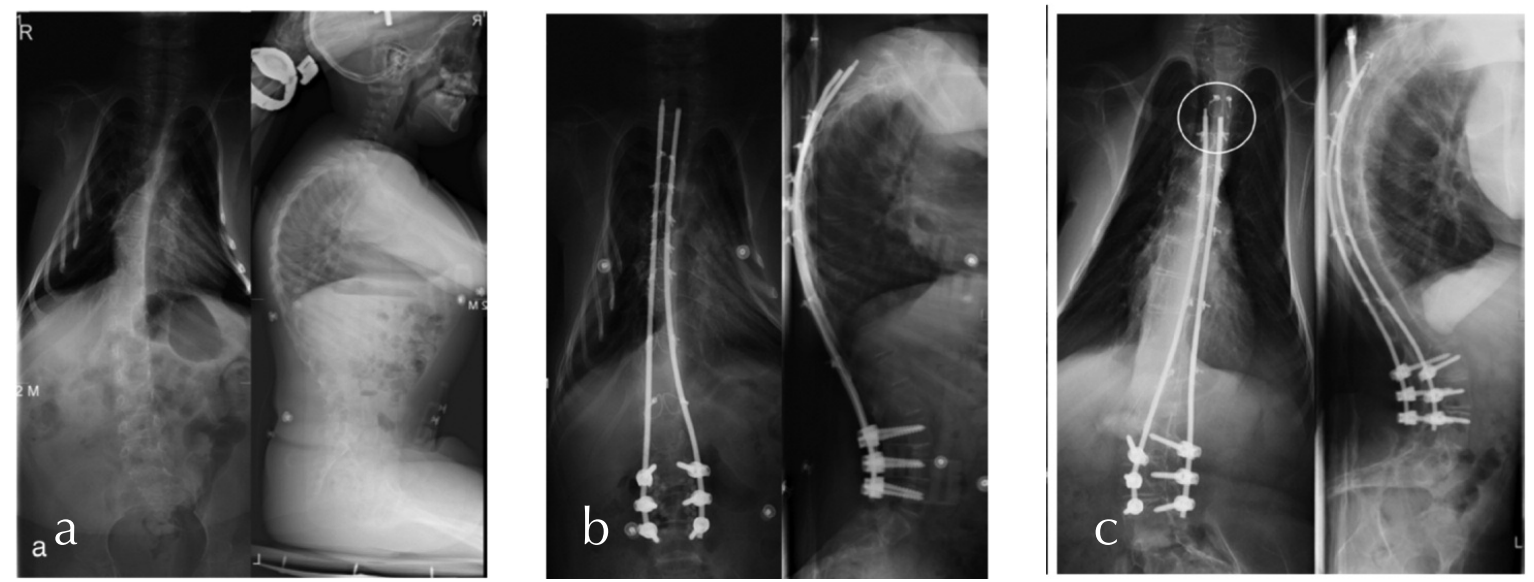

Figure 5. Coronal and sagittal radiographs. (a) Preoperative curvature with a mild frontal Cobb angle and increased upper thoracic kyphosis. (b) Postoperative instrumentation (c) At 6-year followup the sliding effect facilitated substantial growth. The distal rods have grown out of the T4 sublaminar wire (circle). Growth was measured as the difference in length between the distance of the T4 sublaminar wires and rod ends direct postoperatively and at 6-year followup radiography. 


\section{DISCUSSION}

Growth-guidance systems have regained interest in the treatment of early onset scoliosis patients, in which it is imperative to retain longitudinal spine growth, thereby maintaining thoracic cage and lung volume development. ${ }^{16}$ In the reported cases the instrumentation technique consisted of a modified Luque trolley (an 'internal brace' concept) with insertion of lumbar pedicle screws, in which $\mathrm{CoCr}$ rods were stabilized with multi-stranded Ti sublaminar cables to the thoraco-lumbar spine. Correction of the curve was performed by gradually applying tension to these wires. In two reported cases with minor curves (i.e. Cobb angles $29^{\circ}$ and $24^{\circ}$ ) the internal brace concept was successful. The sliding effect between the wires and rod in these cases allowed for ongoing growth of the spine. The use of a supportive crosslink in one case probably contributed to increased (rotatory) stability. In the 2 other cases the deformities were more severe (i.e. Cobb angles $69^{\circ}$ and $67^{\circ}$ ) and the instrumentation failed. These high curvatures demand for more corrective strength and support of the instrumentation and have to withstand high correction and derotation forces. Probably, in these 2 cases metal fatigue as observed during the electron microscopy analysis eventually led to the breakage of the wires and subsequent instrumentation failure. Ti wear debris caused severe metallosis in the surrounding tissues, which necessitated extensive debridement. In these cases a revision surgery with fusion of the spine was necessary. Future growth of the spine was thus restricted in these cases.

Multi-stranded cables replaced monofilament sublaminar wires in the early 1990's. These new cables offered higher static and fatigue strength. ${ }^{17,}{ }^{18}$ This improved wire design with better cable conformance to the shape of the lamina also addressed neurological injury risks. Penetration of the spinal canal seemed less than that of monofilament wire. ${ }^{19}$ Despite the improved wire features, neurological injury can still occur during insertion and removal of the wires. When sublaminar wires are used in growth-guided surgery the continuous cyclic loading, because of lack of support by e.g. pedicle screws and a bony fused spine, increases the risk of wire breakage. ${ }^{14}$ Ongoing abrasion of the wires against the metal rods can lead to metallosis, as described in this report, which can negatively affect the soft tissue and spinal structures. ${ }^{20,21}$ Spinal metallosis has been described weeks to years after spinal 


\section{Chapter 3}

fusion instrumentation, in both titanium (as used in our patients) and stainless steel constructs. ${ }^{22}$ Recently, metallosis-associated complications with the formation of seroma and sinuses and concentrations of $\mathrm{Ti}$ and Vanadium $(\mathrm{V})$ ions in the blood were found in patients after instrumentation of growth guidance sliding instrumentation. ${ }^{23}$ Surgeons should be aware of possible complications associated with the use of metal laminar wires in spinal fusion and growth-guidance scoliosis surgery.

In order to avoid metal-wires associated complications artificial polymeric and polyethylene sublaminar bands have been developed for its use in scoliosis surgery. The Universal clamp, using polymeric sublaminar bands as part of a rod/pedicle screw system, is already used in human corrective spinal fusion scoliosis surgery. ${ }^{24}$ Currently, novel radiopaque ultra high molecular weight poly-ethylene (UHMWPE) sublaminar wires have been tested in a pre-clinical setting for their use in growthguidance scoliosis surgery. ${ }^{25}$ The mechanical and biochemical properties of these novel wires can decrease the risk of spinal injury during insertion and removal of the wires while simultaneously attaining higher fatigue strength and low friction. ${ }^{25}$,

${ }^{26}$ In this manner, metallosis associated complications could also be addressed and instrumentation failure, as a result of high rotatory and corrective forces, decreased. Simultaneously, a lower friction coefficient will allow for enhanced sliding of the wires along the rod.

\section{CONCLUSION}

The described growth guidance technique in the reported cases seems a valuable option in patients with moderate scoliotic curves in which corrective surgery is indicated and preservation of spinal growth is imperative. Improvement of wire characteristics and instrumentation design is still necessary to decrease the risk of complications and increase the stability in correction of more severe scoliosis in growth guiding scoliosis surgery. The challenge still remains in selecting the timing of procedure and patient groups in which the described 'internal brace' principle will lead to a satisfactory combination of curve correction, preserved instrumentation stability and maximum spinal growth. 


\section{REFERENCES}

1. Vitale $M G$, Matsumoto $H$, Bye $M R$, et al. A retrospective cohort study of pulmonary function, radiographic measures, and quality of life in children with congenital scoliosis: an evaluation of patient outcomes after early spinal fusion. Spine. 2008;33:1242-9.

2. Dubousset J, Herring JA, Shufflebarger H. The crankshaft phenomenon. J Pediatr Orthop. 1989;9:541-50.

3. McCarthy RE, Sucato D, Turner JL, Zhang H, Henson MA, McCarthy K. Shilla growing rods in a caprine animal model: a pilot study. Clin Orthop Relat Res. 2010;468:705-10.

4. Ouellet J. Surgical technique: modern Luque trolley, a self-growing rod technique. Clin Orthop Relat Res. 2011;469:1356-67.

5. Luque ER. Segmental spinal instrumentation for correction of scoliosis. Clin Orthop Relat Res. 1982:192-8.

6. Bernard TN, Jr., Johnston CE, 2nd, Roberts JM, Burke SW. Late complications due to wire breakage in segmental spinal instrumentation. Report of two cases. J Bone Joint Surg Am. 1983;65:1339-45.

7. Cervellati S, Bettini N, Bianco T, Parisini P. Neurological complications in segmental spinal instrumentation: analysis of 750 patients. Eur Spine J. 1996;5:161-6.

8. Geremia GK, Kim KS, Cerullo L, Calenoff L. Complications of sublaminar wiring. Surg Neurol. 1985;23:629-35.

9. Diab M, Smith AR, Kuklo TR, Spinal Deformity Study G. Neural complications in the surgical treatment of adolescent idiopathic scoliosis. Spine. 2007;32:2759-63.

10. Reames DL, Smith JS, Fu KM, et al. Complications in the surgical treatment of 19,360 cases of pediatric scoliosis: a review of the Scoliosis Research Society Morbidity and Mortality database. Spine. 2011;36:1484-91.

11. Wilber RG, Thompson GH, Shaffer JW, Brown RH, Nash CL, Jr. Postoperative neurological deficits in segmental spinal instrumentation. A study using spinal cord monitoring. J Bone Joint Surg Am. 1984;66:1178-87.

12. Eysel P. [Biomechanical principles of ventral and dorsal instrumentation correction in scoliosis]. Orthopade. 2000;29:507-17.

13. Yazar T, Gurkan I, Yilmaz C. A new approach to scoliosis. Eur Spine J. 1999;8:86-92.

14. Boeree NR, Dove J. The selection of wires for sublaminar fixation. Spine. 1993;18:497-503. 


\section{Chapter 3}

15. Nectoux E, Giacomelli MC, Karger C, Herbaux B, Clavert JM. Complications of the LuqueGalveston scoliosis correction technique in paediatric cerebral palsy. Orthop Traumatol Surg Res. 2010;96:354-61.

16. Thompson GH, Lenke LG, Akbarnia BA, McCarthy RE, Campbell RM, Jr. Early onset scoliosis: future directions. The Journal of bone and joint surgery American volume. 2007;89 Suppl 1:163-6.

17. Songer MN, Spencer DL, Meyer PR, Jr., Jayaraman G. The use of sublaminar cables to replace Luque wires. Spine. 1991;16:S418-21.

18. Weiss HR. Is there a body of evidence for the treatment of patients with Adolescent Idiopathic Scoliosis (AIS)? Scoliosis. 2007;2:19.

19. Parsons JR, Chokshi BV, Lee CK, Gundlapalli RV, Stamer D. The biomechanical analysis of sublaminar wires and cables using luque segmental spinal instrumentation. Spine. 1997;22:267-73.

20. Mardjetko SM, Hammerberg KW, Lubicky JP, Fister JS. The Luque trolley revisited. Review of nine cases requiring revision. Spine. 1992;17:582-9.

21. Pratt RK, Webb JK, Burwell RG, Cummings SL. Luque trolley and convex epiphysiodesis in the management of infantile and juvenile idiopathic scoliosis. Spine. 1999;24:1538-47.

22. Goldenberg Y, Tee JW, Salinas-La Rosa CM, Murphy M. Spinal metallosis: a systematic review. Eur Spine J. 2016;25:1467-73.

23. Lukina $\mathrm{E}$, Laka $\mathrm{A}$, Kollerov $\mathrm{M}$, et al. Metal concentrations in the blood and tissues after implantation of titanium growth guidance sliding instrumentation. Spine J. 2016;16:380-8.

24. Mazda K, Ilharreborde B, Even J, Lefevre Y, Fitoussi F, Pennecot GF. Efficacy and safety of posteromedial translation for correction of thoracic curves in adolescent idiopathic scoliosis using a new connection to the spine: the Universal Clamp. Eur Spine J. 2009;18:158-69.

25. Bogie R, Roth A, Faber S, et al. Novel Radiopaque UHMWPE Sublaminar Wires in a Growth-Guidance System for the Treatment of Early Onset Scoliosis: Feasibility in a Large Animal Study. Spine. 2014.

26. Takahata $M$, Ito $M$, Abumi $K$, et al. Comparison of novel ultra-high molecular weight polyethylene tape versus conventional metal wire for sublaminar segmental fixation in the treatment of adolescent idiopathic scoliosis. J Spinal Disord Tech. 2007;20:449-55. 
Metal sublaminar wires in growth-guidance surgery: case reports 


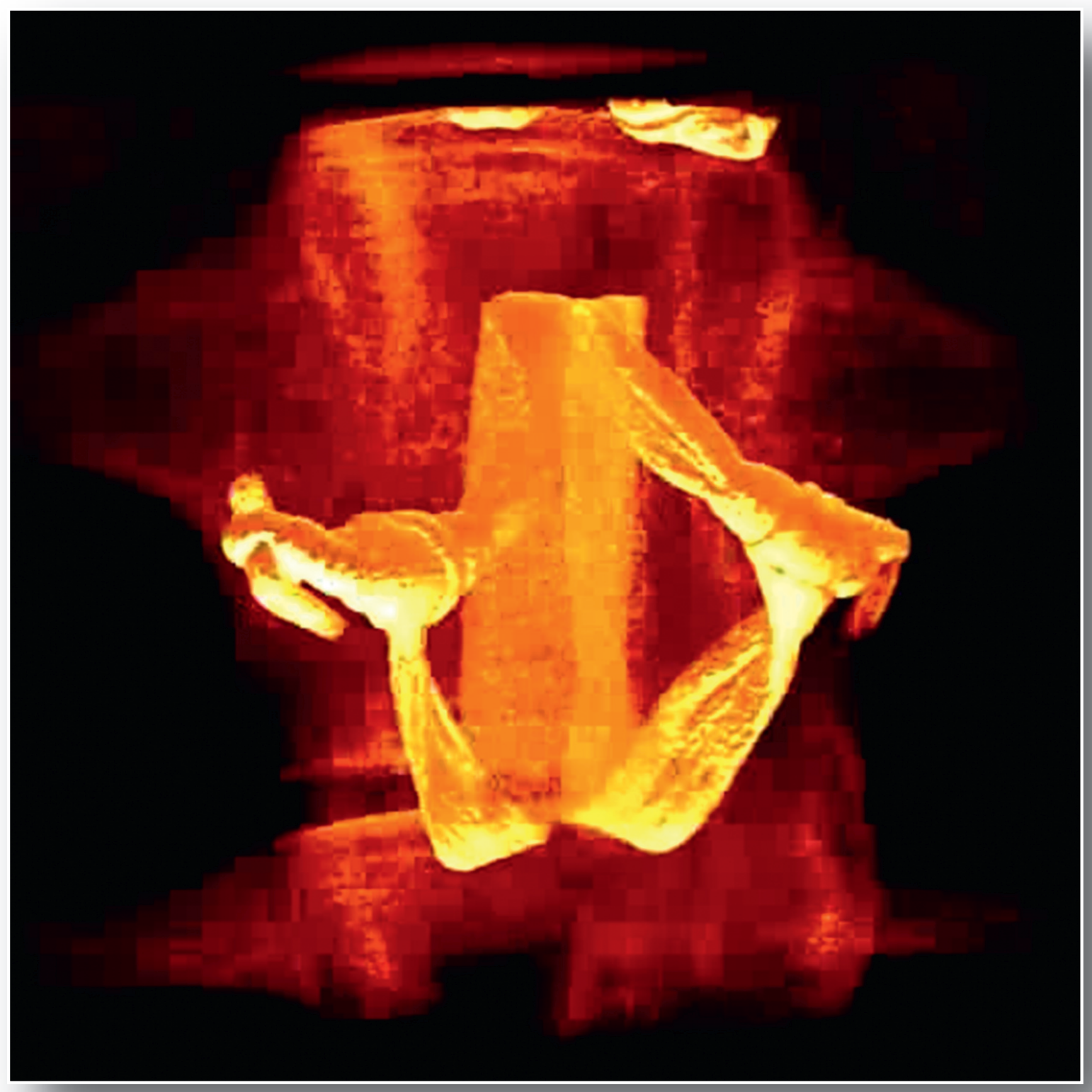




\section{CHAPTER 4}

\section{UHMWPE sublaminar wires in}

posterior spinal instrumentation: stability and biocompatibility assessment in an ovine pilot study

J. Spinal Disord Techn 2014, [published online ahead of print January 8, 2014] Clin Spine Surg. 2016 Dec;29(10):E542-E549

Rob Bogie, Laura Voss, Jacobus J. Arts, Arno M.A. Lataster, Paul C. Willems, Boudewijn Brans, Lodewijk W. van Rhijn, Tim J.M. Welting 


\section{Chapter 4}

\section{ABSTRACT}

Study design. An animal study

Objective. To explore ultra high molecular weight polyethylene (UHMWPE) sublaminar wires in spinal surgery and to assess stability and biocompatibility of the UHMWPE instrumentation in an ovine model.

Summary of background data. Sublaminar wiring is a well established technique in segmental scoliosis surgery. However, during introduction and/or removal of the metal sublaminar wires neurologic problems can occur. Abrasion after cutting metal wires for removal can lead to damage to the dural sac. Sublaminar wires have to withhold large forces and breakage of the wires can occur. Different types of sublaminar wires have been developed to address these problems. UHMWPE sublaminar wires can potentially substitute currently used metal sublaminar metal wires. In vivo testing and biocompatibility analysis of UHMWPE wires are recommended before clinical use in spinal surgery.

Methods. In 5 immature sheep, pedicle screws were instrumented at lumbar level L4 and attached with titanium rods to four thoracolumbar vertebrae using $3 \mathrm{~mm}$ and $5 \mathrm{~mm}$ wide UHMWPE sublaminar wiring constructions. Titanium sublaminar wires were applied in one animal to function as a comparison. After a follow-up period of 16 weeks, the animals were sacrificed and the spines were isolated. Radiographs and CT-scans were made to assess stability of the instrumentation. The vertebrae were dissected for macroscopic and histological evaluation.

Results. None of the wires had loosened and the instrumentation remained stable. CT-scans and radiographs showed no signs of failure of the instrumentation and no neurological complications occurred. Although several bony bridges were seen on $\mathrm{CT}$, growth was observed at the operated levels. Biocompatibility was assessed by macroscopical and histological analysis, showing no signs of dural or epidural inflammation.

Conclusions. This pilot animal study shows that UHMWPE sublaminar wiring is a safe technique. The UHMWPE wires are biocompatible and provide sufficient stability in spinal instrumentation. Heterotopic ossification due to periost reactions in the ovine spine led to some restrictions in this study. 


\section{INTRODUCTION}

Currently, there are several options for the surgical correction of spinal deformities in children ${ }^{1,2}$. Rod fixation with pedicle screws, laminar hooks or sublaminar wires can be used. ${ }^{3}$ Luque was the first to describe the use of sublaminar wires for segmental instrumentation in $1982{ }^{4}$. However, a complication rate as high as $17 \%$ has been described for spinal surgery using sublaminar wires ${ }^{5,6}$. Neurological complications and wire breakage have been reported when using stainless steel or titanium sublaminar wires both in fusion and non-fusion techniques ${ }^{7-13}$. Although, different types of sublaminar wires have been used in spinal surgery, non-metal sublaminar wires have not been thoroughly described ${ }^{14}$. Preclinical in vivo testing of these non-metal materials is essential to evaluate biocompatibility and material characteristics as compared to the classic metal wires.

Chemically inert and biocompatible Dyneema Purity ${ }^{\circledR}$ is already successfully used in orthopedic surgery, such as rotator cuff repair and knee ligament repair. Due to its high tensile strength and low friction characteristics, it is expected to provide sufficient stability and if necessary is able to slide along spinal rods, thereby possibly allowing some degree of growth of the spinal column. In wire passage and removal or in case of wire breakage, it is expected that there is a decreased risk of neurological damage in comparison to metal wires, because the UHMWPE wire is soft and flexible.

The purpose of this study was to test ultra high molecular weight polyethylene (UHMWPE) as an alternative for the currently used metal wires in spinal surgery and to test whether it supports the spinal dynamics by virtue of its low friction characteristics on metal rods and high tensile strength. It was hypothesized that UHMWPE sublaminar wires can safely replace currently metal sublaminar wires, while providing sufficient stability of the spinal instrumentation. Integrity of instrumentation, local spinal tissue biocompatibility and surgical handling of UHMWPE sublaminar wires were evaluated using immature sheep. 


\section{Chapter 4}

\section{MATERIALS AND METHODS}

\section{Animal model and surgical procedure}

Six immature Tesselaar sheep (ewes, 6 months old) with an average weight of $33 \mathrm{~kg}$ (range $27-36 \mathrm{~kg}$ ) were used for this study. All animal procedures were approved by the Animal Ethical Committee of the Maastricht University Medical Centre (approval number: DEC 2009-128). Each operation was performed under general anesthesia with strict sterile conditions. Antibiotics (amoxicillin/clavulan acid 1.2 gr.) were administered intravenously preoperatively and 6 hours after surgery. Pain medication was given and adjusted if needed during surgery (remifentanyl $1 \mu \mathrm{g} / \mathrm{kg}$ per minute intravenously). ECG registration, ventilation curves, saturation and heart rate were continuously monitored. Each animal was sedated with intravenous administration of thiopental $(25 \mathrm{mg} / \mathrm{kg})$ followed by endotracheal intubation and general anesthesia using $1 \%$ to $2 \%$ isoflurane. The ovine spine consists of 7 cervical, 13 thoracic and 6 lumbar vertebrae ${ }^{16}$. With the animal in prone position a posterior midline incision was made from spinous processes T12 to L5 under fluoroscopic control. The transverse processes and the facet joints were exposed by partially detaching the erector spinae using electrocautery. Under radiographic magnification two pedicle screws (Legacy ${ }^{\circledR}$, Medtronic, Heerlen, the Netherlands) were placed in the L4 vertebral body. After removal of the spinous process, the ligamentum flavum was opened interlaminarly and partially removed with a punch. In this manner the laminae of $\mathrm{T} 12$ to $\mathrm{L} 2(\mathrm{~T} 12, \mathrm{~T} 13, \mathrm{~L} 1, \mathrm{~L} 2)$ were exposed with protection of the dura. The UHMWPE sublaminar wires, made with Dyneema Purity ${ }^{\circledR}$ fiber (DSM Dyneema B.V., Urmond, the Netherlands), were passed underneath the laminae. Subsequently, two titanium rods (CD Legacy ${ }^{\circledR} 4.5 \mathrm{~mm}$, Medtronic, Heerlen, the Netherlands) were fixed to the pedicle screws. The vertebrae were attached to the rods using $3 \mathrm{~mm}$ wide UHMWPE sublaminar wires on the left side and $5 \mathrm{~mm}$ wide wires on the right side. A customized double loop sliding knot secured the wires to the rods ${ }^{17}$. A custom made tensioning device (Instrument Design Engineering \& Evaluation, $\mathrm{MUMC}^{+}$, Maastricht, The Netherlands) was used to tighten the knots. The double loop sliding knot was locked with multiple granny knots. Titanium sublaminar wires (Atlas ${ }^{\circledR}$ cable, Medtronic, Heerlen, the Netherlands) were applied in one animal to function as a comparison. After obtaining radiographs, the wound was closed in 
layers and AluSpray was applied to it. Postoperative pain management (buprenorphine $6 \mu \mathrm{g} / \mathrm{kg}$, carprofen $1 \mathrm{ml} / \mathrm{kg}$ intramuscularly) and wound care were provided until the animals returned to activities ad libitum. The animals were sacrificed after a follow up period of 16 weeks. X-rays were obtained after which the spines with the instrumentation were excised en block. CT-scans were made and the spines were dissected for histological evaluation. The rods were removed by retracting them from under the screws and wires, leaving screws and wires in situ. The vertebrae were separated and fixed in formalin.

\section{Material specifications}

Before this study was started, laminar cut-through experiments with human vertebrae were performed with different types of UHMWPE constructions. Both woven and braided samples were tested. Although there was no significant difference in the force at which the lamina was cut-through, woven samples were chosen over braided samples because the latter ones deformed when under strain and seemed more susceptible to damage. Two satisfactory woven samples were chosen for application in this animal study. Both samples had a thickness of $0.3 \mathrm{~mm}$, one had a width of $3 \mathrm{~mm}$ and the other version had a width of $5 \mathrm{~mm}$. Titanium Atlas cable was used as a control and had a diameter of $1 \mathrm{~mm}$ (Figure 1). All UHMWPE constructions were Ethylene Oxide sterilized (Isotron, Schiedam, the Netherlands).

\section{Stability of instrumentation and growth of the operated segment}

To assess the position and integrity of the instrumentation, posterior-anterior and lateral radiographs were acquired at surgery and after sacrifice. After extraction of the spines CT-scans were performed to analyze screw position, alignment of the rods and instrumented laminae. Growth of the operated segment was determined by analyzing radiographs from the day of surgery and the day of sacrifice. The position of the top of the rods with respect to the ribs at that level was used as a landmark for growth.

\section{Cryosection and histology}

Of all animals, one instrumented vertebra with sublaminar wires was used for frozen section analysis. Lumbar vertebrae without wires served as a control. The vertebrae 


\section{Chapter 4}

were embedded and frozen in a carboxymethyl cellulose (CMC) solution. Anteroposterior sections ( $25 \mu \mathrm{m}$ thickness) of the complete vertebrae were made in a cryostat. The frozen block containing the vertebra was photographed after each section. The sections were stained with Masson's trichrome stain. Pictures and sections were analyzed to determine the space the different wires occupied in the vertebral foramen, i.e. possible compression of the dura.

One vertebra (T13) with sublaminar wires of each animal was used for histological analysis. Two vertebrae without sublaminar wires were used as control vertebrae (L5/L6). The laminae of these vertebrae including the sublaminar wires were separated from the vertebral body using a small handsaw. The laminae were embedded in polymethyl methacrylate (PMMA). Transverse sections with a thickness of $50 \mu \mathrm{m}$ were made with a Leica microtome and stained with Giemsa.
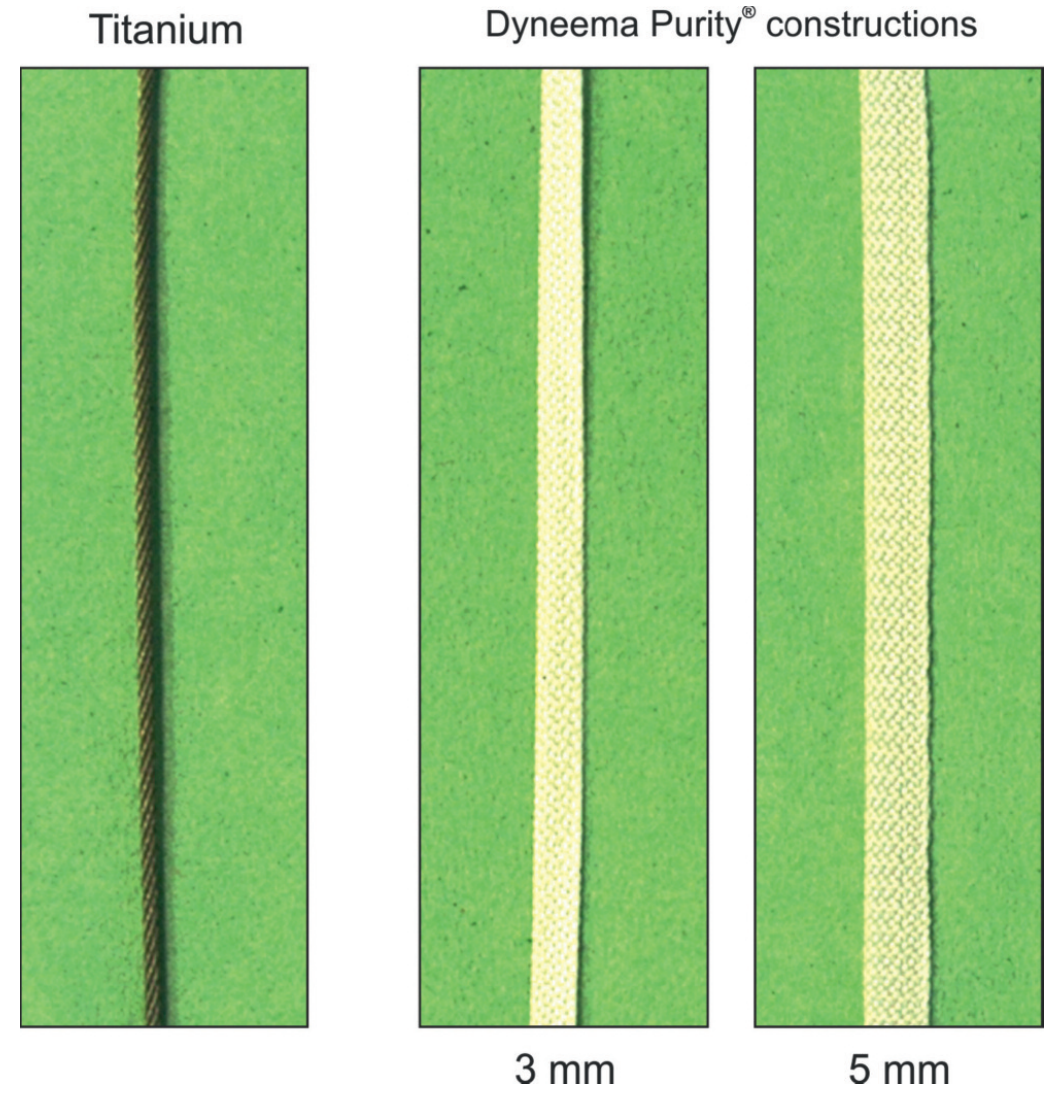

Figure 1. Sublaminar wires tested in this study. From left to right: Titanium Atlas ${ }^{\circledR}$ cable with a diameter of $1 \mathrm{~mm}$ (Medtronic); woven construction with a width of $3 \mathrm{~mm}$ (Dyneema Purity ${ }^{\circledR}$ fiber); woven construction with a width of $5 \mathrm{~mm}$ (Dyneema Purity ${ }^{\circledR}$ fiber). 


\section{RESULTS}

\section{Animal model and surgical procedure}

Five sheep were instrumented with UHMWPE sublaminar wires at levels T12, T13, L1 and L2. At each lamina a $3 \mathrm{~mm}$ and a $5 \mathrm{~mm}$ laminar wire was applied (Figure 1 and 2). One sheep was instrumented with titanium sublaminar cables at both sides of levels T12, L1 and L2 (Atlas ${ }^{\circledR}$ cable, Medtronic) as a comparison. Insertion of the pedicle screws (L4) and sublaminar passage of the wires were performed without complications. The UHMWPE wires showed good handling properties. No problems were encountered with the sublaminar positioning of the wires. After knotting the wires to the rods, each knot could easily be tightened with a custom made tensioning device. One animal died on the first postoperative day due to respiratory problems and one animal developed a wire fistula at the level of a $5 \mathrm{~mm}$ knot, which was noticed after sacrifice. In this case, the proportionally larger knot of the $5 \mathrm{~mm}$ construction protruded the skin. No neurological complications occurred intraoperatively or during follow-up. Mean follow-up was 16.2 weeks (112-133 days).
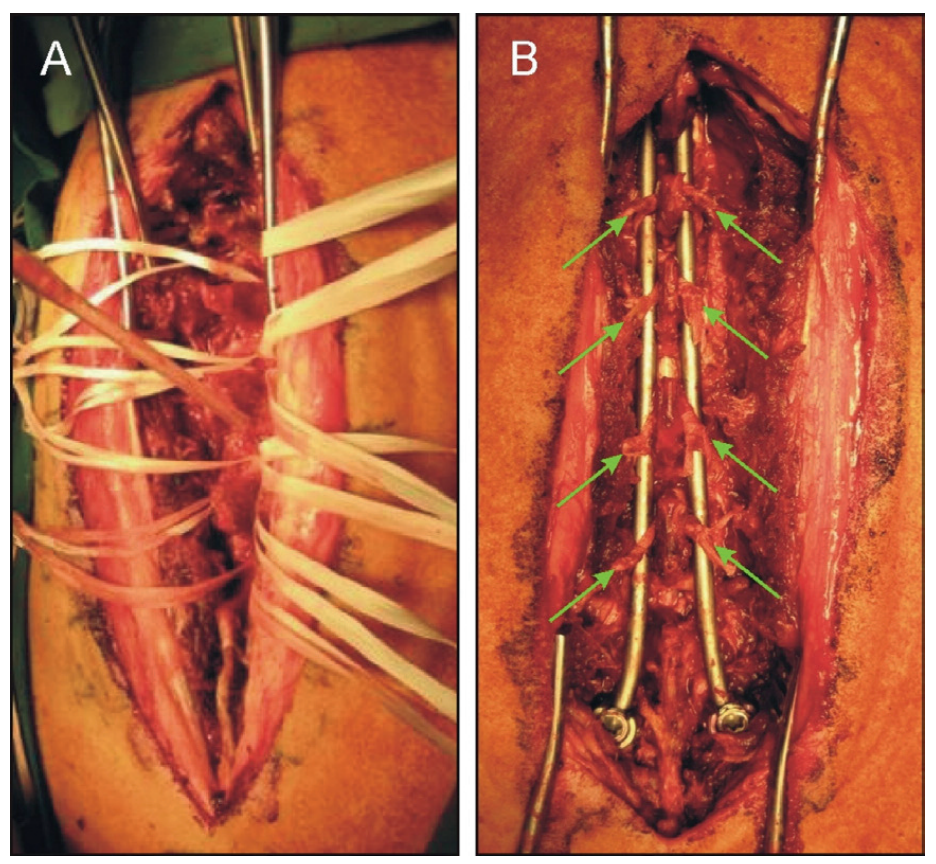

Figure 2. Intraoperative views. Left panel showing the ovine spine with sublaminar wires made with Dyneema Purity ${ }^{\circledR}$ fiber (left $3 \mathrm{~mm}$ wide, right $5 \mathrm{~mm}$ wide) before insertion of the rods and right panel showing the final instrumentation before wound closure. 


\section{Chapter 4}

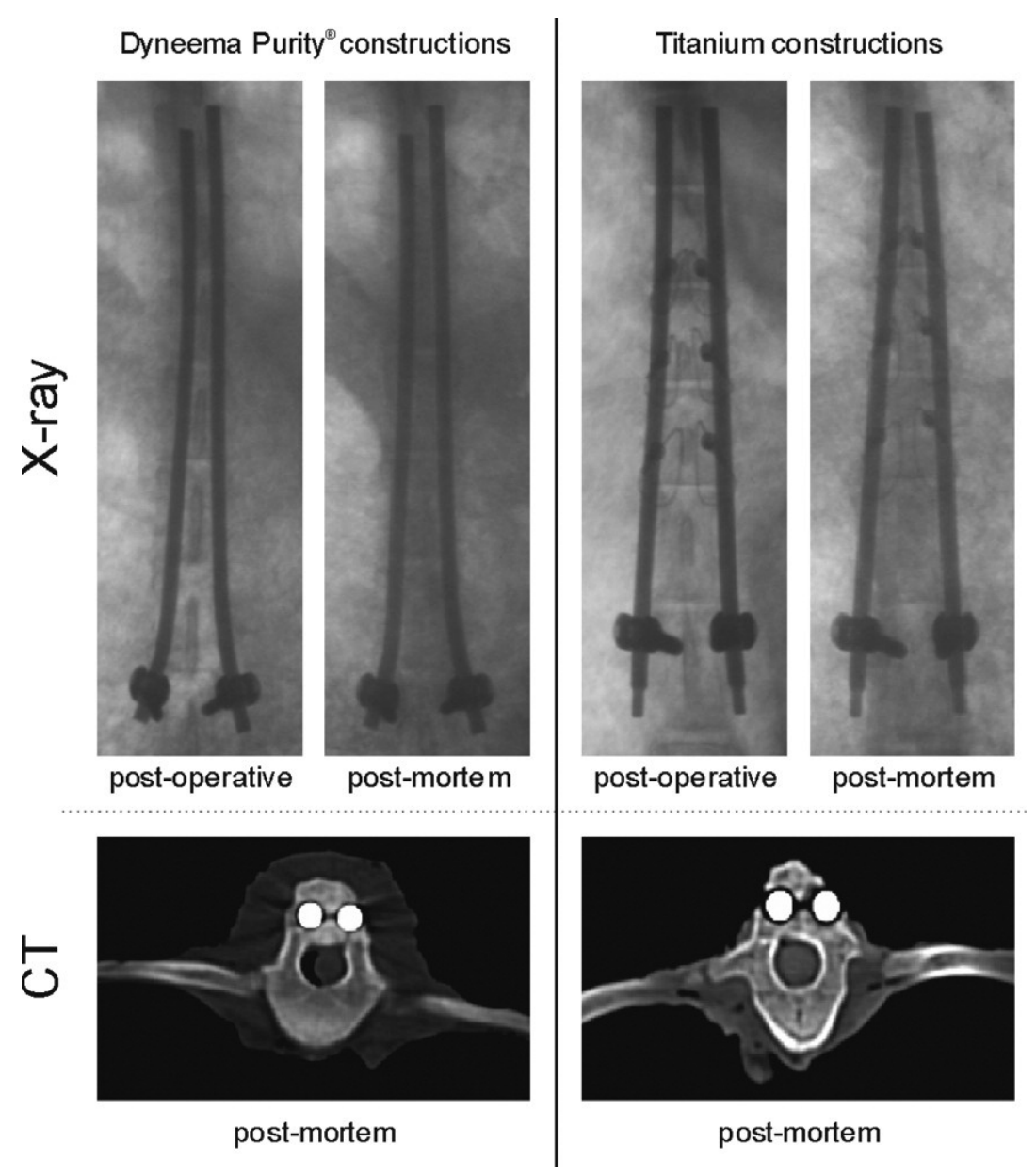

Figure 3. Stability of the constructions. Post operative and post mortem AP radiographs show preserved stability of the instrumentation with Dyneema Purity ${ }^{\circledR}$ and titanium sublaminar wires. Post mortem CT images confirm this stability by visualizing the rods situated close to the laminae.

\section{Material specifications and stability of instrumentation}

No differences in terms of handling and tensioning between the 3 and $5 \mathrm{~mm}$ wide UHMWPE sublaminar wires were experienced and no macroscopical damage to the UHMWPE and titanium sublaminar wires was observed after sacrifice of the sheep. The UHMWPE knots did not show any signs of loosening. Peri-implant inflammation was never observed macroscopically, except for the case in which the $5 \mathrm{~mm}$ knot protruded the skin and caused a wire fistula. Post mortem, the stability of the instrumentation was assessed. Macroscopically all instrumentation remained intact. CT as well as plain radiographs confirmed the preserved stability of all instrumentation (Figure 3). Even though no decortication was performed, several 
bony bridges were observed macroscopically and confirmed by CT-scans both with titanium and UHMWPE wires (Figure 4). Comparison of radiographs taken on the day of surgery and on the day of sacrifice indicated growth in all sheep during follow-up (Figure 5).

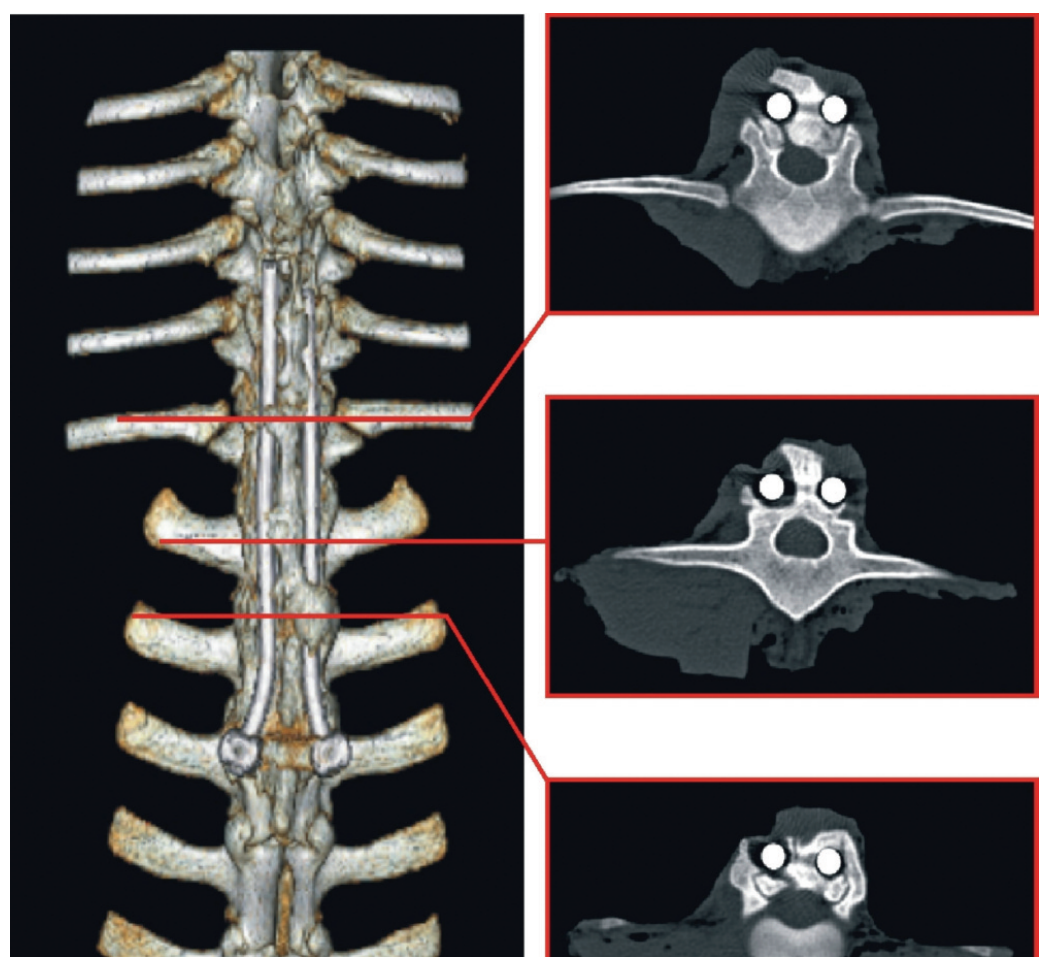

Figure 4. Heterotopic ossification. Left: post mortem representative 3D CT-scan of an ovine spine containing instrumentation with UHMWPE sublaminar wires, showing heterotopic ossification around the rods. Right: cross sections of depicted areas, showing the heterotopic ossification.

\section{Cryosectioning and histology}

To determine how the UHMWPE and titanium sublaminar constructions performed in vivo, cryosections were prepared from vertebrae with sublaminar wires as well as from not instrumented control vertebrae. The rods were removed before dissecting the vertebrae. Analysis of the cryosections showed that the wires were tightly looped around the lamina. Only minimal migration of the wire into the laminar bone was observed. The spinal cord was not or minimally compressed by the different wires and no damage to the dura was observed (Figure 6). Vertebrae with sublaminar wires 


\section{Chapter 4}
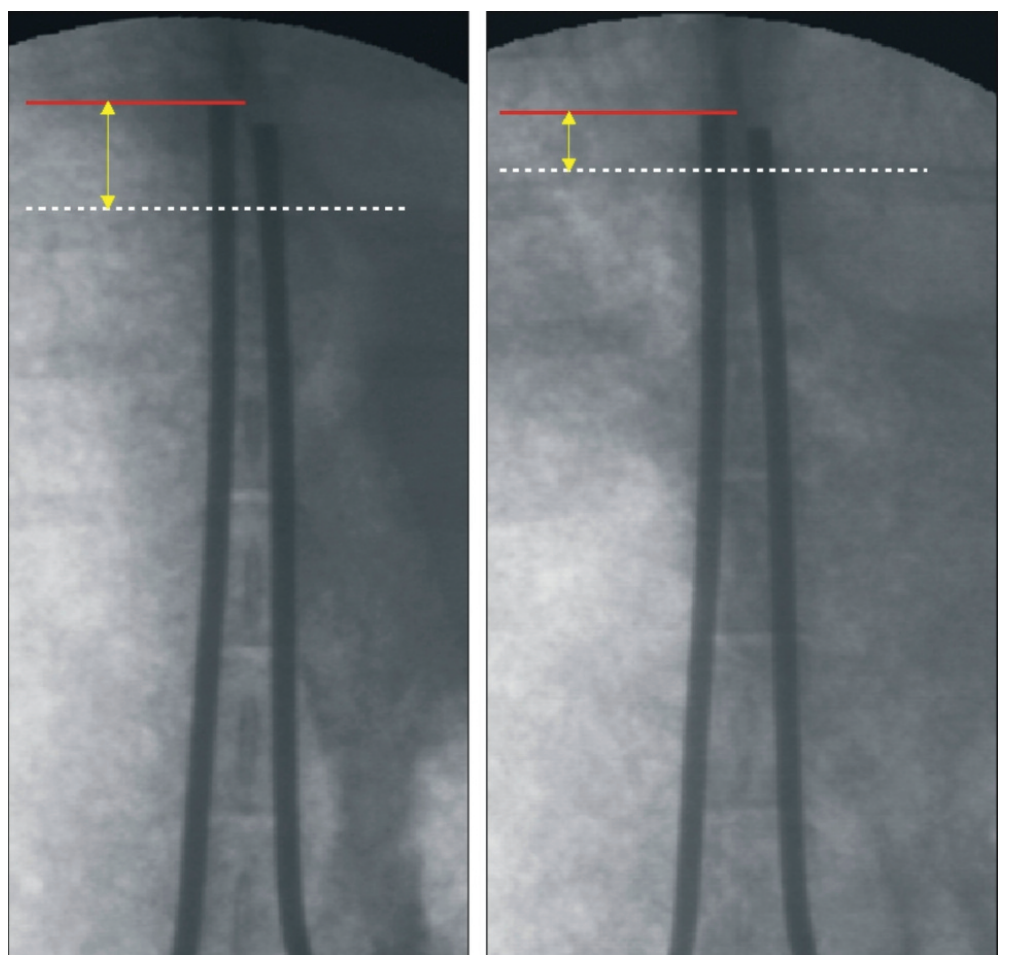

Figure 5. Growth of the spine. Postoperative and post mortem radiographs of a UHMWPE instrumented spine show a decrease in the relative distance (yellow arrows) between the end of the titanium rod and the rib-lining, indicating growth of the instrumented segment.
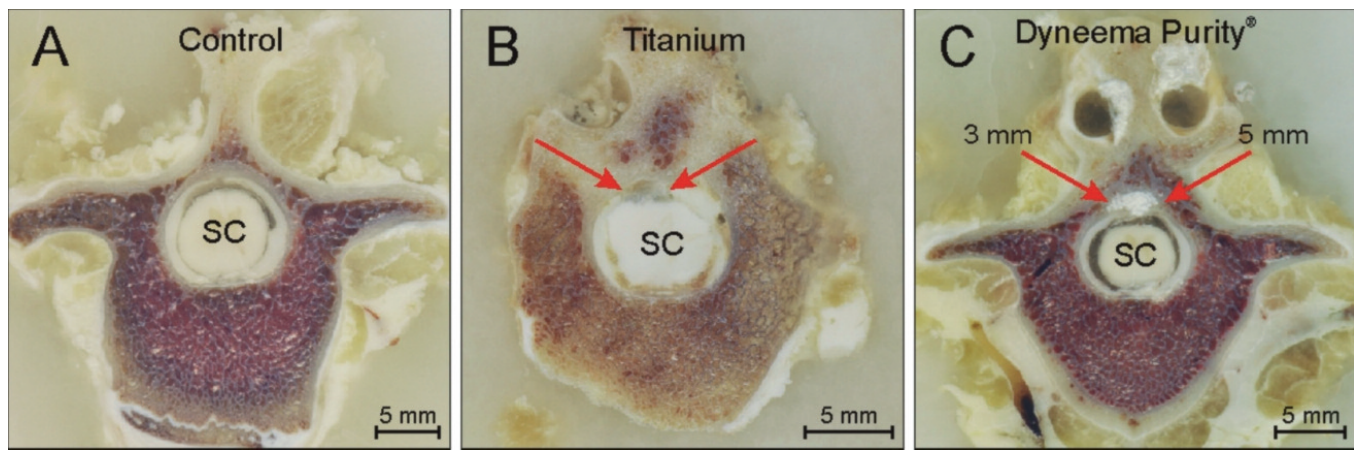

Figure 6. Cryogenic sections of the sheep vertebrae. Left to right: $A$ : Control vertebra (L5); B: vertebra with Atlas cable (T12) (red arrows); C: vertebra with Dyneema Purity ${ }^{\circledast}$ sublaminar wires (T11) (red arrows). SC = spinal cord.

showed tissue characteristics comparable to control vertebrae. No signs of inflammatory reactions (e.g. osteolysis) or scar tissue formation were observed in the instrumented vertebrae, indicating overall good biocompatibility of both titanium 
and UHMWPE wires. Cryosections also confirmed the ectopic bone remodeling around the rods and wires at the posterior side of the laminae (Figure 6).

Microscopical analysis of the bone-wire interface in the spinal canal was carried out to determine whether inflammatory reactions or other foreign body reactions due to the UHMWPE or titanium were present. PMMA histological sections of the laminae showed no signs of inflammatory reactions or osteolysis by granulocyte infiltration or population of osteoclastic giant cells in the tissue. No detectable differences in bone reaction between the UHMWPE and titanium were found. Both types of wires minimally migrated into the laminar bone inside the spinal canal. The UHMWPE wires showed larger surface contact to the laminae compared to the titanium wires. Interestingly, minor bone ingrowth in the UHMWPE wires was found, indicating osteocompatibility of the Dyneema Purity ${ }^{\circledR}$ fiber (Figure 7).
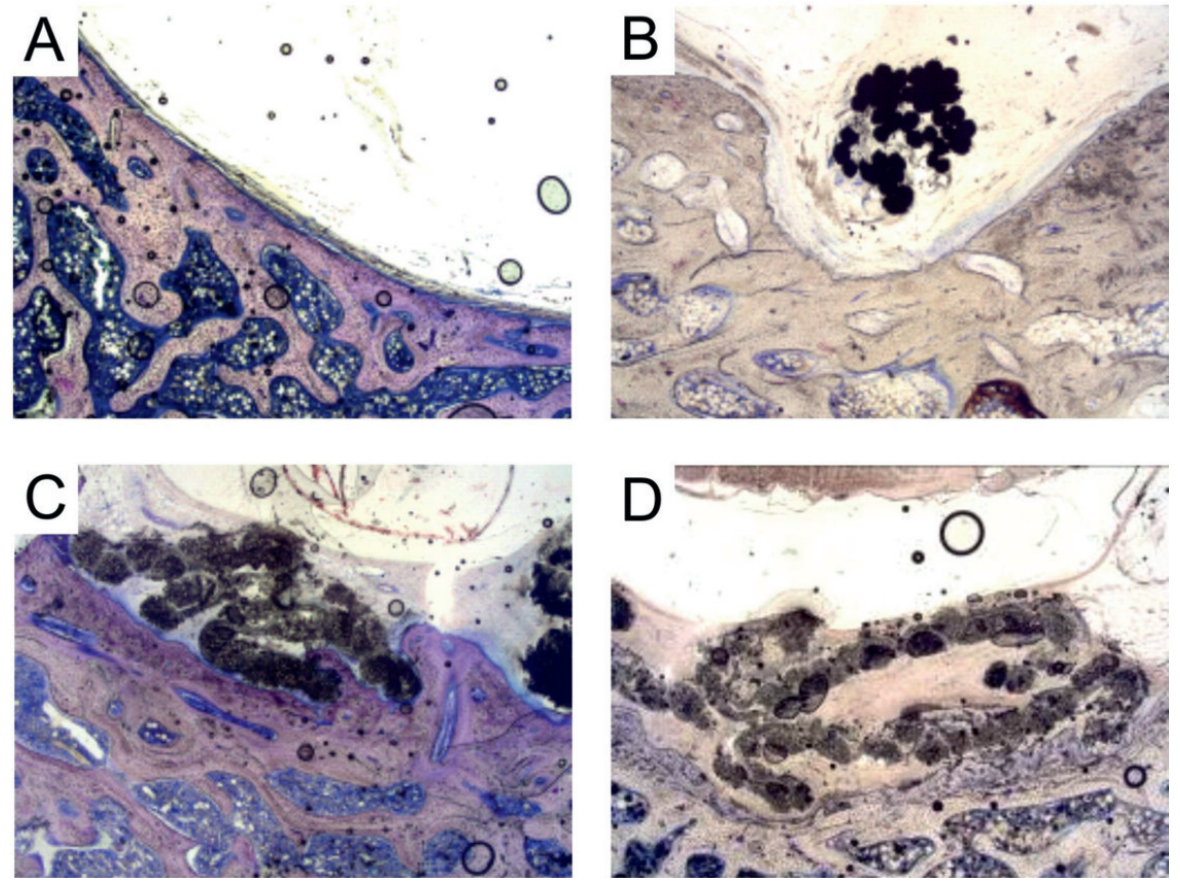

Figure 7. Plastic sections (Giemsa staining) of sheep lamina inside vertebral foramen. A: control lamina. B: titanium cable. C: UHMWPE $3 \mathrm{~mm}$. Note the ingrowth of bone of lamina (purple structure) in between the UHMWPE fibers (black structures) D: UHMWPE $5 \mathrm{~mm}$. 


\section{Chapter 4}

\section{DISCUSSION}

Currently, within scoliosis surgery different types of metal sublaminar wires are used as part of segmental instrumentation. However, there are several complications associated with the use of these wires ${ }^{5-13}$. In this pilot study, we hypothesized that UHMWPE sublaminar wires can safely replace currently used metal sublaminar wires while providing sufficient stability.

In this ovine model the tested UHMWPE sublaminar wires showed good handling and tensioning properties. Both 3 and $5 \mathrm{~mm}$ wide UHMWPE sublaminar wires provided sufficient fixation in the described spinal instrumentation, while allowing a certain degree of growth of the instrumented spinal segments. The $5 \mathrm{~mm}$ wide UHMWPE wires, however, produce a larger knot, which led to a skin protrusion in one animal. Smaller wire width (e.g. 3 or $4 \mathrm{~mm}$ ) could prevent this.

Sheep are widely used in spinal animal experiments and comparative spine anatomy of sheep and man is well described ${ }^{15,17}$. Although it is known that sheep are more susceptible to neurological complications during spinal surgery ${ }^{18}$, in this ovine experiment the UHMWPE sublaminar wires did not cause any neurological problems. Additionally, no macroscopic or histological abnormalities like mechanical tissue damage, inflammatory reactions or fibrous tissue formation around the UHMWPW sublaminar wires were observed.

This study has a number of limitations. First, this pilot study has a small group size. Secondly, the instrumentation was not tested under scoliotic deformity circumstances. Force vectors will be different in scoliosis and may challenge the instrumentation in another way than in a non-deformed spine. Thirdly, due to a short follow-up period, growth and spinal fusion could not be adequately assessed. One animal died on the first postoperative day from respiratory problems, possibly caused by intra-operative admission of the muscle relaxant pancuronium. In the other animals the administration of pancuronium was halted and no respiratory problems were observed.

Currently, sublaminar wires are used in hybrid constructs and Luque trolley systems both in fusion and non-fusion surgery. Non-fusion techniques in scoliosis surgery aim at allowing a certain degree of spinal growth after instrumentation. Therefore, instrumentation in this type of surgery is submitted to other forces than 
in fusion surgery. No failure of the sublaminar constructions used in this study was observed and upon post-mortem inspection of the instrumentation none of the knots had loosened during the follow-up period. The fixation of the instrumentation was also preserved, as was confirmed by radiographs and CT-scans. Despite their different design and high tensile strength, the UHMWPE constructions did not cut into the lamina more than titanium wires.

The non-fusion approach in this experiment aimed at the omission of spondylodesis material and at keeping the intervertebral discs intact. Indeed we were able to show that both in the titanium comparison experiment and the experimental UHMWPE-group a certain degree of growth took place in the instrumented region. Although we were not able to quantify the amount of growth, our data indicate that the use of UHMWPE sublaminar wires allows spinal growth. As a result of spontaneous fusion around the instrumented areas growth of the spine was limited. Heterotopic bone formation and spontaneous fusion in spinal animal experiments have been previously described ${ }^{19,20}$. Periosteal reactions caused by undesirable periosteal stripping may have increased this ectopic bone formation. The titanium comparison as well as the experimental Dyneema Purity ${ }^{\circledR}$-group showed signs of heterotopic ossification, indicating that this type of bone formation is not specifically caused by the use of UHMWPE. Histological analysis showed a small degree of migration of both UHMWPE and titanium wires into the laminar bone. An explanation for this migration can be the force that the wires exert on the laminae in combination with the intrinsic growth of the vertebrae in all directions. Ongoing anterior growth in combination with posterior fusion could have been the cause of the wire migration into the bone. Active ingrowth of bone in between the UHMWPE wires was observed, indicating osteocompatibility. The fact that Dyneema Purity ${ }^{\circledR}$ based sublaminar wires adapt to the shape of the laminae is regarded as highly beneficial as it therefore will occupy the least necessary space in the spinal canal.

The purpose of this study was to test a new material as a replacement of current metal sublaminar wires. This study shows promising results for application of UHMWPE sublaminar wires in spinal instrumentation. The UHMWPE wires are biocompatible and provide sufficient stability in posterior spinal instrumentation. However, to adequately test UHMWPE sublaminar wires in scoliosis surgery it will be necessary to study an animal scoliosis model. Braun et al. described several 


\section{Chapter 4}

animal scoliosis models including sheep ${ }^{17}$. More recently promising porcine scoliosis models have been developed ${ }^{20,21}$. The aim in future studies is to create a realistic scoliosis model to optimally test the UHMWPE constructions for application in scoliosis correction surgery. 


\section{REFERENCES}

1. Steinmetz MP, Rajpal S, Trost G. Segmental spinal instrumentation in the management of scoliosis. Neurosurgery. 2008; 63(3 Suppl):131-8.

2. Smith JT. The use of growth-sparing instrumentation in pediatric spinal deformity. Orthop Clin N Am. 2007;38(4):547-52.

3. Cheng I, Kim Y, Gupta MC, et al. Apical sublaminar wires versus pedicle screws - which provides better results for surgical correction of adolescent idiopathic scoliosis? Spine. 2005; (Phila Pa 1976) 30(18):2104-12.

4. Luque ER. Segmental spinal instrumentation for correction of scoliosis. Clin Orthop Relat Res. 1982;163:192-8.

5. Dove J. Luque segmental spinal instrumentation: the use of the Hartshill rectangle. Orthopedics. 1987;10(6):955-61.

6. Girardi FP, Boachie-Adjei O, Rawlins BA. Safety of sublaminar wires with Isola instrumentation for the treatment of idiopathic scoliosis. Spine. (Phila Pa 1976) 2000;25(6):691-5.

7. Bernard TN Jr, Johnston CE 2nd, Roberts JM, Burke SW. Late complications due to wire breakage in segmental spinal instrumentation. Report of two cases. J Bone Joint Surg Am. 1983;65(9):1339-45.

8. Wilber RG, Thompson GH, Shaffer JW, et al. Postoperative neurological deficits in segmental spinal instrumentation. A study using spinal cord monitoring. J Bone Joint Surg Am. 1984;66(8):1178-87.

9. Cervellati S, Bettini N, Bianco T, et al. Neurological complications in segmental spinal instrumentation: analysis of 750 patients. Eur Spine J. 1996;5(3):161-6.

10. Johnston CE 2nd, Happel LT Jr, Norris R, et al. Delayed paraplegia complicating sublaminar segmental spinal instrumentation. J Bone Joint Surg Am. 1986;68(4):556-63.

11. MacEwen GD, Bunnell WP, Sriram K. Acute neurological complications in the treatment of scoliosis. A report of the Scoliosis Research Society. J Bone Joint Surg Am. 1975;57(3):404-8.

12. Herring JA, Wenger DR. Segmental spinal instrumentation: a preliminary report of 40 consecutive cases. Spine. (Phila Pa 1976) 1982;7(3):285-98.

13. Dove J. Segmental wiring for spinal deformity. A morbidity report. Spine. (Phila Pa 1976) 1989;14(2):229-31. 


\section{Chapter 4}

14. Mazda K, Ilharreborde B, Even J, et al. Efficacy and safety of posteromedial translation for correction of thoracic curves in adolescent idiopathic scoliosis using a new connection to the spine: the Universal Clamp. Eur Spine J. 2009;Feb;18(2):158-69. Epub 2008 Dec 16.

15. Hasler C, Sprecher CM, Milz S. Comparison of the immature sheep spine and the growing human spine: a spondylometric database for growth modulating research. Spine. (Phila Pa 1976) 2010;35(23):E1262-72.

16. Saito R, Hase H, Mikami Y, et al. Clinical study of a modified Brooks technique for atlantoaxial subluxation using polyethylene tape. J Spinal Disord Tech. 2006;19(1):11-7.

17. Braun J, Akyuz E, Ogilvie J. The use of animal models in fusionless scoliosis investigation. Spine. 2005;30(17):835-45

18. Pampliega T, Beguiristain JL, Artieda J. Neurologic complications after sublaminar wiring. An experimental study in lambs. Spine. (Phila Pa 1976) 1992;17(4):441-5.

19. Lowe TG, Wilson L, Chien JT, et al. A posterior tether for fusionless modulation of sagittal plane growth in a sheep model. Spine. (Phila Pa 1976) 2005;30(17 Suppl):S69-74.

20. Schwab F, Patel A, Lafage V, et al. A porcine model for progressive thoracic scoliosis. Spine. (Phila Pa 1976) 2009;34(11):E397-404.

21. Odent T, Cachon T, Peultier B, et al. Porcine model of early onset scoliosis based on animal growth created with posterior mini-invasive spinal offset tethering. A preliminary report. Eur Spine J. 2011: 20(11):1869-76 
Pilot study UHMWPE sublaminar wires 


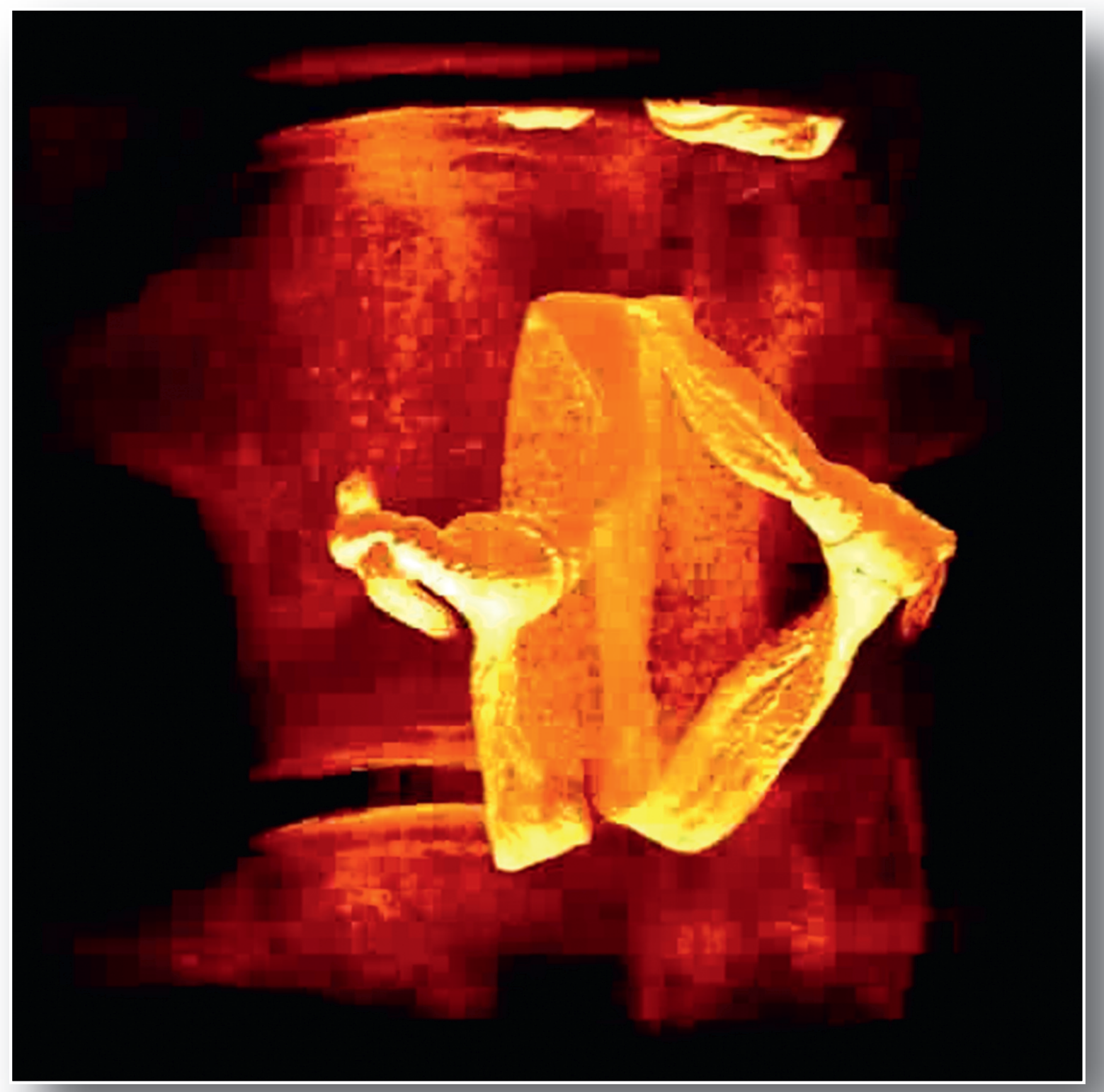




\section{CHAPTER 5}

Novel radiopaque ultra-high molecular weight polyethylene sublaminar wires in a growthguidance system for the treatment of early-onset scoliosis: Feasibility in a large animal study

Spine (Phila Pa 1976). 2014 Dec 1;39(25):E1503-9

Rob Bogie, Alex K. Roth, Sjoerd de Faber, Joost J. De Jong, Tim J.M. Welting, Paul C. Willems, Jacobus J. Arts, Lodewijk W. van Rhijn 


\section{Chapter 5}

\section{ABSTRACT}

Study Design. In vivo analysis in an ovine model.

Objective. To evaluate the feasibility of radiopaque UHMWPE sublaminar wires in a growthguidance spinal system by assessing stability, biocompatibility and growth potential.

Summary of Background Data. Several growth-guidance systems have been developed for the treatment of early onset scoliosis (EOS). The use of gliding pedicle screws and metal sublaminar wires during these procedures can cause metal-on-metal debris formation and neurological deficits. Novel radiopaque UHMWPE wires are introduced to safely facilitate longitudinal growth and provide stability in a growth-guidance system for EOS.

Method. Twelve immature sheep received posterior segmental spinal instrumentation; pedicle screws were inserted at L5 and radiopaque UHWMPE (bismuth trioxide) wires were passed sublaminarly at each level between L3 and T11 and fixed to dual cobalt-chromium rods. Four age-matched, unoperated animals were evaluated to serve as a control group. Radiographs were taken to measure growth of the instrumented segment. After 24 weeks, the animals were sacrificed and the spines were harvested for histological evaluation and high resolution peripheral quantitative computed tomography (HR-pQCT) analysis.

Results. No neurological deficits occurred and all instrumentation remained stable. One animal died from an unknown cause. Substantial growth occurred in the instrumented segments (L5-T11) in the intervention group $(27 \pm 2 \mathrm{~mm})$, which was not significantly different to the control group, $(30 \pm 4 \mathrm{~mm}, \mathrm{p}=0.42)$. HR-pQCT analysis clearly showed safe routing and fixation of the UHMWPE wires and instrumentation. Despite the noted growth, ectopic bone formation with the formation of bony bridges was observed in all animals. Histology revealed no evidence of chronic inflammation or wear debris.

Conclusion. This study shows the first results of radiopaque UHMWPE sublaminar wires as part of a growth-guidance spinal system. UHMWPE sublaminar wires facilitated near-normal longitudinal spinal growth. All instrumentation remained stable throughout follow-up; no wire breakage or loosening occurred and no adverse local tissue response to these wires was observed. 


\section{INTRODUCTION}

Challenging issues are faced in the management of early onset scoliosis (EOS). In the last decades, it has become apparent that early surgery aiming simply to attain a straight spine is not sufficient. ${ }^{1,2}$ Early definitive fusion may not only lead to a short trunk and disproportionate body stature, but also restricts volumetric growth of the thoracic cage and can restrict pulmonary development. ${ }^{3}$

Growth-guidance or self-lengthening rod systems are an alternative to distraction based growth preservation systems, such as growing rods and the vertical expandable prosthetic titanium rib (VEPTR) for the surgical treatment of EOS. ${ }^{1,4}$ A major advantage of growth-guidance systems is the marked decrease in subsequent operative procedures and associated hospitalization. Therefore, growth-guidance systems may be especially suitable for neuromuscular type EOS patients, who often suffer from significant medical comorbidities. ${ }^{5,6}$ Examples of growth-guidance systems are the Shilla system ${ }^{7}$ and a modern Luque trolley ${ }^{8}$, which both rely on gliding pedicle screws and/or sliding titanium sublaminar wires. Animal and in vitro studies have shown that wear at the screw-rod interface in the Shilla system caused considerable amounts of metallic wear debris formation in the surrounding tissue. ${ }^{7,9}$ Furthermore, placement of thoracic pedicle screws can be difficult due to distorted vertebral anatomy which is often seen in scoliosis patients. ${ }^{10}$ In these technically demanding cases sublaminar wires can be a valuable alternative. ${ }^{11}$ The use of metal wires in the original Luque trolley system did not lead to reliable spinal growth after surgery $8,12,13$ and has been frequently associated with a high incidence of neurological complications. ${ }^{14-16}$

We propose the use of novel radiopaque ultra-high molecular weight polyethylene (UHMWPE) woven wires as an alternative to gliding pedicle screws or titanium sublaminar wires for use in a growth-guidance system for EOS. The flat and broad shape of the woven UHMWPE sublaminar wires allow for distribution of contact forces over a greater area, thereby (theoretically) increasing corrective force and lowering risk of wire pull-out in comparison to metal wires. ${ }^{17,18}$ The soft and flexible properties of polymeric wires help avoid neurological injury during insertion or removal of the sublaminar wires. Despite the increased contact surface, UHMWPE wires exhibit lower friction during longitudinal sliding along metal rods as compared to titanium sublaminar wires in an in vitro test setup (internal data, not 


\section{Chapter 5}

published). Furthermore, as no metal-on-metal articulation occurs, the possible consequences of excessive metallic wear particles are not an issue.

We recently performed a pilot study in which we tested spinal instrumentation with UHMWPE sublaminar wires in an immature ovine model. ${ }^{19}$ This study showed that the UHMWPE sublaminar wires had excellent handling properties and that all instrumentation remained stable and intact. We experienced no neurological complications and UHMWPE sublaminar wire biocompatibility in the spinal canal was confirmed using histology. Most importantly, substantial spinal growth after instrumentation was observed. Radiolucency of the UHMWPE sublaminar wires limited the possibility for postoperative radiologic assessment in our initial pilot study. In the current study, we instrumented immature ovine spines using novel radiopaque UHMWPE sublaminar wires, in which bismuth trioxide particles were blended into each fiber. The goal of this study was to assess potential for growthallowance by quantifying spinal growth after instrumentation with UHMWPE sublaminar wires in immature sheep and by making a comparison to unoperated, age-matched control animals. Furthermore, histology was performed to analyze the local tissue response to these novel radiopaque UHMWPE sublaminar wires.

\section{MATERIALS AND METHODS}

\section{Material specifications}

The sublaminar wire used in this study is a $4 \mathrm{~mm}$-wide woven UHMWPE wire made with Dyneema Purity Radiopaque ${ }^{\circledR}$ fibers (DSM Biomedical B.V., Geleen, the Netherlands). Bismuth trioxide particles were blended into each fiber for radiopacity $\left(\mathrm{Bi}_{2} \mathrm{O}_{3}, 20 \%\right.$ wt. additive). ${ }^{20}$ All UHMWPE wires were ethylene oxide sterilized. Dynamic fatigue failure test in a servo-hydraulic testing frame showed that the cables could endure 5 million cycles with a load of $1350 \mathrm{~N}$ without failure.

\section{Surgical procedure}

All animal procedures were approved by the Animal Ethical Committee of the Maastricht University Medical Centre (approval number: DEC 2011-122). Twelve immature Texelaar sheep (ewes, 18 weeks old, weighing $20.1 \pm 3.1 \mathrm{~kg}$ ) were subjected to surgery, while four age-matched, animals $(24.8 \pm 2.8 \mathrm{~kg})$ served as 


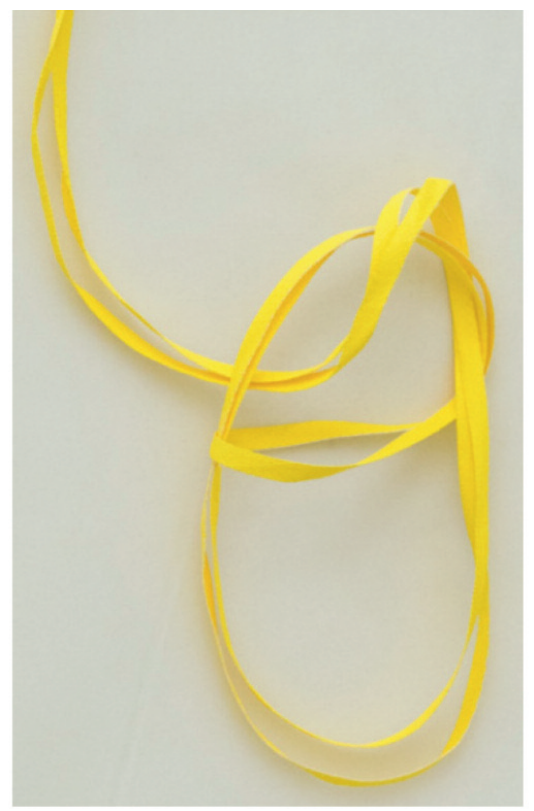

Figure 1. 4 mm-wide radiopaque UHMWPE sublaminar wire and the double loop sliding knot with extra pass used to secure the wire.

radiographic control. Antibiotics (amoxicillin/clavulan acid 1.2 gr.) were administered intravenously preoperatively. Each animal was sedated with intravenous administration of thiopental $(25 \mathrm{mg} / \mathrm{kg})$, and anesthesia was maintained using $1 \%$ to $2 \%$ isoflurane. Pain medication was given and adjusted if needed during surgery (remifentanyl $1 \mu \mathrm{g} / \mathrm{kg}$ per minute intravenously). Electrocardiogram registration, ventilation curves, oxygen saturation level and heart rate were continuously monitored. After a posterior midline incision was made from T11 to L5, the transverse processes and the facet joints were minimally exposed by partially detaching the erector spinae using electrocautery. Under fluoroscopic guidance, two pedicle screws (4.75 mm diameter, $20 \mathrm{~mm}$ length, Solera ${ }^{\circledR}$, Medtronic) were inserted into the L5 vertebral body. The ligamentum flavum was opened interlaminarly and partially removed with a punch, leaving the spinous processes intact. In this manner the laminae of T12 to L3 (T12, T13, L1, L2, L3) were exposed without violation of the dura mater, and UHMWPE wires were subsequently passed sublaminarly. In sheep, facet joints at upper thoracic levels overlap dorsoventrally, making sublaminar wire passage difficult. For this reason, lumbar and lower thoracic levels were selected for instrumentation. Dual cobalt chromium rods $(4.75 \mathrm{~mm})$ were placed along the spine and fixed using setscrews at the attachments. A double-loop sliding knot secured the wires to the rods (as used by Saito et al. ${ }^{21}$ and Takahati et al. ${ }^{22}$, but modified by an additional pass of wire ends through the loop). A single throw square 


\section{Chapter 5}

knot was placed over the sliding knot, tension was applied using a custom-made tensioning device, and the knot was ultimately secured with 5 -throw square knots (Figure 1-2). The wound was closed in layers. Post-operative pain management (buprenorphine $6 \mu \mathrm{g} / \mathrm{kg}$, carprofen $1 \mathrm{ml} / \mathrm{kg}$ intramuscularly) was provided until the animals returned to activities. Antibiotic treatment was administered postoperatively intramuscularly 6 hours after surgery.

X-rays were taken directly postoperatively and subsequently at four-week intervals under light tiletamine-zolazepam ( $8 \mathrm{mg} / \mathrm{kg}$ ) sedation until sacrifice at 24 weeks. Euthanization was performed using pentobarbital overdose $(200 \mathrm{mg} / \mathrm{kg})$. After sacrifice, the spines were harvested and High Resolution Peripheral Quantitative Computed Tomography scans (HRpQCT) were acquired. The spines were cleaned of soft tissue and processed for macroscopical and histological analysis.

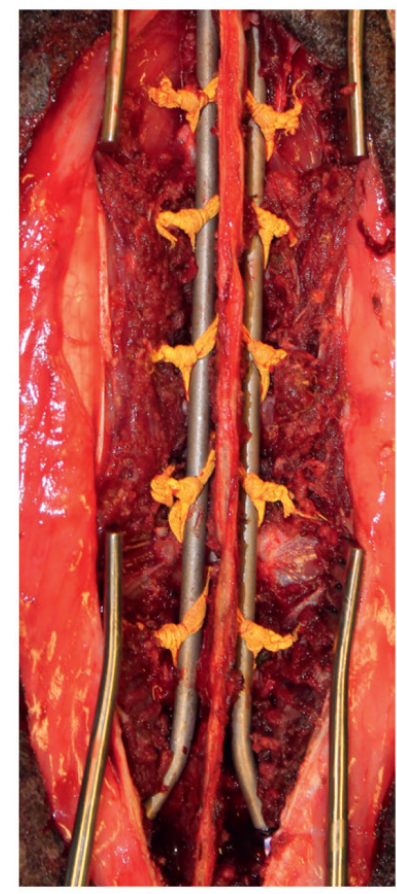

Figure 2. Intraoperative view of spinal instrumentation prior to wound closure.

\section{Radiography and spinal length measurement}

Routine dorsoventral and lateral radiographs were acquired directly postoperatively and subsequently at four-week intervals under light tiletamine-zolazepam (8 mg/kg) sedation until sacrifice at 24 weeks by pentobarbital overdose $(200 \mathrm{mg} / \mathrm{kg})$. Length of the operated segment was determined based on lateral radiographs using a custom written MATLAB code. A radiopaque ruler was placed on the spinal midline during radiographic 
acquisition and was used to calibrate the images. Edges of each individual vertebral body were subsequently manually selected. Length of the operated segment was defined as the summation of the individual vertebrae and the intermediate intervertebral discs.

\section{High Resolution Peripheral Quantitative Computed Tomography}

HRpQCT was performed to analyze routing and stability of the laminar wires and to assess orthotopic bone formation and facet joint changes. HR-pQCT scans were made using clinical in vivo settings (XtremeCT, Scanco Medical AG, Switzerland; effective energy $60 \mathrm{kVp}$, tube current $900 \mu \mathrm{A}, 100 \mathrm{~ms}$ integration time, isotropic voxel size $82 \mu \mathrm{m}$ ). Prior to HR-pQCT scanning, rods were removed from harvested spines by sawing through the L4/L5 intervertebral disc, and subsequently sliding levels L4-T12 in cranial direction.

\section{Histology}

The vertebrae of two spines were dissected for macroscopic and histological evaluation. Instrumented vertebrae were fixed in formalin and embedded in polymethyl methacrylate (Technovit 9100). Transverse sections with a thickness of $60 \mu \mathrm{m}$ were made with a Leica microtome and stained with Masson-Goldner's trichrome and Hematoxyline and Eosin (HE). Sections were analyzed for granulation tissue formation and inflammatory response.

\section{Statistical analysis}

Measurements were performed twice for each image by two individual observers. Inter and intra-observer reliability was assessed using the Intraclass Correlation Coefficient (ICC). Comparisons between the instrumented group and control group were performed using an unpaired Student's t-test. All statistical tests were 2-tailed, and a p-value $<0.05$ was considered to be significant. All analyses were performed using SPSS software, version 19.0.

\section{RESULTS}

All animals tolerated the procedure well and no intra-operative neurological injury occurred during pedicle-screw placement or during sublaminar wire passage. The 


\section{Chapter 5}

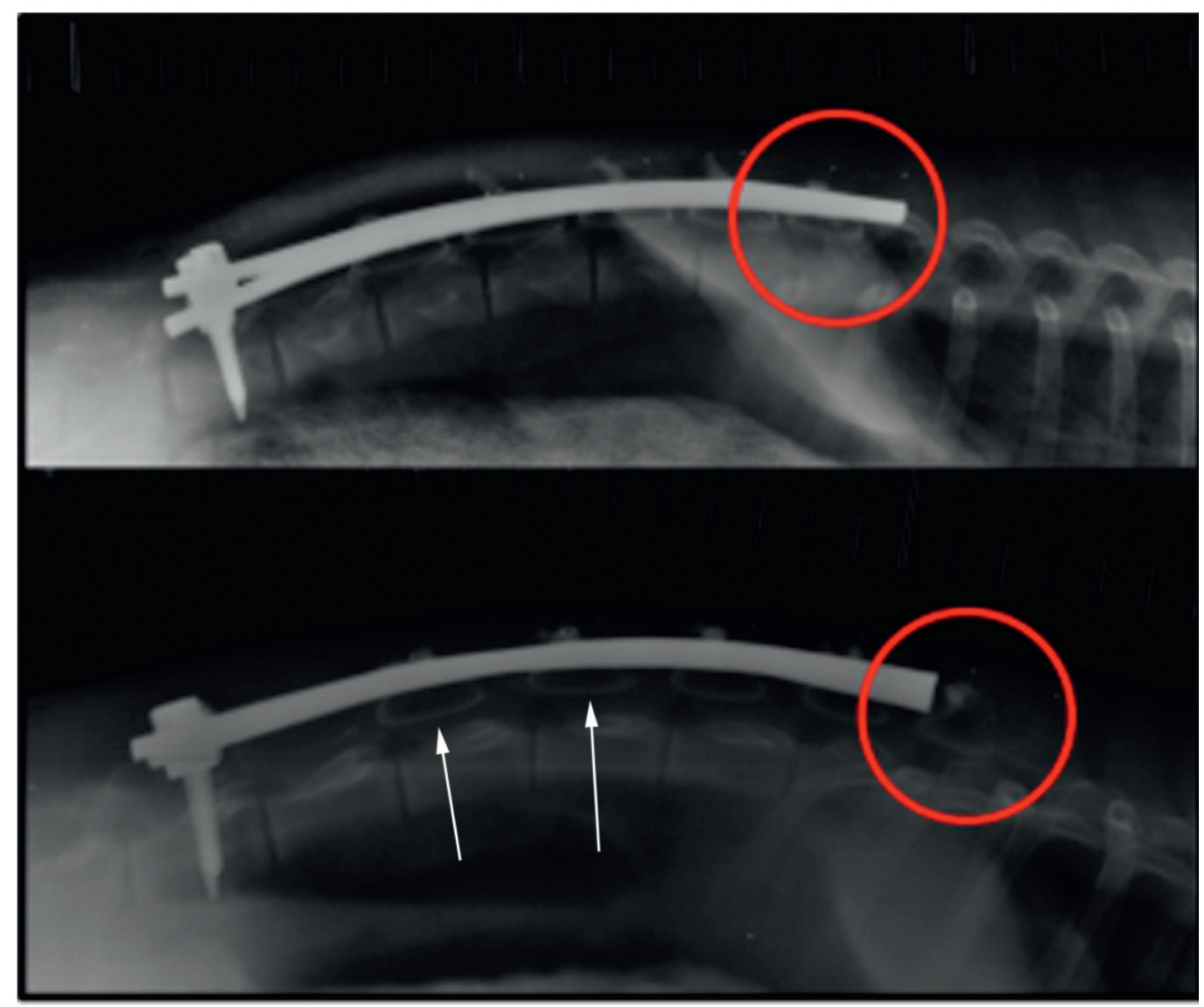

Figure 3. Direct post-operative (upper) and 24-weeks post-operative lateral radiograph (lower) of the instrumented sheep spine. Marked growth of the instrumented segment has occurred as illustrated by sliding of the most cranial UHMWPE sublaminar wire (red circle). Novel radiopaque UHMWPE sublaminar wires are clearly visible on radiography (arrows).

animals were ambulatory within 12 hours. One animal died 3 weeks postoperatively, with no clear cause of death as determined during autopsy. The animal presumably suffered from heat stroke. The other animals experienced no major complications during the 24 weeks follow-up.

Instrumentation remained stable in all animals. The animals in the operated group showed marked growth of the operated segments, with sliding of the UHMWPE laminar wires along the rods. In most animals, the most cranially placed wires slid off of the rods (Figure 3). Quantitatively, the mean length of the operated segment in the experimental group increased by $27 \pm 2 \mathrm{~mm}$, compared to $30 \pm 4$ $\mathrm{mm}$ in the control group after 24 weeks $(P=0.42$, Figure 4$)$. In both groups, growth 


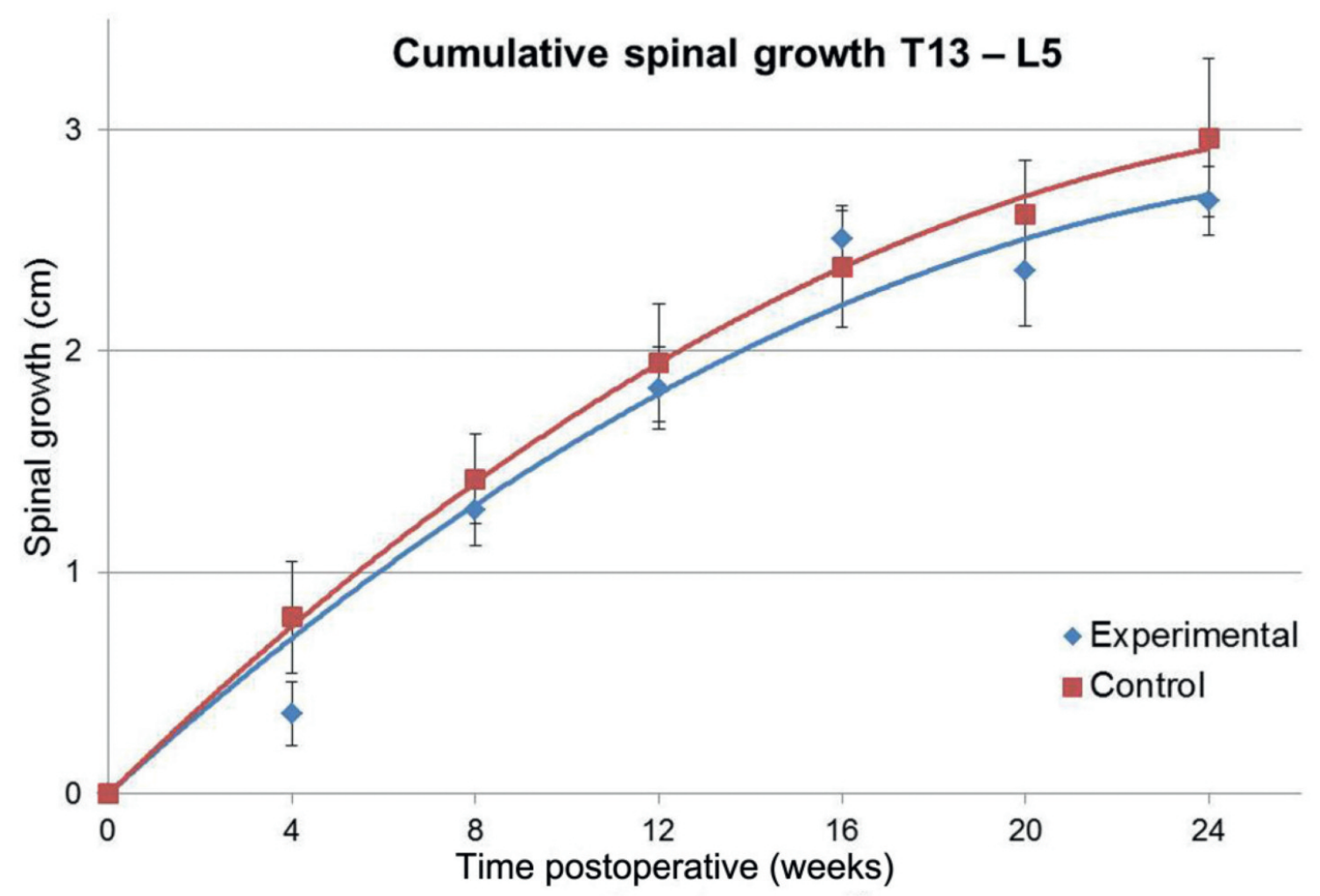

Figure 4. Average growth $(\mathrm{cm})$ and standard deviation values of the experimental group and control group. Both curves show a similar pattern with cessation of growth around 20 weeks.

ceased approximately 20 weeks postoperatively. In terms of normalized growth, both growth curves showed a similar pattern (16\% growth in the experimental group versus $17 \%$ in the control group). Growth measurement showed high inter- and intra-observer reliability, with an ICC of 0.94 and 0.99 respectively.

Removal of the spinal rods was easy, indicating that no bone apposition directly onto the rods had occurred. Subsequent manual palpation detected loss of range of motion of the instrumented levels in all cases. HR-pQCT images revealed interlaminar ectopic bone formation, which did not completely bridge the interlaminar space (Figure 5D). This bone formation did not lead to compression of the dura or encroachment of the spinal canal. Bone formation originating from the spinous process, rounding the spinal rod was also observed (Figure $5 \mathrm{~A}, \mathrm{C}$ ). In some cases, a bony bridge between the spinous process and the facet joint was formed (Figure $5 \mathrm{~A}, \mathrm{~B}$ ). Although joint space narrowing was observed, the facet joint generally did not completely fuse. 


\section{Chapter 5}

A

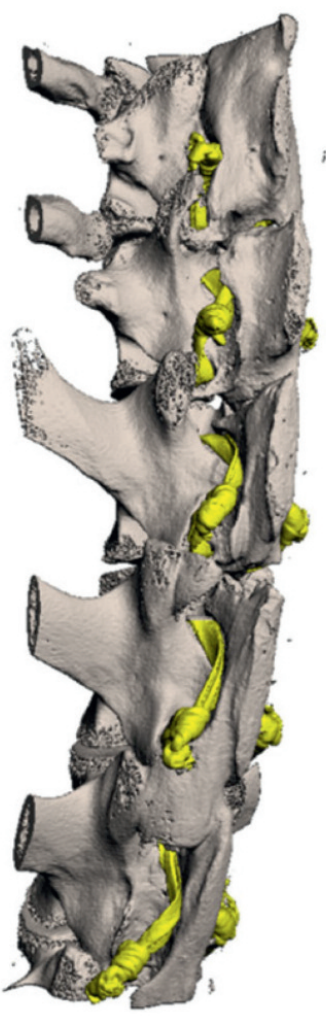

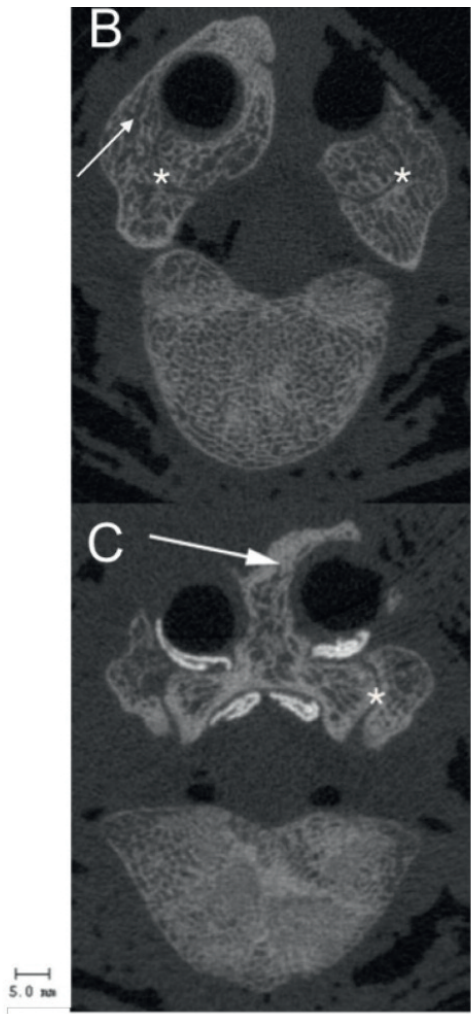

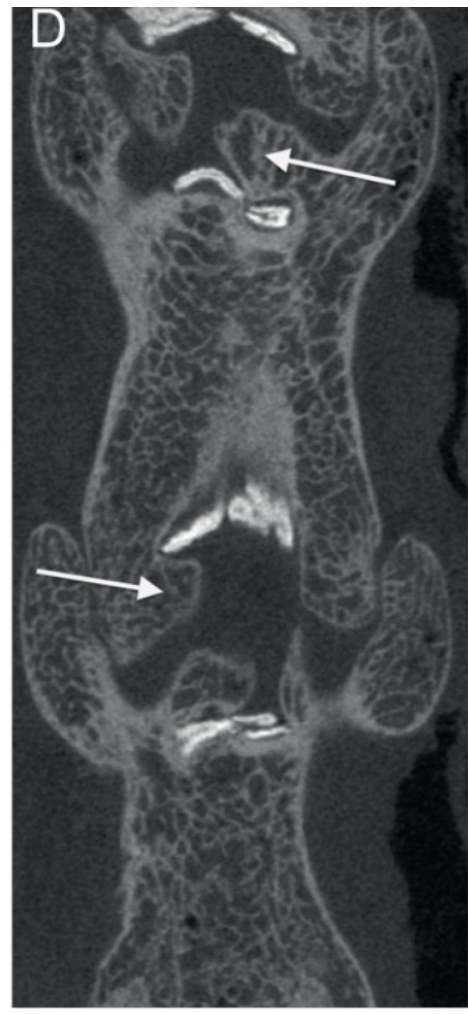

Figure 5. (A) 3-D reconstruction of a HR-pQCT scan of an intervention group spine after extraction of the rods. The formation of a bony bridge between the facet joint and spinous process is observed at the lower lumbar level. (white arrow) (B) Transversal image at the level of the bony bridge as seen in the 3-D reconstruction. Ectopic bone formation has occurred around the rod (arrow), leaving the facet joint intact. (asterisk). (C) Transversal image showing the sublaminar wires in the spinal canal, ectopic bone formation (arrow) starting to encircle the rod and facet joints (asterisk). (D) Coronal HR-pQCT image, clearly visualizing the radiopaque UHMWPE wires around the laminae. Interlaminar ossification is seen in proximity to the UHMWPE wire (arrows).

Macroscopic inspection at harvest showed no signs of wire fraying or discoloration of surrounding tissues. Histological analysis revealed no significant pathological changes; UHMWPE sublaminar wires in the epidural space were encapsulated by fibrous tissue with no signs of chronic inflammatory reactions (Figure 6). No foreign body giant cells were observed and no fragmentation of the UHMWPE wires occurred. Polarized light microscopy assessment of plastic embedded saw sections did not reveal UHMWPE wear particles. 


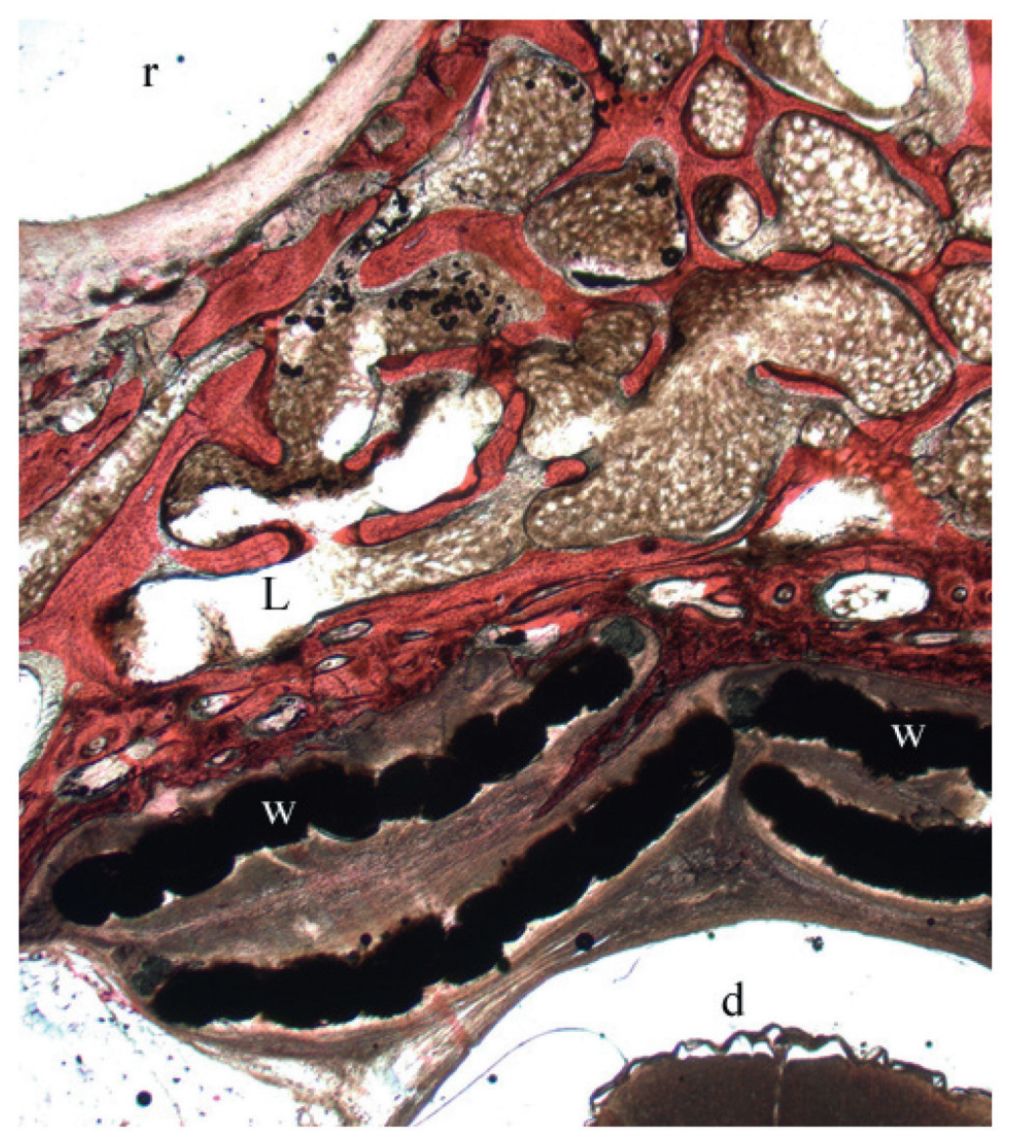

Figure 6. Histologic section (hematoxylin and eosin staining, magnification 2.5x). Rod space ( $r$ ) with fibrous layer is shown in de upper left. The two double layer UHMWPE sublaminar wires $(w)$ are positioned against the lamina (L). The dura $(d)$ is shown to be thin and partially retracted.

\section{DISCUSSION}

In this study, we propose the use of radiopaque UHMWPE sublaminar wires as an alternative to gliding pedicle screws or metal sublaminar wires in a growth-guidance system for EOS treatment. Instrumentation with UHMWPE sublaminar wires did not seem to limit longitudinal spinal growth. At present, UHMWPE sublaminar wires are already clinically used in hybrid constructs for spinal fusion in adolescent scoliosis patients in Japan. ${ }^{17,22,23}$ Wire radiolucency precludes the possibility for direct postoperative radiological follow-up. The first in vivo experience with radiopaque 


\section{Chapter 5}

UHMWPE wires is presented in this study. Novel radiopaque UHMWPE sublaminar wires allow for postoperative radiological assessment and thus allow for more widespread application of UHMWPE sublaminar wires in spinal deformity correction, and as we propose here in a growth-guidance system for the treatment of EOS.

The inherent low friction properties of the UHMWPE wire facilitate longitudinal sliding along the rods without the potentially catastrophic effects of metallic wear particles in developing children. Currently investigated growth-guidance systems show wear-debris accumulation in surrounding soft tissue as a result of metal-onmetal articulation. ${ }^{7-9}$ The long-term consequences of metallic wear particles in the pediatric spine are unknown. The effects of UHMWPE wear particles, although potentially severe, are less detrimental and require a larger volume. Till date only few case reports have described inflammation due to UHMWPE wear in spine. ${ }^{24}$

The fact that no foreign body giant cells were observed and no fragmentation of the UHMWPE wires occurred in this study are encouraging. Polarized light microscopy assessment of plastic embedded saw sections did not reveal UHMWPE wear particles. Standardized in vitro wear assessment will performed in the near future and will elucidate the amount and size of wear debris generated after in vivo placement in an animal model.

Data from our earlier study supported biocompatibility of (radiolucent) UHWMPE wires. ${ }^{19}$ The biological reaction to the novel radiopaque UHMWPE sublaminar wire, with bismuth trioxide particles blended into each fiber, was similar to the radiolucent UHMWPE wire and comparable to what has been described for other polymeric sublaminar wires. ${ }^{25}$ Histological evaluation showed that the UHMWPE sublaminar wire was encapsulated by fibrous tissue and caused no chronic inflammatory reactions. Furthermore, macroscopic and histology evaluation did not show fraying of the UHMWPE sublaminar wires. Damage to the UHMWPE sublaminar wire is not expected, and so far not observed, as the ultimate tensile strength and fatigue strength for the UHWMPE wire including the knot are superior to currently used sublaminar wires (unpublished data; $2250 \mathrm{~N}$, and $1350 \mathrm{~N}$ (run-out at 5 million cycles) respectively). Although the first indication of biocompatibility was positive, local and systemic effects of the bismuth trioxide radiopacifier will be subject to further investigation.

With regard to the surgical treatment of EOS, it remains difficult to extrapolate the attained growth to a prolonged time period in children as growth velocity in an animal model is much higher as in the growing child. Pediatric T1-S1 growth is approximately 
$1 \mathrm{~cm} /$ year between the age of $5-10$, and $1.8 \mathrm{~cm} /$ year between the age of 10 and skeletal maturity. ${ }^{26}$ In our ovine model, the operated segment alone (7 vertebrae) grew approximately $3 \mathrm{~cm}$ in 24 weeks. Due to the limited number of animals in the control group, we could not attain sufficient statistical power needed to make a fair comparison between the operated and the control groups. We deemed the use of more control animal subjects unethical, as we considered small differences to be clinically irrelevant in this early stage of research. The cessation of growth in both the experimental and control group at around 20 weeks postoperatively are as expected from growth curves described in the literature. ${ }^{27}$ In this study, five consecutive levels were instrumented with sublaminar wires. We aimed to illustrate the potential for continued growth after spinal instrumentation with UHMWPE sublaminar wires at five consecutive levels to provide substantial resistance to growth. From a clinical perspective, optimal results in terms of attained growth and correction may be attained with fewer UHWMPE sublaminar wire fixation points at distal and proximal ends, combined with intended fusion at the apex, as proposed for the Shilla system. Spinal growth after instrumentation with the Shilla system was described in a caprine study by McCarthy et al. ${ }^{7}$ An average spinal growth of $48 \mathrm{~mm}$ across 14 instrumented levels was achieved in this study over a similar time period. Although no direct comparison to our study can be made due to differences in age, species and instrumentation, growth per instrumented segment is similar in our study $(0.34 \mathrm{~cm} /$ segment versus $0.38 \mathrm{~cm} / \mathrm{segment}$ in our study respectively).

Despite the noted growth, interlaminar ectopic bone formation and occurrence of bony bridging between the facet joints and spinous processes were seen to a certain extent in all animals. This observation revealed an atypical fusion pattern. During the approach, spinous processes were not removed and effort was made to disrupt spinal musculature as little as possible. However, some degree of periosteal stripping is inevitable for sublaminar wire passage due to dissection of the flaval ligament. The typical bone formation pattern was not noticeable on conventional postoperative radiographs, and could only be noted post-mortem after removal of the cobaltchromium rods due to diffraction on CT. Therefore we were not able to determine the time of onset of bone formation. The resulting ectopic bone formation was expected based on similar findings that have been encountered with the Luque trolley. ${ }^{12}$ However, fusion rates are typically much higher in quadruped models than rates seen clinically. ${ }^{28}$ It has been suggested that spinal loading is higher in quadrupeds due to 


\section{Chapter 5}

a higher vertebral bone density, and for that reason the mechanical stimuli to form new bone are also much stronger. ${ }^{29}$ Facet joint changes are likely a result of changes in mechanical loading of the facet joints brought on by the instrumentation. The thoracolumbar facets joints in sheep are normally rounded, encompassing joints, which provide resistance to both dorsal and ventral shear, as well as to torsion. ${ }^{30}$ Load shift from the facets to posterior instrumentation in combination with the periosteal damage has presumably resulted in the observed changes around the facets.

Cahill et al. ${ }^{31}$ reported high rates (89\%) of spontaneous fusion after growingrod surgery in an immature patient group, even when instrumentation is not placed directly on the spine and bone is not exposed. Betz et al. ${ }^{32}$ reported no difference in fusion rates between groups with and without graft material in a randomized trial in adolescent scoliosis patients. Both observations have led to the idea that immobilization of the spine alone can lead to spontaneous spinal fusion in immature patients. With that in mind, the aim during surgical treatment of EOS with a growthguidance system should be to attain maximum growth before the occurrence of fusion, which may ultimately occur after ectopic bone formation.

Karol et al. specifically stressed the importance of attaining sufficient thoracic spinal height; pulmonary function in early fused patients was severely diminished when the thoracic spinal height did not reach $22 \mathrm{~cm} .{ }^{33}$ Thoracic cage volume has reached only $30 \%$ of the expected volume at maturity by the age of 8 and only $50 \%$ by the age of $10 .^{26}$ Restriction of thoracic cage volumetric growth limits further pulmonary development. ${ }^{3}$ The use of growth-guidance systems may be preferred over growing rods in neuromuscular EOS patients due to the expected marked decrease in operative procedures; complication rates are typically much higher in neuromuscular scoliosis patients due to serious comorbidities.

The first in vivo experience with novel radiopaque UHMWPE sublaminar wires as part of a growth-guidance system for EOS is promising; instrumentation remained stable, no adverse local tissue response to the wires was observed, and substantial longitudinal spinal growth was facilitated. Further research into systemic biocompatibility is required, and corrective ability should be tested in an experimental scoliosis large animal model to allow for clinical application of novel UHMWPE sublaminar wires in EOS. 


\section{REFERENCES}

1. Tis JE, Karlin LI, Akbarnia BA, Blakemore LC, Thompson GH, McCarthy RE, et al. Early Onset Scoliosis: Modern Treatment and Results. J Pediatr Orthop. 2012;32:647-57.

2. Akbarnia BA. Management Themes in Early Onset Scoliosis. J Bone Joint Surg Am. 2007;89 Suppl 1:42-54.

3. Vitale MG, Matsumoto H, Bye MR, Gomez JA, Booker WA, Hyman JE, et al. A Retrospective Cohort Study of Pulmonary Function, Radiographic Measures, and Quality of Life in Children with Congenital Scoliosis: An Evaluation of Patient Outcomes after Early Spinal Fusion. Spine (Phila Pa 1976). 2008;33:1242-9.

4. Gomez JA, Lee JK, Kim PD, Roye DP, Vitale MG. "Growth Friendly" Spine Surgery: Management Options for the Young Child with Scoliosis. The Journal of the American Academy of Orthopaedic Surgeons. 2011;19:722-7.

5. Reames DL, Smith JS, Fu KM, Polly DW, Jr., Ames CP, Berven SH, et al. Complications in the Surgical Treatment of 19,360 Cases of Pediatric Scoliosis: A Review of the Scoliosis Research Society Morbidity and Mortality Database. Spine (Phila Pa 1976). 2011;36:148491.

6. Sharma S, Wu C, Andersen T, Wang Y, Hansen ES, Bunger CE. Prevalence of Complications in Neuromuscular Scoliosis Surgery: A Literature Meta-Analysis from the Past 15 Years. Eur Spine J. 2013;22:1230-49.

7. McCarthy RE, Sucato D, Turner JL, Zhang H, Henson MA, McCarthy K. Shilla Growing Rods in a Caprine Animal Model: A Pilot Study. Clin Orthop Relat Res. 2010;468:705-10.

8. Ouellet J. Surgical Technique: Modern Luque Trolley, a Self-Growing Rod Technique. Clin Orthop Relat Res. 2011;469:1356-67.

9. Singh V, Simpson J, Rawlinson J, Hallab N. Growth Guidance System for Early-Onset Scoliosis: Comparison of Experimental and Retrieval Wear. Spine (Phila Pa 1976). 2013;38:1546-53.

10. Zhu F, Sun X, Qiao J, Ding Y, Zhang B, Qiu Y. Misplacement Pattern of Pedicle Screws in Pediatric Patients with Spinal Deformity: A Computed Tomography Study. J Spinal Disord Tech. 2014;27:431-5.

11. Raney EM. Hooks and Wires-Tried and True Plus How To: Posna1-Daycourse, April 29, 2009. J Pediatr Orthop. 2011;31:S81-7. 


\section{Chapter 5}

12. Mardjetko SM, Hammerberg KW, Lubicky JP, Fister JS. The Luque Trolley Revisited. Review of Nine Cases Requiring Revision. Spine (Phila Pa 1976). 1992;17:582-9.

13. Pratt RK, Webb JK, Burwell RG, Cummings SL. Luque Trolley and Convex Epiphysiodesis in the Management of Infantile and Juvenile Idiopathic Scoliosis. Spine (Phila Pa 1976). 1999;24:1538-47.

14. Cervellati S, Bettini N, Bianco T, Parisini P. Neurological Complications in Segmental Spinal Instrumentation: Analysis of 750 Patients. Eur Spine J. 1996;5:161-6.

15. Dove J. Segmental Wiring for Spinal Deformity. A Morbidity Report. Spine (Phila Pa 1976). 1989;14:229-31.

16. Johnston CE, 2nd, Happel LT, Jr., Norris R, Burke SW, King AG, Roberts JM. Delayed Paraplegia Complicating Sublaminar Segmental Spinal Instrumentation. J Bone Joint Surg Am. 1986;68:556-63.

17. Murakami H, Yamazaki K, Attallah-Wasif ES, Tsai KJ, Shimamura T, Hutton WC. A Biomechanical Study of 3 Different Types of Sublaminar Wire Used for Constructs in the Thoracic Spine. J Spinal Disord Tech. 2006;19:442-6.

18. Mazda K, Ilharreborde B, Even J, Lefevre Y, Fitoussi F, Pennecot GF. Efficacy and Safety of Posteromedial Translation for Correction of Thoracic Curves in Adolescent Idiopathic Scoliosis Using a New Connection to the Spine: The Universal Clamp. Eur Spine J. 2009;18:158-69.

19. Bogie R, Voss L, Arts JJ, Lataster LM, Willems PC, Brans B, et al. Uhmwpe Sublaminar Wires in Posterior Spinal Instrumentation: Stability and Biocompatibility Assessment in an Ovine Pilot Study. J Spinal Disord Tech. 2014.

20. Ceelen K VC, Bremer L, Simmelink J. . Development of a High-Strength, Biocompatible, Radiopaque Uhmwpe Fiber. 24th European Conference on Biomaterials. Dublin, Ireland2011.

21. Saito R, Hase H, Mikami Y, Tsuji Y, Ikeda T, Osawa T, et al. Clinical Study of a Modified Brooks Technique for Atlanto-Axial Subluxation Using Polyethylene Tape. J Spinal Disord Tech. 2006;19:11-7.

22. Takahata M, Ito M, Abumi K, Kotani Y, Sudo H, Ohshima S, et al. Comparison of Novel Ultra-High Molecular Weight Polyethylene Tape Versus Conventional Metal Wire for Sublaminar Segmental Fixation in the Treatment of Adolescent Idiopathic Scoliosis. J Spinal Disord Tech. 2007;20:449-55. 
23. Imagama S, Ito Z, Wakao N, Ando K, Hirano K, Tauchi R, et al. Posterior Surgery for Adolescent Idiopathic Scoliosis with Pedicle Screws and Ultra-High Molecular Weight Polyethylene Tape: Achieving the Ideal Thoracic Kyphosis. J Spinal Disord Tech. 2012.

24. Austen S, Punt IM, Cleutjens JP, Willems PC, Kurtz SM, MacDonald DW, et al. Clinical, Radiological, Histological and Retrieval Findings of Activ-L and Mobidisc Total Disc Replacements: A Study of Two Patients. Eur Spine J. 2012;21 Suppl 4:S513-20.

25. Grobler LJ, Gaines RW, Kempff PG. Comparing Mersilene* Tape and Stainless Steel Wire as Sublaminar Spinal Fixation in the Chagma Baboon (Papio Ursinus). Iowa Orthop J. 1997;17:20-31.

26. Dimeglio A, Canavese F. The Growing Spine: How Spinal Deformities Influence Normal Spine and Thoracic Cage Growth. European spine journal : official publication of the European Spine Society, the European Spinal Deformity Society, and the European Section of the Cervical Spine Research Society. 2012;21:64-70.

27. Roth AK, Bogie R, Jacobs E, Arts JJ, van Rhijn LW. Large Animal Models in Fusionless Scoliosis Correction Research: A Literature Review. Spine J. 2013;13:675-88.

28. Kanayama M, Cunningham BW, Sefter JC, Goldstein JA, Stewart G, Kaneda K, et al. Does Spinal Instrumentation Influence the Healing Process of Posterolateral Spinal Fusion? An in Vivo Animal Model. Spine (Phila Pa 1976). 1999;24:1058-65.

29. Smit TH. The Use of a Quadruped as an in Vivo Model for the Study of the Spine Biomechanical Considerations. Eur Spine J. 2002;11:137-44.

30. Boszczyk BM, Boszczyk AA, Putz R. Comparative and Functional Anatomy of the Mammalian Lumbar Spine. Anat Rec. 2001;264:157-68.

31. Cahill PJ, Marvil S, Cuddihy L, Schutt C, Idema J, Clements DH, et al. Autofusion in the Immature Spine Treated with Growing Rods. Spine (Phila Pa 1976). 2010;35:E1199-203.

32. Betz RR, Petrizzo AM, Kerner PJ, Falatyn SP, Clements DH, Huss GK. Allograft Versus No Graft with a Posterior Multisegmented Hook System for the Treatment of Idiopathic Scoliosis. Spine (Phila Pa 1976). 2006;31:121-7.

33. Karol LA, Johnston C, Mladenov K, Schochet P, Walters P, Browne RH. Pulmonary Function Following Early Thoracic Fusion in Non-Neuromuscular Scoliosis. J Bone Joint Surg Am. 2008;90:1272-81 


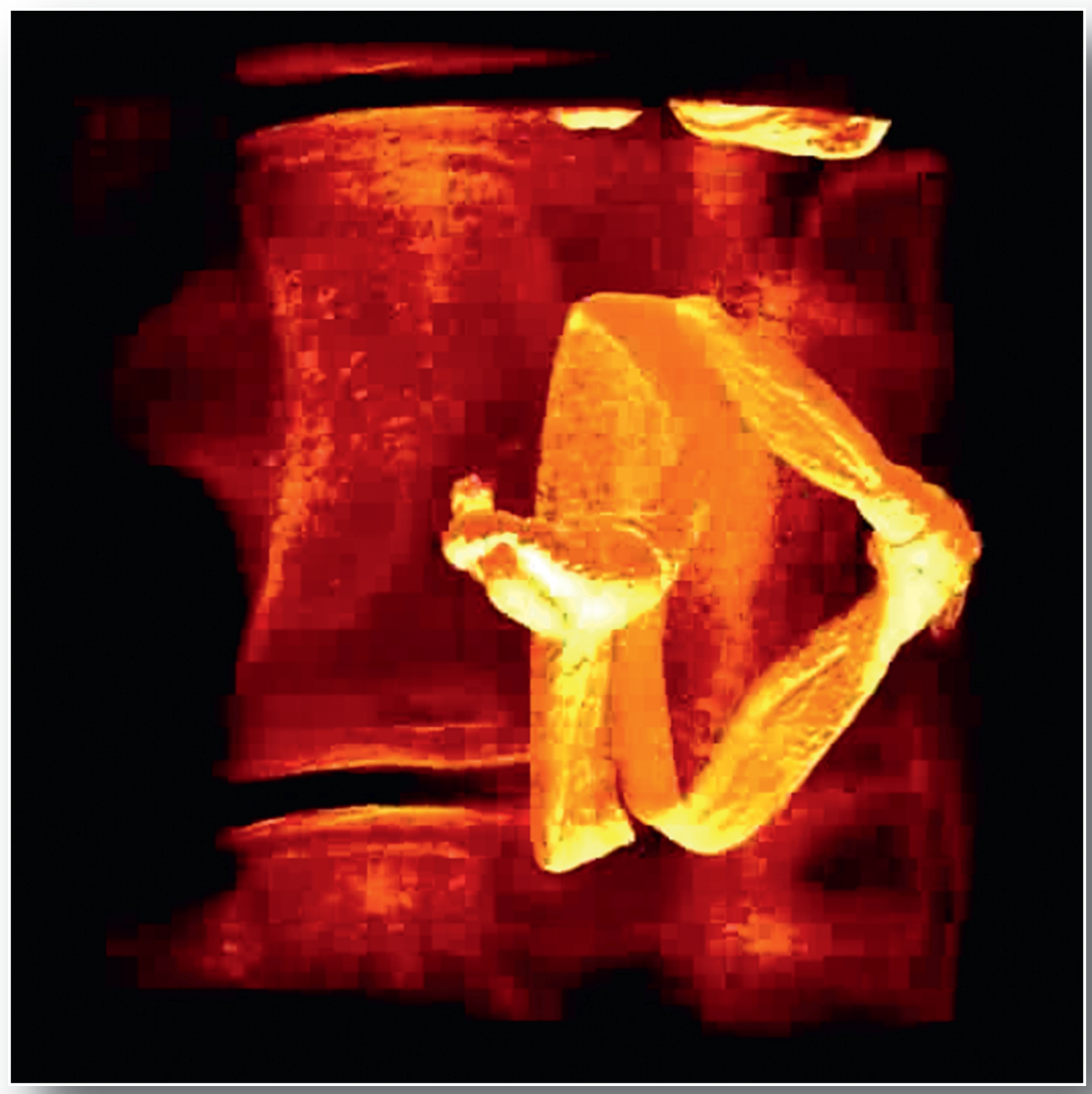




\section{CHAPTER 6}

\section{Large animal models in fusionless scoliosis correction research: a literature review}

Spine J. 2013 Jun;13(6):675-88

Alex K. Roth, Rob Bogie, Eva Jacobs, Jacobus J. Arts, Lodewijk W. van Rhijn 


\title{
Chapter 6
}

\begin{abstract}
Background Context. Numerous prenatal, systemic or local procedures have been described which have created an experimental scoliosis within different animal species. Compressionbased fusionless scoliosis correction devices have been used to induce scoliosis (inverse approach) as an indication for their potential corrective efficacy in large animals. Deformities which most closely approximate the three-dimensional nature of an idiopathic-like scoliosis have been created in large animals using a posterior spinal tether. Fusionless scoliosis correction devices have subsequently been tested in these models.
\end{abstract}

Purpose. To provide an overview of large animal models used for preclinical testing of fusionless scoliosis correction devices and to describe recent advances in the creation of an idiopathic-like scoliosis large animal model.

Study Design. Literature review of large animal models in fusionless scoliosis correction research.

Methods. MEDLINE electronic database was searched for studies in which large animal models for spinal or vertebral growth modulation or the creation of an experimental scoliosis were described. The literature search was limited to articles written in the English language.

Results. The pig appears to be the most suitable animal species for preclinical testing of fusionless scoliosis correction devices due to its large growth potential and the possibility for early weaning. With the inverse approach, it is difficult to gain insight into the possible corrective efficacy of the tested device and therefore a two-step approach is preferred. Using a posterior spinal tether, persistent spinal deformities are attained when the deformity has approximately doubled in comparison to the postoperative measure in a time span of approximately 12 weeks. Sufficient tether midline off-set is required to render rib procedures unnecessary.

Conclusions. An idiopathic-like scoliosis animal model can be created using a posterior spinal tether in a fully reversible procedure. Experimental results will need to be reproduced in order to establish a standard, idiopathic-like scoliosis large animal model. 


\section{INTRODUCTION}

Scoliosis is a complex three-dimensional spinal deformity which is seen in $3-5 \%$ of the adolescent population. ${ }^{1}$ The most common type of scoliosis (80-85\%) is adolescent idiopathic scoliosis (AIS), which presents shortly before or during puberty. The etiology is unknown and presumably multifactorial (genetic, environmental etc.). The risk of deformity progression is increased during periods of rapid skeletal growth due to the effects of asymmetric loading on growth rate; bone growth is suppressed by increased compression and accelerated by tensile forces acting on the endochondral growth plate (Hueter-Volkmann principle). A spinal deformity that leads to asymmetric loading and growth, resulting in deformity progression in a 'vicious cycle' as was proposed by Stokes et al. ${ }^{2}$

The standard treatment for deformities not responding to conservative bracing therapy has been spinal fusion with the goal of acquiring stable correction. However, before surgical intervention in the growing spine is considered, the expected remaining growth in the spine and the thoracic cage must be taken into account. The thoracic cage has only reached approximately $50 \%$ of its mature volume by age ten ${ }^{3}$, and early fusion can hinder lung development. ${ }^{4}$ Possible occurrence of the crankshaft phenomenon, progression of the spinal deformity due to continued growth in the anterior portion of the spine while the posterior portion is fused, also discourages early spinal fusion. ${ }^{5,6}$ Disproportionate stature and a shortened trunk may also result from early fusion.

In order to avoid these issues, surgical techniques and instrumentation are being developed which aim to achieve fusionless scoliosis correction. Fusionless scoliosis correction devices can be classified according to the mechanism by which spinal and thoracic cage growth is modulated: distraction-based (vertical expandable prosthetic titanium rib (VEPTR), growing rods), compression-based (vertebral body staple, anterior spinal tether) or growth-guidance systems (Luque trolley or Shilla technique). ${ }^{7}$ Controlling the deformity in all three dimensions is the largest challenge in the design of new fusionless scoliosis correction devices. To test the efficacy of new fusionless scoliosis correction devices in a preclinical stage, a consistent large animal model representative of an idiopathic scoliosis is ideally used. However, no such large animal model is naturally occurring. 


\section{Chapter 6}

In the past, animal models have been extensively used in attempts to clarify the etiology of scoliosis by inducing scoliosis using various prenatal, systemic or local procedures, as was reviewed in 2011 by Janssen et al. ${ }^{8}$ Compression-based fusionless scoliosis devices have also been used to induce a scoliotic deformity as an inverse analog to the corrective procedure as means to show their potential corrective efficacy. This approach has been dubbed the inverse approach. ${ }^{9}$ Tests have also been performed in animals using a two-step approach; a structural, idiopathiclike scoliosis is created in a first procedure and later corrected using the proposed scoliosis correction device in a second procedure. Although many different methods have been used to create a scoliosis, only posterior spinal tethering produces significant, progressing deformities that approximate the three-dimensional nature of the deformity as seen in idiopathic scoliosis. ${ }^{10}$

An overview of large animal models used for preclinical testing of fusionless scoliosis correction devices was given in 2005 by Braun et al. ${ }^{10}$ In recent years, advances towards a more consistent idiopathic-like scoliosis large animal model have been made and newly proposed fusionless scoliosis correction strategies have been tested using the inverse approach. Therefore, the purpose of this literature review is to provide an up-to-date overview of large animal models used in fusionless scoliosis correction research. The technical details which play an important role in the development of a consistent, idiopathic-like scoliosis animal model will also be reviewed as we will implement these lessons in the setup of an idiopathic-like scoliosis model at our own institution.

\section{METHODS}

The MEDLINE online database was consulted using the following search terms: (scoliosis OR ((spinal OR vertebral) AND (growth modulation))) AND (experimental OR animal model) up until July 2012. The search was limited to studies in large animals and articles published in the English language. References of retrieved articles and relevant review articles were checked to identify additional studies.

The titles and abstracts of the resulting citations $(n=594)$ were scanned by two separate authors. A meeting was held to reach consensus on the articles to be included ( $n=27$ ). In the case of disagreement, a third author was consulted. Figure 
1 illustrates the search terms, and the subsequent classification of included articles as used in this literature review. Included articles were first classified based on one of two methodological approaches which are followed; the inverse approach $(n=13)$ or the two-step approach $(n=14)$. With the inverse approach, the proposed method of surgical treatment is used to create a spinal deformity as an inverse analog to the corrective treatment. In this case, achieving spinal growth modulation is used as a first indication for possible success in scoliosis correction. For studies utilizing the inverse approach, the studies were subsequently classified according to the targeted growth plate: the neurocentral cartilage or the longitudinal vertebral epiphyseal plate. The two-step approach requires a fully reversible procedure to create a consistent, idiopathic-like scoliosis in a growing animal. These criteria have only been met using a posterior spinal tether. ${ }^{10}$ However, technical details vary considerably and will be compared.

An overview of important characteristics of studies utilizing the inverse approach to test fusionless scoliosis correction devices in large animals is given in Table 1. Table 2 summarizes the results and the most important characteristics of the idiopathic-like scoliosis models in large animals created using a posterior spinal tether.

\section{Inverse approach}

Growth modulation by epiphysiodesis of the neurocentral cartilage In 1980, an experimental scoliosis was created by selective epiphysiodesis of the neurocentral cartilage in immature pigs by Beguiristain et al. ${ }^{11}$ Unilateral pedicle screws were introduced in four or five consecutive, midthoracic levels and animals were followed for a period ranging between 4 and 12 months. Structural scoliotic deformities varying between $10^{\circ}$ and $80^{\circ}$ developed.

Zhang and Sucato ${ }^{12,13}$ successfully created scoliotic deformities with unilateral pedicle screw epiphysiodesis of the neurocentral cartilage by using two screws in the right pedicle between T7 and T14 in 1-2 month old pigs. After 6 weeks, the mean spinal deformity measured $35^{\circ}$. Attempts were made to correct the deformity by placing another two screws in the left pedicle in 3 animals, while 3 animals were not treated. Ultimately, the deformity measured $34^{\circ}$ in the untreated group while deformity was corrected to a mean of $20^{\circ}$ at 17 weeks postoperatively in the treated group. 


\section{Chapter 6}

Caballero et al. ${ }^{14}$ have performed growth modulation by hemicircumferential electrocoagulation of the neurocentral cartilage, inferior and superior epiphyseal endplates, and a combination of the above at T5-T9 in 4-week old pigs. The largest deformities $\left(19^{\circ}\right)$ were created in animals in which only the neurocentral cartilage was injured, in comparison to $12^{\circ}$ in the group with epiphyseal endplate injury and $13^{\circ}$ in the combined lesion group.

Growth modulation by epiphysiodesis of the vertebral epiphyseal plates In 1950, Nachlas and Borden ${ }^{35}$ were the first to use fusionless spine implants to create a deformity in a large animal model. A lumbar vertebral body staple spanning multiple (3-4) segments was used to create and subsequently also correct a deformity in immature dogs. Although no deformity measures were given, and staple dislodgement or breakage occurred regularly, this work pioneered fusionless scoliosis device testing in animal models.

Newton et al. have extensively studied growth modulation using an anterolateral thoracic tether in calves ${ }^{15-17}$ and mini-pigs. ${ }^{18,19}$ In the calf model, anterior vertebral body screws were placed at levels T6-T9, with a flexible stainless steel tether connecting all levels. With the calf model, a mean coronal deformity measuring $37^{\circ}$ was created. The rapid growth rate of the calves led to severe deformities considering only 4 levels are involved. This unsuspected outcome in the calf model prompted a change towards a miniature pig model, which has a more similar growth rate compared to the human adolescent. Using a similar procedure, a vertebral staple-screw construct was applied over four consecutive vertebrae, connected by a polyethylene tether in 7 month old mini-pigs. The mean Cobb angle from T8 to T11 was approximately $15^{\circ}$ after six months and $30^{\circ}$ after twelve months. The influence of intraoperative tether tensioning was also studied, and proved to cause an increased coronal Cobb angle during the first 6 postoperative months. At later time points, this effect disappeared with the final coronal Cobb angle (T8-T11) being $28^{\circ}$ in the pretensioned group and $27^{\circ}$ in the untensioned group at 12 months postoperatively. There was no screw pull-out or screw ploughing in either group, which indicates that intraoperative tensioning of the tether was safe. 


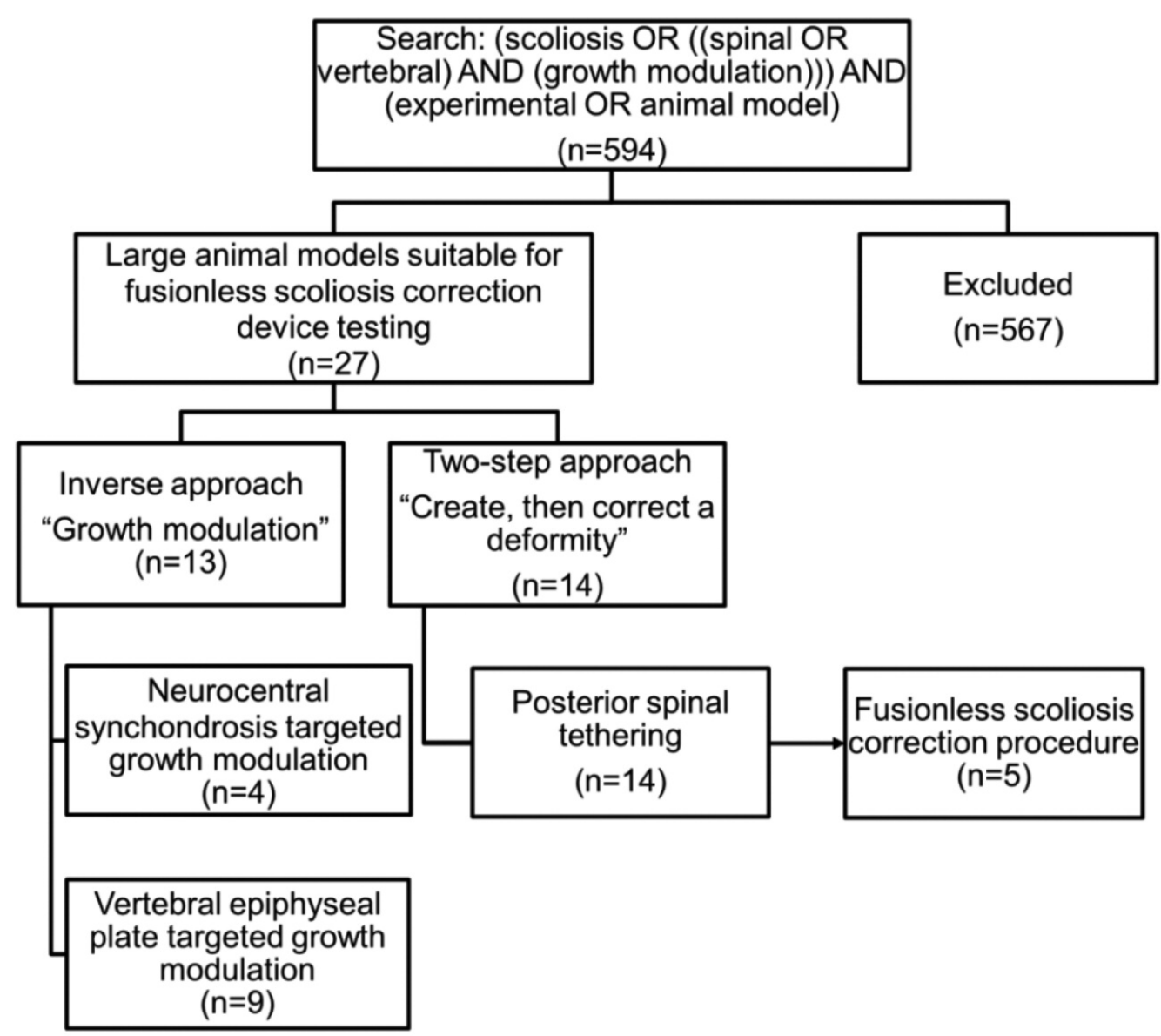

Figure 1. Flowchart illustrating the search terms, number of resulting publications, and the classification according to methodological approach.

\section{RESULTS}

Wall et al. ${ }^{20}$ have introduced six custom anterolateral spine staples between T6 and T12 in pigs approximately 3-4 months of age. Each staple spanned the disc and was fixed using two bone screws. After 8 weeks, a mean coronal plane deformity of $16^{\circ}$ was attained.

Hunt et al. ${ }^{21}$ have tested two different fusionless scoliosis correction devices in goats to assess their influence on the health of the disc. Anterior shape memory alloy staples or an anterior ligament tether with bone anchors were placed at each level between T7 and T12 in 8 week old goats. After a 6 month follow-up, the deformity measured $7^{\circ}$ in the staple group and $41^{\circ}$ in the ligament tether group. 


\section{Chapter 6}

\begin{tabular}{|c|c|c|}
\hline Reference & Animal & Procedure \\
\hline \multicolumn{3}{|c|}{ Neurocentral Cartilage targeted growth modulation } \\
\hline Zhang and Sucato & 8 pigs & Right transpedicular screw placed across \\
\hline \multirow[t]{2}{*}[12,13]{} & 2 months old & the neurocentral cartilage \\
\hline & & T7-T14 \\
\hline Caballero & 30 pigs & Hemicircumferential electrocoagulation \\
\hline [14] & $6-8$ weeks old & of growth plates T5-T9 \\
\hline \multicolumn{3}{|c|}{ Longitudinal epiphyseal plates targeted growth modulation } \\
\hline Newton & 33 calves (M) & Anterior unilateral flexible stainless steel \\
\hline$[15-17]$ & 1 month old & tether with laterally directed screws (Т6-T9) \\
\hline Newton & 12 mini-pigs (M) & Anterior unilateral flexible PE tether \\
\hline \multirow[t]{2}{*}[18,19]{} & 7 months old & pretensioned to $250 \mathrm{~N}$, titanium staple-screw \\
\hline & & (HA coated/uncoated) construct (T8-T11 \\
\hline Wall & 7 pigs (F) & Anterolateral custom spine staples spanning \\
\hline [20] & 3-4 months old & disc fixed by two screws at 2 levels (T6-T12) \\
\hline Hunt & 12 goats (F) & Two anterolateral shape memory staples per \\
\hline \multirow[t]{2}{*}{ [21] } & 8 weeks old & level or an anterolateral ligament tether \\
\hline & & with bone anchor T7-12 \\
\hline Driscoll & 9 pigs (F) & Anterolateral custom epiphyseal staple \\
\hline [22] & 3 months old & exclusive of disc fixed by single screw (T5-T8) \\
\hline
\end{tabular}

Table 1. Overview of results and characteristics of recent animal models using the inverse approach to test fusionless scoliosis correction devices. Positive values indicate kyphosis in sagittal plane, negative values indicate lordosis in sagittal plane. Value in between parentheses indicates standard deviation or range. 
Large animal models in fusionless scoliosis correction research: a literature review

\begin{tabular}{|c|c|c|c|}
\hline Follow-up & Groups & Postop mean angle & Final mean angle \\
\hline \multirow[t]{6}{*}{6 months } & Sham $(n=2)$ & $0^{\circ}$ & Cor. $0^{\circ}$ \\
\hline & & & Sag. $30^{\circ}\left(22-38^{\circ}\right)$ \\
\hline & Single screw/pedicle (n=3) & $0^{\circ}$ & Cor. $15.7^{\circ}(0-43)$ \\
\hline & & & Sag. $42^{\circ}\left(22-75^{\circ}\right)$ \\
\hline & Double screw/pedicle $(n=3)$ & $0^{\circ}$ & $\operatorname{Cor} 38^{\circ}\left(30-42^{\circ}\right)$ \\
\hline & & & Sag. $47^{\circ}\left(42-56^{\circ}\right)$ \\
\hline \multirow[t]{4}{*}{12 weeks } & Superior and inferior epiphyseal & & $12.4^{\circ}\left(10-16^{\circ}\right)$ \\
\hline & plate (EP) lesion $(n=10)$ & & \\
\hline & Neurocentral cartilage(NCC) lesion $(n=10)$ & & $19^{\circ}\left(16-24^{\circ}\right)$ \\
\hline & EP + NCC lesion $(n=10)$ & & $13.1^{\circ}\left(10-14^{\circ}\right)$ \\
\hline \multirow[t]{6}{*}{6 months } & 1 screw/level single tether & $\operatorname{Cor} .1^{\circ}\left(2^{\circ}\right)$ & Cor. $11^{\circ}\left(10^{\circ}\right)$ \\
\hline & $(n=11)$ & Sag. $2^{\circ}\left(3^{\circ}\right)$ & Sag. $7^{\circ}\left(6^{\circ}\right)$ \\
\hline & 2 screws/level double tether & Cor. $5^{\circ}\left(4^{\circ}\right)$ & Cor. $37^{\circ}\left(8^{\circ}\right)$ \\
\hline & $(n=11)$ & Sag. $2^{\circ}\left(1^{\circ}\right)$ & Sag. $19^{\circ}\left(7^{\circ}\right)$ \\
\hline & 1 screw/level & $\operatorname{Cor} 1^{\circ}\left(1^{\circ}\right)$ & $\operatorname{Cor} .5^{\circ}\left(4^{\circ}\right)$ \\
\hline & $(n=11)$ & Sag. $4^{\circ}\left(2^{\circ}\right)$ & Sag. $-1^{\circ}\left(4^{\circ}\right)$ \\
\hline \multirow[t]{4}{*}{$6-12$ months } & Pretensioned group & Cor. $8^{\circ}\left(4^{\circ}\right)$ & Cor. $28^{\circ}\left(18^{\circ}\right)$ \\
\hline & $(n=6)$ & Sag. $12^{\circ}\left(1^{\circ}\right)$ & Sag. $25^{\circ}\left(3^{\circ}\right)$ \\
\hline & Untensioned group ( $n=6$ ) & $\operatorname{Cor} .2^{\circ}\left(1^{\circ}\right)$ & Cor. $27^{\circ}\left(11^{\circ}\right)$ \\
\hline & & Sag. $13^{\circ}\left(1^{\circ}\right)$ & Sag. $22^{\circ}\left(3^{\circ}\right)$ \\
\hline \multirow[t]{2}{*}{8 weeks } & - & Cor. $0.8^{\circ}\left(1.8^{\circ}\right)$ & Cor. $16.4^{\circ}\left(5.4^{\circ}\right)$ \\
\hline & & Sag. $12.6^{\circ}\left(8.3^{\circ}\right)$ & Sag. $14.4^{\circ}\left(13.8^{\circ}\right)$ \\
\hline \multirow[t]{2}{*}{6 months } & Shape memory alloy staple $(n=6)$ & & Cor. $6.5(0.9)$ \\
\hline & Ligament tether $(n=6)$ & & Cor. $41.0(8.3$ \\
\hline 12 weeks & - & Cor. $0^{\circ}$ & Cor. $6.5^{\circ}\left(3.5^{\circ}\right)$ \\
\hline
\end{tabular}




\section{Chapter 6}

\begin{tabular}{|c|c|c|c|c|c|}
\hline Reference & Animal & Procedure & $\begin{array}{l}\text { Rib tether/ } \\
\text { Resection }\end{array}$ & $\begin{array}{l}\text { Retrospectively } \\
\text { formed groups }\end{array}$ & Follow-up \\
\hline $\begin{array}{l}\text { Braun } \\
{[23-26]}\end{array}$ & $\begin{array}{l}40 \text { goats (F) } \\
\text { (7 lost to follow-up) } \\
1-2 \text { months old }\end{array}$ & $\begin{array}{l}\text { Posterior unilateral (left) } \\
\text { rigid stainless steel } \\
\text { tether connected with } \\
\text { sublaminar hooks T5-L1 }\end{array}$ & $\begin{array}{l}\text { Convex rib } \\
\text { resection, } \\
\text { Concave rib } \\
\text { tethering } \\
\text { (ribs 8-13) }\end{array}$ & $\begin{array}{l}\text { Progressive deformity } \\
\text { Group ( } n=27 \text { ) } \\
\text { Non-progressive } \\
\text { group }(n=6)\end{array}$ & 6-15 weeks \\
\hline $\begin{array}{l}\text { Braun } \\
{[27,28]}\end{array}$ & $\begin{array}{l}24 \text { goats (F) } \\
\text { (2 lost to follow-up, } \\
2 \text { non-progressors) } \\
1-2 \text { months old }\end{array}$ & $\begin{array}{c}\text { Posterior unilateral } \\
\text { (left) sublaminar, } \\
\text { flexible tether (braided, } \\
\text { PE core/ polyester sleeve) } \\
\text { T5 -L1 }\end{array}$ & $\begin{array}{l}\text { Convex rib } \\
\text { resection, } \\
\text { Concave rib } \\
\text { tethering } \\
\text { (ribs 8-13) }\end{array}$ & $n=20$ & 8 weeks \\
\hline $\begin{array}{l}\text { Schwab[2] } \\
\text { Patel [30] }\end{array}$ & $\begin{array}{c}18 \text { pigs } \\
\text { (4 lost to follow-up, } \\
3 \text { non-progressors) } \\
\text { (Yorkshire, M) } \\
11 \text { weeks old }\end{array}$ & $\begin{array}{l}\text { Posterior unilateral (left) } \\
\text { flexible polyester tether } \\
\text { fixed by pedicle screws } \\
\text { T4/5-L2/3 }\end{array}$ & $\begin{array}{l}\text { Concave rib } \\
\text { tethering } \\
\text { (5 ribs) }\end{array}$ & $n=11$ & 6-14 weeks \\
\hline $\begin{array}{l}\text { Patel } \\
{[31]}\end{array}$ & $\begin{array}{c}7 \text { pigs } \\
\text { (Yorkshire, M) } \\
11 \text { weeks old } \\
\text { T4/5-L2/3 }\end{array}$ & $\begin{array}{l}\text { Posterior unilateral (left) } \\
\text { flexible polyester tether } \\
\text { fixed by pedicle screws }\end{array}$ & $\begin{array}{l}\text { Concave rib } \\
\text { tethering } \\
\text { (5 ribs) }\end{array}$ & $\begin{array}{c}\text { Persistent } \\
\text { deformity }(n=5) \\
\text { Autocorrection }(n=2)\end{array}$ & 4-10 weeks \\
\hline $\begin{array}{l}\text { Zhang } \\
{[32,33]}\end{array}$ & $\begin{array}{l}14 \text { goats (F) } \\
\text { (2 lost to follow-up, } \\
1 \text { non-progressor) } \\
5-8 \text { weeks old }\end{array}$ & $\begin{array}{l}\text { Posterior unilateral (left) } \\
\text { rigid stainless } \\
\text { steel tether } \\
\text { Pedicle screws } \\
\text { T6/7-L1/2 }\end{array}$ & $\begin{array}{l}\text { Convex rib } \\
\text { resection } \\
\text { (ribs 7-12) }\end{array}$ & $n=11$ & 8-10 weeks \\
\hline $\begin{array}{l}\text { Odent } \\
\text { [34] }\end{array}$ & $\begin{array}{l}6 \text { pigs (Landrace, F) } \\
1 \text { month old }\end{array}$ & $\begin{array}{l}\text { Posterior unilateral (left) } \\
\text { flexible stainless steel tether, } \\
\text { custom offset implant } \\
\text { with pedicle screws } \\
\text { T5/6-L1/2 }\end{array}$ & None & $n=6$ & 2 months \\
\hline
\end{tabular}

Table 2. Results and characteristics of idiopathic-like scoliosis models using a posterior spinal tether to induce scoliosis. Positive values indicate kyphosis in sagittal plane; negative values indicate lordosis in sagittal plane. Value in between parentheses indicates standard deviation or rang 
Large animal models in fusionless scoliosis correction research: a literature review

\begin{tabular}{|c|c|c|c|c|}
\hline Postoperative & Final mean angle & Additional & \multicolumn{2}{|c|}{ After tether release mean angle } \\
\hline Cor. $42^{\circ}\left(33-50^{\circ}\right)$ & Cor. $60^{\circ}\left(44-73^{\circ}\right)$ & 7-12 weeks & Pre-release & Cor. $67^{\circ}\left(61-73^{\circ}\right)$ \\
\hline Sag. $3^{\circ}\left(-10-+18^{\circ}\right)$ & Sag. $-1^{\circ}\left(-16-+15^{\circ}\right)$ & & Post-release & Cor. $61^{\circ}\left(49-75^{\circ}\right)$ \\
\hline Cor. $33^{\circ}\left(13-38^{\circ}\right)$ & Cor. $37^{\circ}\left(14-46^{\circ}\right)$ & & Endpoint & Cor. $60^{\circ}\left(45-77^{\circ}\right)$ \\
\hline
\end{tabular}

\begin{tabular}{|c|c|c|c|c|}
\hline Cor. $55^{\circ}\left(37-75^{\circ}\right)$ & Cor. $74^{\circ}\left(42-93^{\circ}\right)$ & $12-16$ weeks & Post-release & Cor. $80^{\circ}\left(69-89^{\circ}\right)$ \\
\hline \multirow[t]{5}{*}{ Sag. $-19^{\circ}\left(13-27^{\circ}\right)$} & Sag. $-41^{\circ}\left(-28-56^{\circ}\right)$ & & & Sag. $-40^{\circ}\left(-32--47^{\circ}\right)$ \\
\hline & & & & Axi. $29^{\circ}$ \\
\hline & & & Endpoint & Cor. $97^{\circ}\left(89-108^{\circ}\right)$ \\
\hline & & & $n=6$ & Sag. $-61^{\circ}\left(-33--82^{\circ}\right)$ \\
\hline & & & & Axi. $28^{\circ}\left(9-55^{\circ}\right)$ \\
\hline
\end{tabular}

Cor. $25^{\circ}\left(7^{\circ}\right) \quad$ Cor. $55^{\circ}\left(5^{\circ}\right)$

Sag. $-4^{\circ}\left(3^{\circ}\right) \quad$ Sag. $-26^{\circ}\left(10^{\circ}\right)$

Axi. $21^{\circ}\left(7^{\circ}\right)$

\begin{tabular}{|c|c|c|c|c|}
\hline Cor. $25^{\circ}\left(4^{\circ}\right)$ & Cor. $50^{\circ}\left(2^{\circ}\right)$ & \multirow[t]{4}{*}{16 weeks } & & \multirow[t]{2}{*}{ Cor. $55^{\circ}\left(5^{\circ}\right)$} \\
\hline Sag. $-5^{\circ}\left(13^{\circ}\right)$ & Sag. $-23^{\circ}\left(13^{\circ}\right)$ & & & \\
\hline Cor. $37^{\circ}$ & Cor. $51^{\circ}$ & & & \multirow[t]{2}{*}{ Cor. $34^{\circ}$} \\
\hline Sag. $-4^{\circ}$ & Sag. $-9^{\circ}$ & & & \\
\hline \multirow[t]{2}{*}{ Cor. $29^{\circ}\left(23-39^{\circ}\right)$} & Cor. $43^{\circ}\left(36-58^{\circ}\right)$ & 2 months & Post-release & Cor. $41^{\circ}\left(28-56^{\circ}\right)$ \\
\hline & & & $\begin{array}{l}\text { Endpoint } \\
(n=6)\end{array}$ & Cor. $43^{\circ}\left(30-58^{\circ}\right)$ \\
\hline
\end{tabular}

Not described

Cor. $42^{\circ}\left(4^{\circ}\right)$

Sag. $-42^{\circ}\left(4^{\circ}\right)$

2 months

1 month

Cor. $35^{\circ}$

Axi. $22^{\circ}\left(16-25^{\circ}\right)$

$\begin{array}{ll}2 \text { months } & \text { Cor. } 26^{\circ} \\ (n=4) & \text { Sag. }-35^{\circ}\end{array}$




\section{Chapter 6}

Driscoll et al. ${ }^{22}$ performed epiphysiodesis of longitudinal growth plate by inserting custom anterolateral spine staples exclusive of the disc fixed by a single screw. A single epiphyseal device was inserted at levels T5-T8 in four 3-month old pigs. After a follow-up period of 12 weeks, the final deformity measured only a mean of $7^{\circ}$ in the coronal plane.

\section{TWO-STEP APPROACH}

\section{Creating an idiopathic-like scoliosis via a posterior spinal tether}

Smith and Dickson first described a posterior, sublaminar spinal tether to create a structural scoliosis in a rabbit model in $1987 .{ }^{36}$ However, rapid deformity progression was attributed to spinal cord damage resulting from an intended muscle release procedure with a soldering iron instead of growth modulation. Within the last decade, a posterior spinal tether has been used to create idiopathic-like scoliosis in different large animal species. The experimental technique has advanced considerably so that the resulting deformities are becoming more similar to an idiopathic-like scoliosis.

Braun et al. were the first to develop a consistent scoliotic deformity in a goat model using a posterior spinal tether. ${ }^{26}$ The operative procedure consisted of implanting a rigid posterior tethering fixed by sublaminar hooks (T5-L1), combined with concave rib tethering and convex rib resection procedures. The goats (1-2 months old) developed progressive, structural lordoscoliotic curves with a mean Cobb angle of $60^{\circ}$ in the coronal plane after 6-15 weeks. In the sagittal plane, the mean kyphotic Cobb angle was $11^{\circ}$ preoperatively and changed to a $1^{\circ}$ lordotic curve after follow-up. The curves were markedly more rigid, before and after removal of the posterior tether in comparison to the curves usually seen in AIS. Furthermore, the curve progression was to some extent unpredictable, with 6 out of 33 goats $(18 \%)$ failing to develop progressive curves. ${ }^{26}$ In order to address these limitations, the rigid tether and laminar hooks were replaced by a flexible, unilateral tether with sublaminar anchoring. ${ }^{28}$ Again, the posterior tether was accompanied by concave rib tethering and convex rib resection. Using the flexible tether, very large deformities were obtained with a mean Cobb angle of $74^{\circ}$ over an eight week tethering period. ${ }^{27}$ Moreover, a high progression of mean thoracic lordosis (from $11^{\circ}$ kyphosis pre- to $41^{\circ}$ lordosis postoperatively) was seen, and the average maximum axial rotation was 
$28^{\circ}$. The more severe deformities and the quick progression rate can largely be attributed to the postoperative coronal Cobb angle; with the rigid tether the deformity measured $42^{\circ}$ postoperatively, compared to $55^{\circ}$ with the flexible tether. The extremely large deformities in both planes were more than is typical for AIS. Furthermore, the curves were still quite rigid as was seen in the model using the rigid tether. The high curve rigidity was therefore attributed to the more pyramidal shape of the goat thorax compared to the more cubical shape of the human thorax.

After creation of the deformities, correction using different fusionless scoliosis correction devices was also performed in both the rigid and flexible tether models. ${ }^{24,25,27,37,38}$ Treatment consisted of the placement of either anterior shape memory alloy staples or a flexible anterior ligament tether with bone anchors. In the rigid tether deformity model, stapled goats corrected from $52^{\circ}$ to $45^{\circ}$ for a correction of $13 \%$. In the flexible tether model, stapled goats showed deformity progression: from $76^{\circ}$ post-treatment to $94^{\circ}$ at endpoint. Using an anterior loop ligament tether, deformity progressed mildly: from $62^{\circ}$ post-treatment to $70^{\circ}$ at endpoint.

In 2007, Zhang et al. ${ }^{32,33}$ created scoliotic deformities in immature goats (5-8 weeks old) by inserting a rigid, posterior tether with unilateral pedicle screws combined with convex rib resection. The tether was anchored at two adjacent levels for stable fixation (T6-7, L1-2). The deformity measured a mean of $29^{\circ}$ postoperatively, and progressed to $43^{\circ}$ after a follow-up period of up to ten weeks. ${ }^{32,33}$ Although CT analysis was performed, the authors only described the deformity in the coronal plane while no measure was given for the axial or sagittal plane deformity. In comparison to the model described by Braun et al. using a rigid tether, the main difference described by Zhang et al. is that pedicle screws were used instead of laminar hooks and the rib tether was omitted.

In 2009, Schwab et al. ${ }^{29}$ created scoliotic deformities in 11 week old Yorkshire pigs through unilateral posterior ligament tethering of the spine combined with ipsilateral ribcage tethering. The tether was anchored at two adjacent levels (T4-5, L2-3) via pedicle screws. After eleven weeks, the mean Cobb angle was $55^{\circ}$ and the mean lordosis was $24^{\circ}$ (compared to respectively $24^{\circ}$ and $3^{\circ}$ kyphosis preoperatively). The average maximum axial rotation was $20^{\circ} .{ }^{30}$

Odent et al. ${ }^{34}$ created a porcine thoracic scoliosis model by applying a custom offset implant fixed on two adjacent vertebral levels with unilateral pedicle screws 


\section{Chapter 6}

at T5-T6 and L1-L2. The implants were connected by a flexible stainless steel cable in six 1 month old Landrace pigs. As a pilot, different types of offset implants were tested using finite element analysis. The final offset implant design was chosen based on the highest lateral translation of the apex vertebra for identical loads placed on the tether. All tethered spines developed a significant progressive curve. The mean Cobb angle was approximately $42^{\circ}$ in the coronal plane, and a $42^{\circ}$ lordotic deformity was attained at 2 months postoperatively. The average maximum axial rotation was $22^{\circ}$. Growth of the L4 vertebrae was extrapolated to calculate the expected spine growth if no tether had been placed. The variation between the expected spinal growth and the measured spinal growth never exceeded $3 \%$, and therefore it was concluded that the tether did not affect spinal growth and true growth modulation had occurred. No direct postoperative deformity measures were given, which makes comparison to other models more difficult.

\section{Necessity for rib tether/resection}

Early experimental scoliosis animal models have stressed the role of the ribs and the costovertebral joints in the development of scoliotic deformities. Langenskiold and Michelsson were to the first to produce severe scoliotic deformities in a rabbit model using a unilateral rib resection technique ${ }^{39}$ Karaharju first described a porcine scoliosis model in 1967, and achieved progressive lordoscoliotic curves by using a similar technique. Unilateral rib resection of approximately eight centimeters on the dorsal side followed by suturing of the rib to the spinous process led to severe scoliotic deformations in most animals. In spines effected by costal resection only, the deformity progression did not continue regularly over time ${ }^{40}$ Sanders et al. used the technique described by Langenskiold and Michelsson to create an experimental scoliosis in goats and subsequently corrected the deformity using shape memory alloy rods in $1993 .{ }^{41}$ However, both large animals models were not clinically relevant models for a scoliotic spine due to extensive violation of both costovertebral and costotransverse joints, and likely disruption of the disc annulus due to removal of the rib head on the convex side. Furthermore, exposure of the posterior elements to allow tethering of the ribs to the spinous process likely violated the facet joints and lamina and may have promoted ectopic bone formation. 
Before their first successful experiments, Braun et al. first conducted a pilot study in eleven immature goats and found that a substantially progressive scoliotic deformity was not created by a spinal tether alone. ${ }^{26}$ Furthermore, two additional goats underwent convex rib resection (ribs 8-13) combined with concave rib tethering (ribs 8-13) resulting in no significant spinal deformity. Therefore, Braun et al. developed a model in which an asymmetric posterior spinal tether was combined with concave rib tethering and convex rib resection with minimal violation of the spinal and costal elements.

Schwab et al. ${ }^{29}$ also performed a pilot study and concluded that rib resection was not necessary for the progression of the deformity. They noted that rib resection led to rapid healing and fusion of the convex ribs, which inhibited curve progression and added to the overall morbidity of the animal. Ultimately, Schwab et al. successfully opted for left rib tethering and left posterior tethering with pedicle screws.

Odent et al. ${ }^{34}$ acquired significant spinal deformities in immature pigs without rib resection or tethering. A custom offset implant was used to generate a longer moment arm to increase the effective moment working on each vertebra. Essentially, the rib tether creates an additional moment working on the spine in the coronal plane, while rib resection decreases spine stiffness on the contralateral side. Apparently, the increased moment arm in the coronal plane generated by the offset implant renders rib procedures unnecessary.

There are some obvious disadvantages regarding both rib tethering and rib resection procedures. The extent of the thoracoplasty is associated with an increase of the post-operative morbidity (up to $30 \%$ of all animals). ${ }^{33}$ Thoracic procedures make the animal model less suitable for pulmonary parameter analysis. ${ }^{34}$ Rib tethering provokes a periosteal reaction with bone formation around the tether, making rib tether release unconceivable so that complete reversibility of the index procedure is not possible. In the future, thoracic scarring with extensive paraspinal fibrosis may also limit the ability to test new methods of correction.

\section{Deformity persistence after posterior spinal tether removal}

An important criterion for a representative idiopathic-like scoliosis model is that the created scoliotic deformity is progressive or at least persistent; it should not 


\section{Chapter 6}

autocorrect after reversal of the procedure. The animal model should be in accordance with the 'vicious cycle' theory as proposed by Stokes et al. ${ }^{2}$; lateral spinal curvature produces asymmetrical loading of the immature spine which in turn causes asymmetrical growth and hence progressive wedge deformity. However, the threshold values for the vicious cycle theory have not been determined and therefore the time point at which the tether is released has been somewhat arbitrary.

Braun et al. have tested fusionless spinal implants following experimental scoliosis creation using both a flexible and a rigid tether and included a tether release group to serve as a control. No consistent, clearly defined endpoint for the tethering period was defined in the studies performed by Braun et al. In the rigid tether model, a deformity was created in a time period ranging between 6-15 weeks. The mean coronal Cobb angle was $67^{\circ}, 61^{\circ}$ immediately post release, and $60^{\circ}$ after 7-12 additional weeks. In a separate study ${ }^{23}, 15$ goats were operated on using the same procedure. The tether was released in all animals after 12 weeks, and animals were followed for an additional 4 weeks. The authors attempted to retrospectively predict which curves were progressive based on the contribution of vertebral wedging to the overall curve. A significant difference was seen in percentage vertebral wedging between the progressive deformity group and the non-progressive group at the time of tether release. Therefore the authors proposed a threshold of 55.3\% contribution of vertebral wedging to the total deformity as an independent predictor of curve progression. Using this threshold, it would have been possible to predict $85 \%$ of progressors and $88 \%$ of non-progressors. Until now, this has been the only study to retrospectively determine a threshold for deformity progression in an animal model. More severe scoliotic deformities were created by Braun et al. using a flexible tether, with a mean deformity of $79.5^{\circ}$ after 8 weeks. These deformities progressed to a mean angle of $97^{\circ}$ after an additional follow-up of 12-16 weeks following tether release. These more malignant curves clearly have surpassed the thresholds for a progressive deformity, but these acquired deformities are not representative of a typical idiopathic scoliotic deformity which would be eligible for fusionless scoliosis surgery.

In the porcine model described by Schwab et al., a final coronal Cobb angle of $50^{\circ}$ was used as a criterion for the tethering endpoint. Patel et al. ${ }^{31}$ studied the persistence of a created deformity after the release of the spinal tether in 7 animals. 
Five animals showed persistent deformities, while the curve showed autocorrection in two animals. In the autocorrective group, a larger postoperative Cobb angle was seen $\left(33^{\circ}\right.$ and $\left.40^{\circ}\right)$ compared to the persistent deformity group (mean of $24.8^{\circ} \pm$ $3.7^{\circ}$ ). Therefore, progression to $50^{\circ}$ took just a mean of 4.3 weeks for the two animals in the autocorrective group. Presumably, the threshold defined by Braun et al. ${ }^{23}$, a contribution of vertebral body wedging of $55 \%$ to the total deformity, was not met at the time of tether release in the autocorrective group in the study described by Patel et al.

Odent et al. also performed a tether release, albeit in only four animals. The mean coronal Cobb angle of the deformity was $49^{\circ}$ prerelease $(2$ months postoperatively), and autocorrected by approximately $30 \%$ after 1 month to a mean of $35^{\circ}$ and by approximately $50 \%$ to a mean of $26^{\circ}$ after 2 months. The authors stated that curve regression in the first month is likely due to disc viscoelastic behavior. The scoliotic deformities were created over a relatively short time period of two months, and no immediate post-operative deformity measures were available, making comparison to other models difficult. Therefore we suggest that radiographic analysis should be performed both pre- and post-operatively. Furthermore, a rib tether was not used to create the deformity in this study. The inability to perform rib tether release in other models likely helps in sustaining a higher deformity measure following spinal tether release.

\section{Rigid vs. flexible spinal tether}

Both rigid and flexible posterior tethers have been used to create scoliotic deformities in animal models. A rigid, stainless steel, posterior tether was used in the first series of studies described by Braun et al. ${ }^{26}$ and in the studies described by Zhang et al. ${ }^{32,33}$ A much higher spinal rigidity in the experimental goat model compared to a typical idiopathic scoliotic curve led to the use of a flexible tether instead of the rigid tether by Braun et al. ${ }^{28}$ Histologic analysis of the growth plate and the intervertebral disc to evaluate possible unintended fusion was not performed. Rationally, a flexible tether allows for more spinal motion with a more dynamic nature during normal locomotion as compared to a rigid tether. Therefore, the risk of unintended fusion is lowered. In a rat tail model, asymmetrical dynamic loading of an external fixator created significantly greater wedge deformities as compared to the statically loaded 


\section{Chapter 6}
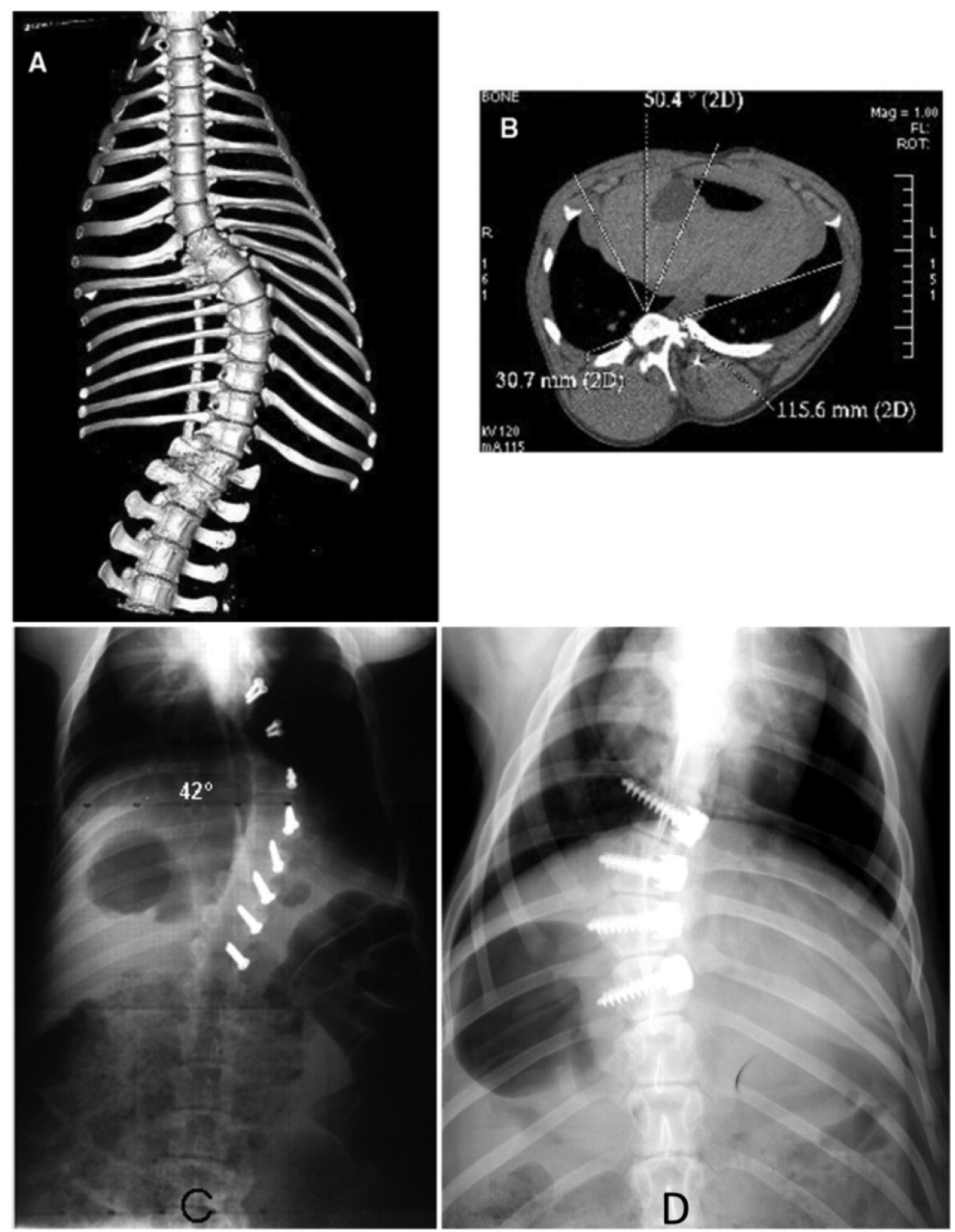

Figure 2. (A) Three dimensional reconstruction of computed tomography (CT) scan of a representative deformity created using a custom offset implant in a porcine model (anterior view). Reproduced with permission from Odent et al. ${ }^{34}$. (B) Axial slice illustrating rotational deformity in the axial plane at thoracic level. Reproduced with permission from Odent et al.34 (C) Anterioposterior radiograph showing results after 6 months of neurocentral cartilage targeted growth modulation using double pedicle screws at T7/T14 in a goat model. Reproduced with permission from Zhang and Sucato. ${ }^{12}$ (D) Anterioposterior radiograph demonstrating the deformity creation after anterior tethering of the porcine spine. Reproduced with permission from Newton et al. ${ }^{18}$ 
group ${ }^{42}$ Hence, a representative structural scoliotic deformity can possibly be created in a shorter time period with a flexible tether than would be possible with a rigid tether.

Flexible tethers consisting of different materials have been used. A flexible stainless steel tether was used by Odent et al. Polyester (Schwab et al.), polyethylene (Newton et al.) and polyester/polyethylene hybrid constructs (Braun et al.) have also been used as a flexible spinal tether. The advantage of using a flexible stainless steel tether is its radiopacity, enabling tracking of tether location and integrity. However, a steel cable causes a hard stop to motion, with abrupt load transfer possibly leading to instrumentation break-out. Braun et al., as well as Schwab et al. included a radiopaque titanium thread within the polyester tether. Using this method, radiopacity is maintained while a more elastic tether is used.

\section{DISCUSSION}

Two methodologically different approaches have been commonly used for the preclinical testing of fusionless scoliosis correction devices in large animals: the inverse approach and the two-step approach. The inverse approach may be suitable for testing fusionless scoliosis correction devices which rely on compression-based growth modulation, but not for the testing of distraction-based or growth-guiding fusionless scoliosis correction devices (growing rods, VEPTR or Shilla, Luque trolley techniques). Furthermore, the ability of the proposed device to modulate spinal growth may be used as an indication of its corrective potential, but only speculations regarding its corrective efficacy can be made using the inverse approach. Much larger compressive forces are needed to reverse the asymmetric load distribution present in a deformed spine and subsequently neutralize vertebral wedging through compression-based growth modulation as compared to creating load asymmetry through compression when inducing a scoliotic deformity. Considering the limitations involved with the inverse approach, utilizing a two-step approach with posterior spinal tethering as an index procedure appears to be the preferred approach towards establishing a universal model for the preclinical testing of fusionless scoliosis correction device. However, careful planning and consideration are required to attain an idiopathic-like scoliosis animal model fulfilling all set requirements using a posterior tether. Key aspects that 


\section{Chapter 6}

require consideration include tether anchoring technique, the potential need for additional rib procedures, tether material, and species selection (regarding timing of the procedures and overall comparative anatomy).

Stable tether fixation is commonly achieved by anchoring the tether at two adjacent levels which can be intentionally fused. Advances in the procedural technique have led to the omission of rib procedures; Schwab et al. have first shown that rib resection is not required and Odent et al. have later shown that the rib tether may also be omitted when sufficient tether offset from the spinal midline is maintained. A flexible tether is preferred over a rigid tether in order to only attain growth modulation in the desired planes (lordoscoliosis) while maintaining maximum spinal mobility. A persistent deformity can be attained in approximately 12 weeks when the deformity has approximately doubled in value as compared to the postoperative measure.

Regardless of which approach is used, the testing of fusionless scoliosis correction devices can be performed in whatever large animal species is deemed appropriate. However, the degree of success (measured by the final Cobb angle of the deformity) depends on a number of aspects; the timing of the first intervention in relation to age, the postoperative Cobb angle and the magnitude of the growth expected during the follow up period in the chosen species. Using the two-step approach, the timing of the interventions becomes very crucial and requires serious planning. The first intervention (posterior tether or fusionless spine implant placement) is ideally performed in young animals as soon as is deemed safe in order to exploit as much of the early growth phase as possible. Growth curves normalized by mature body weight for some specific breeds of pig, sheep, goat, and the minipig are shown in Figure 3 to illustrate the onset of the growth spurt. For the shown breeds of sheep, pigs and goats, the maximum growth velocity occurs at around 3 4 months of age and growth velocity declines afterwards. Generally, the animals in the reviewed articles were operated on at an age of around 1-2 months old, just before the onset of the early growth spurt, with no recurrent issues regarding instrumentation break-out. Using the two-step approach, the corrective intervention must take place with enough growth potential remaining. $80-90 \%$ of the expected growth (by weight) has already occurred in the goat, sheep and pig by the age of approximately 9 months necessitating early intervention and limiting the time available to create and subsequently correct a deformity in these animals. Mini-pigs 

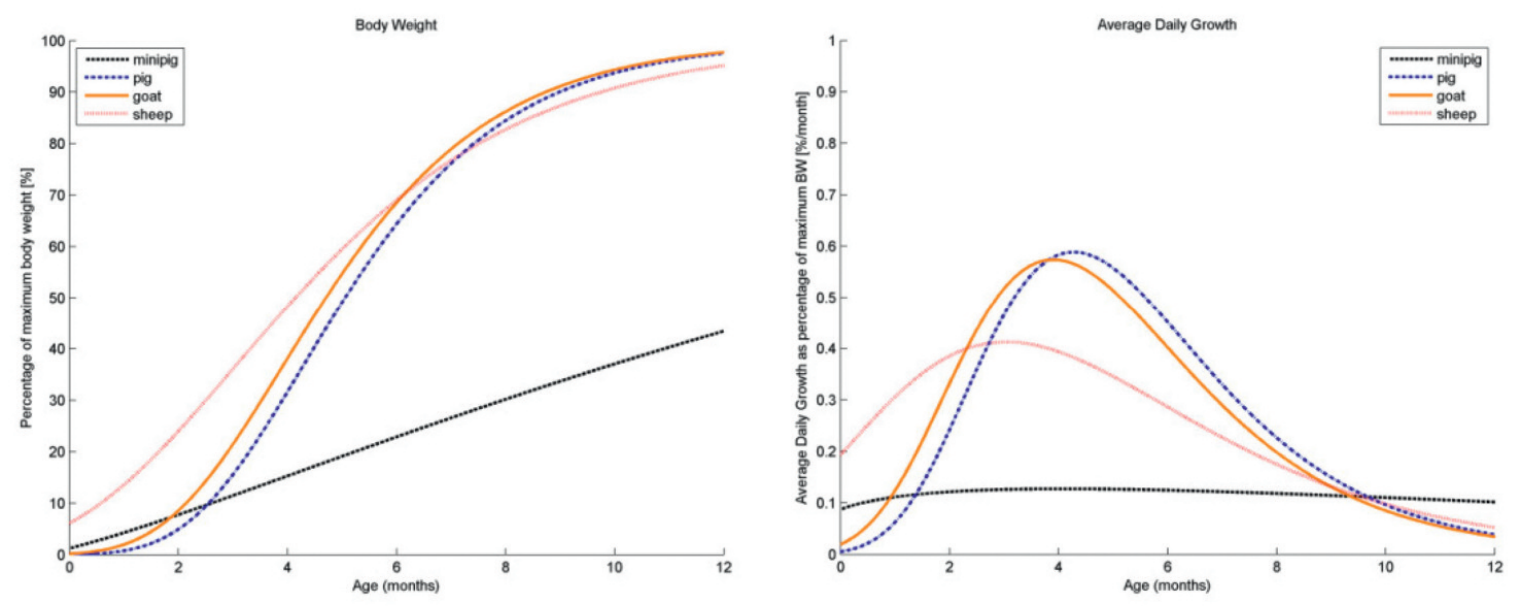

Figure 3. Body weight and average daily growth curves expressed as percentage of the maximum body weight for Gottingen mini-pig, Yorkshire pig, Young Hair goat, and Suffolk sheep. Growth curves acquired from Gompertz or Richards growth function as determined in literature (mini-pig ${ }^{45}$, Yorkshire pig ${ }^{46}$, Young Hair goat ${ }^{47}$, and Suffolk sheep\} ${ }^{48}$

show a much more constant growth velocity and continue to grow over a longer time period. The use of mini-pigs may provide a solution if this time window is not deemed long enough.

In terms of magnitude, pigs show the largest growth potential with spinal length increasing from approximately $25 \mathrm{~cm}$ in one month old animals to $75 \mathrm{~cm}$ in 6 month old animals. A calf spine is representative of the adult human spine at 6-8 weeks of age, but grows very quickly, reaching $270 \mathrm{~cm}$ at adulthood ${ }^{43}$ Therefore, the calf spine is not considered a relevant model for testing fusionless spine implants designed to treat adolescent idiopathic scoliosis. The large magnitude of growth seen in the pig is the reason why it is often used as test subject, but it also has its disadvantages. The tether fixation must be able to accommodate the large load changes encountered during the rapid growth phase. A solid tether anchor was attained by intended fusion of two levels in the studies by both Schwab et al and Odent et al. Furthermore, the rapid weight gain (60-70 $\mathrm{kg}$ at 6 months of age) seen in the domestic pig may pose handling problems. Braun et al. have shown that large deformities can be also be attained in animal species with lesser growth potential. However, large postoperative deformities were required to achieve a successful 


\section{Chapter 6}

model in the goat. The same is likely necessary in sheep. The spine length of a newborn sheep is approximately $25 \mathrm{~cm}$ and increases to $55 \mathrm{~cm}$ in an adult sheep (18 months). ${ }^{44}$

Some general differences between the human spine and spines of different animal species need to be kept in mind when spine instrumentation is tested in an animal model. Whereas the human spine consists of 12 thoracic vertebrae, the goat and calf spines consist of 13 thoracic vertebrae, the pig spine of 15 thoracic vertebrae and the sheep between 12 and 14 thoracic vertebrae ${ }^{49}$ Furthermore, the pig and calf spine consist of 6 lumbar vertebrae, while the goat and sheep spine consists of 6 or 7 vertebrae in comparison to the 5 lumbar vertebrae in the human spine. ${ }^{49-52}$ As in humans, the cervical spine consists of 7 vertebrae in all compared animal species. Compared to the human spine, the pig spine shows more cervical lordosis and less pronounced thoracic kyphosis and lumbar lordosis. ${ }^{50}$ The curvature in the lumbar spine of the sheep, calf and goat is slightly kyphotic rather than lordotic. ${ }^{44,49-52}$

Not all spine instrumentation developed for human use may suitable for use in an animal model due to anatomical dimension differences between an animal and the human spine. Both the anterioposterior vertebral depth and the vertebral body width are smaller than the respective human dimensions for the pig, goat, calf and sheep. Due to the smaller vertebral body size in animals, care must be taken when inserting pedicle screws as they may extend out of the vertebral body on the anterior or lateral side. Pedicle width and height are generally similar to the human adult pedicle width for the goat, calf and pig. However, the use of pedicle screws in very young animals requires extra caution. Care must also be taken when using instrumentation spanning the lamina (laminar hooks or wires) due to a smaller spinal canal width and depth in the pig, goat, calf and sheep spine compared to the human spine. As in the human spine, the spinal canal width increases from the cranial to caudal direction in these animals. However, spinal canal depth decreases in this direction in the pig and sheep spine. ${ }^{49-52}$ Vertebral body height is generally larger in quadrupeds than in humans and leads to no further concern.

In quadrupeds, spinous process length is substantially larger in the high thoracic region as compared to in the human spine. In the calf, pig and sheep spine, the spinous process in the cervical and thoracic regions can be two to three times longer than in the human spine. ${ }^{50,51}$ The large spinous process may hinder placement 
of sublaminar instrumentation and therefore require damage to the posterior elements, promoting unintended fusion in the upper thoracic spine. The transverse processes are generally less pronounced in the cervical and thoracic vertebrae for the calf, sheep and pig spine compared to the human spine. In the lumbar region, the transverse process tends to be more pronounced that in the human spine ${ }^{50,51}$, which may hinder the development of a rotational deformity in this region.

Ex vivo biomechanical testing of explanted scoliotic spines with and without instrumentation is being performed more often. The range of motion (ROM) of different animal spines in comparison to the human spine deserves consideration as well in that case. In all animal species and in humans, the range of motion in axial rotation is larger in the lumbar than in the cervical or thoracic regions. The most pronounced difference in segmental range of motion between the human and all animal species is seen in flexion/extension. In the human spine, flexion moments generally originate in the lumbar spine, with relatively large absolute values of ROM in flexion/extension in the lumbar region. In all animal species, the range of motion in flexion/extension is fairly constant over all levels and much smaller than in humans in absolute sense. ${ }^{53}$ This is largely due to the fact that in the human spine the facet joint surfaces at $\mathrm{L} 3$ are oriented at an angle of more than $60^{\circ}$ relative to the frontal plane, compared to an angle of less than $30^{\circ}$ in the quadruped spine. ${ }^{43}$ Figure 4 compares lumbar vertebral morphometry and spinal segmental range of motion in the spines of humans and different animal species.

Practical aspects also need to be considered when choosing an appropriate animal species. In comparison to the sheep and goat, there is no cyclical breeding in the pig and calf, which means the pig and calf are available all year-round. Early weaning is possible in the pig at around 3 weeks of age, while weaning in sheep is typically done around 8 weeks of age. Early intervention in the sheep and goat likely requires housing of the animal's mother as well, which would increase costs.

It is not to be forgotten that there are some fundamental differences between animal models and true adolescent idiopathic scoliosis. By definition, a scoliotic deformity created using a mechanical tether cannot be classified as being idiopathic, although it shares many characteristics of an idiopathic scoliotic curve. Quadrupedal locomotion in all animal species is responsible for different spinal loading patterns as compared to humans, and likely for the fact that idiopathic scoliosis is naturally 


\section{Chapter 6}

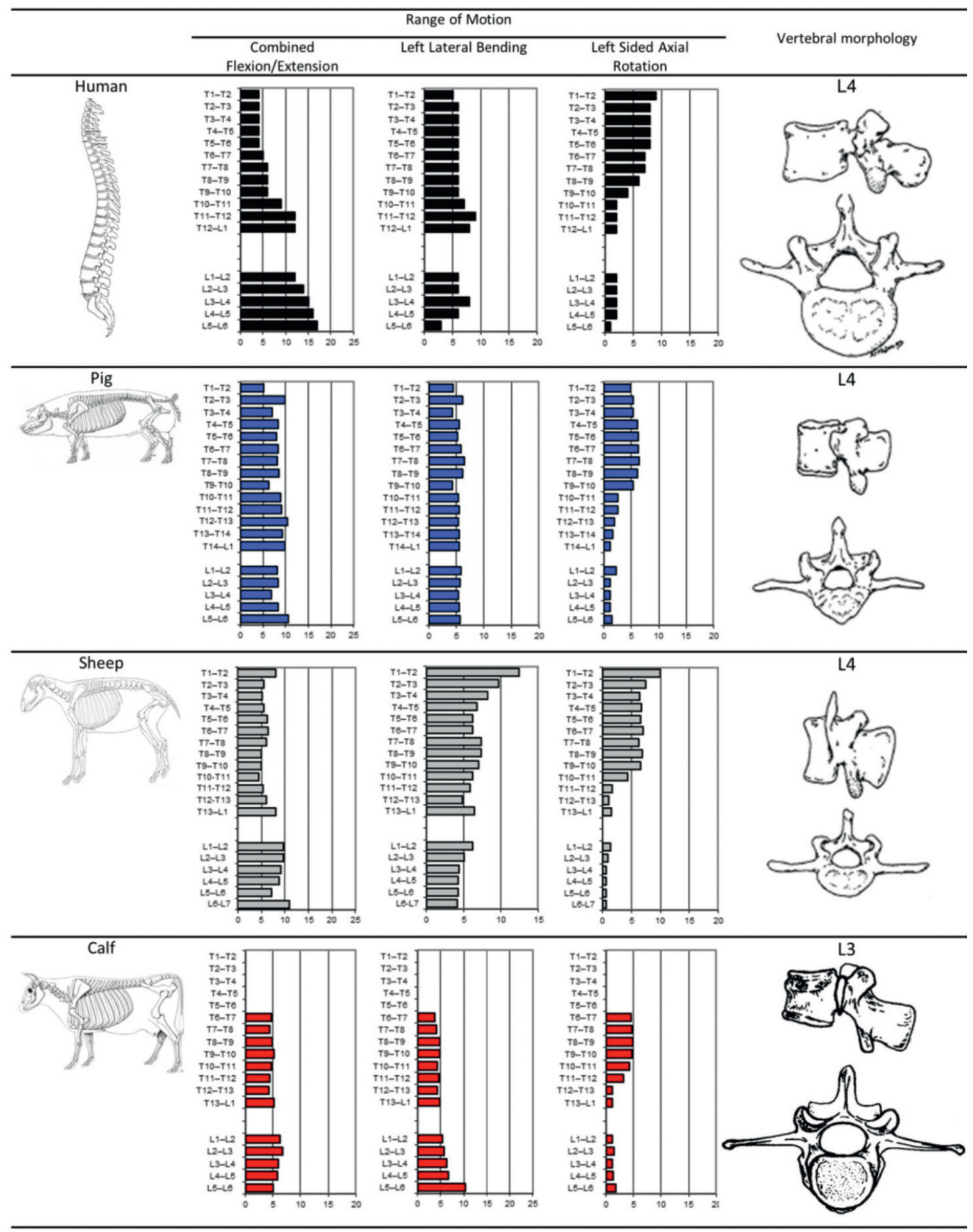


Figure 4. Segmental range of motion (ROM) and vertebral morphology for humans and for the pig, sheep and goat. Human ROM data from White and Panjabi ${ }^{55}$; animal ROM data from Wilke et al. ${ }^{51,56,57}$ Vertebral morphology illustrations reprinted with permission and adapted from McLain et al. ${ }^{58}$ and Cotteril et al. ${ }^{43}$ There are some differences between human and animal spines that may have consequences for the interpretation of experimental results, with the most important difference being the density of the trabecular bone. The architecture of bone and its mechanical function are closely related: bone adapts to its mechanical loads. Due to the fact that the human spine is mainly loaded by axial compression, the bone architecture is oriented from endplate to endplate. The quadruped spine is also mainly loaded by axial compression, due to the dynamic contraction and relaxation of the horizontally orientated musculature on opposing sides of the spinal midline. The axial compression in the quadrupeds may be even higher compared to the human because of a higher anisotropy of trabecular bone architecture and a higher overall bone density. ${ }^{54}$ Because of the higher bone mineral density, quadruped vertebrae are stronger than human vertebrae, and pedicle screws inserted in quadruped vertebrae have a higher fixation strength compared to screws inserted into human vertebrae. ${ }^{54}$

non-occurring in the animal world. Care should be taken in the interpretation of results found in an animal model and especially when transferring results from animal models to the human situation. For example, due to the higher bone mineral density, pedicle screws have better fixation in quadrupeds. On the other hand, due to increased spinal loading, the safety of spinal instrumentation with respect to strength may be underestimated. ${ }^{54}$

\section{CONCLUSION}

The inverse approach does not provide the necessary insight into the potential corrective efficacy of a novel fusionless scoliosis correction device and is only suitable for compression-based devices. Therefore, creating an idiopathic-like scoliosis using a posterior spinal tether and subsequent correction using the proposed fusionless scoliosis correction device in a two-step approach is the preferred method of testing for novel fusionless scoliosis correction devices. The pig 


\section{Chapter 6}

appears to be the most suitable test species due to its large growth potential and early availability due to the possibility of weaning at 3 weeks of age. The index procedure (tether placement) should be completely reversible and therefore no rib tether should ideally be used. However, due to limited test subjects, experimental results need to be reproduced in larger animal populations. 


\section{REFERENCES}

1. Boos NAM. Spinal Disorders: Fundamentals of Diagnosis and Treatment. Verlag Berlin Heidelberg New York: Springer; 2008.

2. Stokes IA, Burwell RG, Dangerfield PH. Biomechanical Spinal Growth Modulation and Progressive Adolescent Scoliosis—a Test of the 'Vicious Cycle' Pathogenetic Hypothesis: Summary of an Electronic Focus Group Debate of the Ibse. Scoliosis. 2006;1:16.

3. Dimeglio A, Canavese F. The Growing Spine: How Spinal Deformities Influence Normal Spine and Thoracic Cage Growth. European spine journal : official publication of the European Spine Society, the European Spinal Deformity Society, and the European Section of the Cervical Spine Research Society. 2012;21:64-70.

4. Campbell RM, Jr., Hell-Vocke AK. Growth of the Thoracic Spine in Congenital Scoliosis after Expansion Thoracoplasty. J Bone Joint Surg Am. 2003;85-A:409-20.

5. Hefti FL, McMaster MJ. The Effect of the Adolescent Growth Spurt on Early Posterior Spinal Fusion in Infantile and Juvenile Idiopathic Scoliosis. The Journal of bone and joint surgery British volume. 1983;65:247-54.

6. Dubousset J, Herring JA, Shufflebarger H. The Crankshaft Phenomenon. Journal of pediatric orthopedics. 1989;9:541-50.

7. Gomez JA, Lee JK, Kim PD, Roye DP, Vitale MG. "Growth Friendly" Spine Surgery: Management Options for the Young Child with Scoliosis. The Journal of the American Academy of Orthopaedic Surgeons. 2011;19:722-7.

8. Janssen MM, de Wilde RF, Kouwenhoven JW, Castelein RM. Experimental Animal Models in Scoliosis Research: A Review of the Literature. The spine journal : official journal of the North American Spine Society. 2011;11:347-58.

9. Schmid EC, Aubin CE, Moreau A, Sarwark J, Parent S. A Novel Fusionless Vertebral Physeal Device Inducing Spinal Growth Modulation for the Correction of Spinal Deformities. European spine journal : official publication of the European Spine Society, the European Spinal Deformity Society, and the European Section of the Cervical Spine Research Society. 2008;17:1329-35.

10. Braun JT, Akyuz E, Ogilvie JW. The Use of Animal Models in Fusionless Scoliosis Investigations. Spine (Phila Pa 1976). 2005;30:S35-45.

11. Beguiristain JL, De Salis J, Oriaifo A, Canadell J. Experimental Scoliosis by Epiphysiodesis in Pigs. International orthopaedics. 1980;3:317-21. 


\section{Chapter 6}

12. Zhang H, Sucato DJ. Unilateral Pedicle Screw Epiphysiodesis of the Neurocentral Synchondrosis. Production of Idiopathic-Like Scoliosis in an Immature Animal Model. The Journal of bone and joint surgery American volume. 2008;90:2460-9.

13. Zhang H, Sucato DJ. Neurocentral Synchondrosis Screws to Create and Correct Experimental Deformity: A Pilot Study. Clinical orthopaedics and related research. 2011;469:1383-90.

14. Caballero A, Barrios C, Burgos J, Hevia E, Correa C. Vertebral Growth Modulation by Hemicircumferential Electrocoagulation: An Experimental Study in Pigs. European spine journal : official publication of the European Spine Society, the European Spinal Deformity Society, and the European Section of the Cervical Spine Research Society. 2011;20 Suppl 3:367-75.

15. Newton PO, Farnsworth CL, Faro FD, Mahar AT, Odell TR, Mohamad F, et al. Spinal Growth Modulation with an Anterolateral Flexible Tether in an Immature Bovine Model: Disc Health and Motion Preservation. Spine (Phila Pa 1976). 2008;33:724-33.

16. Newton PO, Faro FD, Farnsworth CL, Shapiro GS, Mohamad F, Parent S, et al. Multilevel Spinal Growth Modulation with an Anterolateral Flexible Tether in an Immature Bovine Model. Spine (Phila Pa 1976). 2005;30:2608-13.

17. Newton PO, Fricka KB, Lee SS, Farnsworth CL, Cox TG, Mahar AT. Asymmetrical Flexible Tethering of Spine Growth in an Immature Bovine Model. Spine (Phila Pa 1976). 2002;27:689-93.

18. Newton PO, Upasani VV, Farnsworth CL, Oka R, Chambers RC, Dwek J, et al. Spinal Growth Modulation with Use of a Tether in an Immature Porcine Model. J Bone Joint Surg Am. 2008;90:2695-706.

19. Newton PO, Farnsworth CL, Upasani VV, Chambers RC, Varley E, Tsutsui S. Effects of Intraoperative Tensioning of an Anterolateral Spinal Tether on Spinal Growth Modulation in a Porcine Model. Spine (Phila Pa 1976).36:109-17.

20. Wall EJ, Bylski-Austrow DI, Kolata RJ, Crawford AH. Endoscopic Mechanical Spinal Hemiepiphysiodesis Modifies Spine Growth. Spine. 2005;30:1148-53.

21. Hunt KJ, Braun JT, Christensen BA. The Effect of Two Clinically Relevant Fusionless Scoliosis Implant Strategies on the Health of the Intervertebral Disc: Analysis in an Immature Goat Model. Spine. 2010;35:371-7. 
22. Driscoll M, Aubin CE, Moreau A, Wakula Y, Sarwark JF, Parent S. Spinal Growth Modulation Using a Novel Intravertebral Epiphyseal Device in an Immature Porcine Model. European spine journal : official publication of the European Spine Society, the European Spinal Deformity Society, and the European Section of the Cervical Spine Research Society. 2012;21:138-44.

23. Braun JT, Akyuz E. Prediction of Curve Progression in a Goat Scoliosis Model. J Spinal Disord Tech. 2005;18:272-6.

24. Braun JT, Hines JL, Akyuz E, Vallera C, Ogilvie JW. Relative Versus Absolute Modulation of Growth in the Fusionless Treatment of Experimental Scoliosis. Spine (Phila Pa 1976). 2006;31:1776-82.

25. Braun JT, Ogilvie JW, Akyuz E, Brodke DS, Bachus KN. Fusionless Scoliosis Correction Using a Shape Memory Alloy Staple in the Anterior Thoracic Spine of the Immature Goat. Spine (Phila Pa 1976). 2004;29:1980-9.

26. Braun JT, Ogilvie JW, Akyuz E, Brodke DS, Bachus KN, Stefko RM. Experimental Scoliosis in an Immature Goat Model: A Method That Creates Idiopathic-Type Deformity with Minimal Violation of the Spinal Elements Along the Curve. Spine (Phila Pa 1976). 2003;28:2198-203.

27. Braun JT, Akyuz E, Udall H, Ogilvie JW, Brodke DS, Bachus KN. Three-Dimensional Analysis of 2 Fusionless Scoliosis Treatments: A Flexible Ligament Tether Versus a RigidShape Memory Alloy Staple. Spine (Phila Pa 1976). 2006;31:262-8.

28. Braun JT, Ogilvie JW, Akyuz E, Brodke DS, Bachus KN. Creation of an Experimental Idiopathic-Type Scoliosis in an Immature Goat Model Using a Flexible Posterior Asymmetric Tether. Spine (Phila Pa 1976). 2006;31:1410-4.

29. Schwab F, Patel A, Lafage V, Farcy JP. A Porcine Model for Progressive Thoracic Scoliosis. Spine (Phila Pa 1976). 2009;34:E397-404.

30. Patel A, Schwab F, Lafage V, Obeidat MM, Farcy JP. Computed Tomographic Validation of the Porcine Model for Thoracic Scoliosis. Spine (Phila Pa 1976).35:18-25.

31. Patel A, Schwab F, Lafage R, Lafage V, Farcy JP. Does Removing the Spinal Tether in a Porcine Scoliosis Model Result in Persistent Deformity? A Pilot Study. Clin Orthop Relat Res.469:1368-74.

32. Zhang Y, Wang Y, Zheng G, Zhang X, Zhang R, Zhang W. Unilateral Pedicle Screws Asymmetric Tethering: An Innovative Method to Create Idiopathic Deformity. J Orthop Surg Res. 2007;2:18. 


\section{Chapter 6}

33. Zhang YG, Zheng GQ, Zhang XS, Wang Y. Scoliosis Model Created by Pedicle Screw Tethering in Immature Goats: The Feasibility, Reliability, and Complications. Spine (Phila Pa 1976). 2009;34:2305-10.

34. Odent T, Cachon T, Peultier B, Gournay J, Jolivet E, Elie C, et al. Porcine Model of Early Onset Scoliosis Based on Animal Growth Created with Posterior Mini-Invasive Spinal Offset Tethering: A Preliminary Report. Eur Spine J.20:1869-76.

35. Nachlas IW, Borden JN. Experimental Scoliosis; the Role of the Epiphysis. Surgery, gynecology \& obstetrics. 1950;90:672-80.

36. Smith RM, Dickson RA. Experimental Structural Scoliosis. The Journal of bone and joint surgery British volume. 1987;69:576-81.

37. Braun JT, Akyuz E, Ogilvie JW, Bachus KN. The Efficacy and Integrity of Shape Memory Alloy Staples and Bone Anchors with Ligament Tethers in the Fusionless Treatment of Experimental Scoliosis. J Bone Joint Surg Am. 2005;87:2038-51.

38. Braun JT, Hoffman M, Akyuz E, Ogilvie JW, Brodke DS, Bachus KN. Mechanical Modulation of Vertebral Growth in the Fusionless Treatment of Progressive Scoliosis in an Experimental Model. Spine (Phila Pa 1976). 2006;31:1314-20.

39. Langenskiold, Michelsson JE. Experimental Progressive Scoliosis in the Rabbit. J Bone Joint Surg Br. 1961;43-B:116-20.

40. EO. K. Deformation of Vertebrae in Experimental Scoliosis. Acta Orthop Scand. 1967;105:7-79.

41. Sanders JO, Sanders AE, More R, Ashman RB. A Preliminary Investigation of Shape Memory Alloys in the Surgical Correction of Scoliosis. Spine (Phila Pa 1976). 1993;18:1640-6.

42. Akyuz E, Braun JT, Brown NA, Bachus KN. Static Versus Dynamic Loading in the Mechanical Modulation of Vertebral Growth. Spine. 2006;31:E952-8.

43. Cotterill PC, Kostuik JP, D'Angelo G, Fernie GR, Maki BE. An Anatomical Comparison of the Human and Bovine Thoracolumbar Spine. J Orthop Res. 1986;4:298-303.

44. Hasler C, Sprecher CM, Milz S. Comparison of the Immature Sheep Spine and the Growing Human Spine: A Spondylometric Database for Growth Modulating Research. Spine (Phila Pa 1976).35:E1262-72.

45. Kohn F, Sharifi AR, Simianer H. Modeling the Growth of the Goettingen Minipig. Journal of Animal Science. 2007;85:84-92. 
46. Koivula M, Sevon-Aimonen ML, Stranden I, Matilainen K, Serenius T, Stalder KJ, et al. Genetic (Co)Variances and Breeding Value Estimation of Gompertz Growth Curve Parameters in Finnish Yorkshire Boars, Gilts and Barrows. Journal of Animal Breeding and Genetics. 2008;125:168-75.

47. Tatar AM, Tekel N, Ozkan M, Baritci I, Dellal G. The Determination of Growth Function in Young Hair Goat. Journal of Animal and Veterinary Advances. 2009;8:213-6.

48. Lewis RM, Emmans GC, Dingwall WS, Simm G. A Description of the Growth of Sheep and Its Genetic Analysis. Animal Science. 2002;74:51-62.

49. Sheng SR, Wang XY, Xu HZ, Zhu GQ, Zhou YF. Anatomy of Large Animal Spines and Its Comparison to the Human Spine: A Systematic Review. Eur Spine J. 2010;19:46-56.

50. Busscher I, van der Veen AJ, van Dieen JH, Kingma I, Verkerke GJ, Veldhuizen AG. In Vitro Biomechanical Characteristics of the Spine: A Comparison between Human and Porcine Spinal Segments. Spine (Phila Pa 1976). 2010;35:E35-42.

51. Wilke HJ, Kettler A, Claes LE. Are Sheep Spines a Valid Biomechanical Model for Human Spines? Spine (Phila Pa 1976). 1997;22:2365-74.

52. Dyce KM, Sack WO, Wensing CJG. Textbook of Veterinary Anatomy. 4th ed. St. Louis, Mo.: Saunders/Elsevier; 2010.

53. Alini M, Eisenstein SM, Ito K, Little C, Kettler AA, Masuda K, et al. Are Animal Models Useful for Studying Human Disc Disorders/Degeneration? Eur Spine J. 2008;17:2-19.

54. Smit TH. The Use of a Quadruped as an in Vivo Model for the Study of the Spine Biomechanical Considerations. Eur Spine J. 2002;11:137-44.

55. White lii AA, Panjabi MM. Clinical Biomechanics of the Spine. Philadelphia etc..: Lippincott; 1978.

56. Wilke HJ, Geppert J, Kienle A. Biomechanical in Vitro Evaluation of the Complete Porcine Spine in Comparison with Data of the Human Spine. Eur Spine J.20:1859-68.

57. Wilke HJ, Krischak ST, Wenger KH, Claes LE. Load-Displacement Properties of the Thoracolumbar Calf Spine: Experimental Results and Comparison to Known Human Data. Eur Spine J. 1997;6:129-37.

58. McLain RF, Yerby SA, Moseley TA. Comparative Morphometry of L4 Vertebrae: Comparison of Large Animal Models for the Human Lumbar Spine. Spine (Phila Pa 1976). 2002;27:E200-6. 


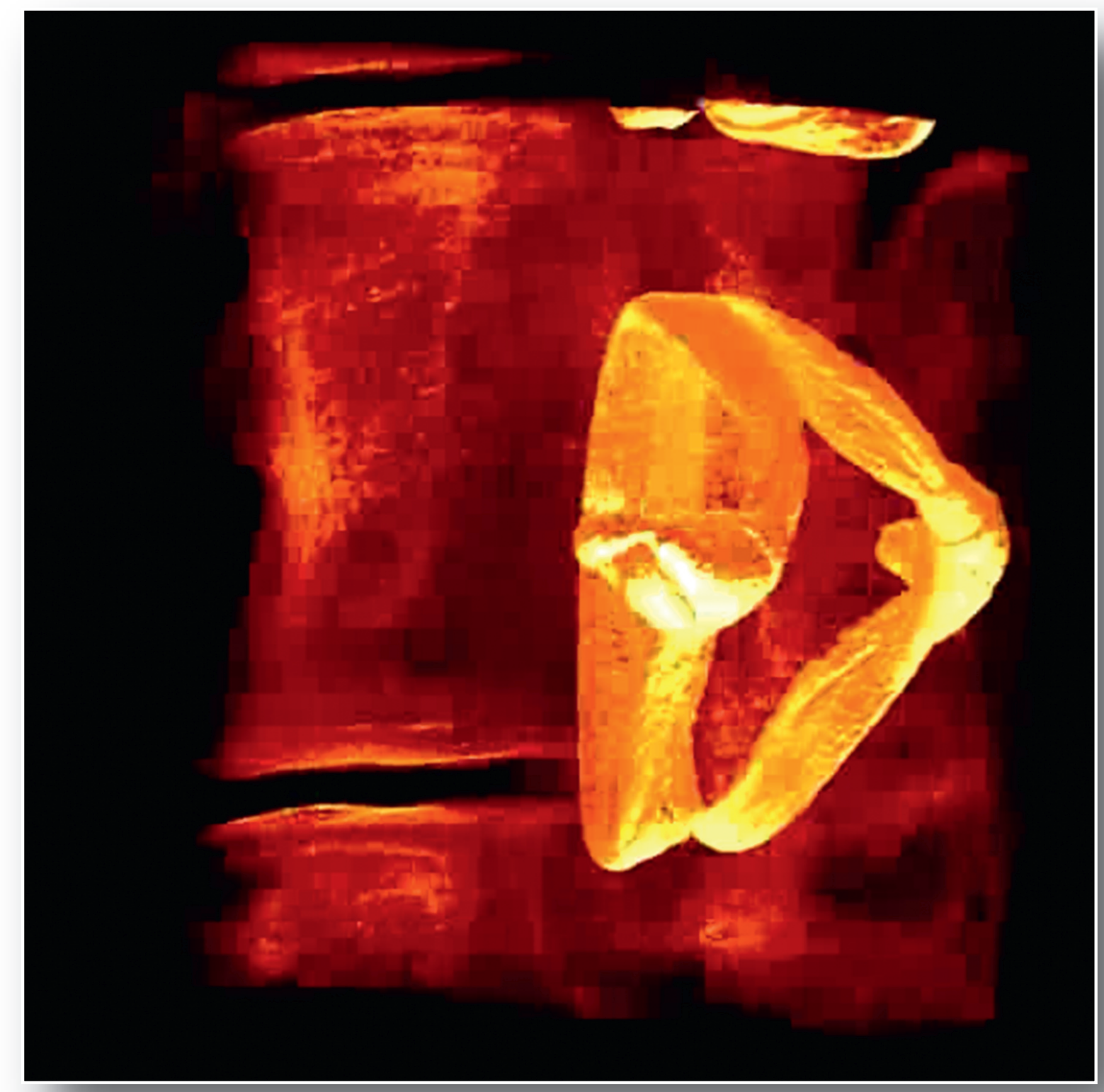




\section{CHAPTER 7}

\section{The development of a representative porcine early onset scoliosis model with a standalone posterior spinal tether}

Spine Deformity 2017: 2017 Jan;5(1):2-10

Rob Bogie, Alex K. Roth, Paul Willems, Walter van der Weegen, Jacobus J. Arts, Lodewijk W. van Rhijn 


\section{Chapter 7}

\section{ABSTRACT}

Study Design. In vivo analysis in a porcine model.

Objectives. To develop a porcine experimental scoliosis model representative of early onset scoliosis (EOS) with the use of a radiopaque UHMWPE posterior spinal tether.

Summary of Background Data. Large animal experimental scoliosis models with substantial growth potential are required to test new fusionless scoliosis correction techniques. Previously described scoliosis models involve rib procedures, which violate the thoracic cage and affect subsequent corrective procedures. Models omitting these rib procedures have experienced difficulties in producing persistent three-dimensional structural deformities representative of EOS.

Methods. Scoliosis was induced in 14 immature pigs using an asymmetric posterior radiopaque UHMWPE spinal tether fixated to an offset device at lumbar and thoracic levels. Radiographs were taken at two-week intervals, and frontal and sagittal Cobb angles were measured. A tether release was performed at 10 week follow-up, and the animals were followed for another 10 weeks.

Results. Four animals suffered complications (infections and/or screw breakout) and were excluded from the study. Eight animals developed progressive curves with mean frontal Cobb angle of $62^{\circ}$. A thoracic lordosis $\left(34^{\circ}\right)$ and a thoracolumbar kyphosis $\left(22^{\circ}\right)$ formed. CT analysis, acquired prior to tether release, showed a mean vertebral rotation of $37^{\circ}$ at the apex with a mean vertebral wedge angle of $10^{\circ}$. After tether release, the frontal Cobb angles decreased to $46^{\circ}$ at 20 weeks follow-up. Sagittal curvature was not substantially affected after tether release.

Conclusions. We describe a large animal scoliosis model, which exhibits a substantial deformity in three planes without the use of rib procedures additional to a posterior spinal tether. The created deformities showed sufficient persistence after tether release. With the management of infection and enhancement of instrumentation stability, the creation of a valid model for testing new devices in fusionless scoliosis surgery seems feasible.

Level of Evidence. Level V. 


\section{INTRODUCTION}

Within the last decades, it has become clear that fusionless surgical scoliosis correction techniques are essential for the treatment of early onset scoliosis (EOS), but their merits and potential are also increasingly explored for the treatment of adolescent idiopathic scoliosis (AIS). For EOS patients, it is imperative to retain longitudinal spine growth, thereby maintaining volumetric thoracic cage growth and lung development. ${ }^{1}$ Fusionless scoliosis correction devices for EOS patients may be classified into growthguidance (Shilla and Luque trolley) or distraction based techniques (growing rods, vertical expandable prosthetic titanium rib). ${ }^{2}$ For AIS patients, compression based anterior devices are used to modulate vertebral growth by utilizing the HueterVolkmann principle 3 to slow or halt growth on the convex side of the deformity, thereby attaining gradual curve correction. Examples of such compression-based modulation are the use of vertebral body staples and an anterior spinal tether. ${ }^{2}$

The most generic method for the preclinical evaluation of fusionless scoliosis correction devices is utilizing a two-step approach: A structural, idiopathic-like scoliosis is created in a first procedure and later corrected using the proposed scoliosis correction device in a second procedure. Posterior spinal tethering is the preferred index procedure ${ }^{4}$, as it produces significant, progressing deformities that most closely approximate the three-dimensional nature of the deformity as seen in idiopathic scoliosis (progressive coronal curvature, loss of thoracic kyphosis and axial vertebral rotation). ${ }^{5-7}$

We have previously reviewed large animal models in fusionless scoliosis correction research. ${ }^{8}$ The similarity between human and porcine spinal anatomy in addition to the fast, large growth rate makes pigs commonly used animals for experimental scoliosis models. The main differences between models described by different authors are age at index procedure, length of follow-up period, pretensioning of the tether, and whether or not rib procedures (rib tethering with or without rib resection) additional to the spinal tether were performed. Rib procedures may lead to high postoperative morbidity and may cause spontaneous rib fusion with a very stiff curve as a result. ${ }^{9}$ These irreversible thoracic changes will affect subsequent testing procedures. Odent et al. ${ }^{10,11}$ have demonstrated that rib tethering may be omitted when sufficient spinal tether offset is used. However, their described 


\section{Chapter 7}

model exhibited substantial loss of deformity, loss of approximately $45 \%$ of the curve magnitude in the frontal plane, after tether release.

The purpose of this study was to create an early onset scoliosis model, without additional rib procedures, in which all three-dimensional scoliosis-like structural changes occur and persist after tether release. A posterior technique with a radiopaque flexible Ultra-High Molecular Weight Polyethylene (UHMWPE) spinal tether with an offset device was used to create a progressive lordo-scoliotic curve. This model should ultimately allow for preclinical testing of fusionless scoliosis correction techniques in a growing animal.

\section{MATERIAL AND METHODS}

\section{Surgical procedure}

All animal procedures were approved by the Animal Ethical Committee of the Maastricht University Medical Center (approval no.: DEC 2011-005). A total of 16 immature landrace pigs (female, 8 weeks old, weight range 10-13 kg) were included in this study. Each operation was performed under strict sterile conditions. Antibiotics (amoxicillin/clavulan acid $1.2 \mathrm{~g}$ ) were administered intravenously one hour prior to incision and 6 hours postoperatively. After 7 days of acclimatization at the institutional animal facility, the animals were sedated by intravenous administration of thiopental (10-15 mg/kg), followed by endotracheal intubation and general anesthesia using $1 \%$ to $2 \%$ isoflurane. Pain medication was administered and adjusted if needed during surgery (sufentanyl 10-30 $\mu \mathrm{g} / \mathrm{kg}$ per hour intravenously). Electrocardiogram registration, ventilation curves, temperature, oxygen saturation level and heart rate were continuously monitored. With the animal in prone position, two small midline incisions were made at thoracic and lumbar levels under fluoroscopic control. The transverse processes and the facet joints were minimally exposed unilaterally on the left side by partially detaching the erector spinae using electrocautery.

\section{Instrumentation technique and material specification}

In a pilot study involving two animals, poly-axial pedicle screws $(4.5 \mathrm{~mm}$ diameter, 22-26 mm length, Vertex ${ }^{\circledR}$, Medtronic) were placed unilaterally at T6-T7 and L1-2 under fluoroscopic guidance. Two custom made offset devices $(28 \mathrm{~mm}$ offset from 
pedicle screws) were fixed using a $3.2 \mathrm{~mm}$ titanium rod in between each set of adjacent pedicle screws (Figure 1). A $4 \mathrm{~mm}$-wide flat wire woven from ultra-high molecular weight polyethylene (UHMWPE) Dyneema Purity® Radiopaque fibers (DSM Biomedical B.V., Geleen, the Netherlands) was used as a posterior tether. Bismuth oxide $\left(\mathrm{Bi}_{2} \mathrm{O}_{3}\right)$ particles are blended into each individual fiber for radiopacity ${ }^{12}$ The wire was folded in half and the two ends were passed through the cranial offset device and through the loop created in the wire, thereby securing the cranial end of the tether. The caudal end was secured using multiple square knots. In these initial two animals, the UHMWPE tether was placed under tension before fixation. This created a Cobb angle of approximately $20^{\circ}$. After 4 weeks, screw breakout was observed at both caudal and cranial levels with loss of deformity. The large offset in combination with pre-tensioning of the tether was assumed to be the reason for this early failure. For this reason, in the definitive series of animals $(n=14)$
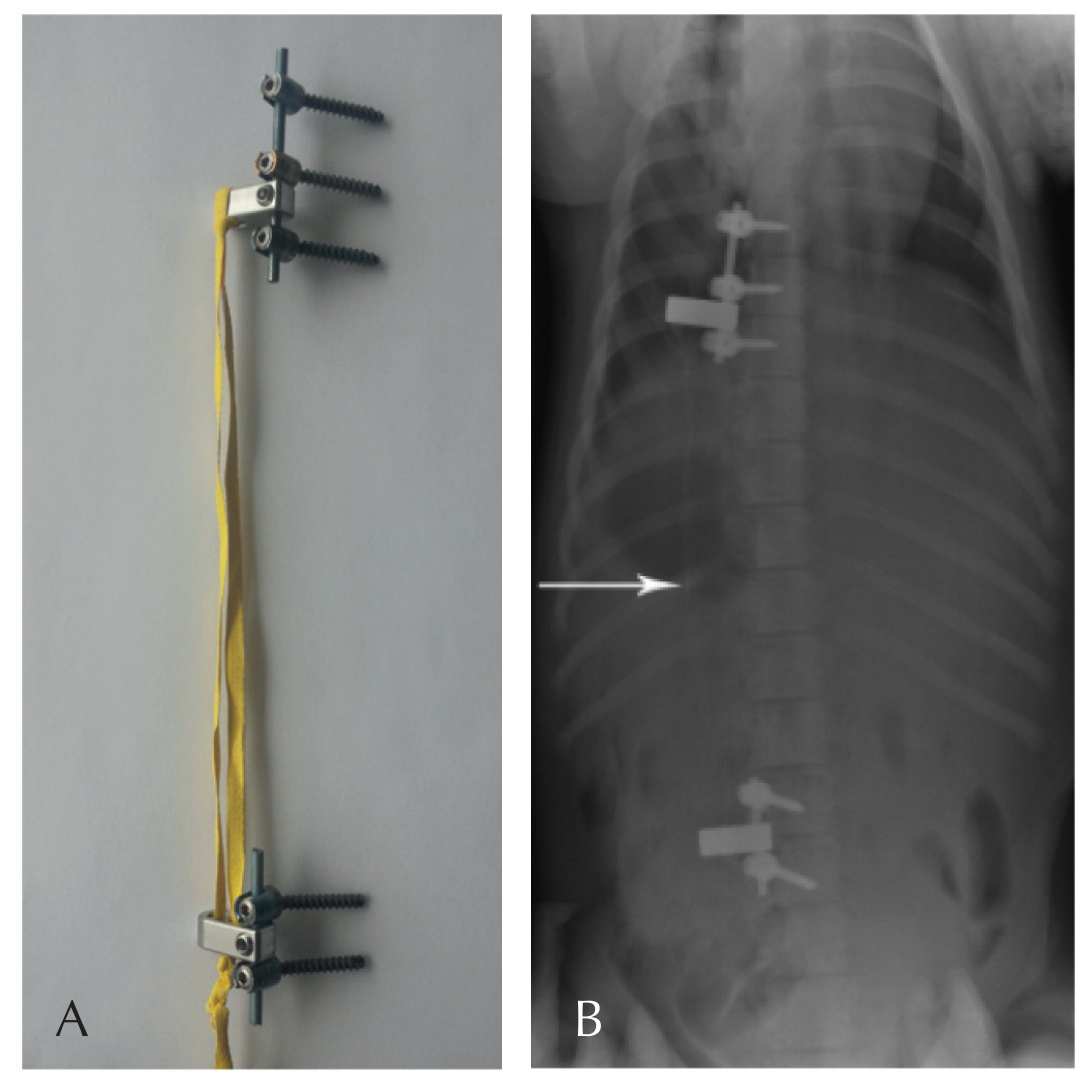

Figure 1. (A) Offset devices with rods, pedicle screws and the radiopaque UHMWPE double loop tether. (B) Offset device implanted in the porcine spine. The radiopaque tether (arrow) is attached to the offset devices without any tension. 


\section{Chapter 7}

the construct was altered slightly. First the thoracic offset device was secured using three instead of two thoracic pedicle screws (T5-T7), and the lumbar instrumentation was reinforced with a UHMWPE sublaminar wire. ${ }^{13}$ Furthermore, no pretension was applied to the tether and the offset was reduced to $20 \mathrm{~mm}$. In the first four animals, proximal fixation was located at levels T5-T7 with caudal fixation on L1-L2. After experiencing problems reaching the deep cranial thoracic vertebra because of thick musculature in these first four procedures, the proximal fixation site was moved to levels T7-T9 and distal fixation site to L2-L3.

\section{Observation, radiology and tether release}

The wound was ultimately closed in layers. Post-operative pain management (buprenorphine $0,05 \mathrm{mg} / \mathrm{kg}$, carprofen $2-4 \mathrm{mg} / \mathrm{kg}$ intramuscularly) was provided until the animals had returned to activities ad libitum. Antibiotic treatment was administered intramuscularly 6 hours after surgery. Initially, no post-operative wound dressing was applied. However, as 3 out of the first 4 animals developed postoperative wound infections, the wound was dressed using an iodide film, which was kept in place for three days post-operatively. No more wound infections occurred in the subsequent animals.

One animal with a profound infection was euthanized because of instrumentation failure and observed animal discomfort. In the other animals with wound infections, the infection was controlled with the administration of antibiotics (amoxicillin/clavulan acid $1.2 \mathrm{~g}$ ) for several days and wound lavage without loss of the curvature.

Plain full spine radiographs were taken directly postoperatively and subsequently at two-week intervals under light tiletamine-zolazepam $(8 \mathrm{mg} / \mathrm{kg})$ sedation. Routine supine dorsoventral and lateral radiographs were acquired to assess curve progression. Frontal and sagittal Cobb angles were measured at each radiological assessment. Radiographs were also analyzed for positioning and possible pullout or breakage of the instrumentation.

\section{Tether release and CT Analysis}

At 10 week follow-up and upon reaching a frontal Cobb angle of minimally $40^{\circ}$, a tether release was performed in eight animals. The radiopaque tether was localized under fluoroscopy and cut through a minimal stab incision at the caudal end. 
Animals were followed for another 10 weeks with radiographs every 2 weeks and euthanization was performed using pentobarbital overdose $(200 \mathrm{mg} / \mathrm{kg})$. After sacrifice, the spines were harvested.

Computed tomography (CT) scans were acquired prior to tether release at 10 weeks follow-up under general anesthesia (Siemens SOMATOM Definition Flash, Erlangen, Germany). 3D reconstructions of each spine were obtained to assess vertebral rotation, rib hump and apical vertebra wedging. Rib hump elevation located at the convex side was considered a positive result for the model. Vertebral rotation was measured relative to the anterior mid-line of the body. ${ }^{14,15}$ Rotation and rib hump were assessed by analyzing a transversal CT-slice at the level of the apex vertebra using the Synedra View program (Synedra, Innsbruck). The position of the apical vertebra was determined in three planes. Apical vertebral wedging was measured from the reconstructed coronal CT images. Convex and concave heights for each apical vertebra were also determined.

\section{RESULTS}

Of the 14 animals included within the definitive surgical protocol, one animal died as a result of respiratory distress after extubation. Autopsy did not reveal any other cause of death. No neurological complications occurred during all surgeries. Mean weight gain was approximately $5 \mathrm{~kg} /$ week. Eight animals developed a structural complex 3D scoliotic curvature with a chest wall deformity and a positive rib hump elevation. In this group, the mean Cobb angle at 10 week follow-up was $62^{\circ}$ (range $43-72^{\circ}$ ) in the frontal plane (Figure 2). In the sagittal plane, a thoracolumbar kyphosis developed between the anchor sites $\left(22^{\circ}\right.$ range $\left.7-44^{\circ}\right)$, and a thoracic lordosis formed at the anchor levels $\left(35^{\circ}\right.$ range $\left.21-53^{\circ}\right)$, presumably as a result of continued anterior growth (crankshafting) (Figure 3). In five animals, a long-segment curvature (11-12 vertebrae in the curvature) with large Cobb angles (mean 68.3 ${ }^{\circ}$ ) developed. In three animals, a shorter (5-6 vertebrae in the curvature) thoracic curve (mean $51.9^{\circ}$ ) developed probably due to an epiphysiolysis or fracture of one vertebra, which was observed in both anchor location groups (T5-4-3/L1-2 and T7-6-5/L2-3). In three animals, screw breakout or slippage of the knot securing the tether was observed, resulting in loss of the curvature and therefore these animals were 


\section{Chapter 7}

sacrificed. In two animals, the cause of this failure was not determined. The other case had developed a postoperative infection with the observation of radiolucency around the screws. Loosening of the screws eventually resulted in failure of instrumentation. The final two animals developed curves with Cobb angles of $31^{\circ}$ and $34^{\circ}$, which did not progress any further due to unknown reasons. These animals were also subsequently sacrificed. CT scanning and subsequent tether release was performed in the eight animals that developed progressive structural scoliosis. These animals were followed for an additional 10 week time period after tether release (Figure 4). CT imaging revealed structural characteristics of the deformity, with most wedging and axial rotation occurring at the apex of the curvature (Figure 5). The mean apical vertebral rotation was $37.3^{\circ}$ (range $25-54^{\circ}$ ), while substantial apical wedging also occurred: convex height minus concave height measured a mean of $4.2 \mathrm{~mm}$, which resulted in a mean vertebral wedge angle of $10.4^{\circ}\left(\right.$ range $\left.5.7-17.2^{\circ}\right)$ (Figure 6).

After tether release, the frontal Cobb angles immediately decreased from $62^{\circ}$ to $56^{\circ}$ and showed a further decrease at 10 weeks additional follow-up to $46.7^{\circ}$ (Figure 7, Table 1). In two animals, there was loss of curvature within the mid segments at 20 weeks follow-up. Lateral tilting of the cranial and caudal segments, however, still resulted in a curvature with persistent thoracic asymmetry. Sagittal profiles did not show substantial changes after tether release (Table 2). 

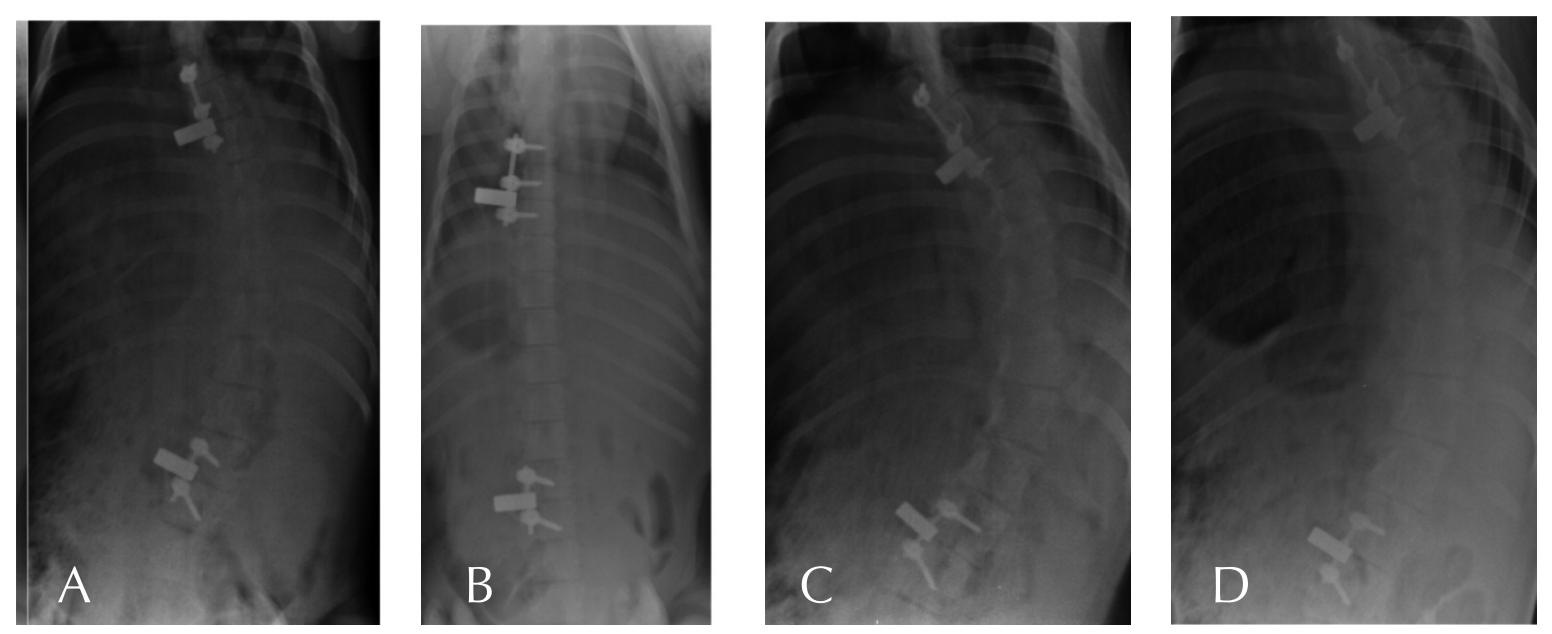

Figure 2. (A) Instrumentation with straight spine direct postoperatively. (B) 4 week follow-up with the development of a C-type curvature with thoracic asymmetry. (C) 10 week follow-up prior to tether release. (D) 20 weeks follow-up with slight loss of curvature 10 weeks after tether release.
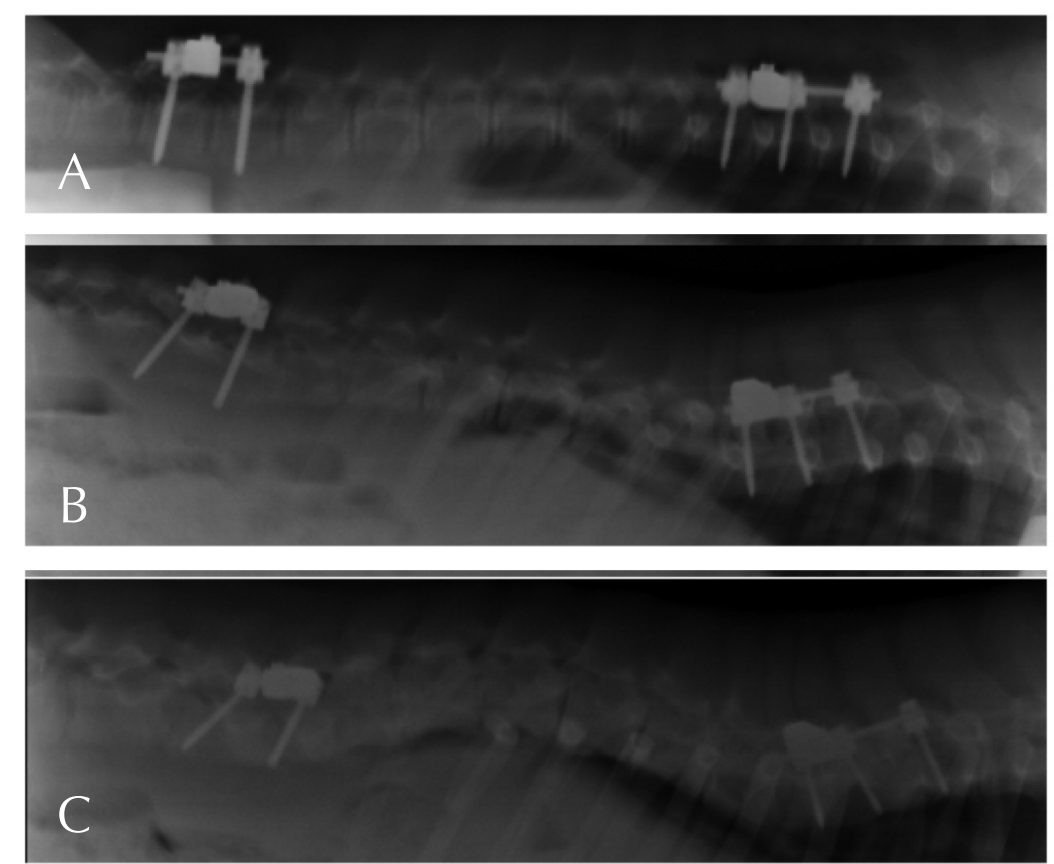

Figure 3. Lateral x-rays. (A) Instrumentation with nearly straight spine postoperatively. (B) 4 week follow-up with the development of a small thoracic lordosis (C) 10 week follow-up prior to tether release

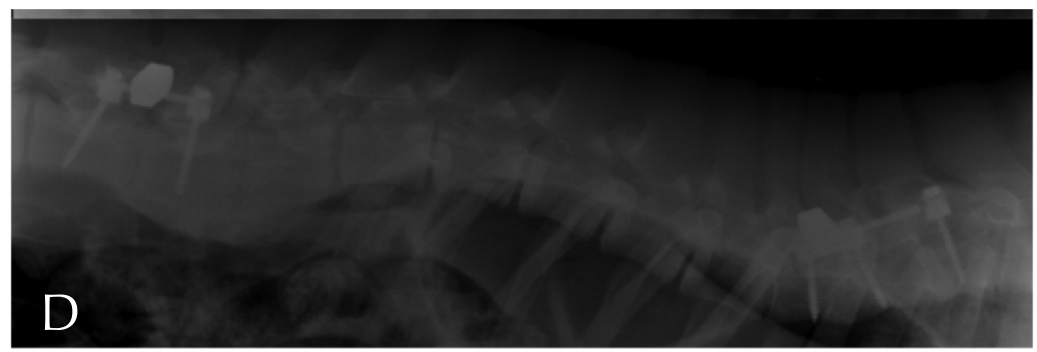
with presence of a thoracolumbar kyphosis and thoracic lordosis. (D) 20 weeks followup with unchanged curvature 10 weeks after tether release. 


\section{Chapter 7}

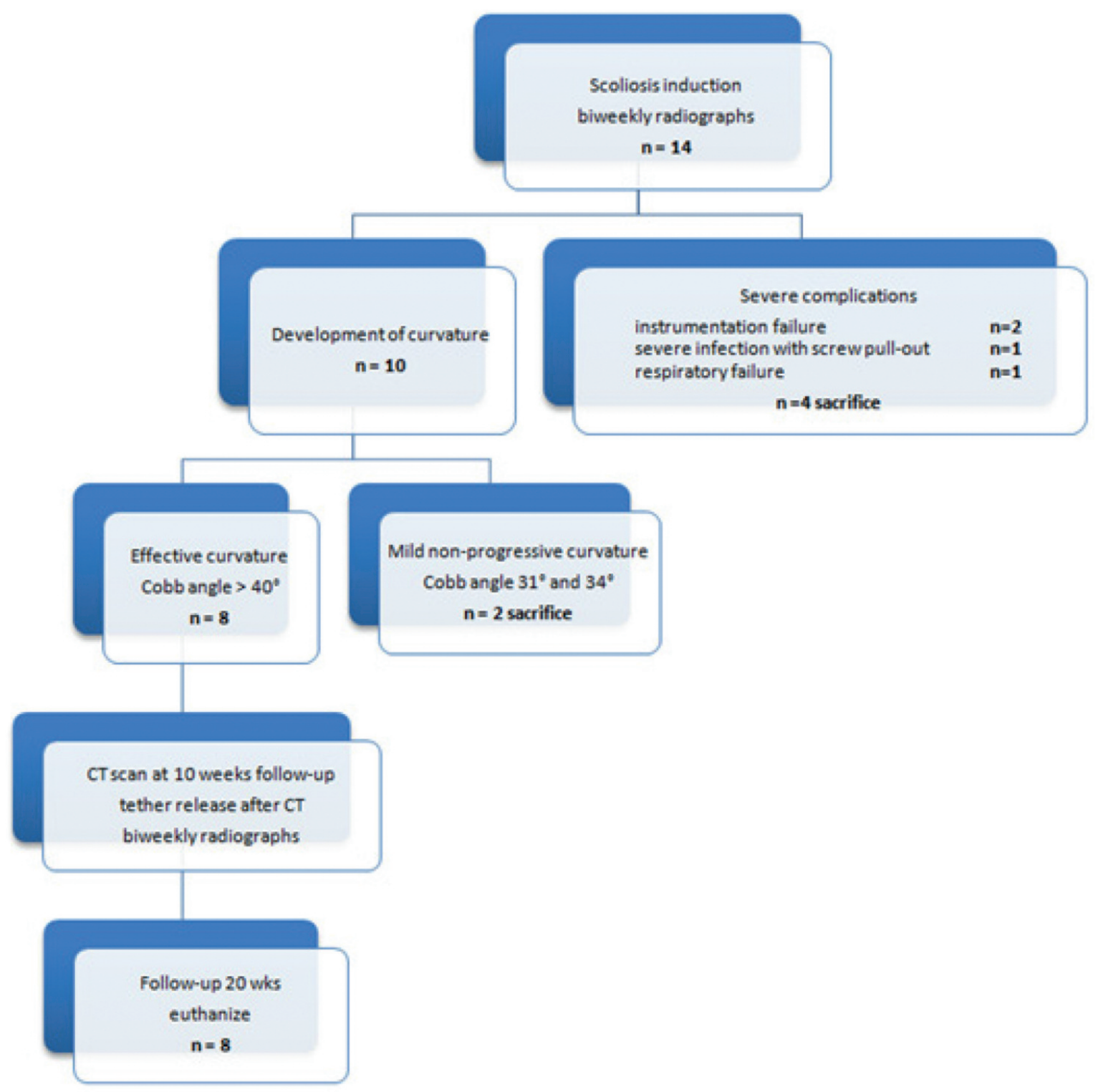

Figure 4. Flowchart of experimental group. 

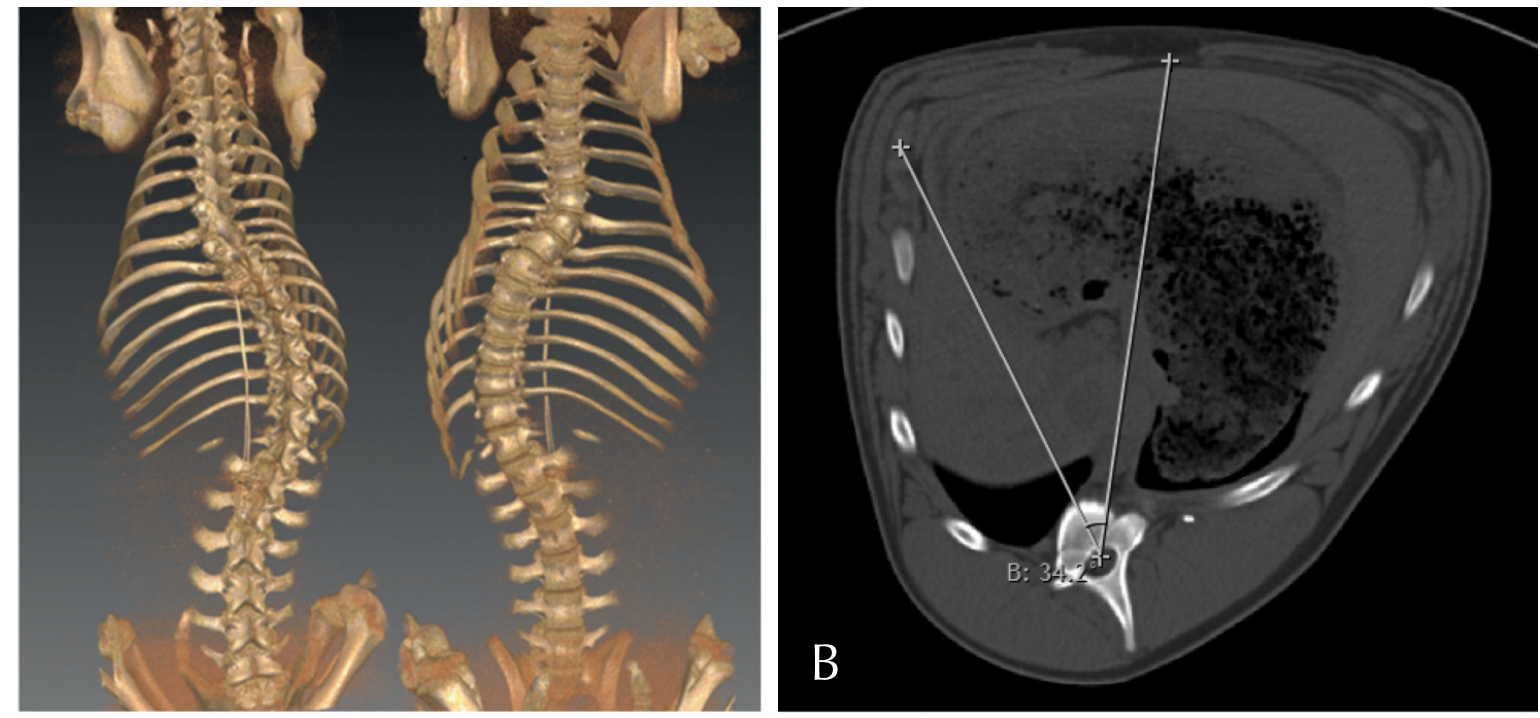

Figure 5. (A) Frontal (right) and posterior (left) view of a 3-D CT reconstruction of the lordo-scoliotic deformity at 10 weeks follow-up prior to release of the tether. Sagittal reconstruction clearly showing the thoracic asymmetry. (B) Axial CT slice showing how rotation was measured at the level of the apical vertebra by measuring the angle between the anterior midline and the line perpendicular to the transverse processes.

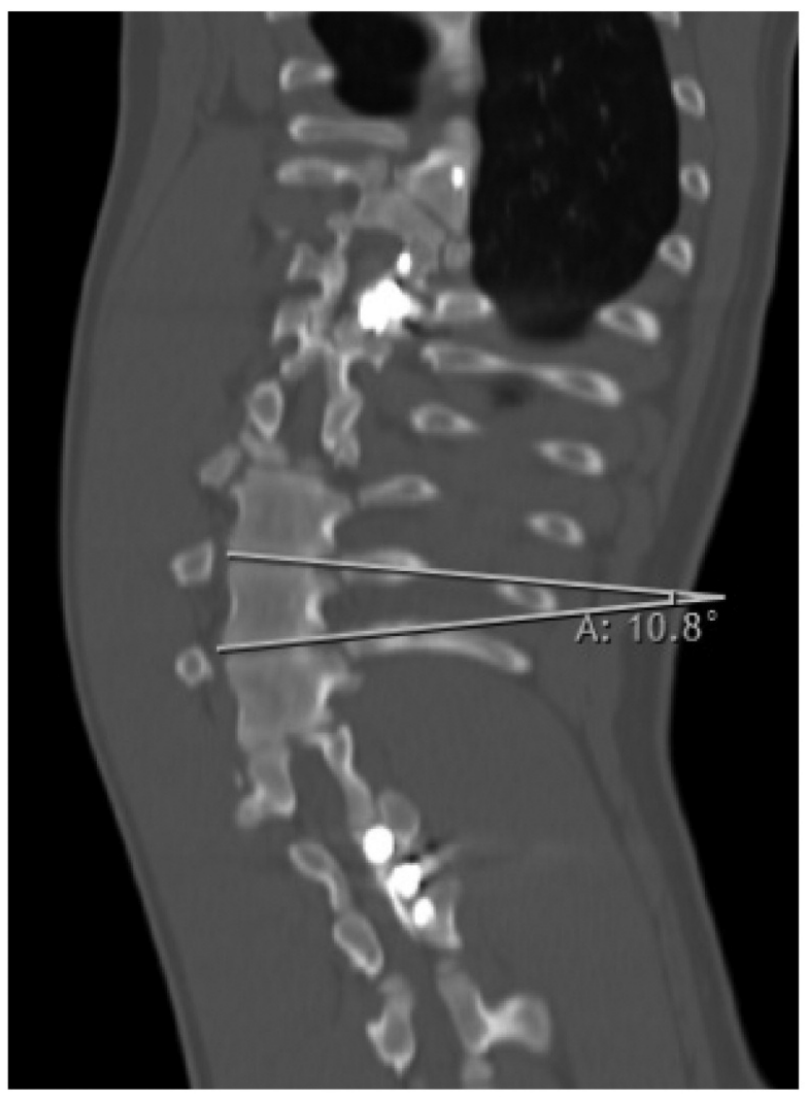

Figure 6. Coronal reconstructed image showing the wedging of the apical vertebrae. 


\section{Chapter 7}

\section{Cobb angle frontal curve (degrees)}

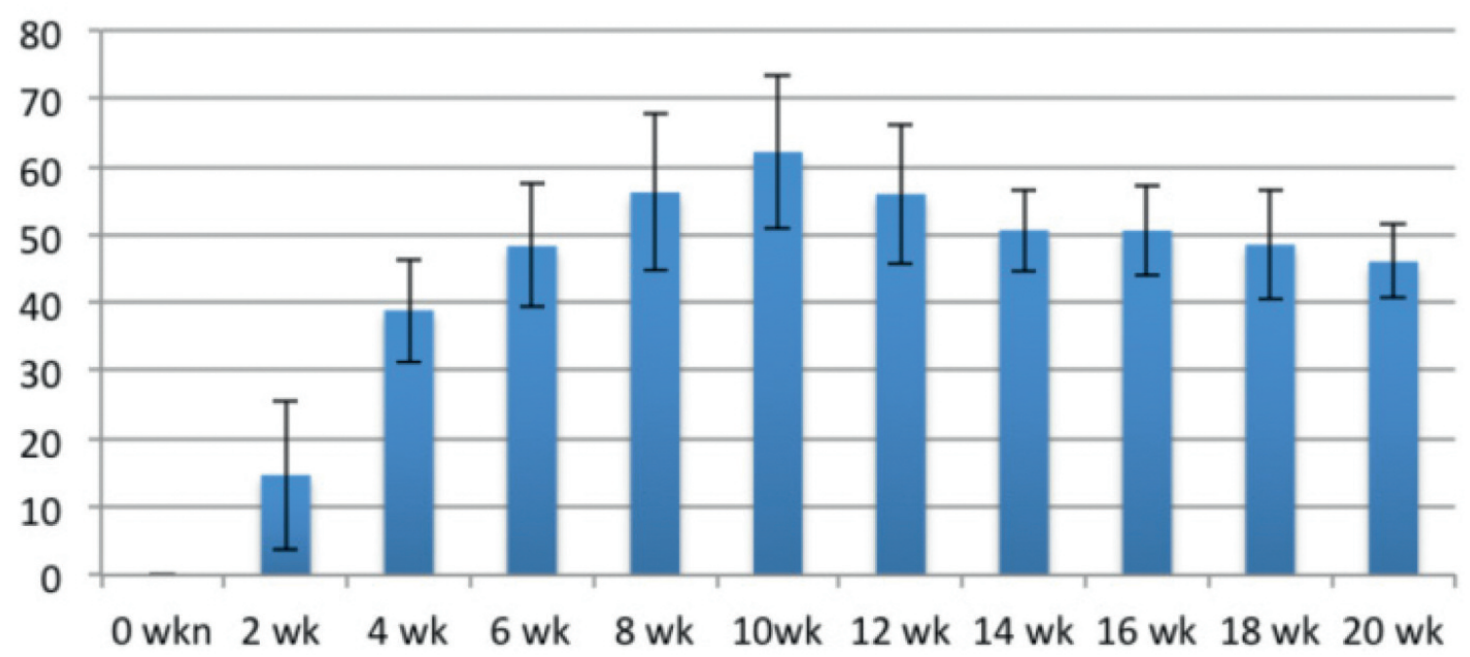

Figure 7. Evolution of scoliosis after placement of the tether. At 10 week follow-up the tether release is performed.

\begin{tabular}{|c|c|c|c|c|c|c|c|c|c|c|}
\hline \multirow[t]{4}{*}{ Animal } & \multirow{4}{*}{$\begin{array}{c}\text { Instrumentation } \\
\text { level }\end{array}$} & \multicolumn{3}{|c|}{ Cobb angle } & \multicolumn{3}{|c|}{ Cobb angle } & \multicolumn{3}{|c|}{ Cobb angle } \\
\hline & & \multicolumn{3}{|c|}{ Precut tether 10 wks } & \multicolumn{3}{|c|}{ Post tether release } & \multicolumn{3}{|c|}{ End follow-up 20 wks } \\
\hline & & frontal & sagittal & & frontal & sagittal & & frontal & sagittal & \\
\hline & & & lordosis & kyphosis & & lordosis & kyphosis & & lordosis & kyphosis \\
\hline 1 & L1-2 / T5-4-3 & 72.4 & 44.1 & 19.8 & 58.2 & 39.1 & 16.6 & 44.5 & 32 & 12 \\
\hline 2 & L1-2 / T5-4-3 & 61.7 & 44 & 20 & 51 & 38.6 & 19.6 & 39.4 & 32.7 & 13.6 \\
\hline 3 & $\mathrm{~L} 1-2$ / T5-4-3 & 43.3 & 21.4 & 6.8 & 38.6 & 28.5 & 6.8 & 40.7 & 30 & 4.4 \\
\hline 4 & $\mathrm{~L} 1-2$ / T5-4-3 & 62.8 & 32 & 21 & 62 & ** & 20.3 & 50.3 & ** & 20 \\
\hline 5 & $\mathrm{~L} 2-3 / \mathrm{T} 6-5-4-3^{*}$ & 75.6 & 29.1 & 15.4 & 65.6 & 51.1 & 15 & 50.7 & 49.4 & 12 \\
\hline 6 & L2-3 / T7-6-5 & 70.7 & 30.2 & 17 & 65.2 & 28.1 & 14.6 & 52.6 & 40.7 & 4.5 \\
\hline 7 & L2-3 / T7-6-5 & 60.9 & 20.1 & 30 & 58.8 & 20.4 & 23.2 & 43.2 & 29.8 & 20 \\
\hline 8 & L2-3 / T7-6-5 & 49.7 & 53.3 & 44 & 48.2 & 35.8 & 31.2 & 51.8 & 36.6 & 33.5 \\
\hline Mean & & 62.1 & 34.3 & 21.8 & 56.0 & 34.5 & 18.4 & 46.7 & 35.9 & 15 \\
\hline
\end{tabular}

Table 1. Evolution of the Cobb angles before and after tether release and at 10 weeks post tether release. * Extra pedicle screw insertion due to minimal screw support, ** Quality radiographs not suitable for adequate sagittal measurements. 


\begin{tabular}{lcccccc} 
Animal & $\begin{array}{c}\text { Cobb } \\
\text { frontal }\left({ }^{\circ}\right)\end{array}$ & $\begin{array}{c}\text { Apical Vertebral } \\
\text { rotation }\left({ }^{\circ}\right)\end{array}$ & $\begin{array}{c}\text { No. Vertebrae } \\
\text { in curve }\end{array}$ & $\begin{array}{c}\text { Vertebral } \\
\text { wedging }\left({ }^{\circ}\right)\end{array}$ & $\begin{array}{c}\text { Height } \\
\text { Convex (mm) }\end{array}$ & $\begin{array}{c}\text { Height } \\
\text { Concave (mm) }\end{array}$ \\
\hline 1 & 72.4 & 44.4 & 11 & 5.7 & 25.9 & 24.4 \\
2 & 61.7 & 36.2 & 11 & 6.8 & 25.1 & 22.1 \\
3 & 43.3 & 25.2 & 6 & 8.1 & 26 & 24.2 \\
4 & 62.8 & 54.4 & 6 & 9.7 & 28.2 & 23.4 \\
5 & 75.6 & 36.9 & 12 & 16.1 & 26.6 & 19.5 \\
6 & 70.7 & 43.1 & 11 & 8.5 & 28.8 & 24.7 \\
7 & 60.9 & 34.6 & 11 & 10.4 & 29 & 25.1 \\
8 & 49.7 & 23.8 & 5 & 17.2 & 25.7 & 21 \\
\hline mean & 62.1 & 37.3 & 9.1 & 10.4 & 27 & 22.8 \\
\hline
\end{tabular}

Table 2. Spinal parameters with Cobb angle, apical vertebrae rotation and wedging of the different specimen at 10-week follow-up prior to tether release.

\section{DISCUSSION}

Numerous attempts have been made to create reproducible large animal scoliosis models for preclinical evaluation of fusionless scoliosis correction techniques. ${ }^{4,8,10,14,16-19}$ A representative experimental early onset scoliosis model should exhibit the following features: structural, persistent frontal and sagittal curvatures with sufficient rotation and wedging at the apex of the curvature, and adequate growth potential remaining to perform subsequent correction procedures. ${ }^{8}$

Despite experiencing several technical problems in our study, we were able to create a scoliosis-like deformity, progressive while the tether was in situ in eight out of 14 animals without the use of rib tethering procedures. Magnitudes and threedimensional characteristics of the attained curves showed idiopathic-like features, with a mean Cobb angle of $62^{\circ}$, and a mean vertebral rotation of $37^{\circ}$ at the apex vertebra. The sagittal profile was not predominantly lordotic, and curves were therefore not idiopathic-like in that sense. The three shorter thoracic curves with rigid segments, formed as a result of vertebra fracture or epiphysiolysis, are less idiopathic-like and perhaps more similar to a congenital scoliosis. Such curves 


\section{Chapter 7}

would be of limited usefulness for the assessment of fusionless scoliosis correction techniques. The low yield and the low consistency of our model remains a concerning issue. Four animals were sacrificed as a result of instrument failure or infection. Infections were prevented after changing the surgical preparation protocol. Despite not applying tether pretension, screw pullout still occurred in three animals. In one case, osteolysis surrounding the screws caused by infection probably resulted in this loss of fixation at the bone screw interface.

After our pilot study in which pretension was applied to the tether and instrumentation failure occurred within two week postoperatively, we reasoned that pretensioning of the tether causing an immediate scoliosis should not be performed. Schwab et al., however, demonstrated that the larger the initial curve (up to approximately 25 degrees) as induced by applying tension at surgery, the higher the rate of progression was observed. ${ }^{11}$ In their study, sublaminar cables were used to reinforce the screws and instrumentation was probably partially protected by an ipsilateral rib tether. Zheng et al. have also described a porcine scoliosis model with the use of a posterior tether in combination with an ipsilateral rib tether. ${ }^{20} \mathrm{By}$ pretensioning the posterior tether a curvature of $29^{\circ}$ was initiated and progressed to $65^{\circ}$ at an 8 week tethering period. Apparently, the rib tether aids in early induction of the deformity, reduces load on the spinal tether anchors, and helps avoid screw pullout. Our objective was to develop a persistent spinal deformity representative of EOS with the use of a radiopaque UHMWPE posterior tether and without additional rib procedures. We believe a rib tether violates the chest wall structures and causes irreversible ribcage deformity with the formation of ectopic bone and stiff curves as result. Subsequent corrective surgery may therefore be more difficult to perform. By omitting rib procedures we aimed to create less rigid curves, especially around the apex, which subsequently resulted in non-progressive curves after tether release. Odent et al. have shown earlier that rib procedures can be omitted. ${ }^{10}$ However, release of the tether after 2 months led to a regression of the deformity by $45 \%$ in their study. In our study, the mean frontal Cobb angle decreased from $62.1^{\circ}$ tot $46.7^{\circ}$ over a 10 week period after tether release. Despite the decline of $25 \%$, a substantial deformity ultimately remains which is close to the magnitude, which would be considered for surgery. Prior to tether release, the apical vertebrae showed a mean wedge angle of $10^{\circ}$. The emergence of vertebral wedging is 
necessary for the persistence of scoliotic deformity after tether release. Similarly, in the human spine apical vertebral wedging is an essential factor in the progression of idiopathic scoliosis according to the Hueter-Volkmann principle. ${ }^{16}$ Regression of the deformity can be seen as evidence of a flexible curve, which is a crucial prerequisite for apply growth modulation techniques. The omission of the rib tether exhibited two downsides in a porcine model: the incapability of applying pretension to the tether, and slight curve regression after tether release.

Selection of animal species with anatomy similar to humans' and timing of the procedures are vital factors for creating a successful scoliosis model with sufficiently large Cobb angles. ${ }^{8}$ Braun was the first to produce progressive lordo-scoliotic deformities in a goat model. However, large pathological curves were obtained. ${ }^{16,17}$ In addition to the pyramidal shape of the thorax, the relatively small size of the goat's vertebra as compared to the human vertebra, makes the goat model less suitable for implant testing. ${ }^{21}$ The porcine spine is most similar to the human spine in terms of vertebral body height and has the largest growth potential compared to other large animals, with a maximum growth velocity around 3-4 months of age. ${ }^{8}$ We opted for pigs, reasoning that the large growth potential is required when no pretension is applied to the spinal tether. We performed the initial procedure at 8 weeks of age and a mean weight of $12 \mathrm{~kg}$. This is well before the growth velocity peak, leaving enough residual growth to evaluate the deformity after tether release (and perform a corrective procedure in the future). However, we experienced some handling problems with the animals, who reached a weight of approximately $50 \mathrm{~kg}$ at the time of tether removal and approximately $100 \mathrm{~kg}$ at 6 months of age (sacrifice). Other studies describing experimental scoliosis models report different rates of weight increase in pigs, and different rates of growth of the porcine spine, probably the result of discrepancy between porcine races. ${ }^{10,11,20}$ The size of our animals during the possible implant test phase (between $50-100 \mathrm{~kg}$ ) is not representative of children under the age of 10, but allows for conceptual feasibility assessment of fusionless scoliosis correction techniques. The described low yield due to screw pull-out and low consistency (epihphysiolysis) are also probably related to the rapid porcine growth phase. The use of mini-pigs or species with a slower growth rate such as sheep or goats may help avoid these problems. ${ }^{10,22}$ Mini-pigs show a constant growthvelocity, but lack a growth spurt and will need longer observational periods. ${ }^{8}$ 


\section{Chapter 7}

Different types of tether materials have been used and flexible tethers are preferred over a rigid tether in order to maintain spinal mobility and allow for growth modulation in different planes (lordo-scoliosis). ${ }^{10,14,20}$ Non-metal flexible tethers are also used although visualization of the integrity of the tether during follow-up is not possible. The use of a flexible, radiopaque UHMWPE tether ${ }^{13}$, facilitated percutaneous tether release with a minimally invasive stab incision under fluoroscopic control. The tensioning and potentially loosening of the radiopaque tether could easily be monitored during the postoperative radiological evaluation, with minimal animal discomfort as a result of leaving the tether in place.

It is evident that measures should be taken to minimize the occurrence of wound infections; not only to decrease the incidence of instrumentation failure, but also to decrease overall morbidity. Further limitations of our study include the lack of CT analysis at 20 weeks follow-up. Therefore, we were not able to compare rotational deformity between different time-points. Although we encountered several problems, we were able to create the foundation for a large animal scoliosis model, which exhibits a substantial three-dimensional deformity without the use of rib procedures additional to a posterior spinal tether. The resulting deformities were not progressive, but showed persistence after tether release. The high complication rate remains a concern and poses questions regarding the feasibility of subsequent corrective operative procedures. We conclude that despite extensive research and incorporating previous recommendations from other models, the development of a reproducible experimental scoliosis large animal model without severe complications remains challenging. We would like to emphasize that the current work requires further work and validation prior to adoption, preferably in an animal model with a slower growth rate in order to improve the yield and consistency. 


\section{REFERENCES}

1. Thompson GH, Lenke LG, Akbarnia BA, et al. Early onset scoliosis: future directions. The Journal of bone and joint surgery American volume 2007;89 Suppl 1:163-6.

2. Gomez JA, Lee JK, Kim PD, et al. "Growth friendly" spine surgery: management options for the young child with scoliosis. The Journal of the American Academy of Orthopaedic Surgeons 2011;19:722-7.

3. Schmid EC, Aubin CE, Moreau A, et al A novel fusionless vertebral physeal device inducing spinal growth modulation for the correction of spinal deformities. European spine journal : official publication of the European Spine Society, the European Spinal Deformity Society, and the European Section of the Cervical Spine Research Society 2008;17:1329-35.

4. Braun JT, Akyuz E, Ogilvie JW. The use of animal models in fusionless scoliosis investigations. Spine. 2005;30:S35-45.

5. Graf H, Hecquet ], Dubousset J. [3-dimensional approach to spinal deformities. Application to the study of the prognosis of pediatric scoliosis]. Revue de chirurgie orthopedique et reparatrice de I'appareil moteur 1983;69:407-16.

6. Dubousset J. [Idiopathic scoliosis. Definition—pathology—classification—etiology]. Bulletin de l'Academie nationale de medicine 1999;183:699-704.

7. Dubousset J. Scoliosis and its pathophysiology: do we understand it? Spine 2001;26:1001.

8. Roth AK, Bogie R, Jacobs $E$, et al. Large animal models in fusionless scoliosis correction research: a literature review. The spine journal: official journal of the North American Spine Society 2013;13:675-88.

9. Zhang YG, Zheng GQ, Zhang XS, et al. Scoliosis model created by pedicle screw tethering in immature goats: the feasibility, reliability, and complications. Spine 2009;34:2305-10.

10. Odent T, Cachon T, Peultier B, et al. Porcine model of early onset scoliosis based on animal growth created with posterior mini-invasive spinal offset tethering: a preliminary report. European spine journal : official publication of the European Spine Society, the European Spinal Deformity Society, and the European Section of the Cervical Spine Research Society 2011;20:1869-76.

11. Schwab F, Patel A, Lafage V, et al. A porcine model for progressive thoracic scoliosis. Spine 2009;34:E397-404.

12. Ceelen K, Vaz C, Bremer L, et al. Development of a high-strength, biocompatible, radiopaque UHMWPE fiber. 24th European Conference on Biomaterials. Dublin, Ireland 2011. 


\section{Chapter 7}

13. Bogie R, Roth A, Faber S, et al. Novel Radiopaque UHMWPE Sublaminar Wires in a Growth-Guidance System for the Treatment of Early Onset Scoliosis: Feasibility in a Large Animal Study. Spine 2014;39:E1503-9.

14. Burke JG, Vettorato E, Schoffmann G, et al. Creation of an ovine model of progressive structural lordo-scoliosis using a unilateral laminar tether. European spine journal : official publication of the European Spine Society, the European Spinal Deformity Society, and the European Section of the Cervical Spine Research Society 2015;24:1382-90.

15. Lam GC, Hill DL, Le LH, et al. Vertebral rotation measurement: a summary and comparison of common radiographic and CT methods. Scoliosis 2008;3:16.

16. Braun JT, Ogilvie JW, Akyuz E, et al. Experimental scoliosis in an immature goat model: a method that creates idiopathic-type deformity with minimal violation of the spinal elements along the curve. Spine 2003;28:2198-203.

17. Braun JT, Ogilvie JW, Akyuz E, et al. Creation of an experimental idiopathic-type scoliosis in an immature goat model using a flexible posterior asymmetric tether. Spine 2006;31:1410-4.

18. Moal B, Schwab F, Demakakos J, et al. The impact of a corrective tether on a scoliosis porcine model: a detailed 3D analysis with a 20 weeks follow-up. European spine journal: official publication of the European Spine Society, the European Spinal Deformity Society, and the European Section of the Cervical Spine Research Society 2013;22:1800-9.

19. Ouellet J, Odent T. Animal models for scoliosis research: state of the art, current concepts and future perspective applications. European spine journal: official publication of the European Spine Society, the European Spinal Deformity Society, and the European Section of the Cervical Spine Research Society 2013;22 Suppl 2:S81-95.

20. Zheng X, Sun X, Qiu Y, et al. A porcine early-onset scoliosis model created using a posterior mini-invasive method: a pilot study. Journal of spinal disorders \& techniques 2014;27:E294300.

21. Braun JT, Akyuz E, Udall H, et al. Three-dimensional analysis of 2 fusionless scoliosis treatments: a flexible ligament tether versus a rigid-shape memory alloy staple. Spine 2006;31:262-8.

22. Newton PO, Upasani VV, Farnsworth $\mathrm{CL}$, et al. Spinal growth modulation with use of a tether in an immature porcine model. The Journal of bone and joint surgery American volume 2008;90:2695-706. 
A porcine early onset scoliosis model with a standalone posterior spinal tether 


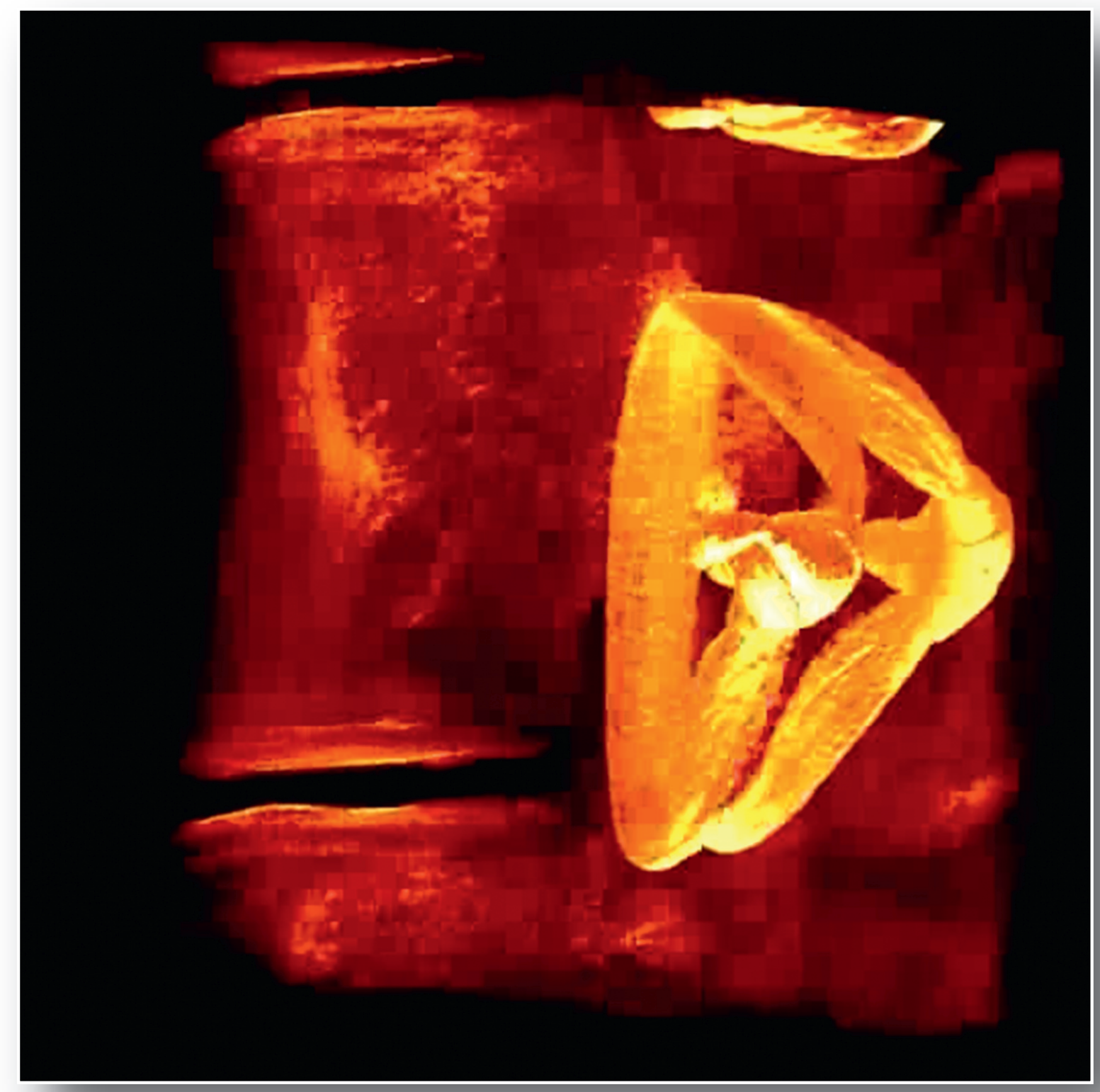

8 
ChAPTER 8

Summary 
Chapter 8

8 


\section{SUMMARY}

Unlike in adolescent or adult spinal deformity, untreated deformity in early onset scoliosis (EOS) can cause significant health problems, particularly the development of thoracic insufficiency syndrome. The treatment of EOS should focus not solely on the correction of the spinal curvature, but also on the preservation of growth with subsequent chest cavity and pulmonary development. Growth-friendly procedures that facilitate spine and chest growth instead of inhibition of growth by fusion of the spine have gained popularity in the treatment of EOS. In addition to distraction- and compression-based implants, several growth-guided techniques have recently been developed. The focus of this thesis was to develop a growth-guided trolley system for the treatment of EOS with the implementation of novel ultra-high molecular weight polyethylene (UHMWPE) sublaminar wires. The wires allow for gradual translation of the curvature to precontoured rods and they function as sliding anchors to facilitate spinal growth. We hypothesized that this concept of growth-guidance instrumentation could offer several advantages. First, the increased fatigue strength of these woven UHMWPE wires in comparison to standard metal laminar wires will reduce the risk of instrument failure and subsequent loss of deformity. Second, a decreased sliding friction is to be expected with the use of UHMWPE wires and generation of metal wear particles is prevented. Finally, by providing radiopacity to the UHMWPE wires, instrumentation integrity of the anchoring can be followed radiologically. We performed a preclinical assessment of instrumentation with these novel UHMWPE sublaminar wires with a special focus on the in vivo analysis of biocompatibility and safety.

In Chapter 2 we evaluated the different outcomes of previously used growthguidance systems with the use of sublaminar wiring in the treatment of EOS. A systematic review of the literature was performed for all techniques that described the use of single or double rod instrumentation connected to sliding metal sublaminar wires. High rates of instrument failure and subsequent loss of curve correction were found. Only partial preservation of spinal growth was achieved and some techniques reported the occurrence of metallosis. This high complication rate of the described techniques led to discontinuation of most of the described metal sublaminar wire growth-guided instrumentations. 


\section{Chapter 8}

Chapter 3 describes the outcome of 4 patients diagnosed with EOS and treated with a growth-guidance trolley system involving metal rods and Titanium sublaminar cables. In two patients, abrasion of the titanium wires against the Cobalt Chrome rods caused severe metallosis and the instrumentation failed in these cases resulting in curvature regression and subsequent revision surgery necessity. In two other cases, the concept of this trolley system in achieving curve correction, preservation of longitudinal spinal growth and maintaining stability was proven successful. We stated that the implementation of materials with higher fatigue strength and lower friction properties could address these potential complications.

To assess the stability and biocompatibility of UHMWPE sublaminar wires in growth-guidance surgery we performed a pilot study in a non-scoliotic ovine model described in Chapter 4. In immature sheep, a posterior instrumentation was performed involving lumbar pedicle screws and dual rods, which were secured to the spine using UHMWPE sublaminar wires. The wires were secured to the rods using a double-loop sliding knot and a custom made tensioning device was used to tighten the UHMWPE knots. Titanium sublaminar wires were applied in one animal to function as a control. No neurological complications occurred and instrumentation remained stable in all subjects, which was confirmed by CT-scans and plain radiography. Although CT scanning revealed the formation of ectopic bone, unrestricted growth was observed at the operated levels. Macroscopic and histological analysis showed no signs of dural or epidural inflammation. The UHMWPE wires adapted well to the shape of the laminae and occupied less intramedullary space compared to the Titanium cables. Suggestions were made to develop 3 or $4 \mathrm{~mm}$ wide UHMWPE wires, as the $5 \mathrm{~mm}$ produced large, bulky knots, which protruded the skin in one animal.

In the previously described pilot study, the routing and integrity of UHMWPE sublaminar wires could not be assessed radiologically. This is a general finding when using radiolucent polymer wires in orthopedic surgery. Especially in growthguidance surgery, in which breakage of anchors/wires often takes place as a result of high continuous loads, radiographic follow-up of the wire or cable anchoring seems vital. Therefore, before implantation of the UHMWPE wires in a follow-up 
study, radiopacity of the wires was desired. This was achieved through cooperation with DSM Biomedical (Geleen, the Netherlands) who developed a radiopaque UHMWPE fiber by using a Bismuth trioxide additive $\left(\mathrm{Bi}_{2} \mathrm{O}_{3}, 20 \%\right.$ wt. additive). In Chapter 5 these novel UHMWPE sublaminar wires were evaluated in a large animal model to assess radiopacity, stability and biocompatibility. In an immature ovine model spinal growth after growth-guidance construct implantation was quantified in 12 animals and compared to 4 age-matched, un-operated animals. Posterior instrumentation was performed with insertion of lumbar pedicle screws fixed to dual Cobalt Chrome rods. $4 \mathrm{~mm}$ wide radiopaque UHMWPE wires were passed sublaminarly at each level between L3 and T11 and attached to the rods with the previously described technique. Lateral radiographs clearly showed safe routing of the radiopaque UHMWPE cables around the laminae. No neurological injuries occurred and the UHMWPE cable integrity was maintained during the follow-up period. Instrumentation with UHMWPE sublaminar cables did not limit longitudinal spinal growth in this animal trial; length of the instrumented segment did not differ from the un-operated control animals after a post-operative follow-up period of 24 weeks. In most animals, the most cranial wire slid off of the rod during follow-up providing us with proof of concept. High-resolution peripheral computed tomography (HR-pQCT) images revealed facet joint changes and heterotopic bone formation, which did not affect spinal growth. These images could easily visualize the positioning of the radiopaque wires around the laminae. Easy removal of spinal rods prior to HR-pQCT analysis indicated that no bone apposition directly onto the rods had occurred. Histological evaluation showed that the UHMWPE sublaminar wires were encapsulated by fibrous tissue and caused no adverse local tissue response.

In Chapter 6, an extensive literature overview of large animal models used for preclinical testing of fusionless scoliosis correction devices was provided and recent advances in the creation of an idiopathic-like scoliosis large animal model were described. We concluded that when using a two-step approach, with at first inserting a posterior spinal tether to create a scoliosis and subsequently correcting the deformity using the proposed fusionless scoliosis correction device, is the preferred method of testing novel fusionless scoliosis correction devices. The porcine spine 


\section{Chapter 8}

appears to be most suitable for inducing scoliosis and testing new fusionless instrumentation, due to its large growth potential and early availability, which provides the possibility of operating at 3 weeks of age. The placement of rib tethers should ideally not be used, because the index procedure (spinal tether placement) should be completely reversible. In addition, rib procedures often result in high morbidity. However, a higher rate of deformity regression following tether removal is to be expected when no rib tether is used. Key aspects that require consideration include tether anchoring technique, tether material and species selection with practical aspects in terms of handling, breeding and weaning. Difference in spinal anatomy between the human spine and spines of different animal species need to be kept in mind as well when spine instrumentation is tested. When using a posterior spinal tether, persistent spinal deformities can be obtained. Sufficient tether midline off-set is required to omit rib procedures.

A representative experimental EOS animal model should exhibit the following features: structural, persistent frontal and sagittal curvatures with sufficient rotation and wedging at the apex of the curve. Also, adequate remaining growth potential is needed to perform subsequent correction procedures. The development of a porcine experimental scoliosis model with a standalone posterior spinal tether was subsequently described in Chapter 7. A structural scoliotic curve with a chest wall deformity was created in eight out of fourteen animals, and the created deformities showed sufficient persistence after tether release. In the eight animals with deformity, the mean Cobb angle at 10 weeks follow-up was $62^{\circ}$ in the coronal plane, while the mean apical vertebral rotation was $37^{\circ}$. Sagittal profiles showed the development of a lordotic curve at the anchor sites due to anterior overgrowth. Substantial complications and technical problems were encountered. During the study we were able to solve several technical pitfalls and after changing the preparation protocol no more infections occurred. The created curves were inconsistent, with three animals displaying atypical short thoracic curves. The rapid porcine growth rate played a dominant role in the occurrence, of the instrumentation failure. This model requires further work and validation prior to adoption, preferably in an animal model with slower growth rate. The high complication rate remains a concern and poses questions regarding the feasibility of testing new growth-guidance instrumentation for EOS in the future. 


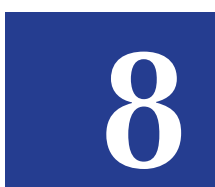




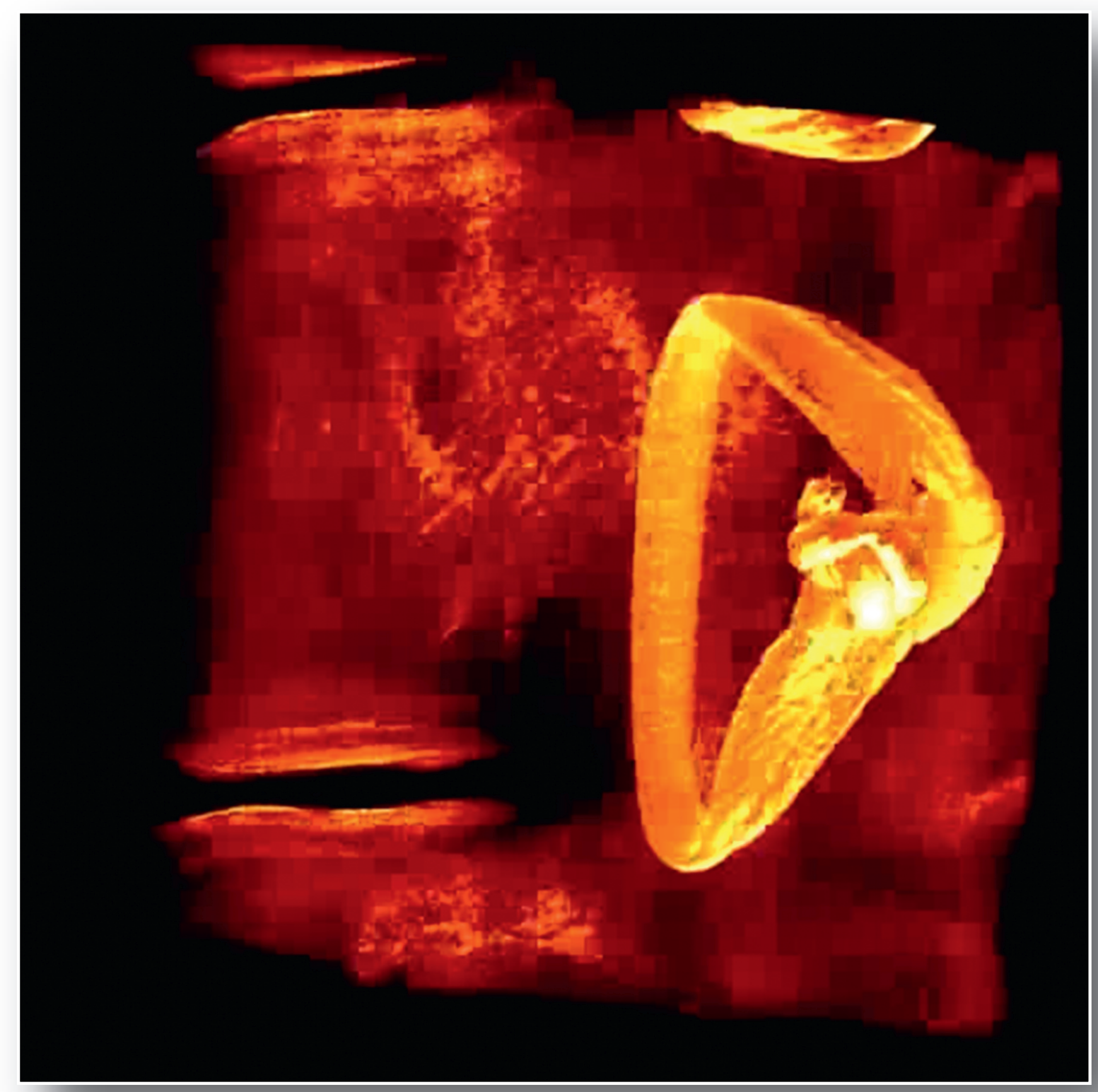

9 


\section{CHAPTER 9}

\section{General discussion}


Chapter 9

9 


\section{GENERAL DISCUSSION}

In the search for enhanced mechanical properties of fixation materials and sliding anchoring in growth-guidance EOS surgery, a multidisciplinary project (BMM Spineguide, BioMedical Materials) was enrolled, in collaboration with DSM Biomedical, Eindhoven University of Technology, the Technical University of Twente and Maastricht University Medical Center. The development of UHMWPE Dyneema Purity $®$ fibers, with high tensile and fatigue strength, has already led to a wide range of use in orthopedic surgery. For example, the Fibertape ${ }^{\circledR}$ and Fiberwire ${ }^{\circledR}$ are used in rotator cuff repair and anterior cruciate ligament repair. So far, the Dyneema Purity $®$ fiber has not been used in growth-guidance scoliosis surgery and its efficacy in spinal surgery and biologic behavior in proximity to spinal structures is unknown.

This thesis describes part of a preclinical assessment of novel UHMWPE sublaminar wires as part of a sliding anchoring in growth-guidance surgery for the treatment of EOS. The focus of this thesis was directed to the in vivo testing and the clinical rationale of the proposed UHMWPE sublaminar wires for growth-guidance instrumentation before implementation in clinical practice.

In answer to the aims of the thesis as presented in the introduction:

Aim 1: To perform a systematic review of the literature on the historical use of growth-guided sublaminar wiring for EOS surgery.

Recent advances in EOS treatment have led to the development of growth-friendly implants that enable the spine and chest cavity to grow whilst correcting the spinal deformity. These types of instrumentation obviate the requirement of long-term external immobilization. ${ }^{1}$ Growth-guidance instrumentation with the use of sublaminar wiring has come a long way in the past. Instrument failure can be expected in growth-guidance surgery, and results from these techniques performed in the past remain far from perfect and require additional improvements (Chapter 2). As a result of high complication rates including wire and rod breakage, most growth-guidance techniques using sublaminar wiring have been abandoned. These growth-guided 'trolley' systems, however, still can provide several advantages above distraction-based instrumentation; especially repetitive lengthening procedures, 


\section{Chapter 9}

which are invasive and place huge socio-economic burdens on patients and their families, may be omitted. 2,3

Aim 2: Outline the benefits and complications of currently used metal sublaminar wires in treatment of EOS patients.

With the advancement of pedicle screws insertion, which prevents spinal rods from migrating, growth-guiding instrumentation with sliding Titanium (Ti) sublaminar wires in a modified Trolley have already been performed at the department of orthopedic surgery in MUMC+ in patients with progressive neuromuscular scoliosis. In a case series, described in Chapter 3, we have shown that growth-guidance surgery with the use of a trolley system is feasible in EOS. Instrument failure with broken cables, as a result of abrasion of the wires to the rods, led to revision surgery in 2 cases. Upon revision severe metallosis was detected. This type of metallosis has also been found in growth-guidance surgery when using sublaminar wires and metallosis-associated complications with the formation of seroma and sinuses and concentrations of Ti and Vanadium (V) ions in the blood have been described. 4, 5, 6 Metallosis also has been found when using gliding pedicle screws (Shilla system) in growth-guidance scoliosis surgery. ${ }^{7,8}$ In the described case series, metallosis was caused by friction of Ti sublaminar wires to the Cobalt Chromium rods. These Cobalt Chromium rods are glass bead blasted by the manufacturer to increase set screw fixation to the rods. The exact type of wear particles was not analyzed. However, wear resistance of titanium is inferior to stainless steel or Cobalt Chromium alloys, but its wear particles are more biocompatible. ${ }^{9}$ Polishing the rods for their use in growth guidance surgery could probably minimize the amount of wear particles and also enhance sliding properties.

With the introduction of new UHMWPE sublaminar wires, these metallosis associated problems can be avoided. In biomechanical experiments, the mechanical properties of the UHMWPE cables showed to be superior to titanium sublaminar wires, and to literature data available for other sublaminar cable or wire systems in terms of tensile and fatigue strength, while possessing stiffness at least comparable to metal cables. ${ }^{10}$ 
Aim 3: Assess safety and biocompatibility of the UHMWPE sublaminar wires in a large animal model.

In vivo studies using animal models (this thesis) confirmed the stability and biocompatibility of the UHMWPE wires in growth-guidance instrumentation. Probably as a result of subperiostal exposure in an immature spine, a high rate of heterotopic ossification was observed. Heterotopic bone formation and spontaneous fusion in spinal animal experiments have been previously described. ${ }^{11,}{ }^{12}$ In fusionless scoliosis correction surgery extra care is taken to perform extraperiostal dissection. ${ }^{13}$ With the introduction of the sublaminar wires in the spine, the flaval ligament has to be incised and partially removed. This procedure necessitates subperiostal exposure and contributes to the ossification process. It is important to take into account that the occurrence of heterotopic ossification leading to spontaneous fusion was a frequent finding in Luque trolley surgery in the past. ${ }^{5}$ This will remain a concern when performing growth-guidance surgery in the immature spine. In both ovine experiments described in Chapter 4 and 5, the formation of ectopic bone formation was also observed, leading to different areas of spontaneous fusion. Unlike the Ti rods used in the pilot study, the Cobalt Chromium rod could easily be removed post-mortem. This is probably the result of the superior osteoconductivity of Titanium. Although heterotopic bone formation between the laminae and facet joints was encountered in the ovine studies, intra-laminar ossification was not observed and the spinal canal was not compromised. Animal studies have reported much higher rates of spinal fusion in quadruped models than rates seen clinically in humans. ${ }^{14}$ It has been suggested that spinal loading is higher in quadrupeds due to a higher vertebral bone density, and for that reason the mechanical stimuli to form new bone are also much stronger. ${ }^{15}$ Facet joint changes, as found in both in vivo studies, are likely a result of changes in mechanical loading of the facet joints brought on by the instrumentation. The thoracolumbar facets joints in sheep are normally rounded, encompassing joints. In this manner they can provide resistance to both dorsal and ventral shear, as well as to torsion. ${ }^{16}$ The combination of the induced periostal damage during exposure and load shift from the facets to posterior instrumentation has presumably resulted in the formation of bone around the facet joints. Minimizing the number of consecutive wired levels will reduce the surgical exposure and the subsequent heterotopic bone formation. 


\section{Chapter 9}

This type of non-segmental sublaminar wiring in a trolley instrumentation was recently described in a biomechanical set-up. ${ }^{17}$ In vivo studies performing these non-segmental wiring techniques, are still lacking.

In the ovine pilot study, the UHMWPE wires showed larger surface contact to the laminae compared to the titanium wires. Interestingly, minor bone ingrowth in the UHMWPE wires was found. The wires adapted to the shape of the laminae and this is regarded as highly beneficial as it therefore will occupy the least space in the spinal canal. First results of a growth-guided capacity of these wires were confirmed in the pilot study, as described in Chapter 4. Possible advantages over metal (TI) sublaminar wires could not fully be assessed because of the lack of a larger control group with Ti sublaminar wires.

Aim 4: Assess safety, biocompatibility and quantify spinal growth of radiopaque UHMWPE sublaminar wires in a large animal model.

Radiopacity of the UHMWPE wires was obtained by using a Bismuth tri-oxide additive. In this manner, routing of the wires and integrity of the wires can be assessed radiologically. The use of bismuth as a radiopacifying agent within biomedical implants is appealing due to its high atomic number $(\mathrm{ZBi}=83)$, and its well-known biological tolerance. ${ }^{18}$ Bismuth (III) complexes are renally cleared and are routinely used as a radiopacifying agent in root end fillers for endodontic surgery in a derivation of Portland cement known as mineral trioxide aggregate (MTA). ${ }^{19}, 20$ The feasibility of the use of bismuth compounds as radiopacifying agent in orthopedic bone cements has also been reported. ${ }^{21}$ Data from our pilot study (Chapter 4) supported biocompatibility of (radiolucent) UHWMPE wires. The biological reaction to the radiopaque UHMWPE sublaminar wires was similar. Histological evaluation showed that the UHMWPE sublaminar wire with Bismuth trioxide particles were encapsulated by fibrous tissue and caused no chronic inflammatory reactions. Biological assessment was further defined in a separate study in which different biopsies were taken from kidneys, liver and surrounding muscles. Highest Bismuth concentrations were found in the kidneys. ${ }^{10}$ However, these levels were below levels as found after therapeutic dosages, and far below toxic levels. ${ }^{22,} 23$

The radiopaque UHMWPE wires could be clearly seen on plain radiography during follow-up and the integrity of all wires was preserved. The routing of the 
sublaminar wires was best seen on the lateral radiographs. Biomechanical experiments showed that the mechanical properties of the radiopaque UHMWPE wires were not affected by the addition of the Bismuth oxide particles. ${ }^{10}$ The in vivo experiments confirmed the stability of the wires without signs of fraying or loosening macroscopically or on CT scans.

Biomechanical experiments conducted in previous experiments showed that longitudinal sliding friction of the UHMWPE wires was reduced to 50\% compared to titanium cables. ${ }^{24}$ Despite the occurrence of heterotopic bone formation observed in the ovine studies, the sliding capacity of the UHMWPE wires allowed for normal growth of the instrumented levels. With regard to the surgical treatment of EOS, we are not able to extrapolate the attained growth in this nonscoliotic animal model to clinical practice.

Aim 5: Based on a review of the literature, start the development of a scoliosis animal model in which instrumentation can be assessed after the formation of a scoliotic curvature.

Numerous attempts have been made in the search for an experimental animal scoliosis model. In the past, (small) animal models have been extensively used in attempts to clarify the etiology of scoliosis by inducing scoliosis using various prenatal, systemic or local procedures, as was reviewed in 2011 by Janssen et al. ${ }^{25}$ Management of the three-dimensional deformity in all planes is the main challenge in the design of new fusionless scoliosis correction devices. To test the efficacy of new fusionless scoliosis correction devices in a preclinical stage, a consistent large animal model representative of an idiopathic scoliosis is ideally used. However, scoliosis is not naturally prevalent is such large animals.

Although many different methods have been used to create a scoliosis, only posterior spinal tethering produces significant, progressing deformities that approximate the three-dimensional nature of the deformity as seen in idiopathic scoliosis. ${ }^{26}$ After performing a literature review, we found that the porcine spine showed to be the most suitable test species due to its large growth potential and early availability for surgery. Although rib tethering may provide more consistent curvatures, we believed the index procedure (tether placement) should be completely reversible and therefore no rib tether should ideally be used. During the 


\section{Chapter 9}

development of our own porcine experimental scoliosis model we have often encountered technical difficulties. This was probably the common result of our learning curve, rapid growth rate of the pigs with high loads on the instrumentation, and the moderate fixation of the pedicle screws in the cartilaginous bone. Despite a high failure rate, a structural scoliotic curve was created in eight out of fourteen animals, and the created deformities showed sufficient persistence after tether release. We were able to address most of the technical problems and minimized infection by adapting the protocol in the course of the study. Despite extensive research and incorporating previous recommendations from other models, the development of a reproducible experimental large animal scoliosis model without severe complications remains a challenge.

The model requires further work and validation prior to adoption, preferably in an animal model with a slower growth rate in order to improve the yield and consistency. We concluded that a scoliotic deformity created using a mechanical tether cannot be classified as being idiopathic, although it shares many characteristics of an idiopathic scoliotic curve. In all animal species, the quadrupedal locomotion causes different spinal loading patterns as compared to humans, and this will contribute to the fact that idiopathic scoliosis is naturally non-occurring in the animal world.

\section{FUTURE DIRECTIONS}

Recently the radiopaque UHMWPE cable has been approved for sublaminar wiring in spinal trauma surgery. Based on results presented in this thesis and biomechanical studies performed by AK Roth, U.S Food and Drug Administration FDA clearance was applied for and granted. The implementation of the wires in scoliosis correction, especially in pediatric surgery is still not approved. Although the in vivo experiments are not completed with a validated large animal scoliosis model and the proposed growth-guidance trolley was not assessed in vivo in a scoliotic spine, a stepwise introduction of the wires seems legitimate and will be proposed in controlled pilot clinical trials. The first step will include the use of UHMWPE sublaminar wires as part of a hybrid instrumentation for fusion scoliosis surgery in adult deformity patients. In this manner, biologic response and safety of the wires in human spinal 
surgery can be assessed and correlated to previous animal trials and in vitro results. As a second step, the efficacy of a growth-guidance instrumentation with a combination of dual rods, pedicle screws and radiopaque UHMWPE sublaminar wires will be evaluated in EOS patients. The Shilla growth-guidance instrumentation as presented by McCarthy et al has recently shown encouraging results. ${ }^{7}$ With this technique, bilateral pedicle screws are placed at the apex and the apex is fused. Growth is facilitated with distal sliding pedicle screws. Although the concern of metallosis persists when using these metal-on-metal articulating sliding pedicle screws, the principle of apical fixation and cranial and caudal sliding anchors is attractive. (Figure 1) The use of apical pedicle screws and apical fusion could provide

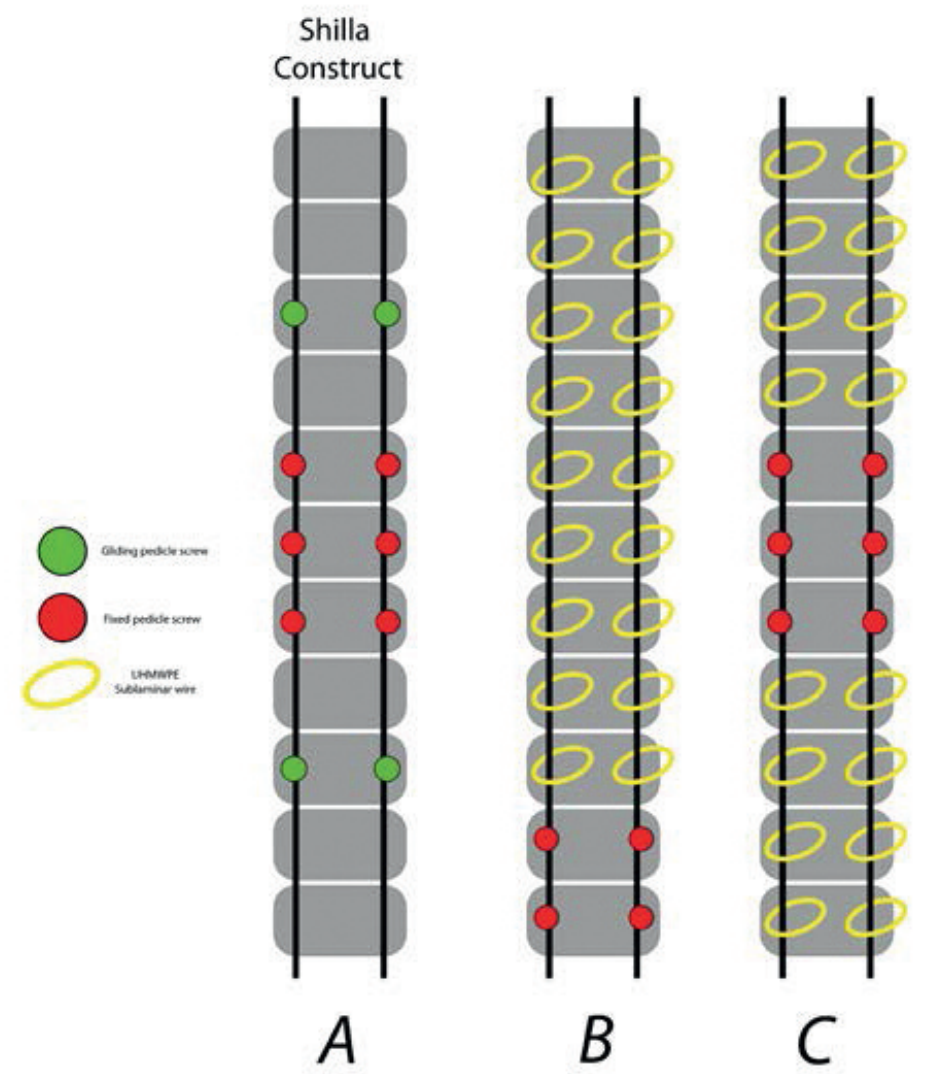

Figure 1. (A) Shilla construct; pedicle screws are used at the apex to secure rods and non-constraining pedicle screws allow for sliding at the proximal and distal ends. (B) Example of a modified Luque Trolley with constraining pedicle screws securing dual rods with sliding sublaminar wiring. (C) Example of a combination of apical screw fixation and sliding sublaminar anchoring at the proximal and distal ends. 


\section{Chapter 9}

rotational correction and could reduce the risk of crankshafting. Ouellet et al recently described sliding pedicle anchoring without metal-on-metal articulation. ${ }^{27}$ This Trolley Gliding Vehicle consists of two overlapping rods anchored with a combination of pedicle screws with UHMWPE bearing and a PEEK cable at each side at the apex. However, in EOS surgery, with the use of four rods, hardware prominence and increased stiffness can be very challenging. In the ongoing development of a novel growth-guidance system with the use of UHMWPE wires a combination of these techniques could be considered. In order to minimize derotation of the spine after instrumentation of a growth guidance system, the use of a cross-link between the rods can aid in improving (rotatory) stability.

Besides the FDA cleared intended use for the radiopaque UHMWPE wires in spinal trauma surgery, the wires were also cleared for other trauma indications (e.g. olecranon, ankle, patellar and femoral fractures) and for the fixation of osteotomies and sternum re-wiring in cardiac surgery. Another interesting application of the wires would be as supplementary fixation in degenerative scoliosis surgery, in which screw pull-out or proximal junctional failure are often encountered. Regulatory approval would need to be obtained for this application.

\section{FINAL CONCLUSION}

In this project we have proposed a growth-guidance technique with novel sliding anchoring for the correction of EOS. It should be emphasized that because of the large diversity of etiology and clinical appearance of EOS, no conclusive overall guideline or treatment algorithm can be provided. There is considerable variation regarding the optimal timing and indication for surgery. The growth-guidance technique is one of the possible surgical treatment options for EOS and all techniques have their pros and cons. On the one hand, we do think that a single surgical procedure may outweigh the risks and psychological burden of multiple lengthening procedures and that in specific cases spinal fusion is a viable option for some of these patients. On the other hand, repetitive lengthening procedures cannot be avoided when performing corrective surgery in the very young child although spontaneous fusion and hardware failure will remain a challenge as a result of the ongoing growth. After performing an extensive preclinical setup we can state that 
the proposed radiopaque UHMWPE wires can be safely introduced, in a careful stepwise approach, as sliding anchoring systems in growth-guidance EOS surgery. The final concept of the 'trolley' growth-guided instrumentation will depend on future research, which has started in the PoSTuRe project in 2017. Within this project the first clinical implementation of the wires will be achieved. 


\section{Chapter 9}

\section{REFERENCES}

1. Akbarnia BA, Campbell RM, Dimeglio A, et al. Fusionless procedures for the management of early-onset spine deformities in 2011: what do we know? J Child Orthop. 2011;5:159-72.

2. Caldas JC, Pais-Ribeiro JL, Carneiro SR. General anesthesia, surgery and hospitalization in children and their effects upon cognitive, academic, emotional and sociobehavioral development - a review. Paediatric anaesthesia. 2004;14:910-5.

3. Suliman S, Mkabile SG, Fincham DS, Ahmed R, Stein DJ, Seedat S. Cumulative effect of multiple trauma on symptoms of posttraumatic stress disorder, anxiety, and depression in adolescents. Comprehensive psychiatry. 2009;50:121-7.

4. Lukina E, Laka A, Kollerov M, et al. Metal concentrations in the blood and tissues after implantation of titanium growth guidance sliding instrumentation. Spine J. 2016;16:380-8.

5. Mardjetko SM, Hammerberg KW, Lubicky JP, Fister JS. The Luque trolley revisited. Review of nine cases requiring revision. Spine (Phila Pa 1976). 1992;17:582-9.

6. Pratt RK, Webb JK, Burwell RG, Cummings SL. Luque trolley and convex epiphysiodesis in the management of infantile and juvenile idiopathic scoliosis. Spine. 1999;24:1538-47.

7. McCarthy RE, Sucato D, Turner JL, Zhang H, Henson MA, McCarthy K. Shilla growing rods in a caprine animal model: a pilot study. Clin Orthop Relat Res. 2010;468:705-10.

8. McCarthy RE, McCullough FL. Shilla Growth Guidance for Early-Onset Scoliosis: Results After a Minimum of Five Years of Follow-up. J Bone Joint Surg Am. 2015;97:1578-84.

9. BD R. Biomaterials Science : An Introduction to Materials in Medicine. San Diego: Academic Press; 1996.

10. Roth AK, Boon-Ceelen K, Smelt H, et al. Radiopaque UHMWPE sublaminar cables for spinal deformity correction: Preclinical mechanical and radiopacifier leaching assessment. J Biomed Mater Res B Appl Biomater. 2017.

11. Lowe TG, Wilson L, Chien JT, et al. A posterior tether for fusionless modulation of sagittal plane growth in a sheep model. Spine (Phila Pa 1976). 2005;30:S69-74.

12. Schwab F, Patel A, Lafage V, Farcy JP. A porcine model for progressive thoracic scoliosis. Spine (Phila Pa 1976). 2009;34:E397-404.

13. Klemme WR, Denis F, Winter RB, Lonstein JW, Koop SE. Spinal instrumentation without fusion for progressive scoliosis in young children. J Pediatr Orthop. 1997;17:734-42. 
14. Kanayama M, Cunningham BW, Sefter JC, et al. Does spinal instrumentation influence the healing process of posterolateral spinal fusion? An in vivo animal model. Spine (Phila Pa 1976). 1999;24:1058-65.

15. Smit TH. The use of a quadruped as an in vivo model for the study of the spine biomechanical considerations. Eur Spine J. 2002;11:137-44.

16. Boszczyk BM, Boszczyk AA, Putz R. Comparative and functional anatomy of the mammalian lumbar spine. Anat Rec. 2001;264:157-68.

17. Roth AK, van der Veen AJ, Bogie R, et al. Range of Motion in Segmental Versus Nonsegmental Ultrahigh Molecular Weight Polyethylene Sublaminar Wire Growth Guidance Type Constructs for Early-Onset Scoliosis Correction. Spine (Phila Pa 1976). 2015;40:E1212-8.

18. Briand GG, Burford N. Bismuth compounds and preparations with biological or medicinal relevance. Chem Rev. 1999;99:2601-58.

19. Roberts HW, Toth JM, Berzins DW, Charlton DG. Mineral trioxide aggregate material use in endodontic treatment: a review of the literature. Dent Mater. 2008;24:149-64.

20. Sun H, Li H, Harvey I, Sadler PJ. Interactions of bismuth complexes with metallothionein(II). J Biol Chem. 1999;274:29094-101.

21. Deb S, Abdulghani S, Behiri JC. Radiopacity in bone cements using an organo-bismuth compound. Biomaterials. 2002;23:3387-93.

22. Lee SP, Lim TH, Pybus J, Clarke AC. Tissue distribution of orally administered bismuth in the rat. Clin Exp Pharmacol Physiol. 1980;7:319-24.

23. Taylor EG, Klenerman P. Acute renal failure after colloidal bismuth subcitrate overdose. Lancet. 1990;335:670-1.

24. AK R. Preclinical Assessment of Novel Radiopaque UHMWPE Sublaminar Wires in a Growth-Guidance System for Early Onset Scoliosis Correction. MUMC. Maastricht: MUMC; 2017

25. Janssen MM, de Wilde RF, Kouwenhoven JW, Castelein RM. Experimental animal models in scoliosis research: a review of the literature. Spine J. 2011;11:347-58.

26. Braun JT, Akyuz E, Ogilvie JW. The use of animal models in fusionless scoliosis investigations. Spine (Phila Pa 1976). 2005;30:S35-45.

27. Ouellet JA, Ferland CE, Klein K, et al. Evaluation of the Modern Luque Trolley Construct for the Treatment of Early-onset Scoliosis Using a Gliding Implant in an Immature Animal Model. Clin Spine Surg. 2017;30:E460-E5. 


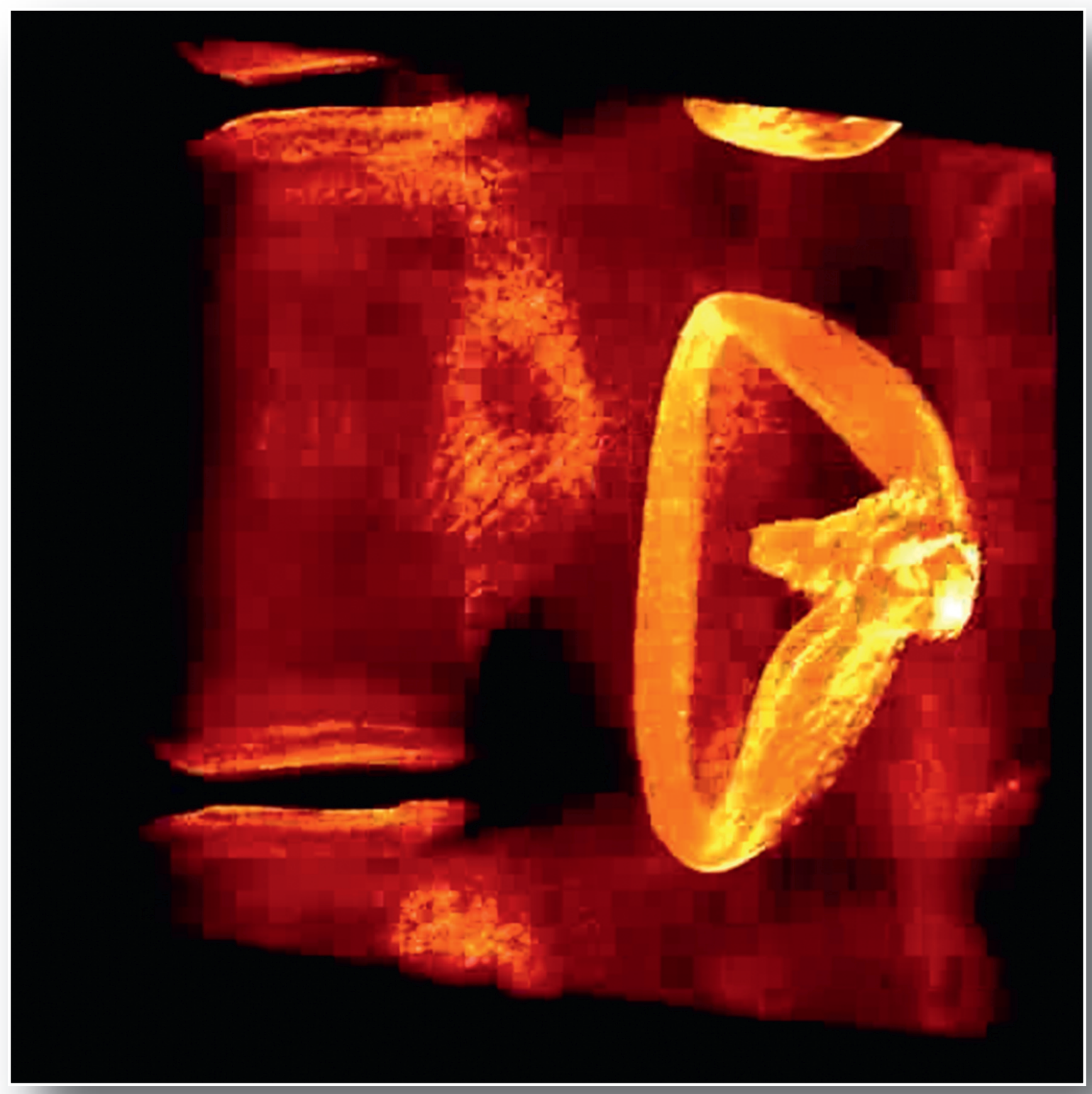

\section{0}




\section{CHAPTER 10}

Valorization

Nederlandse samenvatting

List of publications

Dankwoord

Curriculum vitae 
Chapter 10 


\section{VALORIZATION}

This appendix describes the social and economic value of the results described in this thesis.

Early onset scoliosis (EOS) is defined as scoliosis of any etiology before the age of $10 .{ }^{1}$ The incidence of EOS in Europe is $1-2$ per 10,000 people. ${ }^{2}$ In $10 \%$ of EOS patients the deformity will progress to a severe and disabling condition. ${ }^{2,3}$ Because of the substantial residual growth, the originally orthopedic problem, may become a serious pediatric systemic disorder. Because of reduced height of the thoracic spine, thorax insufficiency can cause serious pulmonary problems. ${ }^{4}$ EOS requires special attention as the deformity occurs in very young children and without treatment it will progress to cosmetic disfigurement and poor quality of life, mainly caused by the abovementioned thorax insufficiency syndrome. ${ }^{4-6}$ Orthotic bracing and casting generally have limited effectiveness due to thorax and spine compliance, pulmonary compromise and skin breakdown. ${ }^{7}$ If early spinal fusion is performed, spine and thoracic growth are restricted, resulting in severe pulmonary compromise. Negative outcomes of conservative treatment and concomitant morbidity of EOS patients lead to substantial medical costs.

In the past years, EOS has become an emerging field of spinal surgery. Advancements in implant technology have led to various techniques of spinal instrumentation, which have made severe deformities become correctable. However, in the growing young child correcting the curve is not always synonymous with treating the disease. ${ }^{8}$ With the increased insight in the negative effects of early spinal fusion, fusionless techniques have emerged. Although there still are many unresolved issues regarding the fusionless instrumentation methods, it has become clear that these techniques can improve the quality of life of these small children both by negating the requirement for long-term external immobilization, and by effectively controlling the deformity while facilitating spinal growth and lung development. ${ }^{8}$ As a result of the distinctly different etiologies of EOS and a shortage of evidencebased clinical research, the treating physicians will rely on their clinical experience and knowledge to form a treatment plan. ${ }^{8}$ Consequently, there is no consensus between surgeons with regard to the optimal surgical treatment and the decisive growth-friendly instrumentation. ${ }^{9}$ The term growth instrumentation seems somewhat 


\section{Chapter 10}

misleading, as the 'growth' often requires surgical lengthening, which is especially the case in spine-based and rib-based distraction surgery. These repeated surgeries have severe effects on the general health of the patients and can also affect the psychological state of the children and parents. ${ }^{10}$ Matsumoto et al have shown that when patients were of younger age at the initial time of surgery and had an increasing number of repetitive surgeries, psychosocial scores diminished. ${ }^{10}$ In traditional growing rod (TGR) surgery, which requires repetitive procedures, the overall wound complication rate is $16 \%$ increasing with $24 \%$ during each additional surgery. ${ }^{11}$ Magnetic controlled growing rods (MCGR) avoid the need for repeated surgical intervention and early results are promising. Long-term data are not yet available for this technique. Similar to other growth-friendly implants, the complication rates are still high. ${ }^{12}$ Implant related complications, such as rod fracture, implant dislodgement and proximal junction failure have been reported in both distraction surgery and growth-guidance surgery. ${ }^{13-15}$

The Spineguide project, resulting in this thesis, was started as part of the BioMedical Materials research program, co-funded by the Dutch Ministry of Economic Affairs. Project members from Maastricht University Medical Center, Eindhoven University of Technology, the University of Twente and DSM Biomedical collaborated in this public-private partnership, each with their own specific expertise within one of the different work packages. This partnership finds its origin in a common concern and interest in a young vulnerable and challenging patient group for whom optimal treatment should become available.

In this thesis we have assessed the feasibility of UHMWPE wires as sliding anchors along a dual rod instrumentation system for the treatment of early onset scoliosis (EOS). The mechanical properties of the UHMWPE cables were shown to be superior to other sublaminar cables or wires in terms of tensile and fatigue strength, while possessing stiffness at least comparable to metal cables. ${ }^{16}$ Using UHMWPE sublaminar wires in a growth-guiding instrumentation has several important advantages: the occurrence of metal wear particles and concomitant tissue reactions will be minimized, hardware failure as a result of wire breakage will be diminished because of the high fatigue strength, while continued spinal growth will be facilitated by low friction characteristics. Radiopacity of the wires can preclude false routing and instability of the wires. Whilst optimal anchoring sites (e.g. apical 
pedicle screw fixation) still have to be determined, we expect that a growth-guidance system consisting of these radiopaque UHMWPE sublaminar wires will be worth considering because of the reduced complication rate and acceptable medical costs.

Industry and clinicians should consider health-care economics prior to testing or initiating any new treatment or medical device. Besides a French cost analysis study comparing MCGR and $\mathrm{TGR}^{17}$, no studies reporting current costs of EOS management have been described. The MCGR system is recently CE marked but its use may be limited as a result of the substantial costs of this device. The unit costs of the MCGR system varies from 23,000 to 33,000 € in France to 5,200 $€$ in China, depending on the type of construct. ${ }^{17}$ Charroin et al. stated that the estimated costs of traditional growing rod (TGR) surgery and MCGR systems were respectively $49,067 €$ and $42,752 €$. In case of TGR surgery, increased hospital stay expenses due to the need for repetitive surgery resulted in incremental costs. The costs of the MCGR systems contributed to $59.5 \%$ of the total amount. ${ }^{17}$ No cost analysis studies have been performed on the use of growth-guidance systems in EOS surgery. However, it is to be expected that with the use of growth-guidance systems medical costs are reduced. System costs are expected to be lower (compared to MCGR) as well as the number of re-operations (compared to TGR). If a definitive fusion procedure can be avoided, which is often performed after growing rod surgery, the overall morbidity, psychological impact and medical costs may further decrease. Future research and clinical studies have to determine feasibility, specific indications and cost-effectiveness of growth-guiding surgery using UHMWPE wires. It would be interesting to compare such results to those of the use of MCGR.

The results of this thesis can contribute to future preclinical assessment of growth-friendly instrumentation in EOS surgery and animal research scoliosis studies. The Spineguide project successfully led to FDA clearance for the use of radiopaque UHMWPE wires in certain indications in spinal trauma surgery. Considering ongoing insights, future research will determine the feasibility of a definitive growth-guiding system including radiopaque UHMWPE gliding anchoring and the amount of required fixation points. UHMWPE wires have not been approved for application in pediatric patients in growth-guiding surgery yet. A follow-up project (PoSTuRE: Patient-specific Scoliosis TREatment, a new recently granted Biomedical program) will focus on the clinical implementation of the proposed 
UHMWPE sublaminar wires. Other interesting applications of the wires, for which regulatory approval would need to be obtained, are supplementary fixation in degenerative scoliosis surgery and as cerclage wires in (periprosthetic) fracture fixation. 


\section{REFERENCES}

1. Williams BA, Matsumoto H, McCalla DJ, et al. Development and initial validation of the Classification of Early-Onset Scoliosis (C-EOS). J Bone Joint Surg Am. 2014;96:1359-67.

2. Debnath U. Current Concepts in the Management of Early-Onset Idiopathic Scoliosis. Pediatr Health. 2010;4:343-54.

3. Lloyd-Roberts GC, Pilcher MF. Structural Idiopathic Scoliosis in Infancy: A Study of the Natural History of 100 Patients. J Bone Joint Surg Br. 1965;47:520-3.

4. Campbell RM, Jr., Smith MD, Mayes TC, et al. The characteristics of thoracic insufficiency syndrome associated with fused ribs and congenital scoliosis. J Bone Joint Surg Am. 2003;85-A:399-408.

5. Goldberg CJ, Gillic I, Connaughton O, et al. Respiratory function and cosmesis at maturity in infantile-onset scoliosis. Spine (Phila Pa 1976). 2003;28:2397-406.

6. Wong $\mathrm{CKH}$, Cheung JPY, Cheung PWH, Lam CLK, Cheung KMC. Traditional growing rod versus magnetically controlled growing rod for treatment of early onset scoliosis: Cost analysis from implantation till skeletal maturity. J Orthop Surg (Hong Kong). 2017;25:2309499017705022.

7. Upasani VV, Parvaresh KC, Pawelek JB, et al. Age at Initiation and Deformity Magnitude Influence Complication Rates of Surgical Treatment With Traditional Growing Rods in Early-Onset Scoliosis. Spine Deform. 2016;4:344-50.

8. Akbarnia BA, Campbell RM, Dimeglio A, et al. Fusionless procedures for the management of early-onset spine deformities in 2011: what do we know? J Child Orthop. 2011;5:15972.

9. Vitale MG, Gomez JA, Matsumoto H, Roye DP, Jr., Chest W, Spine Deformity Study G. Variability of expert opinion in treatment of early-onset scoliosis. Clin Orthop Relat Res. 2011;469:1317-22.

10. Matsumoto H, Williams BA, Corona J, et al. Psychosocial effects of repetitive surgeries in children with early-onset scoliosis: are we putting them at risk? J Pediatr Orthop. 2014;34:172-8.

11. Bess S, Akbarnia BA, Thompson GH, et al. Complications of growing-rod treatment for early-onset scoliosis: analysis of one hundred and forty patients. J Bone Joint Surg Am. 2010;92:2533-43. 


\section{Chapter 10}

12. Yang S, Andras LM, Redding GJ, Skaggs DL. Early-Onset Scoliosis: A Review of History, Current Treatment, and Future Directions. Pediatrics. 2016;137.

13. Cheung JP, Cahill P, Yaszay B, Akbarnia BA, Cheung KM. Special article: Update on the magnetically controlled growing rod: tips and pitfalls. J Orthop Surg (Hong Kong). 2015;23:383-90.

14. Mardjetko SM, Hammerberg KW, Lubicky JP, Fister JS. The Luque trolley revisited. Review of nine cases requiring revision. Spine (Phila Pa 1976). 1992;17:582-9.

15. Ouellet J. Surgical technique: modern Luque trolley, a self-growing rod technique. Clin Orthop Relat Res. 2011;469:1356-67.

16. Roth AK, Boon-Ceelen K, Smelt H, et al. Radiopaque UHMWPE sublaminar cables for spinal deformity correction: Preclinical mechanical and radiopacifier leaching assessment. J Biomed Mater Res B Appl Biomater. 2017.

17. Charroin C, Abelin-Genevois K, Cunin V, et al. Direct costs associated with the management of progressive early onset scoliosis: estimations based on gold standard technique or with magnetically controlled growing rods. Orthop Traumatol Surg Res. 2014;100:469-74. 


\section{NEDERLANDSE SAMENVATTING}

'Early onset scoliose' (ofwel EOS) is een wervelkolomdeformiteit die zich ontwikkelt vóór de leeftijd van 10 jaar. Doordat de patiënt nog jong is en het lichaam nog in ontwikkeling, ziet de chirurg zich bij de behandeling voor een aantal extra uitdagingen gesteld. Bij adolescenten en volwassenen met een scoliose wordt doorgaans een spondolydese (een operatie waarbij een of meerdere wervels aan elkaar worden vastgezet) verricht. Een dergelijke procedure kan echter bij kinderen de groei van de wervelkolom en de ontwikkeling van de thorax en de longen ernstig belemmeren. De behandeling van EOS moet niet alleen gericht zijn op de correctie van de scoliose maar er moet ook gestreefd worden naar het maximale behoud van de groei van de wervelkolom en pulmonale ontwikkeling. Recent zijn er meerdere correctiesystemen ontwikkeld voor de behandeling van EOS die groei faciliteren en waarbij geen spondylodese verricht hoeft te worden. Deze 'growth-friendly' systemen kunnen worden onderverdeeld in compressiesystemen (stapling), distractiesystemen (groeistaven) en groeigeleidingsstystemen (dit proefschrift). Momenteel is de meest gangbare methode het gebruik van groeistaven. Hierbij zijn elke 6 tot 9 maanden nieuwe operaties nodig om groei van de wervelkolom mogelijk te maken. Deze ingrepen gaan gepaard met vele complicaties en leiden tot hoge zorgkosten. Daarnaast veroorzaken deze herhaaldelijke operaties een toename van de psychosociale stress bij de patiënten en hun ouders. Bij chirurgie met behulp van groeigeleidingssystemen wordt de wervelkolom gefixeerd terwijl groei van de wervelkolom mogelijk blijft. Deze groei wordt mogelijk gemaakt doordat metalen kabels of schroeven langs metalen staven glijden. Een nadeel hiervan is echter, dat de combinatie van de frictie tussen metalen oppervlakten en de continue aanhoudende krachten zorgen voor een zeer hoge belasting van het fixatiemateriaal. Dit leidt vaak tot complicaties als materiaalfalen, waarbij het systeem kan uitbreken en de correctie verloren gaat, alsmede tot de vorming van slijtagepartikels (metallose) welke een chronische ontsteking kunnen veroorzaken.

Dit proefschrift beschrijft de ontwikkeling en evaluatie van een nieuw groeigeleidingssysteem voor de operatieve behandeling van EOS, waarbij de nadelen van huidige en eerder gebruikte technieken vermeden kunnen worden. In 


\section{Chapter 10}

dit systeem worden 'ultra-high molecular weight polyethylene' (UHMWPE) sublaminaire kabels gebruikt als fixatiepunten voor de metalen staven. Deze kabels fungeren als glijankers zodat de wervelkolom langs de staven kan groeien en zo zou een enkele ingreep voldoende kunnen zijn. Dit systeem zou verder nog enkele belangrijke voordelen kunnen opleveren: de verhoogde treksterkte en vermoeiingssterkte van de UHMWPE kabels ten opzichte van metalen kabels zal het risico op materiaalfalen verminderen. Daarnaast zal door de verminderde glijweerstand van deze UHMWPE kabels en de staven de frictie verminderd worden en zal het optreden van metalen slijtagepartikels voorkomen worden. Door het toevoegen van radiopaciteit (mate van zichtbaarheid op röntgenfoto's) aan de kabels kan de stabiliteit en routing van deze kunststof draden radiologisch vervolgd worden. Dit proefschrift is een preklinische evaluatie van deze vernieuwde UHMWPE sublaminaire kabels met speciale aandacht voor de in vivo analyse.

In Hoofdstuk 2 zijn in een systematisch review de resultaten bekeken van groeigeleidingssystemen die in het verleden werden toegepast bij de behandeling van EOS en waarbij gebruik werd gemaakt van metalen sublaminaire kabels. Hierbij was er in het algemeen sprake van een beperkte groei van de wervelkolom, onder meer door het optreden van autofusie. Deze systemen zijn in onbruik geraakt door de hoge complicatiepercentages als gevolg van het uitbreken van metalen kabels en staven met verlies van de correctie en metallosevorming.

Hoofdstuk 3 beschrijft het resultaat van vier casussen uit de recente praktijk waarbij het groeigeleidingsprincipe werd toegepast bij EOS patiënten. Titanium sublaminaire kabels werden gebruikt als glijankers langs twee kobalt chroom staven die gefixeerd werden met pedikelschroeven op lumbaal niveau. In twee casussen heeft het toepassen van dit instrumentatiesysteem geleid tot een adequate correctie zonder tekenen van materiaalbreuk. Daarnaast was er in deze gevallen sprake van een behoud van de longitudinale groei van de wervelkolom. In de andere twee casussen was er sprake van een significant grotere curve. Hierbij trad er draadbreuk op van meerdere titanium kabels, met verlies van correctie van de curve ten gevolge. Frictie van de kabels langs de staven had metallose veroorzaakt met veel weefselreactie rondom. Een revisieoperatie was noodzakelijk. Het groeigeleidings- 
principe met gebruik van metalen sublaminaire glijankers blijkt een toepasbaar principe. Wanneer er echter een grote correctie nodig is, worden er hogere eisen gesteld aan het materiaal en wordt het risico op complicaties hoger. Materialen met verhoogde vermoeiingssterkte en verlaagde glijweerstand zouden hierin een oplossing kunnen bieden.

Om het principe en de haalbaarheid van UHMWPE sublaminaire kabels in een groeigeleidingssysteem te testen, werd een in vivo pilotstudie verricht, zoals beschreven in Hoofdstuk 4. De belangrijkste onderzoeksvragen waren of deze UHMWPE sublaminaire kabels voldoende stabiliteit kunnen bieden en daarnaast biocompatibel zijn. In een juveniel schapenmodel werd een posterieure instrumentatie verricht waarbij twee titanium staven werden verankerd met UHMWPE sublaminaire kabels van verschillende breedtes gefixeerd met lumbale pedikelschroeven. De UHMWPE kabels werden bevestigd aan de staven met een 'double-loop' glijknoop en een aangepast spanningsapparaat. Dezelfde instrumentatie werd verricht in een controlestudie waarbij titanium kabels gebruikt werden. Er traden geen neurologische complicaties op. Radiologische evaluatie middels röntgenopnames en CT scans toonde een behoud van de stabiliteit van de instrumentatie. Hoewel er sprake was van een hoge mate van ectopische botvorming, werd er een substantiële groei waargenomen van de wervelkolom. De UHMWPE sublaminaire kabels lieten voldoende glijcapaciteit zien, net als de titanium kabels bij de controle studie. Bij macroscopisch onderzoek bleken alle kabels en knopen intact en er werden geen ontstekingsverschijnselen gevonden in de omringende spinale structuren hetgeen de biocompatibiliteit aantoont. De platte structuur van de UHMWPE kabels zorgde voor een vlakke afwikkeling langs de laminae, waarbij minder intra-medullaire ruimte werd ingenomen dan bij de titanium kabels. De knopen van $5 \mathrm{~mm}$ brede UHMWPE draden namen veel ruimte in beslag en veroorzaakte bij 1 dier huidproblemen. De keuze voor een draadbreedte van 3 of 4 $\mathrm{mm}$ met nog voldoende contactoppervlak zou dit probleem kunnen verminderen.

Een belangrijk nadeel van groeigeleidingssystemen waarin gebruik wordt gemaakt van metalen draden is de hoge mate van materiaalfalen en draadbreuk (zoals vermeld in de hoofdstukken 2 en 3). De eerste resultaten van de UHMWPE 


\section{Chapter 10}

sublaminaire kabels waren veelbelovend, maar om een beeld te kunnen vormen van de integriteit en stabiliteit van de kabels was het wenselijk om een radiologische analyse van de UHMWPE kabels te kunnen verrichten. In samenwerking met DSM Biomedical (Geleen, Nederland) werd radiopaciteit van de UHMWPE kabels verkregen door toevoeging van homogeen verdeelde bismuth-oxide $\left(\mathrm{Bi}_{2} \mathrm{O}_{3}\right)$ deeltjes binnen de vezels. In een follow-up studie beschreven in Hoofdstuk 5 wordt naast deze radiopaciteit, de stabiliteit en het biologisch gedrag geanalyseerd van deze vernieuwde UHMWPE kabels. UHMWPE kabels (verrijkt met $\mathrm{Bi}_{2} \mathrm{O}_{3}$ ) werden in een groeigeleidingssysteem in een uitgebreider juveniel schapenmodel getest en de groei van de wervelkolom werd na 24 weken follow-up gekwantificeerd. De instrumentatie werd toegepast in 12 dieren en de controlegroep bestond uit vier dieren van dezelfde leeftijd zonder instrumentatie. Kobalt chroom staven werden gefixeerd met pedikelschroeven en $4 \mathrm{~mm}$ brede UHMWPE sublaminaire kabels werden gebruikt als glijankers tussen L3 en Th11. Er traden geen neurologische complicaties op en de UHMWPE kabels behielden hun stabiliteit. De kabels waren goed zichtbaar op de röntgenfoto's, waarbij met name op de laterale foto's de positionering rond de laminae goed vervolgd kon worden. Het groeigeleidingssysteem liet een normale groei toe van de wervelkolom; er was geen verschil tussen de experimentele groep en de controlegroep voor wat betreft de lengte van het geïnstrumenteerde segment. Hoge resolutie CT (HR-pQCT) beelden toonden morfologische veranderingen van de facetgewrichten en heterotope botformatie, hetgeen de lengtegroei niet beperkt heeft. Op deze beelden was de platte configuratie van de kabels rondom de laminae en de positie in het spinale kanaal goed zichtbaar. Er was nauwelijks sprake van botgroei op de kobalt chroom staven en deze konden eenvoudig verwijderd worden. Histologische analyse toonde aan dat de kabels omgeven waren door een fibreuze laag waarbij er geen tekenen waren van ontsteking en osteolyse. De biocompatibiliteit van de kabels was hiermee verder aangetoond.

In Hoofdstuk $\mathbf{6}$ wordt een overzicht gegeven van grote proefdiermodellen voor de preklinische evaluatie van fusieloze scoliose correctietechnieken bij EOS en worden de huidige ontwikkelingen en opvattingen samengevat. Het gebruik van een 2-stappen benadering wordt aanbevolen. In een eerste procedure wordt de scoliose geïnduceerd met gebruik van een posterieure spandraad. Vervolgens kan dan een 
correctie worden toegepast met gebruik van de te onderzoeken correctietechniek. De varkenswervelkolom lijkt het meest geschikt voor deze procedure in verband met de vergelijkbare anatomie met de humane wervelkolom. Tevens is bij het varken sprake van een snelle en langdurige groeifase en vroege speenleeftijd. Het verrichten van ribprocedures dient bij voorkeur achterwege gelaten te worden aangezien de index procedure volledige reversibel zou moeten zijn en er verhoogde morbiditeit van dieren hierbij optreedt. Er is echter wel een verhoogde regressie van de curve te verwachten na verwijderen van de spandraad bij het achterwege laten van ribprocedures. Belangrijke factoren voor een succesvol resultaat zijn het verkrijgen van voldoende houvast met additionele verankering en voldoende offset van de spandraad.

Een representatief experimenteel scoliose model dient de volgende kenmerken te bevatten: een structurele, persisterende spinale curve zowel in het frontale als sagittale vlak, met voldoende rotatie en wigvorming van de wervels rond de apex van de bocht. Verder dient er voldoende groeipotentieel te zijn voor het toepassen van een correctieprocedure. Hoofdstuk 7 beschrijft de ontwikkeling van een eigen scoliose varkensmodel waarbij gebruik wordt gemaakt van een flexibele spandraad. Een posterieure UHMWPE spandraad werd gebruikt, gefixeerd met pedikelschroeven en verankerd met sublaminaire kabels via een minimaal invasieve methode. In 8 van de 14 dieren werd een structurele scoliotische curve gecreëerd. De Cobbse hoek van de bochten was gemiddeld $62^{\circ}$ met een axiale rotatie van $37^{\circ}$ op de apex. Hierbij werd een zichtbare thoraxdeformiteit gevormd. In het sagittale vlak werd een lokale lordose gezien rondom de verankeringsplaatsen. Dit was mogelijk het gevolg van de anterieure groei van de wervellichamen in combinatie met posterieure remming van de groei door plaatsing van de pedikelschroeven. Het niveau en de lengte van de scoliose bleken niet consistent. De voornaamste oorzaak van falen bij de overige dieren was schroefuitbraak. De hoge groeisnelheid en gewichtstoename van de varkens spelen hier waarschijnlijk een rol bij. Ook traden er een aantal diepe infecties op. Na het toepassen van extra verankering van de spandraad en het verscherpen van het infectieprotocol namen deze complicaties af. Toekomstig onderzoek zal zich richten op verdere aanpassing en verbetering van dit scoliosemodel. De haalbaarheid van een experimenteel scoliose proefdiermodel waarbij tevens een correctietechniek voldoende getest kan worden blijft echter nog onzeker. 


\section{DISCUSSIE EN TOEKOMST}

De onderzochte radiopaque UHMWPE kabels bieden voldoende houvast en zijn biocompatibel voor gebruik als groeiankers in een spinaal groeigeleidingssysteem. De kabels bieden meerdere voordelen ten opzichte van metalen sublaminaire kabels. Dit proefschrift levert een bijdrage aan toekomstig preklinisch onderzoek van 'growthfriendly' instrumentatie in scoliosechirurgie en dierexperimentele scoliosestudies. Het onderzoek heeft geleid tot "FDA (Food and Drug Administration) clearance" voor de radiopaque UHMWPE kabels voor een aantal specifieke indicaties, zoals cerclageen fixatie technieken in traumachirurgie. Tot op heden is er nog geen goedkeuring verkregen voor gebruik van de kabels in pediatrische scoliose chirurgie. De eerste stappen naar klinische implementatie van de UHMWPE kabels zullen plaats gaan vinden in het PoSTuRE project. In dit project zal middels eindige-elementenmodellen, aanvullende dierstudies en uiteindelijk klinische trials de toepasbaarheid van de UHMWPE kabels in een groeigeleidingssysteem bij scoliosechirurgie in de kliniek onderzocht worden. De kabels zullen eerst getest gaan worden bij volwassen scoliosechirurgie, waar ze gebruikt kunnen worden als versterking van huidige pedikelschroeffixatie.

Het is een positieve ontwikkeling dat er steeds meer onderzoek gedaan wordt naar groei- en correctiesystemen voor de behandeling van EOS. Mogelijk zal een combinatie van de geteste kabels met technieken uit andere nieuwe groeigeleidingssystemen, zoals apicale schroeffixatie uit het Shilla systeem, kunnen leiden tot nog betere resultaten. Uiteindelijk dienen de resultaten van de verschillende 'growthfriendly' systemen met elkaar in de kliniek vergeleken te worden en zal een behandelingsprotocol opgesteld dienen te worden om de EOS patiënt optimaal te kunnen behandelen. 


\section{LIST OF PUBLICATIONS}

\section{Journal Papers}

The use of sublaminar wires for growth-guidance in early onset scoliosis surgery: $A$ systematic review of the literature. Bogie R, Koole SN, Arts JJ, van der Weegen W, van Rhijn LW, Willems PC. Submitted.

The use of metal sublaminar wires in modern growth guiding scoliosis surgery. A report of 4 cases. Bogie R, Arts JJ, Koole SN, van Rhijn LW, Willems PC. Submitted.

The development of a representative porcine early onset scoliosis model with a standalone posterior spinal tether. Bogie R, Roth AK, Willems PC, Arts JJ, van der Weegen W, van Rhijn LW. Spine Deformity 5 (2017):2-10.

Novel radiopaque UHMWPE sublaminar wires in a growth-guidance system for the treatment of early onset scoliosis: feasibility in a large animal study. Bogie R, Roth AK, Faber S, de Jong JJA, Welting TJM, Willems PC, Arts JJ, van Rhijn LW. Spine (Phila Pa 1976). 2014 Dec 1;39(25):E1503-9.

UHMWPE Sublaminar Wires in Posterior Spinal Instrumentation: Stability and Biocompatibility Assessment in an Ovine Pilot Study. Bogie R, Voss L, Welting TJ, Lataster LM, Willems P, Arts JJ, van Rhijn LW. J. Spinal Disord Techn 2014, [published online ahead of print January 8, 2014] Clin Spine Surg. 2016 Dec;29(10):E542-E549.

Large animal models in fusionless scoliosis research: a review of the literature. Roth A, Bogie R, Jacobs E, Arts JJ, van Rhijn LW. Spine J. 2013 Jun;13(6):675-88.

Range of Motion in Segmental Versus Nonsegmental Ultrahigh Molecular Weight Polyethylene Sublaminar Wire Growth Guidance Type Constructs for Early-Onset Scoliosis Correction. Roth AK, van der Veen AJ, Bogie R, Willems PC, van Rietbergen B, van Rhijn LW, Arts JJ. Spine (Phila Pa 1976). 2015 Dec;40(23):E1212-8. 


\section{Chapter 10}

Isolated Tibial Tunnel Infection after Revision of ACL Reconstruction with the LARS device. A Case Report. Wassink JS, van der Weegen W, Bogie R. NtvO 2017 Mar;24(1):22-25.

Ulnar carpometacarpal dislocations: can it be treated conservatively? Storken G, Bogie R, Jansen EJP. Hand (N Y). 2011 Dec;6(4):420-3.

Acute thrombosis of an abdominal aortic aneurysm; a short report. Bogie $\mathbf{R}$, Willigendael EM, de Booij M, Meesters B, Teijink JAW. Eur J Vasc Endovasc Surg. 2008 May;35(5):590-2.

Experience in the first four years of rapid Recovery; is it safe? Pilot P, Bogie R, Draijer WF, Verburg AD, van Os JJ, Kuipers H. Injury. 2006 Dec;37 Suppl 5:S37-40.

Bloedverbruik aan banden. Pilot P, Moonen AFCM, Stuart WC, Bell CAMP, Bogie R, Pinckaers J, Draijer WF, van Os JJ. Medisch Contact 2005 (Sept).

Klinische resultaten van 4 jaar totale heupplaatsing in een geïntegreerd heup-en knieprogramma. Bogie R, Pilot P, van Os JJ, Draijer WF. Medisch Contact 2005 (Mar).

\section{CONFERENCE ABSTRACTS}

Novel radiopaque UHMWPE sublaminar wires in a growth-guidance system for the treatment of early-onset scoliosis: feasibility in a large animal model Roth AK, Bogie R, Willems PC, Welting TJ, de Jong JJ, Arts JJ, van Rhijn LW, Poster presentation at the Annual Meeting of the Orthopedic Research Society (ORS), New Orleans USA, 2014.

Efficacy of UHMWPE Dyneema Purity ${ }^{\circledR}$ in fusionless posterior spinal instrumentation in an ovine model. Bogie R, Voss L, Welting TJ, Lataster LM, Willems P, Arts JJ, van Rhijn LW. Poster presentation ORS Los Angeles, 2011.

Efficacy of UHMWPE laminar wires in fusionless spinal instrumentation in an animal model. Bogie R, Voss L, Welting T, Arts JJ, Willems PC, van Rhijn LW. Oral presentation NOV Groningen, 2011. 
Assessment of Dyneema Purity for scoliosis corrective surgery. Voss L, Welting TJM, Bogie R, Nelis M, Lataster LM, Arts JJ, van Rhijn LW. Oral presentation EFORT Kopenhagen, 2011.

The Vanguard ${ }^{\mathrm{TM}}$ Total Knee Replacement compared to the Maxim ${ }^{\circledR}$ total knee replacement; a preliminary study. Bogie R, Kort NP. Poster presentation NOF, 2008.

Experience in the first four years of rapid recovery; is it safe? Bogie R, Verburg AD, van Os JJ, Pilot P. Poster presentation Managing for improved quality in joint replacement. Rome, 2004.

The development of an ischemia/reperfusion pig model and analysis of the affected myocardium. Bogie R, Bär FWHM, van der Veen LFH, Cleutjens J. Poster presentation NVVC najaarsvergadering Ermelo, 2001. 
Chapter 10 


\section{DANKWOORD}

Dit proefschrift zou niet tot stand zijn gekomen zonder de hulp van vele anderen. Op deze plaats zou ik deze mensen dan ook willen bedanken voor hun hulp.

Mijn promotor prof. Dr. L.W. van Rhijn. Beste Lodewijk, het project is jaren geleden ontstaan vanuit een onderzoeksvraag van jouw kant. En ik ben blij dat ik op deze trein ben gestapt. Het was voor mij erg leerzaam om zo de wereld van het experimenteel onderzoek te leren kennen en de samenwerking aan te gaan met technische universiteiten, bedrijven en het orthopedisch onderzoekslab. Je hebt me gedurende het onderzoek altijd goed begeleid en ik waardeer het erg dat je mij tijdens je vakantie hebt geholpen met het afronden van het manuscript. Binnen jullie vakgroep heb ik als assistent en later als chef de clinique de kans gekregen om mij te ontwikkelen binnen de sportorthopedie. Dit heeft er mede toe geleid dat ik uiteindelijk een mooie plek heb gekregen in Geldrop. Jouw tactisch vermogen en de manier waarop je de vakgroep in Maastricht leidt bewonder ik zeer. Bedankt voor alle begeleiding en de geboden mogelijkheden. Ik zal ons 'eindgesprek' in Maastricht nooit vergeten.

Mijn co-promotor dr. P.C. Willems. Beste Paul, jij was natuurlijk al langer nauw betrokken bij het Spineguide project en altijd beschikbaar en bereikbaar. Met jouw hulp is het gelukt om het traject goed door te zetten en het proefschrift te voltooien. Jouw feedback was steeds opbouwend en vooral altijd raak! Jij hebt me echt geleerd kritisch en analytisch naar de inhoud te kijken. Je stuurde de corrigeerde stukken altijd heel snel door zodat ik ook weer direct verder kon. Ik wil je dan ook hierbij hartelijk bedanken voor al de tijd en moeite die je hierin gestoken hebt.

Mijn co-promotor dr. J.J.C. Arts. Beste Chris, wat hebben we toch allemaal samen meegemaakt. Van pizzameetings tot congressen, het bedenken en uitvoeren van proeven en het schrijven van artikelen. Je was overal bij betrokken en ik heb je hulp altijd erg gewaardeerd. Je hebt me geleerd altijd te blijven geloven in het eindresultaat. Gelukkig hebben we in jouw kleine hokje met eigen koffieapparaat of met een biertje in de hand ook vaak kunnen relativeren. Bedankt voor alle begeleiding en hulp en het altijd tonen van interesse. 


\section{Chapter 10}

Dr. A.K. Roth. Beste Alex, in 2001 volgde je Laura Voss op in dit project en samen begonnen we aan een mooi avontuur. Al snel werd je talent opgepikt door andere collega's en moest je in veel projecten bijspringen. Je stond aan de basis van veel ideeën binnen het Spineguide project en we hebben samen veel meegemaakt tijdens alle experimenten. Daarbij hebben we veel tegenslagen moeten verwerken, maar we hebben altijd doorgezet. Ik ben je dankbaar voor alle hulp. We hebben veel kunnen bespreken tijdens onze gezamenlijke lunches in de mensa en tijdens het fietsen door de Limburgse heuvels. Jouw veelzijdigheid is samengekomen in jouw fraaie proefschrift begin dit jaar. Heel veel succes met het vervolgproject en de toekomstige onderzoekslijnen.

De leden van de beoordelingscommissie, prof. dr. Martijn Poeze, prof. dr. Maarten van Kleef, prof. dr. Marinus de Kleuver, dr. Moyo Kruijt en Dr. Mariëlle ter Laak wil ik danken voor de tijd die zij besteed hebben aan de beoordeling van dit manuscript. Daarnaast wil ik tevens de overige leden van de corona bedanken, prof. dr. Eppo Wolvius en dr. André van Ooij. Beste Eppo, ik waardeer het zeer dat jij als hoogleraar en specialist verbonden aan het St. Annaziekenhuis plaats wil nemen in deze corona. André, ik vind het heel bijzonder dat jij in de corona plaats neemt aangezien jij met het voorstel kwam om mijn onderzoek te starten binnen het Spineguide project en ik mede onder jouw prettige en leerzame supervisie de opleiding heb kunnen voltooien.

Medewerkers van CPV groot, Sanne Bout, Petra Dijkstra en Joyce Suyk. Jullie flexibiliteit, inventiviteit en met name deskundigheid tijdens de experimenten hebben ervoor gezorgd dat ik altijd met een goed gevoel weer naar huis ging. Ongelooflijk eigenlijk hoe jullie de expertise van een operatieassistente en anaesthesiemedewerker kunnen combineren. Ook dank aan drs. Saskia Seeldrayers voor alle adviezen en betrokkenheid.

Laura Voss, we zijn samen gestart met het Spineguide project en hebben de eerste studies opgezet en uitgevoerd. De term experimentele chirurgie was hier wel heel toepasselijk. Mede door jouw werk heb we de basis kunnen leggen voor de rest van dit proefschrift. 
Tim Welting, door jouw begeleiding en adviezen heb ik alle facetten van het onderzoek leren kennen en (deels) begrijpen en heb je me wegwijs gemaakt in jullie fraaie onderzoekslaboratorium.

Stafleden Orthopedie MUMC; bedankt voor de leuke en leerzame tijd tijdens opleiding en jaar als chef de clinique. Ik koester nog veel leuke herinneringen aan deze tijd en heb er meerdere kennissen en vrienden aan overgehouden.

Dames van het secretariaat Orthopedie in Maastricht en in het bijzonder Will van Erk. Bedankt voor alle hulp.

Dank ook aan alle co-autheurs die hebben bijgedragen aan de inhoud van dit proefschrift. In het bijzonder Simone Koole. Simone, jij hebt naast het opzetten van de studie, heel veel tijd gestoken in het zoeken en inscannen van alle artikelen en je hebt mij de wereld van de systematische reviews leren kennen. Helaas hebben we je niet kunnen overtuigen van de mooie wereld van de orthopedie. Veel succes in jouw gynaecologische carrière!

Karlien Boon-Ceelen, we hebben vooral in de begin en nu op het einde van het Spineguideproject veel contact gehad. Ik vond het altijd een heel prettige samenwerking. Ik heb veel geleerd van de samenwerking met een groot bedrijf zoals DSM. Graag wil ik ook de andere Spineguide consortiumleden vanuit DSM Biomedical bedanken.

De vakgroep orthopedie St. Annaziekenhuis in Geldrop. Henk Hoekstra, Thea Sybesma, Wart van Zoest, Rogier van Drumpt, Dirk Das en Joris de Kort. Ik ben in Geldrop volledig op mijn plek. Wat hebben we toch een uniek gevarieerd team, waarbij we het ene na het andere enthousiaste idee verder exploreren. Naast al het harde werk staat collegialiteit voorop en krijgt ieder de mogelijkheid om zich verder te ontwikkelen. We begeven ons momenteel in een tijd met veel veranderingen maar ik ben ervan overtuigd dat we onze sterke eigenschappen als groep kunnen behouden en verder kunnen ontwikkelen in de toekomst. Dit kunnen we niet bereiken zonder Ellis Bos en Walter van der Weegen. Jullie zijn onlosmakelijk 


\section{Chapter 10}

verbonden met onze vakgroep. Walter, bedankt voor alle hulp tijdens de afronding van dit proefschrift. Met de komst van Pieter Oomen kunnen we nu het kenniscentrum in de sport ook verder uitbreiden.

Bas Jacobs. Beste Bas, naast jouw muzikale talenten bleek je ook een kei op grafisch gebied. Bedankt voor de afbeeldingen!

Het St. Anna Ziekenhuis, collega's, poli en secretariaat van de orthopedie en medewerkers van Topsupport, OK, gipsmeesters en afdeling, bedankt voor de prettige werkomgeving en 'no nonsense' cultuur!

De orthopedisch chirurgen van het Orbis Medisch Centrum (en voorheen Maasland Ziekenhuis), beste Aart Verburg, Hans van Os, Frits Draijer, Pieter Tilman, Nanne Kort en Edwin Jansen. Bedankt voor de geweldige tijd en ervaringen als assistent zowel tijdens als voor de opleiding!

Verder wil ik nog graag de DAC (Dinsdag Avond Club) bedanken. Ik had me geen betere integratie in Brabant kunnen wensen; voetballen en nadien naborrelen bij Freek. Het voetbalanalytisch vermogen is helaas wel het voetballende vermogen voorbij aan het streven.

Vrienden in Leende en in onze straat, de Loonwerker, wil ik ook bedanken voor alle hulp de afgelopen jaren. Vaak moesten we een beroep op jullie doen en jullie stonden altijd klaar!

Mijn schoonouders. Beste Mart en Ellen, jullie zijn ook altijd bereid geweest om bij te springen wanneer dit nodig was en hebben hiervoor vele kilometers gereden. Tijdens de vakanties in Zeeland kon ik altijd rustig bijkomen en uitwaaien aan het strand. Ik beloof jullie dat jullie nog steeds veel op de kinderen mogen passen!

Beste Nicole, mijn lieve zus. Ik ben heel trots dat je straks achter me staat als paranimf. We kunnen altijd alles met elkaar bespreken en ik beloof ons mam nog steeds dat ik tijdens het stappen op je zal letten. 
Beste Sjoerd. Uiteindelijk sta jij natuurlijk aan de basis van alles wat ik binnen de geneeskunde heb gedaan en bereikt en dus ook dit proefschrift. Wat hebben we toch een mooie tijd gehad samen in Maastricht. Ik vind het dan ook heel bijzonder dat jij ook mijn paranimf bent.

Lieve pap en mam. Het drong bij jullie (en wellicht ook bij mij) wat later door dat ik aan het promoveren was. Desondanks hebben gevraagd waarom ik nu weer moest werken of waarom jullie weer op de kinderen moesten passen. Altijd waren jullie er en zijn jullie er gelukkig nog steeds, onvermoeibaar!

Speciale dank gaat uiteraard naar mijn vrouw Wieteke. Je hebt het niet makkelijk gehad de laatste jaren en jouw gezondheid liet en laat je nog helaas regelmatig in de steek. Ik vind het enorm knap hoe jij je iedere keer weer kunt oppakken. We moesten vaak hulp vragen om alles geregeld te krijgen en ik heb me daarbij dan ook vaak schuldig gevoeld wanneer ik weer naar Maastricht moest of moest schrijven. Ik heb er zeker aan gedacht om te stoppen met dit proefschrift. Ik heb het alleen kunnen doorzetten doordat jij het gezin toch draaiende hield en nooit 1 keer hebt geklaagd over de tijd het die ons dit samen gekost heeft. Gezien het ontbreken van een talenknobbel bij mij heb je ook vaak teksten moeten corrigeren waarmee je ook op die manier een belangrijke bijdrage hebt geleverd aan dit proefschrift. Tenslotte onze kinderen, Thijs en Lise, ik verheug me nog iedere dag op het 'thuiskomen' waarbij jullie de deur voor me openmaken. Vanaf nu gaan we nog meer genieten samen! 
Chapter 10

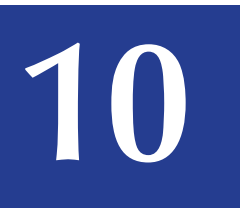

200 


\section{CURRICULUM VITAE}

Rob Bogie was born on November 18th 1977 in Weert, the Netherlands. After graduating from high school (Gymnasium, Bisschoppelijk College Weert) and acquiring the Propaedeutic Certificate of Health Sciences, he studied Medicine at Maastricht University (1997-2003). In 2003 he started as a resident at the orthopedic department of the Maasland Hospital in Sittard (dr A.D. Verburg). His specialization started in 2005 and as part of his orthopaedic training he completed a residency in general surgery from 2005 to 2007 at the Atrium Medical Centre in Heerlen under supervision of dr. R.J.Th.J. Welten. His orthopaedic training continued at the Maastricht University Medical Centre (prof. dr. L.W. van Rhijn) and the Orbis Medical Centre in Sittard (dr. A.D. Verburg). During his training in Maastricht he participated in the multi-disciplinary BMM Spineguide project, which resulted in this thesis.

In January 2012 he started working as an orthopedic surgeon in the Maastricht University Medical Centre where he specialized in shoulder and knee surgery. He developed an increased interest in sports injuries and participated as consultant at MVV Maastricht footballclub.

In 2013 he joined the orthopaedic staff at St. Anna Hospital in Geldrop and TopSupport Sports Medical Centre in Eindhoven. As an orthopaedic surgeon he has a practice in sports injuries and is specialized in arthroscopic shoulder and knee surgery, ligament repair and shoulder replacement. Besides his clinical practice, he is also an orthopedic consultant at PSV.

Rob is married to Wieteke and they have two children; Thijs and Lise. They live in Leende. 
